\title{
A post-synaptic forgetting mechanism controlled by synaptotagmin 3
}

\author{
Dissertation \\ for the award of the degree \\ "Dr. rer. nat." \\ of the Georg-August-Universität Göttingen
}

within the doctoral program 'Molecular physiology of the brain' of the Georg-August University School of Science (GAUSS)

\author{
submitted by \\ Ankit Awasthi \\ from Visakhapatnam, India
}

Göttingen, 2017 


\section{Thesis Committee}

Camin Dean, $\mathrm{PhD}$

(Reviewer)

Prof. Dr. Erwin Neher

(Reviewer)

Dr. Jeongseop Rhee

Dr. Dr. Oliver Schlüter
Trans-synaptic signaling group

European Neuroscience Institute,

Göttingen

Professor Emeritus

Max Planck Institute for Biophysical Chemistry, Göttingen

Neurophysiology group

Max Planck Institute for Experimental Medicine, Göttingen

Molecular Neurobiology group

European Neuroscience Institute,

Göttingen

\section{Members of the Examination Board}

$\begin{array}{ll}\begin{array}{l}\text { Camin Dean, PhD } \\ \text { (Reviewer) }\end{array} & \begin{array}{l}\text { Trans-synaptic signaling group } \\ \text { European Neuroscience Institute, } \\ \text { Göttingen }\end{array} \\ \begin{array}{l}\text { Prof. Dr. Erwin Neher } \\ \text { (Reviewer) }\end{array} & \begin{array}{l}\text { Professor Emeritus } \\ \text { Max Planck Institute for Biophysical Chemistry, } \\ \text { Göttingen }\end{array} \\ \text { Todd C. Sacktor, M.D. } & \text { Distinguished Professor } \\ \text { (External thesis } & \text { SUNY Downstate Medical Center } \\ \text { reviewer) } & \text { New York, United States of America }\end{array}$

\section{Further members of the Examination Board}

Prof. Dr. rer. nat. Nils Brose Department of Molecular neurobiology

Max Planck Institute for Experimental Medicine, Göttingen

Prof. Dr. André Fischer German Center for Neurodengenerative Diseases, Göttingen

Date of the oral examination: $04^{\text {th }}$ May 2017 


\section{Table of Contents}

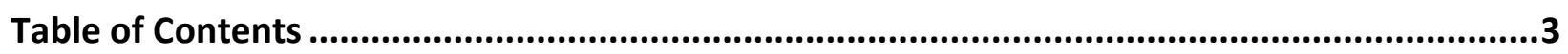

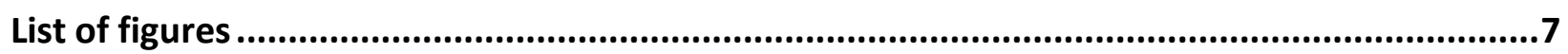

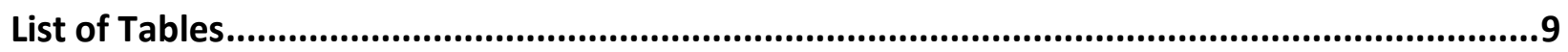

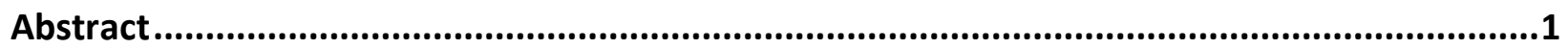

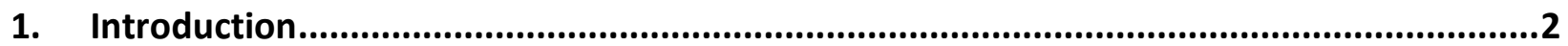

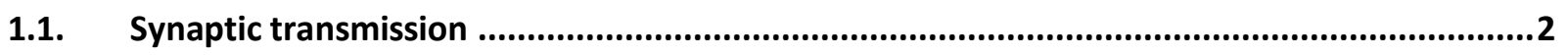

- Types of neurotransmitter release …...............................................................................

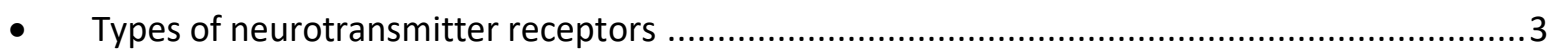

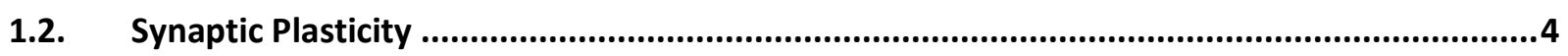

- Homosynaptic vs heterosynaptic plasticity ................................................................... 5

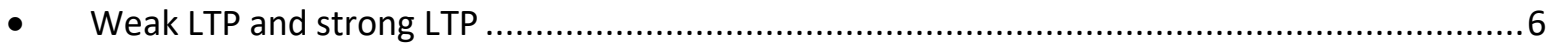

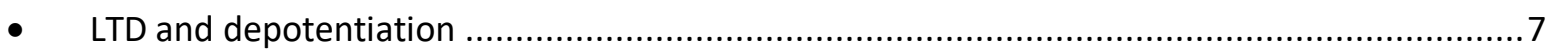

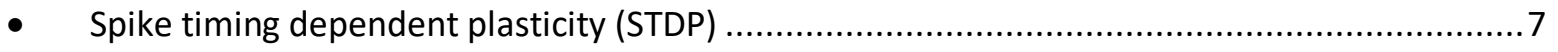

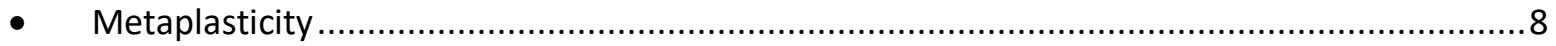

- Calcium is an important regulator of synaptic plasticity ................................................ 8

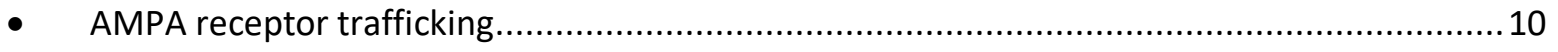

1.3. Constitutive trafficking of AMPA receptors mediates basal synaptic transmission ...............11

- Molecular machinery mediating clathrin mediated endocytosis ........................................11

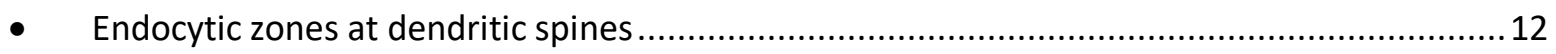

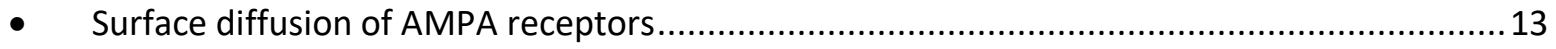

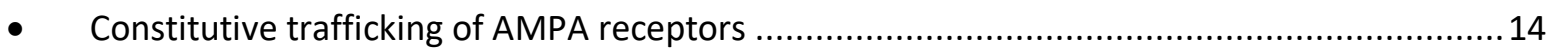

1.4. Activity dependent trafficking of AMPA receptors mediates synaptic plasticity ...................16

- Stimulation induced internalization of AMPA receptors ..................................................... 16

- Subunit rules of activity dependent AMPA receptor internalization....................................... 18

1.5. Important players in activity dependent AMPA receptor internalization.............................19

- $\quad$ PICK1 recruits AMPA receptors to sites of clathrin mediated endocytosis ............................19

- $\quad$ Rab5 internalizes AMPA receptors into the recycling endosome pathway ............................21 
- $\quad$ BRAG2 binds to dephosphorylated Y876 and is necessary for LTD .................................. 21

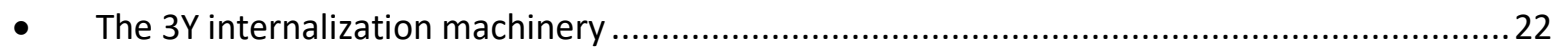

- $\quad$ Other known players in activity dependent AMPA receptor internalization...........................23

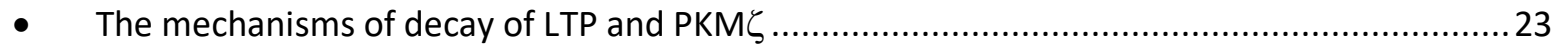

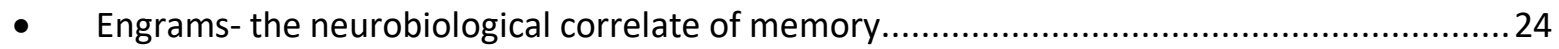

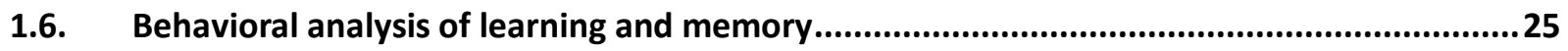

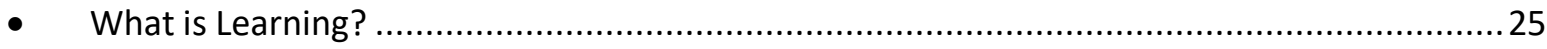

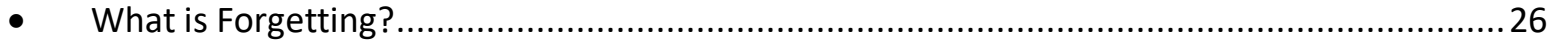

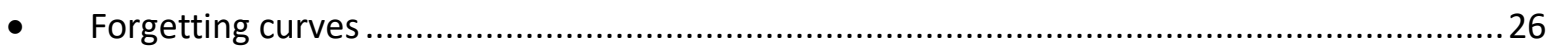

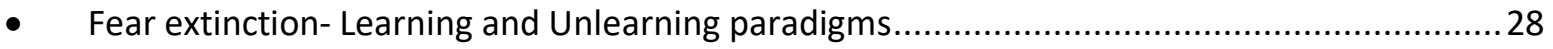

- Interfering with a memory update (reconsolidation) can erase memories...........................28

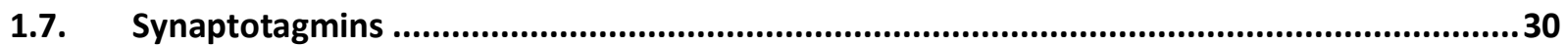

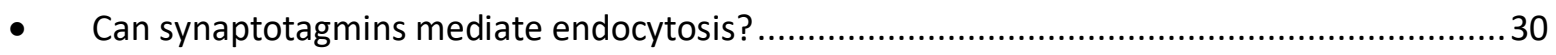

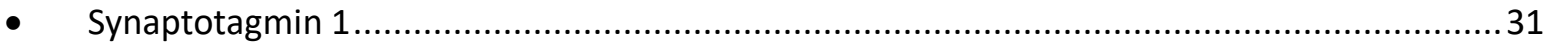

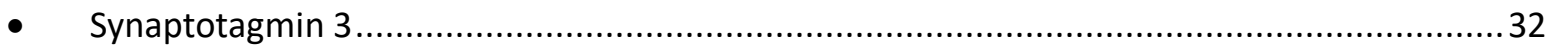

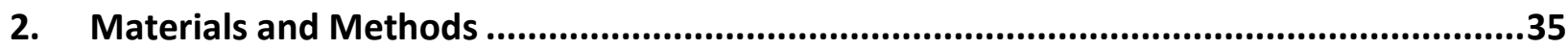

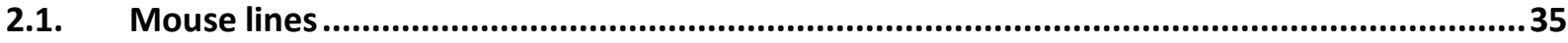

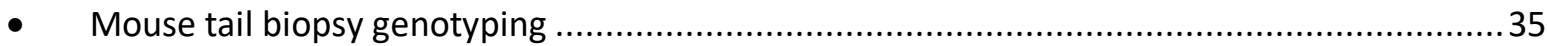

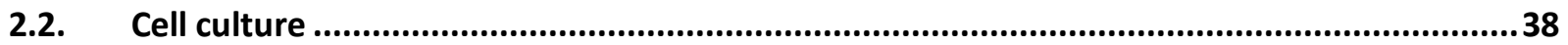

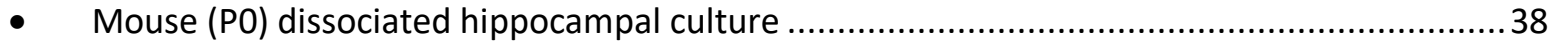

- $\quad$ Rat embryonic (E18 to E19) dissociated hippocampal cultures ...........................................42

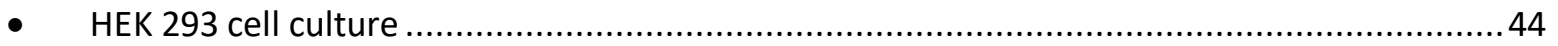

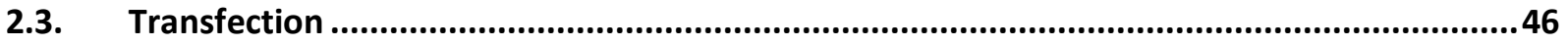

- $\quad$ Calcium phosphate transfection of HEK cells for Western blot analysis ............................... 46

- Lipofectamine 2000 transfection of primary neuronal cultures .......................................... 46

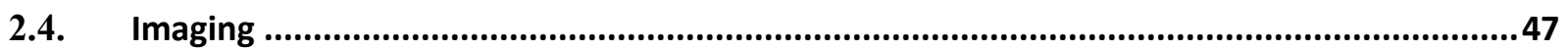

- Immunohistochemistry (IHC) of acute hippocampal slices ............................................... 47

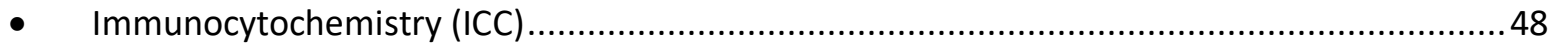

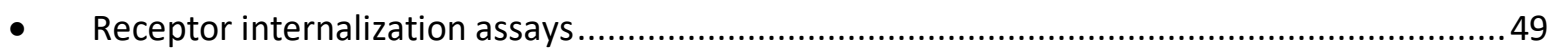

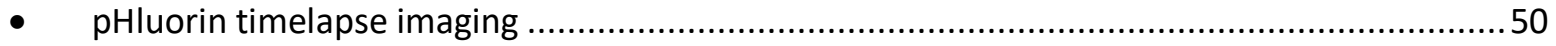

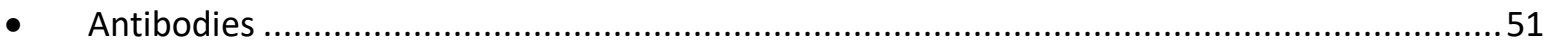




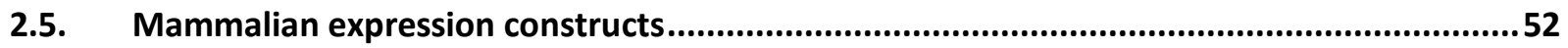

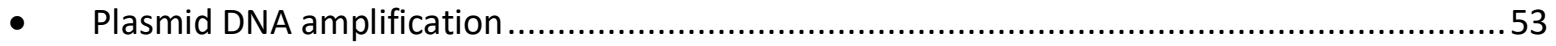

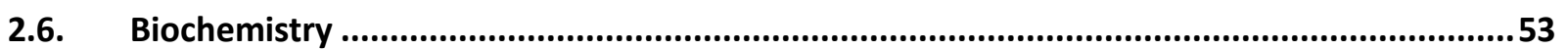

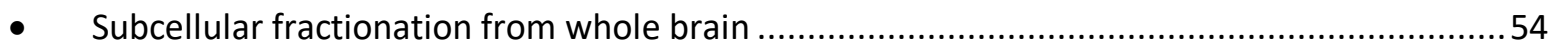

- Immuno-organelle isolation of synaptic vesicles.................................................................5

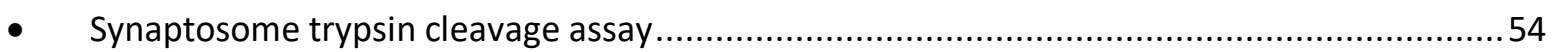

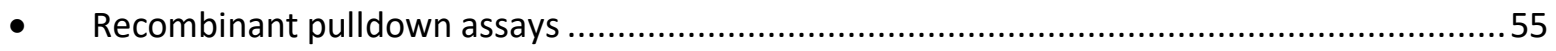

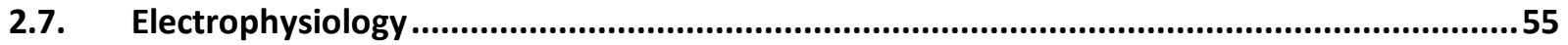

- Whole-cell electrophysiology in dissociated hippocampal embryonic rat cultures .................55

- Whole-cell electrophysiology in dissociated hippocampal postnatal mouse cultures .............56

- Whole-cell electrophysiology in acute hippocampal slices................................................58

- $\quad$ Extracellular recordings from acute hippocampal brain slices..............................................61

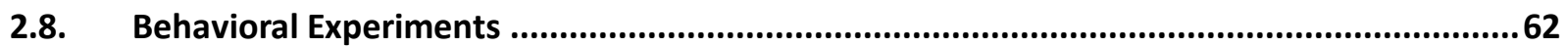

- Open field, novel object recognition and elevated plus maze ............................................63

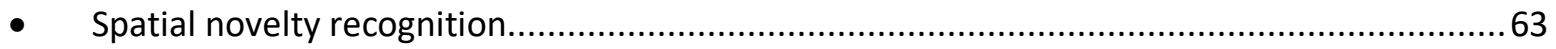

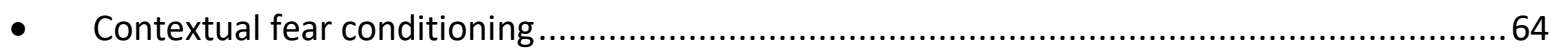

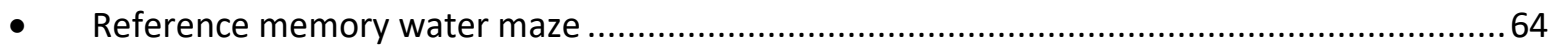

- $\quad$ Delayed matching to place water maze..................................................................................65

- $\quad$ Occupancy plots to analyze watermaze search paths .......................................................67

- $\quad$ Strategy classification algorithm to analyze watermaze search paths .................................69

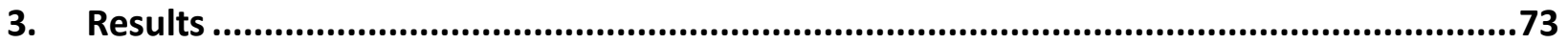

3.1. Synaptotagmin 3 is expressed on the post-synaptic plasma membrane ...............................73

- $\quad$ A polyclonal antibody was validated to detect syt3 specifically ......................................... 73

- $\quad$ Syt3 is expressed in dendrites at excitatory and inhibitory synapses ................................. 73

3.2. Syt3 undergoes activity-dependent endocytosis upon stimulation ...................................78

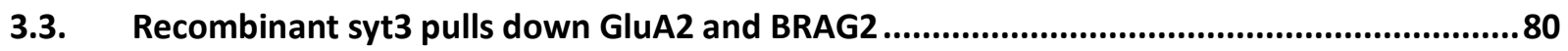

3.4. Syt3 mediates AMPA and NMDA induced AMPA receptor internalization............................82

3.5. Syt3 does not affect basal synaptic transmission or receptor composition ...........................87

3.6. Syt3 is necessary for AMPA induced synaptic AMPA receptor internalization .....................89

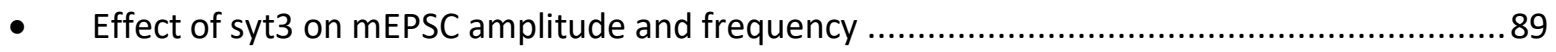

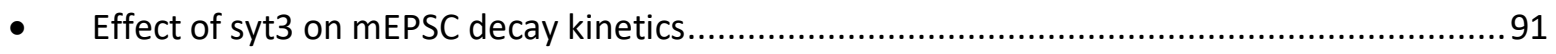


3.7. Syt3 mediates LTP decay after induction.

3.8. Syt3 KO mice show normal learning but impaired forgetting ...............................................97

- $\quad$ Syt3 KO mice show no anxiety, hyperactivity or impairments in recognition memory ...........97

- Syt3KO mice can acquire short-term and long-term fear memories ...................................99

3.9. Syt3 KO mice acquire a spatial memory normally in the reference memory watermaze but persevere to the original platform position after reversal ...................................................................100

- Syt3 KO mice learn as well as or better than WT mice ................................................... 100

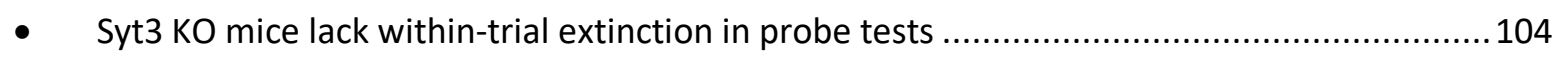

- $\quad$ An older memory doesn't interfere with acquisition of a newer one in syt3 KO mice .......... 104

- $\quad$ Syt3 KO mice persevere to the original platform after reversal....................................... 106

3.10. Syt3 KO mice persevere to older platform positions in the delayed matching to place

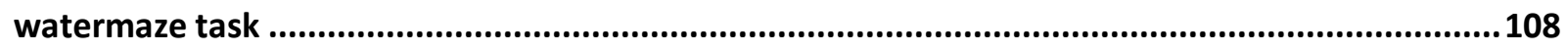

- $\quad$ The delayed matching to place (DMP) watermaze is a test for working memory ................ 108

- $\quad$ Syt3 KO mice are strongly impaired in the DMP watermaze ............................................ 109

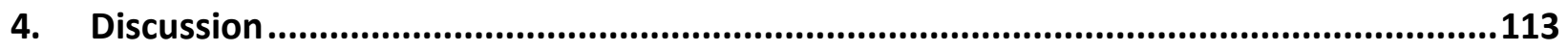

4.1. Syt3 is expressed on post-synaptic membranes ................................................................ 113

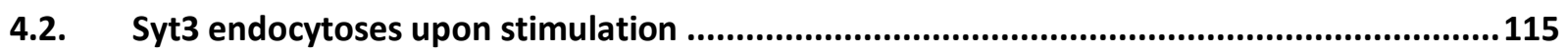

4.3. Syt3 is a novel addition to the GluA2 $3 Y$ internalization machinery .................................116

4.4. Syt3 is necessary for AMPA/ NMDA induced AMPA receptor internalization ....................119

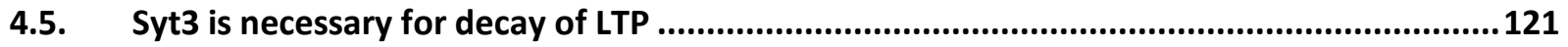

4.6. Syt3 is necessary for forgetting of spatial memories ......................................................122

- $\quad$ Syt3 KO mice show impaired forgetting in the reference watermaze................................. 122

- $\quad$ Syt3 KO mice show impaired forgetting in the DMP watermaze ....................................... 124

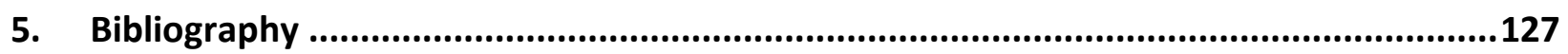

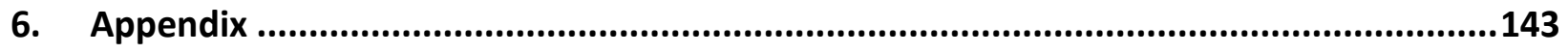

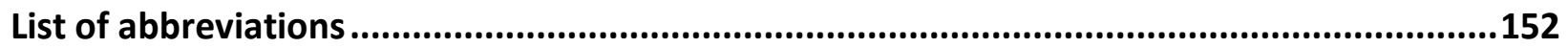

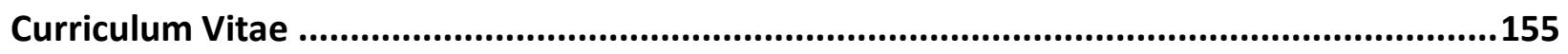

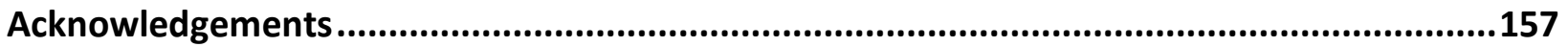




\section{List of figures}

INTRODUCTION FIGURE 1: AMPA RECEPTOR TRAFFICKING IN DENDRITES. ...................................................10

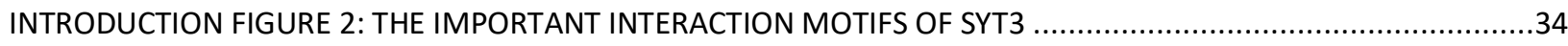

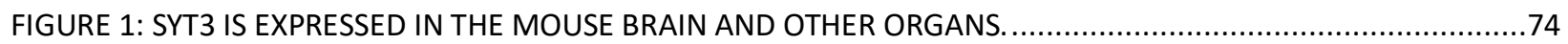

FIGURE 2: ENDOGENOUS SYT3 IS LOCALIZED TO DENDRITES AT SYNAPSES ….................................................

FIGURE 3: SYT3 IS PREDOMINANTLY LOCALIZED TO POST-SYNAPTIC MEMBRANES ….......................................77

FIGURE 4: PHLUORIN-SYT3 UNDERGOES CALCIUM DEPENDENT ENDOCYTOSIS UPON STIMULATION IN CULTURE..79

FIGURE 5: RECOMBINANT SYT3 PULLS DOWN GLUA2, AP-2 AND BRAG2 FROM BRAIN HOMOGENATE..................81

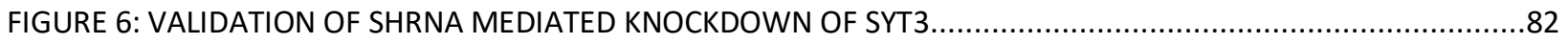

FIGURE 7: POST-SYNAPTIC SYT3 MEDIATES AMPA \& NMDA INDUCED AMPA RECEPTOR INTERNALIZATION...........83

FIGURE 8: SYT3 IS NECESSARY FOR NMDA INDUCED GLUA1 AND GLUA2 INTERNALIZATION .............................84

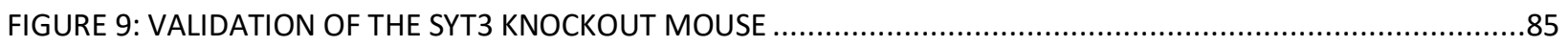

FIGURE 10: AMPA AND NMDA INDUCED GLUA2 INTERNALIZATION IS BLOCKED IN SYT3 KO MOUSE CULTURES.....86

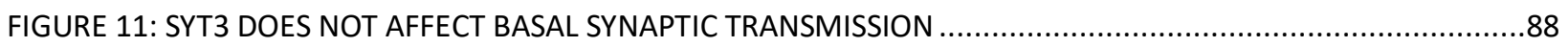

FIGURE 12: SYT3 IS NECESSARY FOR THE AMPA INDUCED INTERNALIZATION OF SYNAPTIC AMPA RECEPTORS.......90

FIGURE 13: SYT3 IS NECESSARY FOR THE AMPA STIMULATION INDUCED DECREASE IN MEPSC DECAY TIME ..........92

FIGURE 14: WEAK-LTP IS STRONGLY REINFORCED IN SYT3 KO HIPPOCAMPAL SLICES .........................................94

FIGURE 15: ZIP MEDIATED DECAY OF LTP IS BLOCKED IN THE SYT3 KO MICE ....................................................96

FIGURE 16: SYT3 KO MICE SHOW NO ABNORMALITIES IN ANXIETY, HYPERACTIVITY OR SPATIAL MEMORY ............98

FIGURE 17: SYT3 KO MICE CONSOLIDATE SHORT-TERM AND LONG-TERM MEMORIES IN CONTEXTUAL FEAR

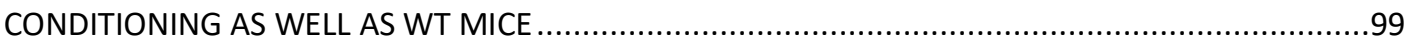

FIGURE 18: SYT3 KO MICE LEARN THE PLATFORM POSITION BETTER THAN OR AS WELL AS WT MICE, BOTH BEFORE

AND AFTER PLATFORM REVERSAL IN THE REFERENCE MEMORY WATERMAZE TASK.....................101

FIGURE 19: SYT3 KO MICE PERFORM BETTER OR AS WELL AS WT MICE IN REFERENCE WATERMAZE PROBE TESTS.

FIGURE 20: SYT3 KO MICE LACK WITHIN-TRIAL EXTINCTION IN WATERMAZE PROBE TESTS...............................105

FIGURE 21: SYT3 KO MICE ACQUIRE THE NEW PLATFORM POSITION MEMORY AS WELL AS WT MICE, SHOWING NO

PROACTIVE INTERFERENCE FROM THE ORIGINAL PLATFORM POSITION MEMORY.......................106

FIGURE 22: SYT3 KO MICE PERSEVERE TO ORIGINAL PLATFORM AFTER REVERSAL ..............................................107

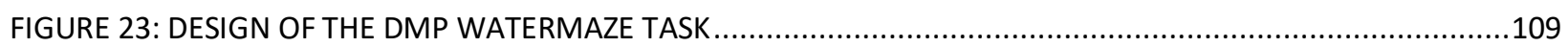

FIGURE 24: SYT3 KO MICE ARE STRONGLY IMPAIRED IN THE DMP WATERMAZE TASK ...................................110

FIGURE 25: SYT3 KO MICE PERFORM WORSE IN THE DMP WATERMAZE BECAUSE OF IMPAIRED FORGETTING ....112

FIGURE 26: SUMMARY OF THE ROLE OF SYT3 IN AMPA RECEPTOR TRAFFICKING .........................................126 
APPENDIX FIGURE 1: OCCUPANCY PLOTS FOR COHORT 1 IN REFERENCE MEMORY WATERMAZE.

APPENDIX FIGURE 2: OCCUPANCY PLOTS FOR COHORT 2 IN REFERENCE MEMORY WATERMAZE. 144 APPENDIX FIGURE 3: INDIVIDUAL MOUSE TRAJECTORIES IN PROBE TEST 1 OF REFERENCE MEMORY WATERMAZE

APPENDIX FIGURE 4: INDIVIDUAL MOUSE TRAJECTORIES IN PROBE TEST 2 OF REFERENCE MEMORY WATERMAZE 146

APPENDIX FIGURE 5: INDIVIDUAL MOUSE TRAJECTORIES IN PROBE TEST 3 OF REFERENCE MEMORY WATERMAZE

APPENDIX FIGURE 6: STRATEGY ANALYSIS OF REFERENCE MEMORY WATERMAZE 148 APPENDIX FIGURE 7: OCCUPANCY PLOTS FOR SUB-COHORT CB 1 IN DELAYED MATCHING TO PLACE WATERMAZE 149

APPENDIX FIGURE 8: OCCUPANCY PLOTS FOR SUB-COHORT CB 2 IN DELAYED MATCHING TO PLACE WATERMAZE 150

APPENDIX FIGURE 9: STRATEGY ANALYSIS OF DELAYED MATCHING TO PLACE WATERMAZE. 151 


\section{List of Tables}

TABLE 1: THE SYT3/ SYT5/ SYT6/ SYT10 QUADRUPLE TARGETED MUTATION MOUSE LINE ....................................36

TABLE 2: FORMULATION OF REAGENTS NEEDED FOR MOUSE (PO) DISSOCIATED HIPPOCAMPAL CULTURES............40

TABLE 3: FORMULATION OF REAGENTS NEEDED FOR EMBRYONIC RAT DISSOCIATED HIPPOCAMPAL CULTURES ...43

TABLE 4: FORMULATION OF REAGENTS NEEDED FOR CULTURING HEK CELLS ................................................45

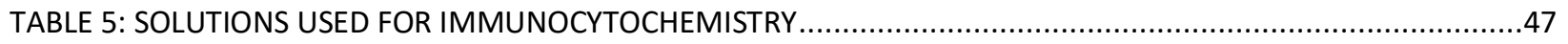

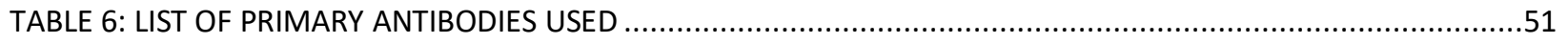

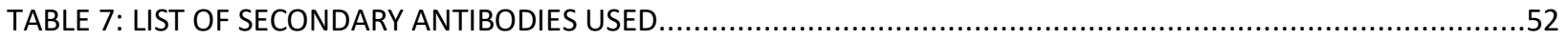

TABLE 8: FORMULATION OF EXTRACELLULAR SOLUTION FOR WHOLE-CELL RECORDINGS IN DISSOCIATED

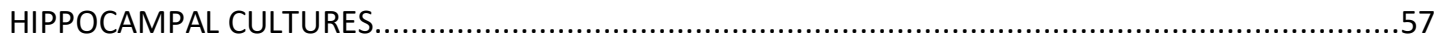

TABLE 9: FORMULATION OF INTRACELLULAR SOLUTION FOR WHOLE-CELL RECORDINGS FROM DISSOCIATED

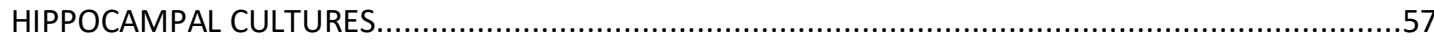

TABLE 10: FORMULATION OF NMDG CUTTING BUFFER FOR SLICING OF AUTE HIPPOCAMPAL SLICES FOR WHOLE-

CELL RECORDINGS

TABLE 11: FORMULATION OF ARTIFICIAL CEREBROSPINAL FLUID (ACSF) FOR WHOLE-CELL RECORDINGS FROM ACUTE MOUSE HIPPOCAMPAL SLICES...

TABLE 12: FORMULATION OF INTERNAL SOLUTION FOR RECORDING EVOKED EPSCS FROM ACUTE HIPPOCAMPAL SLICES .60

TABLE 13: FORMULATION OF ARTIFICIAL CEREBROSPINAL FLUID (ACSF) FOR EXTRACELLULAR FIELD RECORDINGS FROM ACUTE MOUSE HIPPOCAMPAL SLICES 


\section{Abstract}

Activity-induced regulation of surface post-synaptic receptor number is a well-known mechanism underlying synaptic plasticity, but the molecular machinery mediating this process is poorly understood. In a screen of synaptotagmin (syt) isoforms, we found that pHluorin-syt3 undergoes $\mathrm{Ca}^{2+}$-dependent endocytosis in hippocampal neurons upon stimulation. Syt3 was present at synapses, and enriched on post-synaptic membranes. Recombinant syt 3 pulled down the endocytic protein AP-2 and GluA2, but not GluA1, GluN1, GluN2 or GABAAR1, and also pulled down BRAG2, a protein important for activity-dependent internalization of AMPA receptors. Overexpression or knockdown of syt3 post-synaptically did not change mEPSCs, and basal transmission in hippocampal syt3 knockout slices was unchanged. However, syt3-overexpressing neurons internalized more GluA1 and GluA2 than control neurons upon stimulation with AMPA or NMDA. This internalization was blocked in syt3 KO, syt3 knockdown, and syt3 calciumbinding mutant expressing neurons, and was mimicked by application of the GluA2-3Y peptide, a tyrosine rich sequence important for activity-mediated GluA2-AMPAR internalization.

Strong LTP was normal in syt3 KO hippocampal slices, but weak LTP failed to decay and persisted for hours, consistent with syt3 internalizing receptors, which is necessary for decay of weak LTP. The reinforcement of weak LTP in syt3 KO slices was mimicked and occluded by the GluA2-3Y peptide. ZIP (a peptide that blocks atypical PKCs leading to GluA2-AMPAR internalization and decay of potentiation) failed to cause decay of synaptic potentiation in both strong and weak LTP in syt3 KO hippocampal slices consistent with a defect in receptor internalization. LFS-LTD was also abolished in syt3 KO slices. Syt3 KO mice learned as well as wild-type littermates in the reference memory version of the water maze, but persevered to the original platform position more than WT mice even 4 days after platform reversal. In addition, syt3 KO mice performed worse than WT mice in the delayed matching to place task, and persevered to previous platform positions more than WT, indicating a higher consolidation of working memory and/or an impairment in forgetting.

In summary, we found that syt3 is involved in a post-synaptic 'forgetting' mechanism by which receptors are internalized following stimulation to promote decay of synaptic potentiation. 


\section{Introduction}

\subsection{Synaptic transmission}

Neurons are electrically active specialized cells in vertebrates and invertebrates and are the building blocks of their nervous systems. They communicate with each other via a) electrical synapses composed of channels that allow diffusion of ions between them or b) chemical synapses, which are specialized junctions where electrical signals are transduced to a chemical signal in the pre-synaptic neuron and back to an electrical signal in the post-synaptic neuron.

Chemical synapses are critical components of the brain, which can be thought of as a complex network of a large number of neurons, in simple terms. The chemical messengers at such chemical synapses, called neurotransmitters, diffuse across the synaptic cleft by Brownian motion and activate receptors on the post-synaptic membrane. Neurotransmitter binding to their respective (ionotropic) receptors initiates a membrane depolarization which propagates towards the soma of the post-synaptic neuron. The most common excitatory neurotransmitter is L-glutamic acid or glutamate, which occurs at most of the excitatory synapses in the brain (Graham L Collingridge, Isaac, \& Wang, 2004; J. E. Lisman, Raghavachari, \& Tsien, 2007).

Communication at such synapses can be rapid, i.e., the delay between the electrical signal reaching the pre-synaptic membrane and being initiated on the post-synaptic membrane is on the millisecond scale, and $0.6 \mathrm{~ms}$ at hippocampal mossy fiber synapses (J. E. Lisman et al., 2007). Some synapses in the mammalian central nervous system have evolved to sustain extremely high frequencies of transmission. For example, the highest known rate of synaptic transmission is at the mossy fiber synapse in the cerebellum at $1.6 \mathrm{kHz}$ (Delvendahl \& Hallermann, 2016), while other synapses have evolved to transmit with high temporal precision, for example at the Calyx of Held synapse in the auditory brainstem (Borst \& Soria van Hoeve, 2012). 


\section{- Types of neurotransmitter release}

Spontaneous neurotransmitter release is defined as the release from pre-synaptic terminals observed after inhibition of voltage gated sodium channels, i.e. in the absence of action potentials. In this case, stochastic fusion of single synaptic vesicles releases a quantum of neurotransmitter. Synchronous release, on the other hand, is evoked by an action potential such that the release of transmitter is tightly synchronized with the arrival of the action potential at the axon terminal. Synaptotagmin 1 (or synaptotagmin2) is the calcium sensor that is necessary for this type of release. It is thought that a distinct synaptic vesicle pool marked by the non-canonical SNARE Vtila mediates spontaneous release (D. M. Ramirez, Khvotchev, Trauterman, \& Kavalali, 2012) and spontaneous and evoked vesicle pools are distinct (Fredj \& Burrone, 2009), although this is debated (Groemer \& Klingauf, 2007; Hua, Sinha, Martineau, Kahms, \& Klingauf, 2010; Wilhelm, Groemer, \& Rizzoli, 2010).

Asynchronous release is the release of transmitter that occurs from approximately $10-500 \mathrm{~ms}$ after the arrival of the action potential (following synchronous release that occurs in the first few $\mathrm{ms})$.

\section{- Types of neurotransmitter receptors}

Ionotropic receptors are membrane proteins that change conformation upon ligand (neurotransmitter) binding. This opens a transmembrane pore, providing a transient conductance through which ions can flow into or out of the post-synaptic neuron and change its local transmembrane potential. These receptors can be selective to certain ions.

The most relevant glutamatergic ionotropic receptors to synaptic transmission are $\alpha$-amino-3hydroxy-5-methyl-4-isoxazolepropionic acid (AMPA), and N-methyl D-Aspartic acid (NMDA) receptors. The AMPA receptor, named after its artificially developed selective agonist AMPA, is a tetrameric membrane protein composed of four subunits, GluA1-4, and two splice isoforms of GluA2 and GluA4. All AMPA receptors are permeable to sodium and potassium but only GluA2lacking AMPA receptors are permeable to calcium. As these receptors open and desensitize very 
quickly, they are said to mediate fast synaptic transmission in the central nervous system and are the most common glutamate receptor (Henley \& Wilkinson, 2016; Shepherd \& Huganir, 2007).

The NMDA receptor is named after its selective agonist, NMDA. It is also an ionotropic receptor that is permeable to sodium, potassium and calcium. It opens upon binding glutamate and glycine. However, it doesn't conduct at resting membrane potentials because its pore is blocked by external $\mathrm{Mg}^{2+}$ ions. It only conducts at depolarized membrane potentials when the $\mathrm{Mg}^{2+}$ block is relieved. NMDA receptors are a necessary source of calcium influx to the post-synaptic side of the synapse upon simultaneous pre- and post-synaptic activation and hence, play a critical role in synaptic plasticity (Paoletti, Bellone, \& Zhou, 2013).

\subsection{Synaptic Plasticity}

Another unique, and arguably most critical property of synapses, is the ability to modulate their transmission properties. This change in efficacy of transmission is called synaptic plasticity. A neuron in the mammalian brain receives $\sim 10,000$ synaptic connections but synaptic plasticity allows a neuron to selectively change its connection strength with distinct pre-synaptic partners (Henley \& Wilkinson, 2016).

Chemical synapses between two neurons have a stable input-output response characteristic until the pre-and post-synaptic sides of the synapse undergo a distinct pattern of coordinated activity resulting in an increase or decrease in strength. An increase in synaptic strength is termed synaptic potentiation whereas a decrease in synaptic strength is termed synaptic depression. In 1973, Tim Bliss and Terje Lomo (in Per Andersen's laboratory in Oslo, Norway) published findings from field recordings in the hippocampi of anesthetized rabbits demonstrating that brief high frequency bursts of pre-synaptic action potentials caused a persistent potentiation of the post-synaptic current, calling this phenomenon "frequency potentiation". Four $10 \mathrm{sec}$ long $15 \mathrm{~Hz}$ trains of stimulation each separated by at least 20 minutes in perforant path synapses led to a pathway-specific increase in field potentials recorded from post-synaptic granule cells that persisted for at least 5 hours (Bliss \& Lømo, 1973; Lomo, 2003). This persistent shift in the input-output response characteristic of a synapse towards higher response was termed long-term potentiation (LTP) and the above 
publication is credited for the discovery of this phenomenon, which is now firmly believed to be the synaptic correlate of learning and memory (A et al., 2015; Nabavi et al., n.d.; Poo et al., 2016; S. Ramirez et al., n.d.; Redondo et al., 2014; Roy et al., 2016; Ryan, TJ, Roy, DS, Pignatelli, M, Arons, A, \& Tonegawa, S, n.d.). A persistent weakening of synapses was first discovered in the cerebellum in 1980 and termed long-term depression (LTD) (Ito M \& Kano M, 1982). In 1983, Graham Collingridge showed that the NMDA receptor serves as a coincidence detector for the post-synaptic expression of plasticity, owing to its unique property of requiring both glutamate binding to an extracellular ligand binding site and relief of its magnesium block by membrane depolarization. Post-synaptically expressed NMDA receptors mediate post-synaptic calcium influx only when the pre- and post-synaptic sides of the synapse undergo simultaneous depolarization. While pre-synaptically released glutamate activates NMDA receptors, postsynaptic depolarization via AMPA receptors or back propagating action potentials are required to relieve their magnesium block (G. L. Collingridge, Kehl, \& McLennan, 1983).

\section{- Homosynaptic vs heterosynaptic plasticity}

Heterosynaptic plasticity refers to the input specific modulation of synaptic strength, as discussed above. However, in 1998, Gina Turrigiano (Brandeis University, USA) discovered that neuronal firing is also subject to a homeostatic regulation, similar to other physiological variables like body temperature and blood glucose levels. A neuron employs molecular mechanisms to tune the synaptic strength of all its synapses at once, termed synaptic scaling or homeostatic plasticity. Chronic silencing of neuronal cultures with tetrodotoxin for 24-48 hours causes neurons to homeostatically scale up synaptic strength whereas increasing activity of cultures with bicuculline causes neurons to scale down synaptic strength (Gina G. Turrigiano, Kenneth R. Leslie, Niraj S. Desai, \& Lana C. Rutherford \& Sacha B. Nelson, 1998; Turrigiano \& Nelson, 2004).

It was also shown that such homeostatic mechanisms can operate at individual synapses (Bartlett \& Wang, 2011). Chronic optogenetic activation of a subset of synapses on the dendrite of a postsynaptic neuron decreased surface AMPA receptor levels only at activated synapses, leaving nearby synapses unaffected (Qingming Hou, Gilbert, \& Man, 2011). Conversely, silencing a subset of synapses increased surface AMPA receptor levels only on the synapses that were silenced (Q Hou, Zhang, \& Jarzylo, 2008). 


\section{- Weak LTP and strong LTP}

Strong-LTP, or late-LTP, refers to potentiation that persists for at least few hours in vitro or even up to several weeks in vivo. It is most well-studied in the Schaffer collateral CA3 to CA1 connection in the hippocampus, but occurs in multiple brain regions. Using extracellular field recordings, brief high frequency stimulation of afferent fibers of hippocampal CA1 pyramidal neurons has been shown in a number of studies to lead to robust LTP in acute hippocampal slices (in vitro) or in freely behaving animals (in vivo). Strong-LTP derives its name from the strength of the LTP induction stimulus whereas late-LTP derives its name from the duration of persistence of LTP, but they refer to the same phenomenon. Strong-LTP induction protocols are a) spaced high frequency stimulation (HFS), typically employing three $100 \mathrm{~Hz}$ trains with a duration of 1 second separated by at least 5 minutes (P. Park et al., 2013), or b) theta burst stimulation, which involves pairing coincident EPSPs and postsynaptic action potentials in a burst, i.e., 5 times at $100 \mathrm{~Hz}$. Multiple theta stimulation trains are usually delivered at $0.1 \mathrm{~Hz}$, each theta train consisting of 5 bursts at $5 \mathrm{~Hz}$. (Hoffman, Sprengel, \& Sakmann, 2002). Strong-LTP induction requires de novo protein synthesis and NMDA receptor activation (P. Park et al., 2013).

Weak-LTP, or early-LTP, refers to potentiation that decays completely in less than 1-2 hours (Villarreal, Do, Haddad, \& Derrick, 2002; Xiao, Niu, \& Wigström, 1996). Weak-LTP derives its name from the strength of the LTP induction stimulus whereas early-LTP derives its name from the duration of persistence of LTP, but they refer to the same phenomenon. Weak-LTP induction stimuli are typically weaker versions of strong-LTP induction stimuli. For instance, while a strong HFS (4 trains of 30 pulses at $100 \mathrm{~Hz}$, with an inter-train interval of 5 minutes) induced strong-LTP that persisted for at least 24 hours, a weak HFS ( 2 trains of 30 pulses at $100 \mathrm{~Hz}$, with an inter-train interval of 5 minutes) induced weak-LTP that decayed to baseline in 2 hours at the CA3-CA1 synapse in vivo in the hippocampus (Z. Dong et al., 2015). Weak LTP is thought to be the early phase of strong LTP, that might not require de novo protein synthesis and depend on NMDA receptors (P. Park et al., 2013; Raymond, 2007; Reymann \& Frey, 2007). 


\section{- LTD and depotentiation}

On the other hand, low frequency pre-synaptic stimulation for more extended periods of time leads to robust long-term depression or LTD. A typical LTD induction protocol, termed low frequency stimulation (LFS) is $1 \mathrm{~Hz}$ stimulation for $15 \mathrm{~min}$. LTD induced via NMDA receptor activation requires protein synthesis (G. Collingridge, Peineau, Howland, \& Wang, 2010).

Depotentiation refers to the reversal of LTP by stimulation protocols similar to those used to induce LTD. Although depotentiation induction mechanisms strongly overlap with LTD induction protocols, there are some reported differences. For example, $2 \mathrm{~Hz}$ LFS was reported to induce depotentiation but not LTD (G. Collingridge et al., 2010; T. M. Sanderson, 2012).

\section{- Spike timing dependent plasticity (STDP)}

In addition to the use of field stimulation and recordings from many neurons at once in the protocols described above, LTP or LTD can also be evoked in individual pairs of pre-and postsynaptically connected neurons, using whole cell recordings, and pairing of stimulation in a temporally coordinated fashion (also discussed above in Theta burst stimulation). Induction of presynaptic action potentials followed within 10 milliseconds by post-synaptic stimulation yields LTP. On the other hand, if post-synaptic action potentials precede pre-synaptic action potentials by up to 15 milliseconds, LTD is induced. This phenomenon was conceptualized as spike timing dependent plasticity (STDP) (Dan Y, Poo MM, 1992; Edelmann et al., 2015). Donald Hebb, a Canadian psychologist, hypothesized in 1949 a phenomenon, which was later aptly summarized as "neurons that fire together, wire together" (Lowel S, Singer W, 1992). The discovery of STDP provided the neurobiological correlate for this theory of Hebbian learning. Temporally noncorrelated firing of connected neurons doesn't affect their connection strength. However, temporally correlated firing of two connected neurons within a short time window of 10-15 milliseconds can change connection strength, such that the post-synaptic neuron firing later is "rewarded" (the synapse is strengthened) whereas post-synaptic firing earlier than pre-synaptic is "punished" (the synapse is weakened). 


\section{- Metaplasticity}

The increased excitability of two recently potentiated neurons increases the likelihood of potentiation of other synapses in the network. Thus, in a large network of inter-connected neurons, the Hebbian plasticity model is prone to lead to uncontrolled potentiation of all synapses. The Bienenstock Cooper Munro (BCM) theory of sliding plasticity thresholds accounts for how this is prevented. In a more active network, the threshold for LTP induction is increased, such that those stimuli that would have originally caused LTP will now be too weak to cause any further potentiation (Cooper \& Bear, 2012). This "metaplasticity" may be regulated by adjustment of the number or composition of synaptic NMDARs, and thus the amount of calcium influx the postsynaptic side of the synapse experiences in response to pre-synaptic stimulation (Philpot, Cho, \& Bear, 2007). Reductions in post-synaptic calcium influx via metaplasticity can increase the threshold of plasticity induction, potentially protecting potentiated synapses from any depotentiating stimuli and could be the mechanism used by synapses to lock away memories safely for posterity (Hardt, Nader, \& Wang, 2014).

\section{- Calcium is an important regulator of synaptic plasticity}

Calcium ion influx and changes in spatiotemporal $\left[\mathrm{Ca}^{2+}\right]$ in dendrites is crucial for the induction and expression of synaptic plasticity. Dendritic spines are protrusions consisting of a bulbous head separated from the dendrite by a thin neck, as in the "mushroom spines" commonly found in hippocampal CA1 pyramidal neurons (Sabatini, Oertner, \& Svoboda, 2002). The spine neck isolates the spine from the dendritic shaft biochemically, by acting as a diffusion barrier for calcium, second messengers and other enzymes critical to plasticity (Govindarajan, Israely, Huang, \& Tonegawa, 2012; J. Lisman, Yasuda, \& Raghavachari, 2012). It also isolates the spine electrically, by virtue of its high input resistance (Harnett, Makara, Spruston, Kath, \& Magee, 2012). A biochemical cascade will occur in the spine if the signaling cascade in a spine culminates before there is significant diffusion of components across the spine neck. This property allows a neuron to independently regulate the strength of its synaptic connections with multiple presynaptic partners. As described in the next few sections, the spine architecture also regulates the trafficking of AMPA receptors (Choquet \& Triller, 2013). 
Calcium is essential for both LTP and LTD. While LTP is induced by rapid and large accumulations of calcium, LTD is induced by small calcium influxes over extended periods of time. It is not entirely clear how calcium influx can lead to extremely divergent consequences for synaptic plasticity (G. Collingridge et al., 2010). Calmodulin, a cytosolic C2 domain containing $\mathrm{Ca}^{2+}$ binding protein, can regulate the balance between LTP and LTD in spines by binding incoming $\mathrm{Ca}^{2+}$ and subsequently activating Calmodulin dependent Kinase II (CamKII), which has low calcium affinity and leads to LTP, or calcineurin, which has high calcium affinity and leads to LTD (Li, Stefan, \& Le Novère, 2012).

The resting $\left[\mathrm{Ca}^{2+}\right]$ in spines and dendrites is in the range 40-100 $\mathrm{nM}$ (Sabatini et al., 2002). Spines in CA1 pyramidal neurons have $\sim 5-10$ fold higher surface to volume ratios and $\sim 2-3$ fold lower endogenous $\mathrm{Ca}^{2+}$ buffering capacity than apical dendrites, thus allowing large and extremely rapid $\left[\mathrm{Ca}^{2+}\right]$ changes in spines compared to dendrites. For example, a single action potential evokes a $\mathrm{Ca}^{2+}$ influx of $\sim 1.5 \mu \mathrm{M}$ in spines but only $\sim 0.2 \mu \mathrm{M}$ in dendrites (Sabatini et al., 2002). At the same time, $\mathrm{Ca}^{2+}$ is rapidly extruded from the spine with a time constant of $\sim 12 \mathrm{~ms}$ (Sabatini et al., 2002).

The most important dendritic plasma membrane calcium ion channels are NMDA receptors and L type/ R-type voltage gated calcium channels (Sabatini et al., 2002). Calcium influx from these sources can also be amplified by calcium release from internal stores via Ryanodine receptors (RyRs) and Inositol-1,4,5-triphosphate (InsP $\mathrm{P}_{3} \mathrm{Rs}$ ) receptors on the endoplasmic reticulum (ER) or its extensions in spines known as the spine apparatus, in a phenomenon termed calcium induced calcium release (CICR) (Berridge, 1998). Almost all of the $\mathrm{Ca}^{2+}$ that flows in is rapidly extruded from the spine by ion channels on the post-synaptic membrane, like the plasma membrane $\mathrm{Ca}^{2+}$ ATPase (PMCA), or sequestered into internal stores via Sarco/endoplasmic reticulum $\mathrm{Ca}^{2+}$ ATPase (SERCA) pumps (Sabatini et al., 2002). Although bulk $\left[\mathrm{Ca}^{2+}\right]$ in spines reaches a few $\mu \mathrm{M}$ at most, regions within a few nanometers of the $\mathrm{Ca}^{2+}$ source, called nanodomains, can reach $10-$ $100 \mu \mathrm{M}$ for a few microseconds. $\mathrm{Ca}^{2+}$ currents evoked by action potentials (APs) are brief $(<1 \mathrm{~ms})$ and small whereas synaptically evoked NMDAR currents are much larger and last longer $(>100$ ms) (Sabatini et al., 2002). 


\section{- AMPA receptor trafficking}

The trafficking of AMPA receptors between synaptic and extra synaptic surface compartments, and between the surface and internal compartments in dendrites, is tightly regulated (Carroll RC, Lissin DV, von Zastrow M, Nicoll RA, Malenka RC, 1999). Dendritic spines are not only isolated electrical and biochemical subcompartments on dendrites but also contain intricate machinery to regulate AMPA receptor trafficking. The number (or conductance) of receptors on the plasma membrane surface at the post-synaptic density (PSD) directly correlates with synaptic strength. Surface AMPA receptor composition, which results from a balance between surface diffusion, endocytosis and exocytosis is widely regarded as the most important mechanism underlying

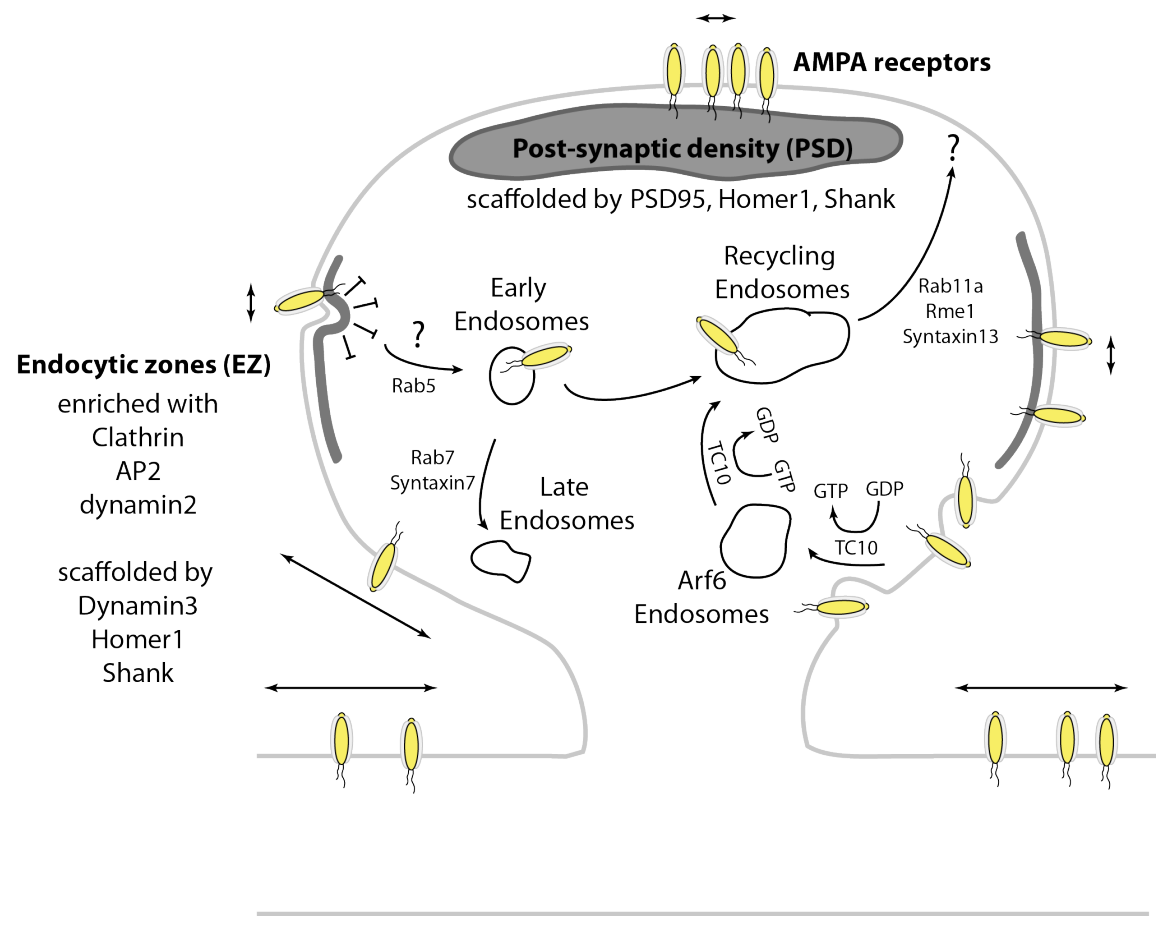

\section{Introduction figure 1: AMPA receptor trafficking in dendrites.}

AMPA receptors are highly mobile in extra-synaptic zones but diffusionally trapped at the post-synaptic density (PSD) or at endocytic zones (EZ). The PSD is enriched in DLG-MAGUKs (Disc Large Homologues-Membrane associated Guanylate Kinases) like PSD95, Homer1 and Shank which serve an important scaffolding and functional role. BRAG2 is aso enriched in the PSD. The endocytic zones are plasma membrane regions skirting the PSD which are enriched in Clathrin, AP2, dynamin2 and Endophilin2,3 and held close to the PSD by dynamin3 oligomers linked to Homer1 and Shank. Constitutive AMPA receptor internalization proceeds via the clathrin independent endocytosis pathway onto Arf6 containing endosomes and subsequently into recycling endosomes. Activity dependent internalization proceeds via clathrin dependent endocytosis, which recycles transferrin receptors in resting conditions via recycling endosomes. TC10, a Rho GTPase, controls loading and unloading of AMPA receptors onto Arf6 endosomes. The various Rab GTPases and syntaxin isoforms in the different vesicle trafficking stages are shown. 
synaptic plasticity and consequently, learning and memory (Derkach, Oh, Guire, \& Soderling, 2007; Henley \& Wilkinson, 2016; Shepherd \& Huganir, 2007).

\subsection{Constitutive trafficking of AMPA receptors mediates basal synaptic transmission}

AMPA receptors recycle even in basal conditions, with complete turnover of surface receptors occurring in $\sim 15$ mins (J. W. Lin et al., 2000). AMPA receptors are constitutively endocytosed via clathrin mediated endocytosis at specialized endocytic zones close to PSDs (Blanpied, Scott, \& Ehlers, 2002; Lu et al., 2007; Petrini et al., 2009; Rácz, Blanpied, Ehlers, \& Weinberg, 2004) into recycling endosomes, with subsequent exocytosis via Rab11 and Rme1 (M. Park, Penick, Edwards, Kauer, \& Ehlers, 2004; Petrini et al., 2009). The clathrin mediated endocytosis pathway is known to constitutively recycle transferrin receptors (Jurado et al., 2013; Tao-Cheng et al., 2011), also via recycling endosomes (Ehlers, 2000; M. Park et al., 2004).

\section{- Molecular machinery mediating clathrin mediated endocytosis}

Clathrin mediated endocytosis is initiated by BAR domains (named after proteins they were found in: Bin, Amphiphysin, Rvs), wedge shaped structures that insert into the plasma membrane and curve it by occupying a larger volume on the membrane surface than at the midline of the membrane. Membrane binding proteins bind the phospholipid PIP2 (phosphatidylinositol-4,5bisphosphate or PtdIns $\left.(4,5) \mathrm{P}_{2}\right)$ on the cytoplasmic face of the plasma membrane and generate the initial membrane curvature (McMahon \& Boucrot, 2011).

This is followed by recruitment of AP2 (McMahon \& Boucrot, 2011), which in turn recruits cargo, together with clathrin (Kelly BT, Graham SC, Liska N, Dannhauser PN, Höning S, Ungewickell EJ, Owen DJ, 2014; Kirchhausen, Owen, \& Harrison, 2014; Robinson, 2004). The core domain of AP2 binds to plasma membrane cargo, including the C-termini of AMPA receptors and also clusters multiple AP2 complexes at the membrane by binding to other accessory proteins. Other domains attached to the core domain via appendage-like long flexible linkers, cluster AP2 complexes effectively at endocytic sites and also serve as a binding interface for clathrin (which 
cannot bind membranes directly). In some cases, cargo specific adaptors bind to AP2 linker domains and recruit receptors to AP2 (McMahon \& Boucrot, 2011; Schmid \& McMahon, 2007).

Clathrin polymerizes to form a lattice or vesicle coat (Schmid \& McMahon, 2007). Clathrin coat assembly, dispersal, and reassembly occurs in $\sim 30 \mathrm{~s}$ in dendrites of neurons transfected with clathrin-GFP, similar to the time-course for synaptic vesicle endocytosis. The clathrin coat is rapidly recycled in spines whereas events in dendritic shafts drew clathrin from distant pools (Blanpied et al., 2002). Dynamin is a GTPase that forms a spiral around the neck of a coated vesicle and uses energy derived from GTP hydrolysis to constrict and pinch off a coated vesicle from the plasma membrane (Ferguson \& De Camilli, 2012).

\section{- Endocytic zones at dendritic spines}

Like synaptic vesicles, which are endocytosed at regions lateral to active zones, AMPA receptors are also thought to be endocytosed at clathrin rich 'endocytic zones' in regions lateral to PSDs in dendritic spines. Clathrin coated pits have been observed in dendrites and lateral domains of spines but almost never in the PSD by electron microscopy (Petrini et al., 2009). Immunogold labelling experiments revealed that AP2 levels peaked $\sim 290 \mathrm{~nm}$ lateral to the PSD, clathrin at $\sim 340 \mathrm{~nm}$ and dynamin-2 at $\sim 390 \mathrm{~nm}$ from the PSD, the furthest tangential point being $\sim 700 \mathrm{~nm}$ on average. These endocytic proteins were found even in the absence of coated endocytic pits, suggesting they are always present at specific endocytic zones (Rácz et al., 2004). In culture, endocytic zones (EZs) marked with clathrin-DsRed are normally very stable next to PSD95-GFP puncta whereas clathrin puncta in dendritic shafts show some random movement (Blanpied et al., 2002).

The post-synaptic endocytic zone is stabilized structurally by a dynamin3-Homer-Shank complex (Lu et al., 2007). While dynamin-1 is important for SV endocytosis in pre-synaptic terminals, dynamin-2 and dynamin-3 have important post-synaptic functions. While dynamin-1 and dynamin-2 are involved in membrane scission, dynamin-3 has a scaffolding function at endocytic zones. The dynamin-3 immunogold signals peaked at $\sim 350 \mathrm{~nm}$ from the PSD edge, coinciding with that of clathrin. The oligomerization of dynamin-3 with itself and dynamin-2 is necessary for its scaffolding function. Dynamin-3 also binds actin associated endocytic adaptors in the PSD bringing it in close proximity to receptors ( $\mathrm{Lu}$ et al., 2007). 


\section{- Surface diffusion of AMPA receptors}

AMPA receptors diffuse in the plasma membrane, and are much more diffusive at extra-synaptic sites than within the PSD. Synaptic activity increases extra-synaptic diffusion of AMPA receptors (Groc, Heine, Cognet, \& Brickley, 2004). Stargazin interacts with PSD95 via its PDZ domain (Schnell E, Sizemore M, Karimzadegan S, Chen L, Bredt DS, Nicoll RA, 2002), and stabilizes AMPA receptors at the PSD in $\sim 80 \mathrm{~nm}$ nanodomains (MacGillavry, Song, Raghavachari, \& Blanpied, 2013; Nair et al., 2013). Glutamate binding to AMPA receptors disrupts the AMPA receptor-stargazin interaction, increasing their mobility out of the PSD (Constals et al., 2015). Like the PSD, dynamin-3 scaffolded endocytic zones (described in on page 12 above) in the lateral domains of PSDs on spines, provide a second barrier to AMPA receptor diffusion (Petrini et al., 2009).

AMPA receptors are diffusionally slowed down at EZs as much as at PSD surfaces. EZs can be physically dislocated from the lateral domains of spines by expressing a Homer1 binding deficient mutant of dynamin-3 (Lu et al., 2007; Petrini et al., 2009). Uncoupling EZs from the PSD also reduced the number of synaptic GluA1-AMPA receptors by more than half although the total number of surface GluA1-AMPA receptors was unaffected. This is either because constitutively surface trafficked receptors are no longer diffusionally trapped at EZs and, therefore, escape to extra-synaptic areas, or the supply of constitutively internalized AMPA receptors to the local spine recycling endosome pathway is cut off. Thus, endocytic zones, which cover $\sim 85 \%$ of the spine area, are crucial to maintain a basal synaptic surface AMPA receptor population by reducing diffusion of AMPA receptors to extra-synaptic areas and maintaining a supply of AMPA receptors in the local constitutive recycling pathway via AP2-mediated constitutive endocytosis (Rácz et al., 2004; Petrini et al., 2009).

How are AMPA receptors diffusionally slowed at the EZ? Experiments suggest that the intrinsic molecular composition and properties of EZs limit AMPA receptor diffusional mobility, independent of the PSD. Slowed down receptors that spent long enough at the EZ are internalized via clathrin mediated endocytosis. GluA1-AP2 binding via the cytoplasmic C-tail R848 residue on GluA1, is necessary for the internalization and diffusional trapping of AMPA receptors at EZs 
(Petrini et al., 2009). The AP2 complex is thought to exist in an inactive "closed" conformation in the cytosol that prevents unproductive interaction with clathrin. Binding to plasma membrane enriched PIP2 and to transmembrane cargo (like positively charged motifs on AMPA receptor Ctails or on synaptotagmins as shown in Introduction figure 2 on page 34), triggers conformational changes in AP2 that allow efficient binding to clathrin and phospholipids and bud formation which initiates clathrin coat assembly (Grass, Thiel, Honing, \& Haucke, 2004; Kelly BT, Graham SC, Liska N, Dannhauser PN, Höning S, Ungewickell EJ, Owen DJ, 2014).

Thus, the surface diffusion and the constitutive clathrin mediated endocytosis of AMPA receptors are tightly inter-linked.

\section{- Constitutive trafficking of AMPA receptors}

Another important player in constitutive clathrin mediated endocytosis of AMPA receptors is Arc/Arg3.1, an immediate early gene important for LTP and LTD and memory consolidation (Shepherd \& Bear, 2011). Molecularly, Arc mediates constitutive endocytosis of AMPA receptors (Chowdhury et al., 2006) (Waung, Pfeiffer, Nosyreva, Ronesi, \& Huber, 2008), mediated via its interactions with AP2 (DaSilva et al., 2016).

Other studies also showed that AMPA receptors are internalized constitutively by clathrin mediated endocytosis. Competitive inhibition of the GluA2-AP2 interaction in basal conditions by the AP2 binding motif of synaptotagmin1, KRLKKKKTTIKK, increased AMPA receptor surface expression and caused an increase in mEPSC amplitude by $\sim 15 \%$ (Kastning K, Kukhtina V, Kittler JT, Chen G, Pechstein A, Enders S, Lee SH, Sheng M, Yan Z, Haucke V., 2007). Application of the dynamin inhibitory peptide (DIP), which inhibits dynamin-amphiphysin interactions and thus clathrin mediated endocytosis, caused a robust run-up of EPSCs (Glebov, Tigaret, Mellor, \& Henley, 2015; Lüscher C, Xia H, Beattie EC, Carroll RC, von Zastrow M, Malenka RC, Nicoll RA, 1999). However, evidence for clathrin independent endocytosis of AMPA receptors has been mounting as well (Petralia, Wang, \& Wenthold, 2003; Tao-Cheng et al., 2011). Almost all (98\%) coated pits and vesicles near the plasma membrane of neuronal somas and dendrites show immunogold labelling for clathrin. While $\sim 75 \%$ of them contained transferrin receptors, only $\sim 25 \%$ of them contained GluA2 signal in basal conditions. At endocytic zones, although almost 
all $(93 \%)$ coated pits contained transferrin receptors in basal conditions, but almost none of them contained GluA2. This suggests GluA2-AMPA receptors are not preferentially endocytosed by clathrin mediated endocytosis in basal conditions at EZs (Tao-Cheng et al., 2011).

Indeed, very recent studies showed that constitutive internalization of AMPA receptors is clathrin independent, and these evidences are arguably stronger than those showing clathrin-dependence (Glebov et al., 2015; Zheng, Jeyifous, Munro, Montgomery, \& Green, 2015). Multiple approaches used to block clathrin mediated endocytosis (clathrin heavy chain shRNA mediated knock down, expression of dominant negative mutant of AP180 or dynamin2, and inhibition of dynamin2 GTPase activity by dynasore or Pitstop2) significantly reduced internalization of transferrin receptors as expected. However, these perturbations did not affect constitutive internalization of GluA1 or GluA2-containing AMPA receptors whatsoever (Glebov et al., 2015). Inhibiting GluA2AP2 interactions also did not affect EPSCs in basal conditions (Griffiths et al., 2008; S. Lee, Liu, Wang, \& Sheng, 2002). Another study showed that AMPA receptors are constitutively internalized via Arf6 (a GTPase important for membrane trafficking) containing endosomes, which is known to be a clathrin-independent pathway (Zheng et al., 2015). These studies are not in conflict with those showing that AMPA receptors are constitutively internalized via clathrin mediated endocytosis (M. Park et al., 2004; Petrini et al., 2009), because constitutively internalized transferrin receptors and constitutively internalized AMPA receptors converge at recycling endosomes (Glebov et al., 2015). Only the mechanism of internalization at the plasma membrane is different. While the conversion of GDP to GTP by TC10 loads AMPA receptors onto Arf6 endosomes, its GTPase function is important for exit of AMPA receptors from Arf6 endosomes back to the plasma membrane via recycling endosomes (Zheng et al., 2015) (Introduction figure 1 on page 10). Another unexpected player in constitutive AMPA receptor internalization is the GTPase, Rac1, which was so far only implicated in regulation of spine morphology and regulation of membrane trafficking through actin polymerization. Pharmacological blockade of Rac1 also blocked the constitutive internalization of AMPA receptors (Glebov et al., 2015).

AMPA receptors are constitutitvely recycled back to the surface via the GTPase Rab11 and Eps15 homology domain protein EDH1/ Rme1 from recycling endosomes. This exocytosis is 
dependent on syntaxin13, but not syntaxin7, which mediates trafficking of receptors to late endosomes (M. Park et al., 2004) (Introduction figure 1 on page 10).

\subsection{Activity dependent trafficking of AMPA receptors mediates synaptic plasticity}

Depending on the stimulation received at a synapse, the number of AMPA receptors at the PSD surface can be altered to regulate synaptic strength by a) redirecting the flux of existing AMPA receptors through various recycling pathways, or b) increasing or decreasing the total number of AMPA receptors in circulation. During LTP, the trafficking of AMPA receptors in the recycling endosome pathway described above is upregulated. The exocytosis of GluA1 containing AMPA receptors from recycling endosomes via Rab11, Rme1 and syntaxin 13 is necessary for glycine induced chemical LTP in culture and HFS-LTP at the CA3-CA1 synapse in the hippocampus endosomes (M. Park et al., 2004). Although the extent to which AMPA receptors are constitutively internalized via clathrin mediated endocytosis is probably very low (as argued on page 14 above), activity mediated AMPA receptor internalization or LTD is mediated largely via clathrin mediated endocytosis (Carroll et al., 1999; S. Lee et al., 2002; Lüscher C, Xia H, Beattie EC, Carroll RC, von Zastrow M, Malenka RC, Nicoll RA, 1999; Man et al., 2000; Wang YT, Linden DJ, 2000). After NMDA-induced AMPA receptor internalization, GluA2 immunogold label was found twice as often at clathrin coated pits, and the number of labels per pit on extra-synaptic or spine membranes also doubled (Tao-Cheng et al., 2011). In addition, disruption of the GluA2-AP2 interaction by the GluA2 ( $\triangle \mathrm{A} 849-\mathrm{Q} 853)$ peptide blocked LFS-LTD in the hippocampus (S. Lee et al., 2002) and in the perirhinal cortex (Griffiths et al., 2008) and also blocked 'natural forgetting' of memories in rats (Migues et al., 2016). Thus, GluA2-AP2 interactions (and by extension clathrin-mediated endocytosis) are necessary for activity dependent AMPA receptor internalization.

\section{- Stimulation induced internalization of AMPA receptors}

Many plasma membrane receptors, including $\beta 1$ and $\beta 2$ adrenergic receptors (Yoshihara $\mathrm{T}$, Yonoki Y, Saito M, Nakahara T, Sakamoto K, Ishii K, 2013), cannabinoid CB1 receptors (Coutts 
AA, Anavi-Goffer S, Ross RA, MacEwan DJ, Mackie K, Pertwee RG, Irving AJ, 2001), and Neuropeptide Y (Y1) receptors (Pheng et al., 2003) internalize upon binding their agonist. Application of glutamate, insulin, AMPA or NMDA to dissociated neuronal cultures internalizes AMPA receptors, and has been used to examine the underlying molecular machinery (Beattie et al., 2000; Carroll et al., 1999; Ehlers, 2000; T. Hayashi, 2004; S. H. Lee, Simonetta, \& Sheng, 2004; S. Lee et al., 2002; J. W. Lin et al., 2000). Both AMPA or CNQX/DNQX, competitive antagonists of AMPA receptors that occupy the ligand binding site, induce internalization of AMPA receptors (J. W. Lin et al., 2000). However, CNQX induced internalization is smaller in magnitude and not dependent on L-type voltage gated channels or inhibited by serine threonine phosphatases PP1 and PP2A (unlike AMPA induced internalization), indicating different mechanistic underpinnings (J. W. Lin et al., 2000). On the other hand, GYKI 52466, a noncompetitive antagonist that binds an allosteric site of AMPA receptors does not induce AMPA receptor internalization (J. W. Lin et al., 2000).

AMPA stimulation leads to transient internalization of AMPA receptors followed by recycling to the surface (Ehlers, 2000; S. H. Lee et al., 2004). AMPA induced internalization depends on clathrin (J. W. Lin et al., 2000), voltage gated calcium channels (Beattie et al., 2000), calcium influx (Beattie et al., 2000; Ehlers, 2000), and calcineurin, a serine/threonine phosphatase ((Beattie et al., 2000); but see also (J. W. Lin et al., 2000)) but not tyrosine phosphatases (J. W. Lin et al., 2000). Internalization is highly enhanced by PP1 and PP2A inhibitors (J. W. Lin et al., 2000).

NMDA-induced internalization of AMPA receptors (also termed chemical LTD) and LFS-LTD share common signalling pathways (Beattie et al., 2000; Ehlers, 2000). NMDA induced internalization depends on $\mathrm{Ca}^{2+}$ influx and activation of phosphatase pathways including calcineurin (PP2B) (Beattie et al., 2000) and PP1 (Ehlers, 2000), but not on voltage gated calcium channels (Beattie et al., 2000). NMDA stimulation also leads to lysosomal degradation after internalization (Ehlers, 2000; S. H. Lee et al., 2004).

\section{LFS-LTD and mGluR-LTD:}

Low frequency stimulation induced LTD (LFS-LTD), which also causes internalization of AMPA receptors, is dependent on NMDA receptors (Scholz et al., 2010), calcium influx and phosphatases 
but not on tyrosine phosphatases (Scholz et al., 2010). mGluR (metabotropic glutamate receptor)LTD, induced by application of DHPG, a selective agonist of group $1 \mathrm{mGluRs}$, is dependent on dephosphorylation of GluA2 (Moult, Corrêa, Collingridge, Fitzjohn, \& Bashir, 2008). LFS-LTD and mGluR-LTD do not occlude each other (Nicoll RA, Oliet SH, Malenka RC, 1998) but converge on the $3 \mathrm{Y}$ motif of GluA2 (Scholz et al., 2010).

\section{Insulin stimulation mediated AMPA receptor internalization:}

Insulin induced AMPA receptor internalization is much slower than AMPA induced internalization, reaching maximal levels in $\sim 30 \mathrm{~min}$ (J. W. Lin et al., 2000). Internalization is dependent on tyrosine phosphatases (J. W. Lin et al., 2000), dynamin2 and calcium influx (Beattie et al., 2000; Man et al., 2000) and calcineurin (Beattie et al., 2000). Insulin mediated internalization is abolished by mutation of the 3 tyrosine residues (Y869, Y873, Y876) in the GluA2 3Y (869 YKEGYNVYG $_{877}$ ) motif to alanines leaving constitutive trafficking unaffected (Ahmadian et al., 2004). Insulin induced LTD also increases GluA2-AP2 interaction (Man et al., 2000). Although insulin receptors (IGF-1) are expressed on post-synaptic densities, it is not clear exactly how insulin induces AMPA receptor LTD. Thus, although LFS-LTD and insulin-LTD are mediated by different mechanisms, they converge at clathrin mediated endocytosis (Wang YT, Linden DJ, 2000) and occlude each other (Man et al., 2000).

\section{- Subunit rules of activity dependent AMPA receptor internalization}

The unique signalling motifs on the cytoplasmic tails (C-tails) of the different AMPA receptor subunits affect their trafficking in different ways (Henley \& Wilkinson, 2016; Isaac, Ashby, \& J, 2007). The extracellular and transmembrane domains of all subunits are similar but the C-tails, which affect their interacting partners and trafficking mechanisms, can be divided into two classes based on sequence similarity (Shepherd \& Huganir, 2007):

- GluA1, GluA4 and the splice isoform of GluA2 which have longer C-tails.

- GluA2, GluA3 and the splice isoform of GluA4.

The GluA2 subunit seems to dominate over GluA1 with regard to AMPA or NMDA induced internalization (S. H. Lee et al., 2004). The lack of AMPA induced internalization of GluA1 homomers could be rescued by switching their C-tail with the GluA2 C-tail, showing that the 
GluA2 C-tail possesses unique motifs required for AMPA induced internalization (S. H. Lee et al., 2004).

Phosphorylation of residues on the C-tails are well-known regulators of AMPA receptor trafficking. The two important types of residues that can be phosphorylated are:

a) Serine/threonine. Prominent phosphatases include calcineurin, protein phosphatase 1 (PP1) and protein phosphatase 2 (PP2A, PP2B). Dephosphorylation of S845 and phosphorylation of S831 in the GluA1 cytoplasmic tail (C-tail) promotes LTD (Lee HK, Kameyama K, Huganir RL, Bear MF, 1998) and AMPA receptor endocytosis (Ehlers, 2000). Phosphorylation of S880 of GluA2 decreases GluA2-GRIP binding leaving GluA2-PICK1 binding unaffected, leading to AMPA receptor internalization (Chung HJ, Xia J, Scannevin RH, Zhang X, Huganir RL, 2000; Takashi Hayashi \& Huganir, 2004).

b) Tyrosine. Prominent kinases include receptor type kinases Lyn, Src, Fyn and non-receptor type tyrosine kinases Fak, Pyk2.

The GluA C-tails bind AP2 via a stretch of positively charged residues in the GluA2 C-tail (844KRMKV $\mathrm{K}_{848}$ ) (S. Lee et al., 2002). As mentioned above, although AP2 binds GluA2 constitutively (on page 14) and is present at endocytic zones (on page 12), disrupting this interaction doesn't affect basal transmission (S. Lee et al., 2002). However, activity dependent AMPA receptor internalization is dependent on clathrin mediated endocytosis (Glebov et al., 2015; Migues et al., 2016) and the GluA2-AP2 interaction (S. Lee et al., 2002). This implies that mechanisms that induce AMPA receptor internalization either activate AP2 or recruit it to GluA2 and initiate AMPA receptor internalization via clathrin mediated endocytosis.

\subsection{Important players in activity dependent AMPA receptor internalization}

\section{- PICK1 recruits AMPA receptors to sites of clathrin mediated endocytosis}

PICK1 (Protein interacting with protein kinase C-1) is enriched in the PSD (Rocca et al., 2013) and is a multifunctional player in AMPA receptor internalization during LTD in hippocampal neurons. PICK1 is also necessary for NMDA induced internalization of AMPA receptors (Terashima et al., 2008). An N- and C-terminal acidic stretch of amino acids on PICK1 can bind 
calcium and confer a biphasic calcium dependence to its interaction with GluA2 (Hanley JG, Henley JM., 2005). PICK1 interacts with GluA2 (and GluA3 (Kumlesh K. Dev, 1999)) but not with GluA1 via its PDZ domain (Hanley JG, Henley JM., 2005; Rocca et al., 2013) in a calcium dependent manner.

PICK1 regulates AMPA receptor trafficking through the recycling endosome pathway in basal conditions, as it colocalizes with Rab5 and Rab11 but not Rab7 (see Introduction figure 1; (Hanley, 2010)). PICK1 restricts surface trafficking of AMPA receptors (D.-T. T. Lin \& Huganir, 2007), while NSF (N-ethylmaleimide-sensitive factor) promotes constitutive surface trafficking of AMPA receptors by disrupting GluA2-PICK1interactions using $\alpha-/ \beta$ - SNAPs (Hanley, Khatri, Hanson, \& Ziff, 2002).

A more detailed molecular mechanism has recently emerged (Fiuza et al., 2017), suggesting that PICK1 shuttles GluA2-containing AMPA receptors to sites of clathrin coated pits for endocytosis. STED microscopy revealed PICK1 at endocytic zones where it binds GluA2 to a small extent in basal conditions as AMPA receptors are diffusing rapidly in and out of synaptic and endocytic zones. The calcium influx during an NMDA induced AMPA receptor internalization enhanced the PICK1-GluA2 interaction, which could be detected in the first 2 minutes after stimulation. In the next 2 minutes, the PICK1-AP2 interaction was enhanced by calcineurin, which was matched by an increased PICK1-dynamin interaction and a weakening of the PICK1-GluA2 interaction, probably at clathrin coated pits. Additionally, the PICK1 C-tail could catalyze the oligomerization of dynamin in co-sedimentation assays, suggesting PICK1 facilitates pinching off of the neck of the clathrin coated pit.

At the same time, PICK1 also affects actin polymerization leading to AMPA receptor internalization (Rocca et al., 2013). PICK1 directly binds Arf1 (ADP-ribosylation factor-1, a GTPase) in a GTP dependent manner via its PDZ domain. In basal conditions, most Arf1 is present in its GTP-bound state, which forces PICK1 into a locked conformation. This allows PICK1 to only weakly inhibit Arp2/3, a GTPase that mediates polymerization of actin filaments and structural stability of the spine. Upon NMDA receptor activation, GIT1 (an ArfGAP/ Arf GTPase activating protein) activation converts Arf1-GTP to Arf1-GDP. This unlocks PICK1, allowing it 
to inhibit Arp2/3 and block actin polymerization, leading to spine shrinkage and AMPA receptor internalization (Rocca et al., 2013) (See Figure 26).

\section{- Rab5 internalizes AMPA receptors into the recycling endosome pathway}

$\sim 75 \%$ of Rab5 immunogold signal was found at the post-synaptic side of synapses, where it associates with membranes via its C-terminal geranyl geranyl groups at 100-300 $\mathrm{nm}$ from the PSD edge (T. C. Brown, Tran, Backos, \& Esteban, 2005). Rab5 is mostly in its inactive (GDP bound) configuration and converted to its active form upon NMDA stimulation. Rab5 is necessary and sufficient for NMDA and LFS-induced LTD but doesn't affect constitutive AMPA receptor trafficking. The removal of synaptic GluA2-AMPA receptors by Rab5 relies on the GluA2-AP2 interaction (T. C. Brown, Tran, Backos, \& Esteban, 2005).

\section{- BRAG2 binds to dephosphorylated Y876 and is necessary for LTD}

BRAG2 (Brefeldin A-resistant Arf Guanine Nucleotide Exchange Factor 2) is a guaninenucleotide exchange factor (GEF) for the small GTPase, Arf6, which is an important coat recruitment factor at the plasma membrane (D'Souza-Schorey \& Chavrier, 2006) and involved in endosomal trafficking of AMPA receptors (Zheng et al., 2015). BRAG2, like PICK1, is enriched in the PSD. BRAG2 is activated during stimulation by binding to all short AMPA receptor Ctermini, i.e, GluA2, GluA3, GluA4 $4_{\text {short }}$ but not the long C-terminus of GluA1. BRAG2 is activated upon binding the GluA2 C tail Y876 and activates Arf6 by replacing the GDP in Arf6 with GTP. Thus, upon induction of NMDA receptor activation, BRAG2 promotes Arf6-mediated clathrin dependent endocytosis of GluA2- containing AMPA receptors (Scholz et al., 2010).

DHPG induced mGluR-LTD requires dephosphorylation of GluA2 (Moult et al., 2006). Therefore, it is quite possible that mGluR-LTD requires BRAG2 activation via dephosphorylated Y876, although this has not been tested. On the other hand, LFS-LTD doesn't require dephosphorylation of GluA2 and in fact increases phosphorylation of GluA2 (Ahmadian et al., 2004). Although mGluR-LTD and NMDA receptor dependent-LTD have different underlying mechanisms and do not occlude each other (Nicoll RA, Oliet SH, Malenka RC, 1998), they are both blocked by BRAG2 knockdown (Scholz et al., 2010), showing that they converge on BRAG2. 
Insulin-LTD is perhaps independent of BRAG2, as BRAG2 mediated Arf6 activation requires dephosphorylated GluA2 Y876, whereas insulin induced internalization requires one or all tyrosines in the $3 \mathrm{Y}$ motif (Ahmadian et al., 2004). Similarly, it is not clear if AMPA induced internalization is BRAG2 dependent, since AMPA induced internalization of GluA2 3Y->3A, (Ahmadian et al., 2004) and of GluA2 $\Delta 868-883$ (J. W. Lin et al., 2000) was unaffected, but AMPA induced internalization of GluA2 Y876F was abolished (Takashi Hayashi \& Huganir, 2004).

\section{- The 3Y internalization machinery}

The mechanistic link of activity induced AMPA receptor internalization and tyrosine phosphorylation of GluA2 is not entirely clear (Fitzjohn \& Bashir, 2010). However, an effective method to selectively inhibit activity dependent AMPA receptor internalization, leaving constitutive internalization intact, has emerged in the last 12 years. Competitive inhibition of the $3 Y$ machinery by the GluA2-3Y peptide blocked the insulin mediated internalization of AMPA receptors without affecting constitutive trafficking (Ahmadian et al., 2004). A membrane permeable version of the peptide, Tat-GluA2-3Y, blocked the decay of weak-LTP in the hippocampus without affecting baseline transmission or strong-LTP in freely behaving rats ( $Z$. Dong et al., 2015), blocked LFS-LTD in the hippocampus (Ahmadian et al., 2004; Z. Dong et al., 2013), and in the amygdala (Yu, Wu, Liu, Ge, \& Wang, 2008), and blocked depotentiation in the hippocampus (Migues et al., 2016) and morphine induced generation of silent synapses in the nucleus accumbens (Graziane et al., 2016). Thus, the 3Y machinery has emerged to be necessary for NMDA receptor dependent LTD and activity dependent AMPA receptor internalization ( $Z$. Dong et al., 2015). Although it is still not clear what is the phosphorylation profile of the three tyrosines in the GluA2-3Y motif or at other tyrosines and how it is mechanistically linked to the effects of insulin, AMPA and NMDA stimulations, it is quite clear that competitive inhibition of the $3 \mathrm{Y}$ machinery, i.e., those players that require any or all of the three tyrosines in the $3 \mathrm{Y}$ motif, with the GluA2-3Y peptide is an effective means to abolish activity dependent AMPA receptor internalization leaving basal transmission unaffected. 


\section{- Other known players in activity dependent AMPA receptor internalization}

Hippocalcin is a calcium binding protein that is necessary for LTD but not basal transmission or LTP. It is enriched in synaptosomal membranes but not in purified clathrin coated vesicles isolated from rat brain homogenate. It is specifically enriched in PSD fractions but only in the presence of $\mathrm{Ca}^{2+}$, suggesting it recruits AP2 to clathrin coated pits upon a calcium influx (Palmer et al., 2005).

CPG2, through a direct physical interaction, recruits endophilin B2 (EndoB2) to F-actin, thus anchoring the endocytic machinery to the spine cytoskeleton and facilitating glutamate receptor internalization. Specific disruption of EndoB2 or the CPG2-EndoB2 interaction impairs activity dependent, but not constitutive, internalization of both NMDA-and AMPA-type glutamate receptors (Loebrich et al., 2016).

\section{- The mechanisms of decay of LTP and PKM $\zeta$}

The best candidate for the persistent phase of strong-LTP is an atypical protein kinase $\mathrm{C}$ isoform M-zeta (PKM $\zeta)$, which is necessary and sufficient for the persistence of LTP and memory but not for induction (Ling et al., 2002). The catalytic domain of Protein kinase $\mathrm{C}$ is normally inhibited by its regulatory domain until activated by a second messenger. PKM $\zeta$ lacks a regulatory domain, giving it a unique property of being constitutively catalytically active in its protein form. NMDA

receptor dependent LTP releases the translational block on PKM $\zeta$ mRNA in dendrites, following which PKM $\zeta$ is recruited to potentiated spines via PICK1 dimers. Although its autocatalytic function is self-propagating, it is however, still not clear how PKM $\zeta$ can maintain its protein levels long after induction of LTP, despite its turnover (Sacktor, 2011). In fact, it becomes more difficult to inhibit PKM $\zeta$, at longer times after LTP induction. To inhibit persistence of late-LTP 1 hour and 3 hours after induction, the minimum concentrations of ZIP required increase from $1 \mu \mathrm{M}$ to $2.5 \mu \mathrm{M}$ (Serrano, Yao, \& Sacktor, 2005).

The mechanism of PKM $\zeta$ mediated synaptic potentiation has been delineated (Y. Yao et al., 2008): PKM $\zeta$ maintains the increased surface trafficking of GluA2-AMPA receptors, by upregulating NSF-mediated disruption of GluA2-PICK1 interactions (Hanley JG, Henley JM., 2005; Y. Yao et al., 2008). The zeta inhibitory peptide, ZIP, inhibits the catalytic function of PKM $\zeta$. However, the 
specificity of ZIP, and its validity as a specific PKM $\zeta$ inhibitor has been questioned (Frankland PW, Josselyn SA, 2016; LeBlancq, McKinney, \& Dickson, 2016). The role of PKM $\zeta$ itself was also questioned when two studies reported that the constitutive PKM $\zeta$ KO mouse still showed persistent strong-LTP (A. M. Lee et al., 2013; Volk, Bachman, Johnson, Yu, \& Huganir, 2013). However, it was later shown that this was due to persistent activation of PKM $1 / \lambda$, which takes over for PKM $\zeta$ when it is knocked out; An exclusive role of PKM $\zeta$ in the maintenance of lateLTP persistence but not induction was further confirmed using acute shRNA mediated knockdown of PKM (Tsokas P et al, 2016; Wang, Sheng, Ren, Tian, \& Lu, 2016).

To the best of our knowledge, the $3 \mathrm{Y}$ machinery is the only known mechanism which is necessary for the decay of LTP. The decay of strong-LTP upon ZIP application can be blocked by the GluA2$3 Y$ peptide (Z. Dong et al., 2015), and the ZIP mediated decrease in the number of synaptosomal AMPA receptors after LTP induction could be blocked by the GluA2-3Y peptide (Migues et al., 2010). Interestingly, the $3 Y$ machinery does not seem to be continuously active in the persistent phase of strong-LTP, as application of the GluA2-3Y peptide alone 1 hour after induction of strong-LTP did not cause any increase in synaptic potentiation (Z. Dong et al., 2015). Thus, the $3 \mathrm{Y}$ machinery is specifically necessary for the decay of LTP but not for basal transmission.

\section{- Engrams- the neurobiological correlate of memory}

Memory engrams bridge the conceptual gap between synaptic plasticity and behavioral learning. The term engram was originally coined by Richard Semon, who articulated four properties of an engram, the neurobiological manifestation of a memory: a) The event that the engram encodes should cause a modification in the brain, that persists long after the end of the event, b) The engram should be capable of being recalled behaviorally upon relevant environmental cues, c) The engram contains information about what happened during the time of encoding and that predicts what can be retrieved during subsequent retrieval, d) The engram may exist in a latent state between the active processes of encoding and retrieval (Josselyn, Köhler, \& Frankland, 2015).

It is now clear that an engram is the change in signaling efficacy of a specific constellation of synapses across ensembles of neurons, not restricted to one brain region. In the last few years, the 
Susumu Tonegawa lab (MIT, Massachusetts, USA) has managed to label neurons in the hippocampus and the amygdala which were activated during the encoding of an aversive memory. Optogenetic reactivation of these engrams could retrieve the typical fearful behavior in mice long after the aversive experience, in a neutral environmental context (S. Ramirez et al., 2013). Synaptic engrams of learning two distinct motor tasks were also successfully labelled in the mouse motor cortex. Extinguishing the engram from one task did not affect the learning corresponding to the other engram, suggesting acquired motor skills are stored in task-specific synapse ensembles in the brain (Hayashi-Takagi et al., 2015). Granule cells of the dentate gyrus in a fear engram exhibited a higher AMPA/NMDA ratio compared to nearby non-engram granule cells upon stimulation of perforant path afferents, providing a clear demonstration of LTP as the synaptic manifestation of a memory (Ryan, Roy, Pignatelli, Arons, \& Tonegawa, 2015). A causal link between synaptic plasticity and memory was shown by the association of an optogenetically activated auditory input into the amygdala with a foot shock, inactivating it by an optogenetic LTD stimulation protocol and reactivating the same memory by an optogenetic LTP stimulation protocol (Nabavi et al., 2014). Thus, synaptic plasticity is the underlying neurobiological correlate of behavioural learning.

\subsection{Behavioral analysis of learning and memory}

\section{- What is Learning?}

Learning is one of the most important tools of survival that any organism uses to avoid or extricate itself from aversive living conditions and maximise its exposure to favorable ones and thus, increase the chances of survival of itself and its progeny. Memory consolidation refers to the process of stabilization of neurobiological modifications that were initiated upon learning by association of an environmental context with a particular event. Allowing consolidation to complete increases the likelihood of the memory surviving its expected lifetime and not decaying to a state of non-existence or irretrievability. Memory retrieval refers to the expression of a previously learnt behaviour, termed 'conditioned response', upon exposure to the previously associated environmental context by reactivation of a part or whole of the memory engram. 


\section{- What is Forgetting?}

A memory can be forgotten, either because its corresponding memory trace has been erased or the memory cannot be retrieved although it is existent. Other intermediate dysfunctions could lead to forgetting, for instance, the quality of a memory trace could have deteriorated beyond a certain point (for instance, crucial aspects of the memory trace could have been corrupted) such that no meaningful retrieval is possible anymore (Hardt, Nader, \& Nadel, 2013; Hardt et al., 2014). Forgetting in the laboratory is usually tested on rodent models by memory extinction paradigms, which aim to abolish a learned conditioned response, which was previously associated with a conditioned stimulus. Extinction has been found to occur via a) learning, i.e., acquisition of another memory that inhibits the expression of the original conditioned response or b) unlearning, i.e., extinguishing of the original memory trace. The former is thought to be the mechanistic underpinning of most extinction paradigms because the originally learned conditioned response can be retrieved after a sufficiently long time period between the extinction training and the memory recall (K. Myers \& Davis, 2007; Tovote, Fadok, \& Lüthi, 2015).

\section{- Forgetting curves}

A 'natural forgetting' curve refers to the rate of (active/ passive) decay of a memory over time, perhaps because of disuse and gradual deterioration of the memory trace. Increasing the retention delay time period between the consolidation of a memory and its subsequent retrieval is used to study the neurobiology behind natural forgetting. This is a meaningful assay only if the inherent lifetime of the consolidated memory is short, for example, if it decays within hours or days. The activity dependent internalization of GluA2-AMPA receptors in various brain regions is necessary for 'natural forgetting' (Migues et al., 2016). For instance, a long-term 'object location' memory in rats decayed over 13 days and this decay could be blocked by infusing the GluA2-3Y peptide (or a peptide which selectively inhibits GluA2-AP2 interaction) into the dorsal hippocampus twice daily during the entire delay period or from day 8 onwards, by which point the memory had almost completely decayed. Similarly, the decay of a conditioned place preference memory, which decayed over 10 days, could be blocked in rats by two daily infusions of the GluA2-3Y peptide into the dorsal hippocampus. Another example is a 'learned' auditory cued fear extinction memory in the infralimbic cortex which decayed over the course of 7 days in rats, and could be blocked by 
two daily infusions of the GluA2-3Y peptide into the infralimbic cortex (Migues et al., 2016). Thus, natural forgetting is an active process involving internalization of GluA2-containing AMPA receptors from previously potentiated synapses.

Natural forgetting might be the closest to a 'memory erasure' form of forgetting, i.e., for a memory trace to degrade to a quality beyond a certain point, such that no meaningful retrieval is possible.

The watermaze task was first described in 1981 by Prof. Richard Morris, in which mice have to learn the position of a submerged hidden platform in reference to external visual cues. The presence of the memory is indicated by the search path of mice near the platform position in probe tests, where the platform has been removed after traininig. Repetitive probe tests are known to cause extinction of the spatial memory. However, spatial memories in the reference watermaze are highly resistent to natural forgetting in mice (Lattal, Mullen, \& Abel, 2003). A 10-day retention delay period between the last training session and a probe test led to almost no decay in spatial memory. Four daily 60 second probe tests lead to spatial memory extinction, but only after 8 days. The same rate of extinction was achieved by placing the platform in a random position every day. However, a better approach to extinguish a spatial memory was found to be by training mice to a platform in a quadrant opposite to the original platform position (termed platform reversal). After training to a hidden platform in the opposite quadrant, mice spent less time in the quadrant with the original platform position compared to mice which received the other forms of extinction (Lattal et al., 2003).

In a delayed matching to place watermaze task, rodents are trained to find a unique platform position every day (Nakazawa et al., 2003; Zeng et al., 2001). The 'working' memory of the platform position from the first trial is used to find the platform more effectively in the remaining trials of the day, during which the platform position is unchanged. Probe trials in this paradigm are done on trial 2. In rats, increasing the retention delay between trial 1 and trial 2 to 24 hours brought the probe test performance levels to chance level. A big difference of this task with other abovementioned tasks is that this is a working memory task, leading to a weakly consolidated memory (da Silva, Bast, \& Morris, 2014). 


\section{- Fear extinction- Learning and Unlearning paradigms}

Fear conditioned memories are one of the most robust memories and can persist for weeks or even months. Another widely studied memory extinction phenomenon is fear memory extinction. After contextual fear conditioning - achieved by pairing a particular context with an aversive stimulus such as a foot shock - extinction training or exposure to the same context without any foot shocks leads to a reduction in freezing responses. However, the delay between the last training session and the first extinction session alters the mechanism of the extinction involved. When extinction training is done 24 hours after training in the 'learning' fear extinction paradigm, an 'inhibitory' extinction memory is formed, mainly in the infralimbic cortex, which inhibits the expression of the conditioned response leaving the original fear memory, mainly in the amygdala, intact. 1-3 weeks after the extinction training, the infralimbic extinction memory decays, and the original fear memory trace is active (Kimura, Silva, \& Ohno, 2008; K. M. Myers, Ressler, \& Davis, 2006; A. Suzuki et al., 2004). When extinction training is done $15 \mathrm{~min}$ to 1 hour after training in the 'unlearning' fear extinction paradigm, the original fear memory trace is thought to undergo erasure and thus, cannot be retrieved when memory retrieval is attempted 1-3 weeks after the extinction training. However, the only evidence that fear memory is unlearned is the absence of spontaneous reversal (Kimura et al., 2008; Mao, 2006; K. M. Myers et al., 2006). The internalization of GluA1AMPA receptors in the amygdala has been shown to be the underlying mechanism in unlearning fear extinction in rats (Mao, 2006). Both extinction paradigms lead to abolishment of the conditioned response, however, it reappears after 1-3 weeks in the 'learning' fear extinction, a phenomenon called spontaneous reversal, but does not reappear in 'unlearning' fear extinction (Kimura et al., 2008; Migues et al., 2016; K. Myers \& Davis, 2007; Tovote et al., 2015)..

\section{- Interfering with a memory update (reconsolidation) can erase memories}

Memory is, in fact, continuously being updated. Every retrieval has been shown to transiently weaken a memory trace and make it more plastic, perhaps allowing for new information to be integrated into pre-existing memories. Reconsolidation processes, which are mechanistically very similar to those operating during memory consolidation, stabilize the memory trace (Hong et al., 2013; Nader K, Schafe GE, Le Doux JE, 2000; A. Suzuki et al., 2004). In an amazing demonstration of the retrieval based weakening of a memory, human patients with post-traumatic 
stress disorder were cured of their fearful associations of a traumatic experience if they were administered the $\beta$ adrenergic receptor blocker, Propranolol (which can cross the blood brain barrier and block memory reconsolidation mediated by the noradrenergic system) while recalling every detail of the traumatic experience. This removes the fear of the traumatic experience and associated aversive symptoms, but not the memory of the traumatic experience itself (Schwabe, Nader, \& Pruessner, 2013). Blocking reconsolidation by injecting mice with anisomycin, a protein synthesis blocker, and performing a probe test after reference memory watermaze training, has the same effect, and erases the spatial memory of the hidden platform. This effect was prevented if mice were injected with anisomycin but left in their home cages, i.e., both retrieval of the spatial memory and inhibition of protein synthesis were necessary for memory erasure (A. Suzuki et al., 2004). This demonstrates a transient destabilization of a memory upon retrieval, which must be reconsolidated to re-stabilize the memory trace.

The destabilization of fear memories is dependent on NMDA receptor activation and internalization of GluA2 containing AMPA receptors (Hong et al., 2013). Fear memories are significantly weakened by injecting rats with anisomycin 1 hour before retrieval of contextual fear memories. This memory destabilization is prevented by infusion of the GluA2-3Y peptide into the lateral amygdala 1 hour before memory retrieval, indicating that memory retrieval based memory destabilization is dependent on the $3 \mathrm{Y}$ machinery. In an independent experiment, micro-infusion of NASPM (1-Naphthyl acetyl spermine, a selective antagonist of GluA2 lacking/ calcium permeable AMPA receptors) into the lateral amygdala immediately after fear memory retrieval also led to fear memory destabilization, suggesting that calcium influx through calcium permeable AMPA receptors inserted after memory destabilization are important for memory reconsolidation. NASPM mediated memory destabilization was also blocked by GluA2-3Y peptide infusions 1 hour before retrieval. Thus, retrieved fear memory is destabilized by internalization of GluA2containing AMPA receptors. The calcium influx from surface GluA2-lacking calcium permeable AMPA receptors upon retrieval is necessary for fear memory reconsolidation (Hong et al., 2013). In parallel findings relating to late-LTP at the CA3-CA1 synapses in acute hippocampal slices, blocking calcium permeable AMPA receptors with philanthotoxin during the first 30 minutes after induction but not later could block the consolidation of LTP (Adesnik \& Nicoll, 2007; Plant et al., 2006). 
Memory retrieval-based extinction has been observed in the watermaze as well. At the end of training to a platform position, the most spatially precise search of the hidden platform is seen during the 10-20 second time bin of the probe test, and search behavior gradually worsens over the remaining 20-60 seconds (Maei et al., 2009). The repeated retrieval of the hidden platform spatial memory leads to within-trial extinction in probe tests, perhaps via $3 \mathrm{Y}$ machinery mediated AMPA receptor internalization.

\subsection{Synaptotagmins}

Synaptotagmins are a family of calcium sensing proteins, with 17 known mammalian isoforms, that are necessary for calcium triggered membrane fusion and, hence, exocytosis of cargo from neurons. They consist of a short N-terminal domain, a transmembrane domain and a flexible linker region followed by two C-terminal calcium binding C2 domains. Other proteins like Doc2 and rabphilin, which are also involved in transmitter release, contain $\mathrm{C} 2$ domains but lack a transmembrane domain, and are thus not classified as synaptotagmins. The C2A domains of syt3, 5, 7, and 10, which have been hypothesized to be present on the plasma membrane (Südhof, 2002) have $\sim 5$ to 20 times higher $\mathrm{Ca}^{2+}$ binding affinity than those of the synaptic vesicle localized isoforms syt1, and syt2 (Sugita, Shin, Han, Lao, \& Südhof, 2002). Thus, while the vesicular isoforms are known to be necessary for fast synchronous release, the plasma membrane isoforms are thought to mediate slow asynchronous release (Sugita et al., 2002).

\section{- Can synaptotagmins mediate endocytosis?}

Syts1-8 bind AP2, suggesting they may function in endocytosis (Li C et al, 1995). In dissociated hippocampal cultures, syt1-mediated endocytosis of synaptic vesicles requires its calcium binding ability (and/or its SNARE complex binding ability) but not its lipid binding/ membrane bending ability. However, there also seems to be a calcium independent endocytic pathway of synaptic vesicles. (J. Yao, Kwon, Gaffaney, Dunning, \& Chapman, 2012). Syt1 was first shown to bind to clathrin-AP2 with high affinity $(\mathrm{Kd}=0.1 \mathrm{nM})$ via its $\mathrm{C} 2 \mathrm{~B}$ domain (Zhang, Davletov, Südhof, \& Anderson, 1994), which is necessary for endocytosis in PC12 cells (Grass et al., 2004). Oligomerization of the C2B domain is essential for this interaction with AP2 (Grass et al., 2004). Syt1 binds the $\mu 2$ and $\alpha$ subunits of AP2 via residues K326 and K327 within a positive peptide 
stretch in its $\mathrm{C} 2 \mathrm{~B}$ domain (KRLKKK $326 \mathrm{~K}_{327} \mathrm{TTIKK}$ ). This sequence is highly homologous to the syt3 sequence (Grass et al., 2004) and resembles the stretch of positively charged residues of the GluA2 sequence ( ${ }_{844} \mathrm{KRMKV}_{848}$ ) which binds AP2 (S. Lee et al., 2002). In the case of synaptic vesicle endocytosis, SV2 contains two endocytic motifs, YSRF and YRRI, recognized by AP2, suggesting that syt1 and SV2 co-operatively induce clathrin mediated endocytosis of synaptic vesicles (Grass et al., 2004; Maritzen, Podufall, \& Haucke, 2010). However, AP2 was reported to have only a minor role in synaptic vesicle endocytosis compared to Stonin2, since RNAi of AP2 subunits did not affect synaptic vesicle retrieval, but RNAi of Stonin2 strongly impaired endocytosis, which could be rescued by expression of RNAi resistant Stonin2 (Willox \& Royle, 2012). Syt1 binds Stonin2 in a calcium independent manner, most likely predominantly through the $\mathrm{C} 2 \mathrm{~A}$ domain, and recruits it to the plasma membrane. Stonin2 binds AP2- $\mu$, Eps-15 and intersectin as well, indicating it could act as an adaptor for assembling the components necessary for clathrin mediated endocytosis of synaptic vesicles (Maritzen et al., 2010).

Another study showed that a conserved tryptophan based WHXL motif in syt1 is necessary for syt1 internalization; the W404A mutation in syt1 abolished internalization (Jarousse, Wilson, Arac, Rizo, \& Kelly, 2003). Interestingly, the WHQL motif in syt3 is exposed in the $\mathrm{Ca}^{2+}$ unbound state and buried in the calcium bound state (Vrljic et al., 2010) and may therefore bind endocytic components dependent on its state.

\section{- Synaptotagmin 1}

Synaptotagmin-1 (syt1) is the most abundant syt isoform and is necessary for the synchronous release of neurotransmitter from pre-synaptic axon terminals (Geppert M et al, 1994; Nishiki, 2004). When an action potential arrives at the pre-synaptic membrane, voltage-gated calcium channels open, causing 'docked' synaptic vesicles within 10 nanometers of the calcium source to fuse (Eggermann, Bucurenciu, Goswami, \& Jonas, 2011). Before fusion, a stable 4-helix bundle structure called the SNARE (SNAP (Soluble NSF Attachment Protein) REceptor) complex consisting of syntaxin1 and SNAP25 on the plasma membrane and synaptobrevin2 (syb2/ VAMP2) on the synaptic vesicle membrane is held in a 'trans' pre-fusion conformation along with syt 1 and complexin. The influx of calcium and its subsequent binding to the $\mathrm{C} 2$ domains of syt1 set off a chain of events whose exact mechanism is still not clear, despite more than 200 
publications. The $\mathrm{C} 2 \mathrm{~A}$ and $\mathrm{C} 2 \mathrm{~B}$ domains of syt1, which are the most evolutionarily conserved of all synaptotagmin isoforms (Südhof, 2002), exhibit $\mathrm{Ca}^{2+}$-dependent binding to interfaces on the SNARE complex and phospholipids (Sugita et al., 2002; Zhou et al., 2015). Syt1 partially inserts into the plasma membrane upon binding calcium and via its interactions with SNARE complex and phospholipids, brings membranes closer than $0.9 \mathrm{~nm}$, the critical distance to promote stalk formation (Zhou et al., 2015). Once triggered by syt1, membrane fusion of the synaptic vesicle membrane with the pre-synaptic plasma membrane is an almost instantaneous $(<1 \mathrm{~ms})$ reaction.

\section{- Synaptotagmin 3}

Syt 3 is the third most abundant synaptotagmin isoform after syt 1 and syt 2 but nothing is known about its function. The first cloned syt3 cDNA sequence was 2096 base pair long (NCBI Refseq: NM_019122, (Mizuta et al., 1994)). The protein is 588 amino acids long (NCBI Refseq: NP_061995) and weighs 63.3 Kilodaltons. Syt3 probably doesn't undergo alternative splicing (Li $\mathrm{C}$ et al, 1995). Syt3 is expressed on synaptic plasma membranes but not enriched on synaptic vesicles (Butz, R, Schmitz, Jahn, \& Südhof, 1999). The $\sim 10$ fold higher $\mathrm{Ca}^{2+}$-dependent phospholipid binding (Sugita et al., 2002) and at least 200 fold higher $\mathrm{Ca}^{2+}$-dependent syntaxin1 binding ( $\mathrm{Li} \mathrm{C}$ et al, 1995) of syt 3 compared to syt 1 , suggested that syt 3 mediates asynchronous transmitter release by detecting both micro- and nano-domain calcium (Butz et al., 1999; Sugita et al., 2002; Vrljic et al., 2010), rather than only nan-domain calcium like syt1. The syt3 C2A domain can bind $3 \mathrm{Ca}^{2+}$ ions (via D386 and D388) and the C2B domain can bind 2-3 $\mathrm{Ca}^{2+}$ ions (via D520 and D522) (Vrljic et al., 2010), Introduction figure 2 on page 34), like syt1. Syt3 has been shown to bind VAMP-2, syntaxin-1 and SNAP-25 (Vrljic et al., 2010), anionic lipids (Bhalla, Chicka, \& Chapman, 2008; Sugita et al., 2002), negatively charged phosphatidylserine-rich Folch liposomes (Martens, Kozlov, \& T, 2007) and plasma-membrane-like lipids in a SNARE-catalyzed $\mathrm{Ca}^{2+}$ dependent manner (Vrljic et al., 2010).

A unique property of the plasma membrane syt isoforms, syt3, syt5, syt6 and syt10 is that they can homo- or hetero-oligomerize via cysteine disulphide linkages at their N-terminus in vitro (Fukuda $\mathrm{M}$ et al, 1999). Although the closest relative of syt3 is syt6, it is unlikely that functional syt3-syt6

oligomers exist because syt6 is most strongly expressed in the olfactory bulb, where syt3 shows almost no expression (Butz et al., 1999). 
The crystal structure of syt3 has been solved in the $\mathrm{Ca}^{2+}$ unbound (Sutton, Ernst, \& Brunger, 1999) and $\mathrm{Ca}^{2+}$ bound states (Vrljic et al., 2010). Interestingly, the $\mathrm{C} 2$ domains undergo a large displacement upon binding calcium such that the ${ }_{562}$ WHQL565 motif (Jarousse et al., 2003) is available for interactions in the $\mathrm{Ca}^{2+}$ unbound conformation ('extended' conformation) and buried in the $\mathrm{Ca}^{2+}$ bound conformation ('compact' conformation). smFRET (Single molecule-Förster resonance energy transfer) studies with the syt3 $\mathrm{C} 2 \mathrm{AB}$ domain showed that the two syt3 $\mathrm{C} 2$ domains are very dynamic and occupy a broad range of conformations between the extended conformation and the compact conformation in vitro, with the former being predominant. Addition of calcium or the cis (post-fusion state) pre-synaptic SNARE complex shifted syt3 C2AB to a more compact conformation. However, there was a much larger shift to the compact conformation in the presence of both calcium and the SNARE complex, indicating a synergistic rather than an additive effect. Thus, in a manner similar to syt1, interaction of syt 3 with the SNARE complex pushes syt3 into the $\mathrm{Ca}^{2+}$ bound compact conformation (Vrljic et al., 2010)

We report a function for syt3 on the post-synaptic membrane, where it internalizes AMPA receptors as a necessary part of the $3 \mathrm{Y}$ machinery to cause decay of LTP and promote forgetting. 
A

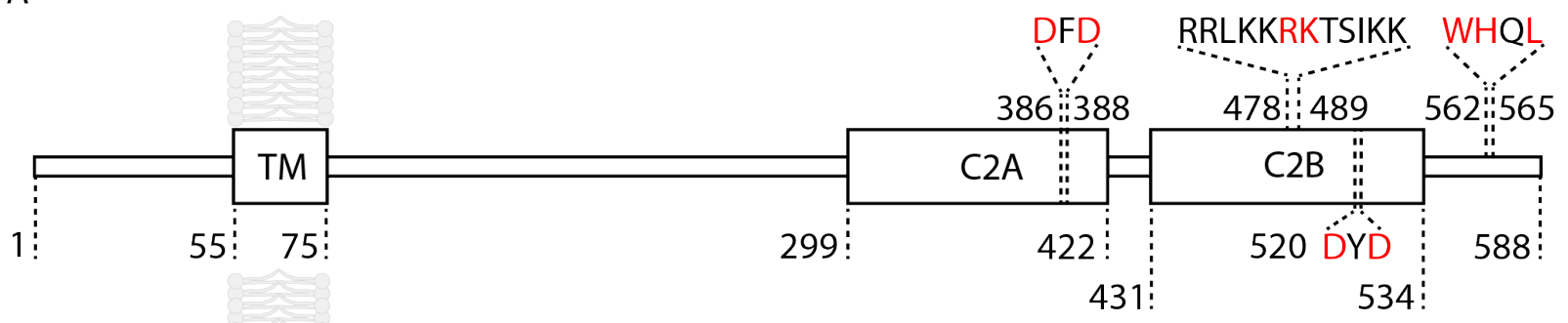

B

Synaptotagmin 1321 KR L K K K KT T I K K 332

Synaptotagmin 3478 R R L KK RKT S I K K 489 GluA2 844 KRMK VAKNPQ 853

\section{Introduction figure 2: The important interaction motifs of syt3}

(A) Syt3 is 588 amino acids long and consists of a trans-membrane domain (TM) and C-terminal calcium sensing C2A and C2B domains. The critical calcum binding aspartate residues are D386, D388, D520 and D522 (Bhalla et al., 2008). Residues, R483 and K484, in the amino acid stretch KKRKTSIKK, are the homologous amino acids in syt1 that are necessary for AP2 binding (Grass et al., 2004). The WHQL motif is exposed for interactions in the extended syt3 $\mathrm{C} 2 \mathrm{AB}$ conformation and buried in the compact conformation (Vrljic et al., 2010). (B) Sequence alignment of AP2 binding regions in syt1, syt3 and GluA2. Conserved residues are shown in red. 


\section{Materials and Methods}

\subsection{Mouse lines}

Prof. Thomas Südhof (Stanford University, USA) created the synaptotagmin 3 (Syt3) knock-out, synaptotagmin 6 (Syt6) knock-out, synaptotagmin 5 (Syt5) knock-in and synaptotagmin 10 (Syt10)

knock-in quadruple targeted mutation mice. These mice were obtained from the Jackson laboratory (B6;129-Syt6 $6^{\text {tm ISud }}$ Syt5 $5^{\text {tmlSud }}$ Syt3 ${ }^{\text {tm ISud }}$ Syt10 $0^{\text {tmISud}} / \mathrm{J}$, stock no. 008413) and then crossed with Black6/J mice to isolate mice with homozygous knock-out alleles of Syt3 but WT alleles of Syt5, Syt6 and Syt10. The genotype of the first breeder pairs was confirmed before initiating the colony. For subsequent generations, only the syt 3 genotype was confirmed. All alleles were detected using standard PCR methods (see section 'Mouse tail biopsy genotyping' below). As far as possible, the breeding pairs were chosen from different litters. Animals were used keeping in mind the 3 Rs of ethics for animal research - 1) Replacement: use strategies that avoid usage of animals as far as possible, 2) Reduction: use strategies to get necessary scientific information from as few animals as possible and 3) Refinement: use methods that minimize pain and suffering and maximize welfare of the animals used. For instance, to reduce the number of mice used for breeding, homozygous breeder pairs were used.

\section{- Mouse tail biopsy genotyping}

$0.2 \mathrm{~cm}$ long tips of tails were clipped from juvenile mice without administration of anaesthesia or from adult mice after sacrificing them (Picazo \& García-Olmo, 2015). Tail biopsies were lysed in $500 \mu \mathrm{l}$ lysis buffer (100 mM Tris-HCl (pH 8.5), 5 mM EDTA (pH 8.0), $0.2 \%$ (w/v) SDS and 200 $\mathrm{mM} \mathrm{NaCl}$ ). $70 \mu \mathrm{g}$ proteinase $\mathrm{K}$ (Ambion AM2546) was added and the solution was incubated overnight at $55^{\circ} \mathrm{C}$ with mixing at $1400 \mathrm{rpm}$ (Eppendorf Thermomixer comfort). The suspension was then centrifuged at maximum speed on a benchtop microcentrifuge (Eppendorf Microcentrifuge 5424 at $14680 \mathrm{rpm}$ ) for $10 \mathrm{~min}$ at room temperature. The genomic DNA was precipitated from the supernatant by adding $500 \mu 1$ of $100 \%$ isopropanol (Roth \#AE73), vortexing thoroughly and centrifuging at maximum speed (as above) for $10 \mathrm{~min}$ at room temperature. The precipitated DNA-pellet was washed with $1 \mathrm{ml}$ of $70 \%$ (v/v) ethanol (Roth \#9065 diluted with 
Table 1: The syt3/ syt5/ syt6/ syt10 quadruple targeted mutation mouse line

\begin{tabular}{|c|c|c|c|c|c|}
\hline \multicolumn{2}{|c|}{ Target gene } & Syt3 & Syt5 & Syt6 & Syt10 \\
\hline \multicolumn{2}{|c|}{$\begin{array}{l}\text { Chromosome position of } \\
\text { gene }\end{array}$} & 7 & 7 & 3 & 15 \\
\hline \multicolumn{2}{|c|}{$\begin{array}{l}\text { Wild-type forward } \\
\text { primer sequence }\end{array}$} & $\begin{array}{l}\text { CAG TCC TGC } \\
\text { TCT AAC AAC } \\
\text { AGG AAG } \\
\text { TGG AG }\end{array}$ & $\begin{array}{l}\text { GAT ATC TCT } \\
\text { GTG AGC CTG } \\
\text { CTA ACC C }\end{array}$ & $\begin{array}{l}\text { CAG CCT CCT } \\
\text { CGC CGT GGT } \\
\text { AGT TAT }\end{array}$ & $\begin{array}{l}\text { CCT ACC AGT } \\
\text { GTG CCT TAT } \\
\text { CAT C }\end{array}$ \\
\hline \multicolumn{2}{|c|}{$\begin{array}{l}\text { Wild-type reverse primer } \\
\text { sequence }\end{array}$} & $\begin{array}{l}\text { CAG CAC CAG } \\
\text { TTA GCG TGT } \\
\text { CAT ATG TGA }\end{array}$ & $\begin{array}{l}\text { CCG AGC TGA } \\
\text { TGG TGT TGG } \\
\text { CTC TG }\end{array}$ & $\begin{array}{l}\text { AGG ATG CTG } \\
\text { GCT CTG TGG } \\
\text { TCT GTC }\end{array}$ & $\begin{array}{l}\text { CAT ATC CAA } \\
\text { GCA GAC CAC } \\
\text { AAG G }\end{array}$ \\
\hline \multicolumn{2}{|c|}{$\begin{array}{l}\text { Wild-type amplicon band } \\
\text { size (base pairs) }\end{array}$} & 527 & 354 & 332 & 550 \\
\hline \multicolumn{2}{|c|}{$\begin{array}{l}\text { Mutant forward primer } \\
\text { sequence }\end{array}$} & $\begin{array}{l}\text { GGA TGC GGT } \\
\text { GGG CTC TAT } \\
\text { GGC TTC TGA }\end{array}$ & $\begin{array}{l}\text { Same as Syt5 } \\
\text { WT forward } \\
\text { primer sequence }\end{array}$ & $\begin{array}{l}\text { TAT CGC CTT } \\
\text { CTT GAC GAG } \\
\text { TTC TTC TG }\end{array}$ & $\begin{array}{l}\text { Same as Syt10 } \\
\text { WT forward } \\
\text { primer sequence }\end{array}$ \\
\hline \multicolumn{2}{|c|}{$\begin{array}{l}\text { Mutant reverse primer } \\
\text { sequence }\end{array}$} & $\begin{array}{l}\text { Same as Syt3 } \\
\text { WT reverse } \\
\text { primer sequence }\end{array}$ & $\begin{array}{l}\text { CTG GCA TCC } \\
\text { AAA TCC TGA } \\
\text { CCT GGG }\end{array}$ & $\begin{array}{l}\text { TCT TTC CCT } \\
\text { TTG ATT GGT } \\
\text { GCC TGT G }\end{array}$ & $\begin{array}{l}\text { Same as Syt10 } \\
\text { WT reverse } \\
\text { primer sequence }\end{array}$ \\
\hline \multicolumn{2}{|c|}{$\begin{array}{l}\text { Mutant amplicon band } \\
\text { size (base pairs) }\end{array}$} & 300 & 860 & 400 & 455 \\
\hline \multicolumn{2}{|c|}{$\begin{array}{l}\text { Type of targeted } \\
\text { mutation }\end{array}$} & Knockout & Knock-in & Knockout & Knock-in \\
\hline \multirow{2}{*}{$\begin{array}{l}\text { Site of } \\
\text { targeted } \\
\text { mutation }\end{array}$} & Exon & Exon 1 & Exon 3 & -- & Exon 2 \\
\hline & $\begin{array}{l}\text { Amino } \\
\text { acid }\end{array}$ & Amino acid 220 & -- & Amino acid 964 & -- \\
\hline
\end{tabular}

Summary of the targeted mutations and the primer sequences by which they could be detected. Further details are available on the website https://www.jax.org/strain/008413.

milli-Q water) and centrifuged at maximum speed (as above) for $10 \mathrm{~min}$ at room temperature. The washed DNA pellet was allowed to dry at room temperature for a few hours. The genomic DNA 
pellet was resuspended in $100 \mu 1$ milli-Q water. Specific DNA sequences were amplified using the polymerase chain reaction (PCR) on a thermal cycler (Eppendorf MasterCycler).

One reaction mix $(50 \mu 1)$ for qualitative PCR was comprised of:

\begin{tabular}{|r|l|}
\hline $2 \mu 1$ & genomic DNA (as isolated above) \\
\hline $5 \mu 1$ & 10 X DreamTaq Buffer (Thermo Fisher Scientific) \\
\hline $1 \mu 1$ & Forward primer $(10 \mu \mathrm{M})$ \\
\hline $1 \mu 1$ & Reverse primer $(10 \mu \mathrm{M})$ \\
\hline $0.4 \mu 1$ & $25 \mathrm{mM}$ dNTPs \\
\hline $0.25 \mu 1$ & $\begin{array}{l}\text { Taq polymerase (Thermo Fisher Scientific } \\
\text { \#EP0702) }\end{array}$ \\
\hline $40.35 \mu 1$ & Milli-Q water \\
\hline
\end{tabular}

The cycling program used to genotype for the presence of the Syt3/Syt5/Syt6/Syt10 allele was:

\begin{tabular}{|c|l|}
\hline Temperature of cycler & Duration \\
\hline $94^{\circ} \mathrm{C}$ & $3 \mathrm{~min}$ \\
\hline $94^{\circ} \mathrm{C}$ & $0.5 \mathrm{~min}$ \\
\hline $69^{\circ} \mathrm{C}$ & $1 \mathrm{~min}$ \\
\hline $72^{\circ} \mathrm{C}$ & $1 \mathrm{~min}$ \\
\hline $72^{\circ} \mathrm{C}$ & $2 \mathrm{~min}$ \\
\hline $4{ }^{\circ} \mathrm{C}$ & infinite \\
\hline
\end{tabular}

After the completion of the PCR, $25 \mu 1$ of the PCR reaction mix was loaded onto a solid agarose gel $(1.5 \%(w / v)$ ultrapure agarose (Invitrogen \#16500) in 1X TAE buffer (40 mM Tris, $20 \mathrm{mM}$ acetic acid, $1 \mathrm{mM}$ EDTA)). For visualization of DNA bands, Roti-safe (Carl Roth \#3865), a fluorescent gel stain was added to the liquid gel after it cooled down to $60-70^{\circ} \mathrm{C}$. To estimate sizes of the amplified DNA fragments, a DNA ladder was also loaded onto the same gel (Thermo Fisher 100 bp GeneRuler \#SM0321). Subsequently, standard nucleic acid electrophoresis (P. Y. Lee, Costumbrado, Hsu, \& Kim, 2012) was performed under constant voltage such that the maximum applied electric field was $5 \mathrm{~V} / \mathrm{cm}$, where the distance is measured between the cathode and anode of the electrophoresis chamber. The amplified DNA fragments were then visualized under a UV lamp (iNTAS Gel iX20 Imager). 


\subsection{Cell culture}

Use of animals for experimentation was approved and performed according to the specifications of the Institutional Animal Care and Ethics Committee of Göttingen University (T10.31), and of the German animal welfare laws.

\section{- Mouse (P0) dissociated hippocampal culture}

The following protocol was modified from that used by Prof. Oliver Schlüter (European Neuroscience Institute Göttingen). This protocol uses very low serum concentrations for longer times ( $0.5 \%$ serum for the $1^{\text {st }}$ week and halved every subsequent week) rather than high serum for short times (5\% serum for $1^{\text {st }}$ day and then no serum). Dissection medium (see Table 2) was kept ice cold before dissection. All surfaces were sterilized with 70\% (v/v) ethanol. All solutions, into which non-sterile components were added, were sterile filtered across $0.22 \mu \mathrm{m}$ pore size membranes (Nalgene rapid flow 151-4020 for $500 \mathrm{ml}$, Milipore X348 for $50 \mathrm{ml}$, PALL life sciences Acrodisc syringe filter for $10 \mathrm{ml}$ ) before use. The incubator (Thermo Scientific Hera Cell $240 \mathrm{i}$ ) used during the protocol was maintained at $37^{\circ} \mathrm{C} \& 5 \% \mathrm{CO}_{2}$. The $5 \%$ serum medium, enzymatic solution and inactivation solution (see Table 2) were pre-incubated in the incubator for at least 0.5 hours before use. Plating medium (see Table 2) was pre-warmed to $37^{\circ} \mathrm{C}$ in the water bath. DNAase1 (see Table 2) was always added just before use and sterile filtration. The cell suspension was always kept in the incubator during waiting times to maximize cell viability. The typical cell yields from this protocol were 220,000-300,000 cells per hippocampus.

The protocol was as follows:

1. $12 \mathrm{~mm}$ (diameter) glass coverslips (Menzel Gläser, thickness \#1) were acid etched by shaking in a $1 \mathrm{M} \mathrm{HCl}$ solution (approximately 1:10 dilution of $32 \% \mathrm{HCl}$, Roth \#P074, in deionized water) for 24-30 hours at room temperature. A large surface area of the glass beaker used for shaking ensured that the entire surface area of all coverslips was thoroughly etched. After etching, the coverslips were washed thoroughly in milli-Q water at least 5 times and left in $100 \%$ ethanol for at least 6 hours before coating. For coating, coverslips were washed thrice with autoclaved milli-Q water under a laminar flow hood and transferred into a 24-well plate (CytoOne). After drying, they were left in PEI coating solution (see Table 2) for 0.5 to 7 days at room temperature outside the laminar flow hood wrapped in silver foil. After coating, 
coverslips were washed with autoclaved milli-Q water once and left in water at room temperature until use.

2. P0 pups were decapitated and the heads were sterilized with a few drops of $70 \%(\mathrm{v} / \mathrm{v})$ ethanol solution (Roth \#T913). The skin was cut open with fine forceps taking care not to let the outer surface of the skin touch or fold back onto the skull or brain in the later steps. The skull was then peeled back the two hemispheres and removed. Piercing both eye sockets with forceps and squeezing the skull at its rostral tip made this step easier and more efficient. 2-3 brains were harvested at once and transferred to ice cold dissection medium.

3. The two brain hemispheres were separated by squeezing along the interhemispheric fissure and the midbrain was scooped out carefully so as not to damage the hippocampus attached to it. The meninges were then removed by peeling them back caudally starting from close to the striatum where they generally tear upon separation of the hemispheres. The meninges strongly adhere to the inferior surface of the hippocampus and extra care was taken not to tear the hippocampus while peeling off the meninges. Hippocampi were collected in fresh dissection medium in a $15 \mathrm{ml}$ falcon tube.

4. Enzymatic solution (+ $10 \mu 1 \mathrm{DNAase} 1$ solution per $\mathrm{ml}$ ) was sterile filtered onto the hippocampi and left in the incubator for $30 \mathrm{~min}$. Using a nutator during this step gave slightly better yields.

5. The papain activity was stopped by removing the enzymatic solution and adding sterile inactivation solution (+10 $\mu$ DNAasel solution per $\mathrm{ml}$ ) and gently inverting the falcon tube 10 times. All hippocampi were then washed thrice with $7-8 \mathrm{ml}$ of $5 \%$ serum medium.

6. After adding $2 \mathrm{ml}$ of 5\% serum medium, the hippocampi were triturated by repeatedly passing a volume of $1 \mathrm{ml}$ through the tip of a $1 \mathrm{ml}$ plastic micropipette tip up to 15 times. $2 \mathrm{ml}$ of $5 \%$ serum medium was added and the cell suspension was allowed to settle for 2 min in the incubator.

7. $2 \mathrm{ml}$ of the suspension was carefully collected from the top, avoiding the bigger chunks. Step 6 was repeated to yield a final cell suspension volume of $4 \mathrm{ml}$.

8. The cell suspension was centrifuged at 500xg (Eppendorf 5810R) at room temperature for 5 min. The cell pellet was resuspended in a mixture of fresh 5\% serum medium and plating medium, keeping in mind that the cell suspension would be diluted further in the next step and that the serum in the final medium must be diluted 10 -fold to $0.5 \%$. 
9. $10 \mu \mathrm{l}$ of the cell suspension was added to $10 \mu \mathrm{l}$ of trypan blue solution and the cell density was estimated using a hemocytometer (Marienfeld Neubauer counting chamber, depth $0.1 \mathrm{~mm}$ ). Cell preparations with good cell viability usually had bright circular cells with tails under the microscope. Extremely small cells, cells with a rough membrane or cells which did not exclude the blue dye were not counted.

10. Cells were plated at a density of 120,000 cells per well. FUDR solution $(2.5 \mu 1 /$ well, see Table 2) was added to the cultures on DIV 4 to stop proliferation of glial cells. On DIV 7, $250 \mu 1$ of the conditioned medium was exchanged with $250 \mu \mathrm{l}$ of feeding medium to reduce the concentrations of glutamate and prevent excitotoxicity of neurons. If cells had to be maintained longer than 2 weeks in culture, $250 \mu 1$ of the conditioned medium was exchanged with $250 \mu 1$ of feeding medium again on DIV 14, DIV 21 and so on.

Table 2: Formulation of reagents needed for mouse (P0) dissociated hippocampal cultures

\begin{tabular}{|c|c|c|c|}
\hline Solution & Final Composition & Catalogue Number & Preparation Instruction \\
\hline \multirow{5}{*}{$\begin{array}{l}\text { Dissection } \\
\text { Medium } \\
\text { (mGBSS, } \\
\text { pH 7.4) }\end{array}$} & $\begin{array}{l}\text { Hanks buffered salt solution } \\
\text { (HBSS) }\end{array}$ & Gibco \#14170-088 & $500 \mathrm{ml} \mathrm{HBSS}$ \\
\hline & $20 \mathrm{mM}$ HEPES & Gibco \#15630-080 & $\begin{array}{l}10 \mathrm{ml} \text { of } 1 \mathrm{M} \text { HEPES stock } \\
\text { solution }\end{array}$ \\
\hline & $1.5 \mathrm{mM} \mathrm{CaCl}_{2}$ & Roth \#HN04 & $\begin{array}{l}750 \mu 1 \text { of } 1 \mathrm{M} \mathrm{CaCl}_{2} \text { stock } \\
\text { solution }\end{array}$ \\
\hline & $10.2 \mathrm{mM} \mathrm{MgCl}_{2}$ & Roth \#KK36 & $\begin{array}{l}0.486 \mathrm{~g} \text { of } \mathrm{MgCl}_{2} \text { stock } \\
\text { solution (As } 1 \mathrm{M} \mathrm{MgCl} 2 \text { stock } \\
\text { solution gets precipitated) }\end{array}$ \\
\hline & $4 \mathrm{mM} \mathrm{NaOH}$ & Roth \#P031 & $\begin{array}{l}250 \mu \mathrm{l} \text { of } 10 \mathrm{M} \mathrm{NaOH} \text { stock } \\
\text { solution }\end{array}$ \\
\hline \multirow{4}{*}{$\begin{array}{l}\text { Enzymatic } \\
\text { Solution } \\
\text { (ES) }\end{array}$} & Dissection Medium (mGBSS) & Prepared as above & $10 \mathrm{ml} \mathrm{mGBSS}$ \\
\hline & $\begin{array}{l}0.2 \mathrm{mg} / \mathrm{ml} \text { L-cysteine } \\
\text { Hydrochloride monohydrate }\end{array}$ & Sigma 30129 & $2 \mathrm{mg}$ of L-cysteine salt \\
\hline & 0.5 mM NaEDTA (pH 8) & Roth (MW 292.25) & $\begin{array}{l}100 \mu \mathrm{l} \text { of } 50 \mathrm{mM} \text { NaEDTA } \\
(\mathrm{pH} 8)\end{array}$ \\
\hline & $1 \mathrm{mM} \mathrm{CaCl}_{2}$ & Roth \#HN04 & $\begin{array}{l}10 \mu \mathrm{l} \text { of } 1 \mathrm{M} \mathrm{CaCl}_{2} \text { stock } \\
\text { solution }\end{array}$ \\
\hline
\end{tabular}


Chapter 2. Materials and Methods

\begin{tabular}{|c|c|c|c|}
\hline & $3 \mathrm{mM} \mathrm{NaOH}$ & Roth \#P031 & $\begin{array}{l}30 \mu \mathrm{l} \text { of } 1 \mathrm{M} \mathrm{NaOH} \text { stock } \\
\text { solution }\end{array}$ \\
\hline & -- & $\begin{array}{l}\text { Worthington systems } \\
\text { \#LS003126 }\end{array}$ & $100 \mu 1$ of Papain suspension \\
\hline $\begin{array}{l}5 \% \text { Serum } \\
\text { Medium } \\
(\mathrm{SM})\end{array}$ & $\begin{array}{l}\text { Dulbecco's modified eagle } \\
\text { medium + Glutamax } \\
(\mathrm{DMEM}+\mathrm{GM})\end{array}$ & Gibco \#31966-021 & $47.15 \mathrm{ml} \mathrm{DMEM}+\mathrm{GM}$ \\
\hline & $\begin{array}{l}5 \%(v / v) \text { heat inactivated Fetal } \\
\text { Bovine Serum }\end{array}$ & Gibco \# 10500-064 & $2.5 \mathrm{ml}$ of FBS \\
\hline & 1x $\mathrm{Mito}^{+}$supplements & VWR 734-1317 & $\begin{array}{l}100 \mu \mathrm{l} \text { of }(500 \mathrm{X}) \mathrm{Mito}^{+} \text {serum } \\
\text { extender stock solution }\end{array}$ \\
\hline & $0.5 \mathrm{x}$ MEM vitamins & Gibco \#11120-037 & $250 \mu 1$ of $100 x$ MEM Vitamins \\
\hline Inactivation & $5 \%$ Serum Medium $(\mathrm{SM})$ & Prepared as above & $10 \mathrm{ml}$ of $5 \% \mathrm{SM}$ \\
\hline $\begin{array}{l}\text { Solution } \\
\text { (IS) }\end{array}$ & $\begin{array}{l}2.5 \mathrm{mg} / \mathrm{ml} \text { Bovine serum } \\
\text { albumin (BSA) }\end{array}$ & Roth \#8076.1 & $25 \mathrm{mg}$ of BSA \\
\hline Feeding & Neurobasal medium (NB) & Gibco \#21103-049 & $48 \mathrm{ml} \mathrm{NB}$ \\
\hline $\begin{array}{l}\text { Medium } \\
\left(\mathrm{NB}^{+}\right)\end{array}$ & $\begin{array}{l}\text { Penicillin }(100 \mathrm{U} / \mathrm{ml})+ \\
\text { Streptomycin }(100 \mu \mathrm{g} / \mathrm{ml})\end{array}$ & Gibco \#15140-122 & $\begin{array}{l}500 \mu 1 \text { of } 100 x \text { Penicillin/ } \\
\text { Streptomycin stock solution }\end{array}$ \\
\hline & $\begin{array}{l}2 \text { mM Glutamax } \\
\text { (L-Alanyl L- Glutamine) }\end{array}$ & Gibco \#35050-038 & $500 \mu 1$ of $100 x$ Glutamax \\
\hline & 1x B-27 supplement & Gibco \#17504-001 & $\begin{array}{l}1 \mathrm{ml} \text { of } 50 \mathrm{x} \mathrm{B}-27 \text { stock } \\
\text { solution }\end{array}$ \\
\hline Plating & Neurobasal medium (NB) & Gibco \#21103-049 & $47.75 \mathrm{ml} \mathrm{NB}$ \\
\hline$(\mathrm{PM})$ & $\begin{array}{l}\text { Penicillin }(100 \mathrm{U} / \mathrm{ml})+ \\
\text { Streptomycin }(100 \mu \mathrm{g} / \mathrm{ml})\end{array}$ & Gibco \#15140-122 & $\begin{array}{l}500 \mu 1 \text { of } 100 x \text { Penicillin/ } \\
\text { Streptomycin stock solution }\end{array}$ \\
\hline & $\begin{array}{l}2 \text { mM Glutamax } \\
\text { (L-Alanyl L-Glutamine) }\end{array}$ & Gibco \#35050-038 & $500 \mu 1$ of $100 x$ Glutamax \\
\hline & 1x B-27 supplement & Gibco \#17504-001 & $\begin{array}{l}1 \mathrm{ml} \text { of } 50 \mathrm{x} \mathrm{B}-27 \text { stock } \\
\text { solution }\end{array}$ \\
\hline & $\begin{array}{l}0.049 \mathrm{mM} \text { L-aspartate }+ \\
0.05 \mathrm{mM} \text { L-glutamate }\end{array}$ & Prepared as below & $\begin{array}{l}250 \mu 1 \text { of } 200 x \text { (L-aspartate }+ \\
\text { L-glutamate) stock solution }\end{array}$ \\
\hline
\end{tabular}




\begin{tabular}{|c|c|c|c|}
\hline \multirow{3}{*}{$\begin{array}{l}\text { 200x (L- } \\
\text { aspartate + } \\
\text { L- } \\
\text { glutamate) } \\
\text { stock } \\
\text { solution }\end{array}$} & $9.78 \mathrm{mM}$ L-aspartate & $\begin{array}{l}\text { Roth } 1690 \\
\text { (MW 133.1) }\end{array}$ & $65.1 \mathrm{mg}$ L-Asp acid \\
\hline & $9.99 \mathrm{mM}$ L-glutamate & $\begin{array}{l}\text { Abcam ab120049 } \\
\text { (MW 147.13) }\end{array}$ & 73.5 mg L-Glu acid \\
\hline & Autoclaved milli-Q water & -- & $\begin{array}{l}50 \mathrm{ml} \text {; Solution sonicated at } \\
37^{\circ} \mathrm{C} \text { and thoroughly vortexed } \\
\text { and dissolution ensured before } \\
\text { freezing aliquots at }-20^{\circ} \mathrm{C}\end{array}$ \\
\hline $\begin{array}{l}\text { PEI coating } \\
\text { solution }\end{array}$ & $\begin{array}{l}0.04 \% \text { Polyethyleneimine } \\
\text { (PEI) solution }\end{array}$ & Sigma \#P3143 & $\begin{array}{l}1 \%(\mathrm{w} / \mathrm{v}) \text { stock solution } \\
\text { diluted } 25 \text {-fold in autoclaved } \\
\text { milli-Q water. }\end{array}$ \\
\hline $\begin{array}{l}\text { Trypan } \\
\text { blue }\end{array}$ & $0.4 \%$ Trypan blue solution & Sigma \#T8154 & Use stock solution directly \\
\hline $\begin{array}{l}\text { DNAase1 } \\
\text { solution }\end{array}$ & $10 \mathrm{mg} / \mathrm{ml}$ DNAse1 & $\begin{array}{l}\text { Sigma \#DN25 or } \\
\text { Roche \#10104159001 }\end{array}$ & $\begin{array}{l}10 \mathrm{mg} / \mathrm{ml} \mathrm{DNAse} 1 \text { in } 150 \mathrm{mM} \\
\mathrm{NaCl} \text { solution, sterile filtered } \\
\text { and stored at }-20^{\circ} \mathrm{C} \text { in } 200 \mu \mathrm{l} \\
\text { aliquots }\end{array}$ \\
\hline \multirow{3}{*}{$\begin{array}{l}\text { FUDR } \\
\text { solution }\end{array}$} & $\sim 41 \mathrm{mM}$ FUDR & Sigma \#F0503 & $100 \mathrm{mg}$ \\
\hline & $\sim 20 \mathrm{mM}$ Uridine & Sigma \#U3003 & $50 \mathrm{mg}$ \\
\hline & Autoclaved milli-Q water & -- & $10 \mathrm{ml}$ \\
\hline
\end{tabular}

\section{- Rat embryonic (E18 to E19) dissociated hippocampal cultures}

Dissection medium (see Table 3) was cooled by placing on ice. The trypsin solution and the plating medium (see Table 3 ) were pre-warmed at $37^{\circ} \mathrm{C}$ in a water bath. All surfaces were sterilized with $70 \%(\mathrm{v} / \mathrm{v})$ ethanol.

The protocol was as follows:

1. Ethanol sterilized $12 \mathrm{~mm}$ glass coverslips (Menzel Gläser, thickness \#1) were washed with autoclaved milli-Q water and placed into 24-well plates (cytoOne). $70 \mu \mathrm{l}$ of PDL coating solution (see Table 3) was applied to each coverslip so as to just cover their entire exposed surface area and left in the dark outside the laminar hood for 1-6 hours. After coating, the coverslips were washed thrice with autoclaved milli-Q water and allowed to dry before plating cells. 
2. Wistar rats pregnant with E18-E19 pups (bred at the University Medical Center of Göttingen (UMG) animal facility) were euthanized with carbogen $\left(95 \% \mathrm{O}_{2}\right.$ and $\left.5 \% \mathrm{CO}_{2}\right)$. The fur on the abdomen was sterilized by spraying with 70\% (v/v) ethanol (Roth \#T913) before cutting it open. The uterus with the pups was then removed and transferred into a $10-\mathrm{cm}$ petri dish (CytoOne) under the dissection hood. The pups were decapitated after cutting them out of the amniotic sac and the heads were collected in a $10-\mathrm{cm}$ petri dish containing dissection medium. After cutting out the cerebellum, the cerebrum was gently squeezed out from under the skull using the blunt end of scissors and collected in fresh dissection medium. After cutting out the midbrain and removing the meninges, the hippocampi were dissected and collected in fresh dissection medium in a $15 \mathrm{ml}$ falcon tube on ice.

3. The collected hippocampi were digested in $2 \mathrm{ml}$ of $0.05 \%$ trypsin solution for 20 min at $37^{\circ} \mathrm{C}$ in a water bath.

4. After aspirating the trypsin, the tissue was washed thrice with $5 \mathrm{ml}$ of $4^{\circ} \mathrm{C}$ dissection medium. The washed hippocampi were then triturated in $1 \mathrm{ml}$ of plating medium by gently pipetting the hippocampi through the tip of a $1 \mathrm{ml}$ plastic micropipette tip up to 15 times. The cell suspension was then filtered with a $100 \mu \mathrm{m}$ pore size cell strainer (Corning \#352360). After pre-wetting the strainer with $1 \mathrm{ml}$ of plating medium, the cell suspension was applied to the membrane and washed through with $8 \mathrm{ml}$ of plating medium.

5. $10 \mu 1$ of the cell suspension was mixed with an equal volume of trypan blue solution. The number of living cells were estimated by excluding the blue dye permeated cells using a hemocytometer (as for mouse P0 cultures above) to estimate the final cell concentration.

6. Cells were plated at a density of 80,000 cells per well and cultured in plating medium in a cell culture Incubator (Thermo Scientific Hera Cell 240i) at $37^{\circ} \mathrm{C}$ and $5 \% \mathrm{CO}_{2}$.

Table 3: Formulation of reagents needed for embryonic rat dissociated hippocampal cultures

\begin{tabular}{|l|l|l|l|}
\hline \multicolumn{1}{|c|}{ Solution } & \multicolumn{1}{|c|}{ Final Composition } & $\begin{array}{c}\text { Catalogue } \\
\text { Number }\end{array}$ & Preparation Instruction \\
\hline Dissection Medium & $\begin{array}{l}\text { Hanks buffered salt } \\
\text { solution (HBSS) }\end{array}$ & Gibco \#14170-088 & $500 \mathrm{ml}$ HBSS \\
\cline { 2 - 4 } & $10 \mathrm{mM}$ HEPES & Gibco \#15630-080 & $\begin{array}{l}5 \mathrm{ml} \text { of 1 M HEPES stock } \\
\text { solution }\end{array}$ \\
\hline
\end{tabular}




\begin{tabular}{|c|c|c|c|}
\hline Trypsin solution & $0.05 \%$ trypsin-EDTA & Gibco \#25300-054 & Stock solution used directly \\
\hline \multirow{4}{*}{$\begin{array}{l}\text { Plating medium } \\
\left(\mathrm{NB}^{+}\right)\end{array}$} & Neurobasal medium (NB) & Gibco \#21103-049 & $48 \mathrm{ml} \mathrm{NB}$ \\
\hline & $\begin{array}{l}\text { Penicillin }(100 \mathrm{U} / \mathrm{ml})+ \\
\text { Streptomycin }(100 \mu \mathrm{g} / \mathrm{ml})\end{array}$ & Gibco \#15140-122 & $\begin{array}{l}500 \mu 1 \text { of } 100 x \text { Penicillin/ } \\
\text { Streptomycin stock solution }\end{array}$ \\
\hline & $\begin{array}{l}2 \text { mM Glutamax } \\
\text { (L-Alanyl L-Glutamine) }\end{array}$ & Gibco \#35050-038 & $\begin{array}{l}500 \mu 1 \text { of } 100 x \text { Glutamax } \\
\text { stock solution }\end{array}$ \\
\hline & 1x B-27 supplement & Gibco \#17504-001 & $\begin{array}{l}1 \mathrm{ml} \text { of } 50 \mathrm{x} \mathrm{B}-27 \text { stock } \\
\text { solution }\end{array}$ \\
\hline \multirow[t]{3}{*}{$0.1 \mathrm{M}$ Borate buffer } & Sodium Tetraborate & Sigma 229946 & $0.475 \mathrm{~g}$ \\
\hline & Boric acid & Sigma B9645 & $0.31 \mathrm{~g}$ \\
\hline & Autoclaved milli-Q water & -- & $\begin{array}{l}100 \mathrm{ml} ; \mathrm{pH} \text { adjusted to } 8.5 \\
\text { with } 32 \% \mathrm{HCl} \text { and sterile } \\
\text { filtered; freshly prepared for } \\
\text { every batch of PDL coating } \\
\text { solution }\end{array}$ \\
\hline $\begin{array}{l}\text { PDL coating } \\
\text { solution }\end{array}$ & $\begin{array}{l}0.5 \mathrm{mg} / \mathrm{ml} \\
\text { Poly-D-Lysine }\end{array}$ & Sigma P7886 & $\begin{array}{l}100 \mathrm{mg} \text { PDL }+200 \mathrm{ml} \text { of } \\
0.1 \mathrm{M} \text { borate buffer } \\
\text { (formulation above) }\end{array}$ \\
\hline
\end{tabular}

\section{- HEK 293 cell culture}

HEK 293 (HEK) cells were cultured in 10-cm cell culture dishes (Greiner \#664160) in $10 \mathrm{ml}$ of HEK 293 plating medium (see Table 4) in the incubator at $37^{\circ} \mathrm{C}$ and $5 \% \mathrm{CO}_{2}$. HEK cells were split first by washing once with $37^{\circ} \mathrm{C}$ warm DPBS (Gibco \#14190-094). They were then removed from the culture dish by treatment with $1 \mathrm{ml}$ of $37^{\circ} \mathrm{C}$ warm $0.25 \%$ Trypsin-EDTA (Gibco \#25200$056)$ and gently tapping the dish. Fresh $37^{\circ} \mathrm{C}$ HEK 293 plating medium $(10 \mathrm{ml} / \mathrm{dish})$ was then added to deactivate trypsin and appropriate dilutions were plated onto new culture dishes. 
For long-term storage, when a dish reached 80-90\% confluence, cells were trypsinized (as above) and centrifuged (3000 rpm for $3 \mathrm{~min}$ at room temperature in an Eppendorf 5810R centrifuge). The pellet was then resuspended in $1 \mathrm{ml}$ of freezing serum (see Table 4). $500 \mu 1$ aliquots were made in cryotubes and transferred to an isopropanol freezing container (Thermo Scientific/Nalgene \#51000001 ) for slow freezing, and subsequently stored at $-80^{\circ} \mathrm{C}$. For starting a culture, one of these cryostocks was thawed in a water bath at $37^{\circ} \mathrm{C}$ and rapidly diluted with $10 \mathrm{ml}$ of HEK 293 plating medium, pelleted and resuspended in $10 \mathrm{ml}$ of fresh HEK 293 plating medium to remove DMSO from the medium.

Table 4: Formulation of reagents needed for culturing HEK cells

\begin{tabular}{|c|c|c|c|}
\hline Solution & Final Composition & $\begin{array}{l}\text { Catalogue } \\
\text { Number }\end{array}$ & $\begin{array}{l}\text { Preparation } \\
\text { Instruction }\end{array}$ \\
\hline \multirow[t]{3}{*}{$\begin{array}{l}\text { HEK } 293 \\
\text { plating medium }\end{array}$} & $\begin{array}{l}\text { Dulbecco's modified eagle } \\
\text { medium (DMEM) }\end{array}$ & Gibco \#41966-029 & $44.5 \mathrm{ml}$ DMEM \\
\hline & $\begin{array}{l}10 \%(\mathrm{v} / \mathrm{v}) \text { heat inactivated Fetal } \\
\text { Bovine Serum }\end{array}$ & Gibco \# 10500-064 & $5 \mathrm{ml} \mathrm{FBS}$ \\
\hline & $\begin{array}{l}\text { Penicillin }(100 \mathrm{U} / \mathrm{ml}) \\
+ \text { Streptomycin }(100 \mu \mathrm{g} / \mathrm{ml})\end{array}$ & Gibco \#15140-122 & $\begin{array}{l}500 \mu \mathrm{l} \text { of } 100 \mathrm{x} \text { (Penicillin } \\
+ \text { Streptomycin) stock } \\
\text { solution }\end{array}$ \\
\hline \multirow[t]{3}{*}{ Freezing serum } & $\begin{array}{l}50 \%(\mathrm{v} / \mathrm{v}) \text { heat inactivated Fetal } \\
\text { Bovine Serum }\end{array}$ & Gibco \# 10500-064 & $500 \mu 1 \mathrm{FBS}$ \\
\hline & $\begin{array}{l}\text { Dulbecco's modified eagle } \\
\text { medium (DMEM) }\end{array}$ & Gibco \#41966-029 & $400 \mu 1 \mathrm{DMEM}$ \\
\hline & $\begin{array}{l}10 \%(\mathrm{v} / \mathrm{v}) \text { Dimethyl sulfoxide } \\
(\mathrm{DMSO})\end{array}$ & Sigma \#276855 & $100 \mu 1 \mathrm{DMSO}$ \\
\hline
\end{tabular}




\subsection{Transfection}

\section{- Calcium phosphate transfection of HEK cells for Western blot analysis}

Upon reaching $80-90 \%$ confluence, the HEK cell culture was passaged and split at 1:6 to 1:10 for transfection on the following day or at 1:20 to maintain the culture. Before transfection, cells were first washed with $10 \mathrm{ml}$ of prewarmed DPBS (Gibco \#14190-094). For transfection of one 10-cm dish, $25 \mu \mathrm{g}$ of plasmid DNA was added to $360 \mu \mathrm{l}$ autoclaved milli-Q $\mathrm{H}_{2} \mathrm{O}$ mixed with $40 \mu \mathrm{l}$ of sterile filtered $2.5 \mathrm{M} \mathrm{CaCl}_{2}$ (Roth \#HN04). $400 \mu \mathrm{l}$ of transfection buffer was then added on a vortex under gentle mixing $\left(274 \mathrm{mM} \mathrm{NaCl}, 10 \mathrm{mM} \mathrm{KCl}, 1.4 \mathrm{mM} \mathrm{Na}_{2} \mathrm{HPO}_{4}, 15 \mathrm{mM}\right.$ D-Glucose, $42 \mathrm{mM}$ HEPES titrated to $\mathrm{pH}$ 7.01-7.05 with $\mathrm{NaOH}$ and sterile filtered). This mixture was incubated at room temperature for $20 \mathrm{~min}$ in the dark and added to the dish. 24-48 hours later, transfected HEK cells in $10 \mathrm{~cm}$ plates were harvested in lysis buffer (50 mM Tris-HCl pH 7.5, $150 \mathrm{mM} \mathrm{NaCl}, 2$ mM EDTA, $0.5 \%$ NP40, and protease inhibitors) for western blotting.

\section{- Lipofectamine 2000 transfection of primary neuronal cultures}

Neurons in dissociated hippocampal cultures were transfected on DIV 10 using Lipofectamine 2000 (Thermofisher Scientific). All Neurobasal medium (Gibco \#21103-049) used was pre-warmed in a water bath at $37^{\circ} \mathrm{C}$. For every well (of a 24 well plate) to be transfected, a) $1 \mu 1$ of Lipofectamine 2000 in $50 \mu \mathrm{L}$ of Neurobasal medium and b) $1 \mu \mathrm{g}$ of plasmid DNA in $50 \mathrm{uL}$ of Neurobasal medium were incubated separately at room temperature for $5 \mathrm{~min}$. Both solutions were mixed together thoroughly by pipetting up and down at least 30 times before incubating for $20 \mathrm{~min}$ at room temperature. Meanwhile, conditioned culture medium (which contains various factors secreted into the plating medium by cells and is crucial for cell viability) was removed (and $\sim 10 \%$ (v/v) fresh medium was added to it), stored in the incubator at $37^{\circ} \mathrm{C}$ and $5 \% \mathrm{CO}_{2}$ and replaced with $400 \mu \mathrm{l}$ Neurobasal medium. $100 \mu \mathrm{l}$ of the lipofectamine-DNA mixture was then added to each well and incubated for 2 hours at $37^{\circ} \mathrm{C}$ and $5 \% \mathrm{CO}_{2}$. The cells were washed once with $500 \mu \mathrm{l}$ of Neurobasal medium and then $\sim 450 \mu \mathrm{l}$ of conditioned medium was returned to each well before being put back into the incubator. Care was taken not to let neurons dry out while exchanging medium. For transfection of mouse $\mathrm{P} 0$ cultures, it was crucial to adjust the osmolarity of the Neurobasal medium to that of the conditioned medium (1 mM D-Mannitol (Sigma \#M4125) was added to increase osmolarity by $1 \mathrm{mOsm}$ and then sterile filtered). Experiments were 
conducted 2 days after transfection at the earliest to allow for expression of plasmids or maximal knockdown in the case of shRNA-mediated knockdown of syt3.

\subsection{Imaging}

\section{- Immunohistochemistry (IHC) of acute hippocampal slices}

This experiment was performed by Dr. Binu Ramachandran (Trans-synaptic signalling group, ENI Göttingen). Acute hippocampal slices were prepared as described (Ramachandran \& Frey, 2009). Briefly, 8-week old mice were anesthetized with isoflurane and decapitated. The hippocampus was removed and $400 \mu \mathrm{m}$ thick slices from the dorsal hippocampus were cut transversely in ice-cold artificial cerebrospinal fluid (ACSF) containing, in mM: $124 \mathrm{NaCl}, 4.9 \mathrm{KCl}, 1.2 \mathrm{KH}_{2} \mathrm{PO}_{4}, 2$ $\mathrm{MgSO}_{4}, 2 \mathrm{CaCl}_{2}, 24.6 \mathrm{NaHCO}_{3}$ and $10 \mathrm{D}$-glucose (saturated with $95 \% \mathrm{O}_{2}$ and $5 \% \mathrm{CO}_{2}, \mathrm{pH} 7.4$, -305 mOsm), using a tissue chopper (Stoelting). Slices were fixed in 4\% paraformaldehyde in PBS (see Table 5) for $30 \mathrm{~min}$ and washed thrice for $20 \mathrm{~min}$ each with PBS. After washing, slices were incubated in antibody buffer ( $2 \%$ donkey serum, $0.1 \%$ Triton X-100 and $0.05 \% \mathrm{NaN}_{3}$ in PBS) for $30 \mathrm{~min}$ at room temperature. Then, slices were incubated with primary antibodies in antibody buffer overnight at $4^{\circ} \mathrm{C}$. Next, slices were washed thrice with PBS for 20 min each and incubated with fluorescently-tagged secondary antibodies for 2 hours at room temp. Slices were then washed thrice for 20 min each with PBS and mounted onto microscope slides with Fluoromount-G (Sigma) and the edges sealed with nail polish. Images were collected using 10x air and 40x oil immersion objectives on a Zeiss A1 laser scanning confocal microscope with Zen software (Carl Zeiss). Digital images were processed using Adobe Photoshop software.

Table 5: Solutions used for immunocytochemistry

\begin{tabular}{|c|l|l|l|}
\hline \multirow{2}{*}{ Buffer } & \multicolumn{1}{|c|}{ Final Composition } & \multicolumn{1}{|c|}{$\begin{array}{c}\text { Catalogue } \\
\text { number }\end{array}$} & \multicolumn{1}{|c|}{ Preparation instructions } \\
\hline \multirow{2}{*}{} & Deioinized $\mathrm{H}_{2} \mathrm{O}$ & -- & $500 \mathrm{ml}$ \\
\cline { 2 - 4 } & $38 \mathrm{mM} \mathrm{NaH}_{2} \mathrm{PO}_{4} \cdot 2 \mathrm{H}_{2} \mathrm{O}$ & Roth $\# 2370$ & $2.96 \mathrm{~g}$ \\
\hline
\end{tabular}




\begin{tabular}{|c|c|c|c|}
\hline $\begin{array}{l}0.2 \mathrm{M} \\
\text { phosphate } \\
\text { buffer }\end{array}$ & $\begin{array}{l}162 \mathrm{mM} \mathrm{Na}_{2} \mathrm{HPO}_{4} \cdot \\
12 \mathrm{H}_{2} \mathrm{O}\end{array}$ & Roth \#T876 & $29.01 \mathrm{~g}$ \\
\hline $\begin{array}{l}8 \% \text { PFA } \\
\text { solution }\end{array}$ & $\begin{array}{l}80 \mathrm{~g} / \mathrm{L} \text { Paraformaldehyde } \\
\text { (PFA) }\end{array}$ & Roth \#0335 & $\begin{array}{l}40 \mathrm{~g} \text { PFA; To dissolve PFA, } 500 \mathrm{ml} \\
\text { deionized water was heated to } 65^{\circ} \mathrm{C} \\
\text { in a draft chamber. After } 15-20 \\
\text { drops of } 5 \mathrm{M} \mathrm{NaOH} \text {, PFA was added } \\
\text { slowly. Solution was filtered and } \\
\text { stored at } 4^{\circ} \mathrm{C} \text {. }\end{array}$ \\
\hline \multirow{2}{*}{$\begin{array}{l}4 \% \text { PFA } \\
\text { solution }\end{array}$} & 8\% PFA solution & As prepared above & \multirow{2}{*}{$\begin{array}{l}\text { Equal volumes of both solutions } \\
\text { mixed together; Stored at } 4^{\circ} \mathrm{C} \text {. }\end{array}$} \\
\hline & $0.2 \mathrm{M}$ phosphate buffer & As prepared above & \\
\hline \multirow[t]{5}{*}{ 10X PBS } & $\mathrm{Na}_{2} \mathrm{HPO}_{4}$ & Roth \#T876 & $14.4 \mathrm{~g}$ \\
\hline & $\mathrm{KH}_{2} \mathrm{PO}_{4}$ & Merck \#104873 & $2.4 \mathrm{~g}$ \\
\hline & $\mathrm{NaCl}$ & Roth \#P029 & $80 \mathrm{~g}$ \\
\hline & $\mathrm{KCl}$ & Roth \#6781 & $2 \mathrm{~g}$ \\
\hline & Deionized $\mathrm{H}_{2} \mathrm{O}$ & -- & $\begin{array}{l}1 \text { liter; } \mathrm{pH} 7.4 \text { with } \mathrm{NaOH} \text {. Solution } \\
\text { filtered and stored at room } \\
\text { temperature. }\end{array}$ \\
\hline \multirow[t]{4}{*}{ Buffer D } & 2\% Donkey serum & Sigma \#D9663 & $1 \mathrm{ml}$ donkey serum \\
\hline & $0.1 \%(\mathrm{w} / \mathrm{v})$ Triton $\mathrm{X}-100$ & Roth \#3051 & $\begin{array}{l}250 \mu \mathrm{l} \text { of } 20 \% \text { Triton } \mathrm{X}-100 \text { stock } \\
\text { solution }(10 \mathrm{~g} \text { Triton } \mathrm{X}-100 \mathrm{in} \\
\left.50 \mathrm{ml} \text { deionized } \mathrm{H}_{2} \mathrm{O}\right)\end{array}$ \\
\hline & $0.05 \%(\mathrm{w} / \mathrm{v}) \mathrm{NaN}_{3}$ & Roth \#K305 & $\begin{array}{l}250 \mu \mathrm{l} \text { of } 10 \% \mathrm{NaN}_{3} \text { stock solution } \\
\left(5 \mathrm{~g} \mathrm{NaN}_{3} \text { in } 50 \mathrm{ml} \text { deionized } \mathrm{H}_{2} \mathrm{O}\right)\end{array}$ \\
\hline & 2x PBS & As prepared above & $\begin{array}{l}10 \mathrm{ml} \text { of } 10 \mathrm{X} \text { PBS stock solution; } \\
\text { Total volume } 50 \mathrm{ml} \text { made with } \\
\text { deionized } \mathrm{H}_{2} \mathrm{O}\end{array}$ \\
\hline \multirow{4}{*}{$\begin{array}{l}\text { Mowiol } \\
\text { solution }\end{array}$} & $9.6 \mathrm{~g}$ Mowiol 4-88 & Roth 0713 & \multirow{4}{*}{$\begin{array}{l}\text { Stirred at } 40-50^{\circ} \mathrm{C} \text { for a few days; } \\
\text { Supernatant aliquoted and frozen in } \\
\text { liquid nitrogen after mixture was } \\
\text { allowed to settle, and stored at }-20^{\circ} \mathrm{C}\end{array}$} \\
\hline & 24 g glycerol & Roth 3783 & \\
\hline & $9.6 \mathrm{ml}$ of $1 \mathrm{M}$ Tris $(\mathrm{pH} 8.5)$ & Roth A411 & \\
\hline & $62.4 \mathrm{ml}$ milli-Q $\mathrm{H}_{2} \mathrm{O}$ & -- & \\
\hline
\end{tabular}




\section{- Immunocytochemistry (ICC)}

Cultured neurons were fixed for 20-30 $\mathrm{min}$ in 4\% PFA solution (see Table 5) at room temperature. After washing thrice in 1X PBS (see Table 5) for 3 min each, the fixed samples were stored in 1X PBS at $4{ }^{\circ} \mathrm{C}$ or used immediately for immunostaining. To prevent non-specific antibody binding, samples were incubated with buffer D (see Table 5) for $30 \mathrm{~min}$. Triton X-100 was included in buffer D when permeabilization of cells was desired, and was omitted for staining surface epitopes in non-permeabilized conditions. Primary antibodies (in buffer D) were added to the samples overnight at $4^{\circ} \mathrm{C}$. The following day, samples were washed thrice in $1 \mathrm{X}$ PBS for 3 min each, after which secondary antibodies (in buffer D) were added and incubated at room temperature in the dark for 2 hours. After secondary antibody incubation, samples were washed thrice in 1X PBS for 3 min each. Next, the coverslips were mounted in $10 \mu \mathrm{l}$ Mowiol solution (see Table 5) on glass slides. After allowing the Mowiol to solidify at room temperature in the dark for 9-48 hours, samples were stored at $4^{\circ} \mathrm{C}$ in the dark. Fixed sample imaging was done using a $63 \mathrm{X}$ oil immersion objective on a Zeiss LSM 710 confocal microscope.

\section{- Receptor internalization assays}

$300 \mu 1$ of conditioned medium from each well of dissociated hippocampal neurons was removed and saved in the incubator. For GluA1, $10 \mu \mathrm{l}$ of $0.05 \mu \mathrm{g} / \mu \mathrm{l}$ anti-GluA1 (extracellular epitope: Calbiochem \#PC246) was added to $200 \mu$ of conditioned medium per well. For GluA2, $1 \mu 1$ of anti-GluA2 (extracellular epitope: Millipore \#MAB397) was added to $200 \mu \mathrm{l}$ of conditioned medium per well. Neurons were incubated for $15 \mathrm{~min}$ in the incubator at $37^{\circ} \mathrm{C}$ and $5 \% \mathrm{CO}_{2}$. Wells were then washed with $500 \mu \mathrm{l}$ pre-warmed $37^{\circ} \mathrm{C} \mathrm{NB}^{+}$(see Table 3 ) for $3 \mathrm{~min}$ in the incubator to remove excess antibody. Medium was then removed and cells were incubated with $200 \mu \mathrm{NB}^{+}$ containing $100 \mu \mathrm{M}$ AMPA (S-AMPA, the active optical isomer of AMPA, abcam \#ab120005, from a $10 \mathrm{mM}$ stock in milli-Q water), $100 \mu \mathrm{M}$ NMDA (Sigma \#M3262, from a $50 \mathrm{mM}$ stock in milli-Q water), or $\mathrm{NB}^{+}$alone (for non-stimulated conditions) for $3 \mathrm{~min}$ in the incubator. Stimulation solutions were then removed and all coverslips were incubated for an additional $8 \mathrm{~min}$ in $250 \mu \mathrm{l}$ conditioned media. Coverslips were then fixed in 4\% PFA solution (see Table 5), and immunostained (see 'Immunocytochemistry (ICC)' on page 48 above for general protocol). First, surface receptors were labelled by blocking cells in non-permeabilizing conditions in buffer D without Triton X-100. Surface receptors were then labelled with Alexa 647 secondary antibodies 
(of species corresponding to primary antibody; see Table 7) for 1 hour at room temperature. Internal receptors would not be labelled in this step because cells are non-permeabilized. Cells were washed thrice in $1 \mathrm{X}$ PBS for $3 \mathrm{~min}$ each. Cells were then permeabilized in buffer D with Triton X-100. Primary antibodies against MAP2 (chick) and GFP (mouse anti-GFP for GluA1 labelling and rabbit anti-GFP for GluA2 labelling) were added and incubated at $4{ }^{\circ} \mathrm{C}$ overnight or for 2-4 hours at room temperature (see Table 6). Cells were then washed thrice in 1X PBS for 3 min each. Internal receptors were then labelled with Alexa 546 secondary antibodies (of species corresponding to primary antibody; see Table 7). Surface receptors would not be labelled in this step because surface epitopes have been saturated with 647 secondary antibodies. For analysis, regions of interest were manually drawn around cell somas in ImageJ (NIH Image), using MAP2 or GFP signal as a guide. The internalization index was calculated as the ratio of internal to surface receptor fluorescence. Only experiments in which control cells showed the expected receptor internalization in stimulated conditions were considered for quantitation.

\section{- pHluorin timelapse imaging}

For timelapse experiments, a $12 \mathrm{~mm}$ diameter glass coverslip (Menzel Gläser, thickness \#1), on which dissociated hippocampal neurons were cultured, was set on top of a $25 \mathrm{~mm}$ diameter glass coverslip (Menzel Gläser, thickness \#0), which in turn was fixed by vacuum grease onto a field stimulation chamber (Warner Instruments) containing $100 \mu \mathrm{l}$ extracellular solution (140 mM $\mathrm{NaCl}, 5 \mathrm{mM} \mathrm{KCl}, 2 \mathrm{mM} \mathrm{CaCl}$, $2 \mathrm{mM} \mathrm{MgCl}_{2}, 5.5 \mathrm{mM}$ D-glucose, $20 \mathrm{mM}$ HEPES, $\mathrm{pH}=7.3$ ). Field stimulation was delivered via a stimulator (A.M.P.I. Master-9) connected to a stimulus isolator (WPI A385). Transfected cells were selected, and images were acquired at $1 \mathrm{~s}$ intervals and $500 \mathrm{~ms}$ exposure times, with 484/20nm excitation and 517/20nm emission filters through 100X oil objectives, on an inverted microscope (Zeiss Axio Observer A1) with a Photometrics Evolve EMCCD camera, and Lambda DG-4 fast-switching light source interfaced with Metamorph software. A baseline of images was collected before addition of high potassium buffer (100 mM NaCl, $45 \mathrm{mM} \mathrm{KCl,} 2 \mathrm{mM} \mathrm{CaCl}$, $2 \mathrm{mM} \mathrm{MgCl}$, $5.5 \mathrm{mM}$ glucose, $20 \mathrm{mM}$ HEPES, $\mathrm{pH}=$ 7.3), $100 \mu \mathrm{M}$ AMPA, $100 \mu \mathrm{M}$ NMDA, or field stimulation to depolarize neurons. All field stimulation experiments were done in the presence of $1 \mu \mathrm{M}$ tetrodotoxin (Tocris). Dendritic regions were selected in Metamorph and fluorescence intensity plotted versus time. 
- Antibodies

Table 6: List of primary antibodies used

\begin{tabular}{|c|c|c|c|c|}
\hline $\begin{array}{c}\text { Primary } \\
\text { Antibodies }\end{array}$ & Host & $\begin{array}{c}\text { Catalogue } \\
\text { number }\end{array}$ & Application & Company \\
\hline GFP & rabbit & Ab290 & $\operatorname{ICC}(1: 1000)$ & Abcam \\
\hline Synaptophysin & guinea pig & 101004 & $\operatorname{ICC}(1: 2000)$ & Synaptic Systems \\
\hline MAP2 & chick & C-1382-50 & ICC $(1: 2500)$ & Biosensis \\
\hline vGlut1 & rabbit & 135303 & $\operatorname{ICC}(1: 1000)$ & Synaptic Systems \\
\hline Gephyrin & mouse & 147011 & ICC $(1: 500)$ & Synaptic Systems \\
\hline vGAT & mouse & 131011 & $\operatorname{ICC}(1: 500)$ & Synaptic Systems \\
\hline PSD-95 & mouse & MA1-045 & $\operatorname{ICC}(1: 1000)$ & Thermo Fisher Scientific \\
\hline piccolo & rabbit & 142003 & WB $(1: 1000)$ & Synaptic Systems \\
\hline $\begin{array}{l}\text { Synaptobrevin2 } \\
\text { (VAMP2) }\end{array}$ & Mouse & $\begin{array}{l}104211 \\
\text { (Clone 69.1) }\end{array}$ & WB $(1: 1000)$ & Synaptic Systems \\
\hline Homer & guinea pig & 160004 & WB $(1: 1000)$ & Synaptic Systems \\
\hline rab-GDI & mouse & 130011 & WB $(1: 1000)$ & Synaptic Systems \\
\hline Tubulin & mouse & 302211 & WB $(1: 1000)$ & Synaptic Systems \\
\hline rab3a & mouse & - & WB $(1: 1000)$ & provided by Reinhard Jahn \\
\hline syntaxin1a & mouse & - & WB (1:1000) & provided by Reinhard Jahn \\
\hline synapsin & mouse & - & WB (1:1000) & provided by Reinhard Jahn \\
\hline Synaptotagmin 1 & mouse & 105101 & WB (1:1000) & Synaptic Systems \\
\hline \multirow{2}{*}{ SNAP25 } & mouse & 111011 & \multirow{2}{*}{ WB $(1: 1000)$} & \multirow{2}{*}{ Synaptic Systems } \\
\hline & guinea pig & 111004 & & \\
\hline \multirow{2}{*}{$\begin{array}{l}\text { Synaptotagmin3 } \\
\text { (SYT3) }\end{array}$} & rabbit & $\begin{array}{l}105133 \\
\text { (syt3NT) }\end{array}$ & $\operatorname{ICC}(1: 500)$ & Synaptic Systems \\
\hline & mouse & $\mathrm{N} 278.19$ & WB $(1: 1000)$ & Neuromab \\
\hline GluA1 & rabbit & PC246 & $1: 100$ & Calbiochem \\
\hline GluA2 & mouse & MAB397 & $\operatorname{ICC}(1: 500)$ & Millipore \\
\hline GluA3 & rabbit & $1731-1$ & WB (1:1000) & Epitomics \\
\hline GluN1 & rabbit & AB9864 & WB (1:1000) & Millipore \\
\hline
\end{tabular}




\begin{tabular}{|l|l|l|l|l|}
\hline GluN2A & mouse & MAB5216 & WB (1:1000) & Millipore \\
\hline GABAAR1 & rabbit & AGA-005 & WB (1:2000) & Alomone \\
\hline EEA1 & rabbit & - & WB $(1: 1000)$ & provided by Reinhard Jahn \\
\hline GRIP & rabbit & 151003 & WB $(1: 1000)$ & Synaptic Systems \\
\hline Pick1 & rabbit & PA1-073 & WB $(1: 1000)$ & Thermo Fisher Scientific \\
\hline BRAG2 & rabbit & - & WB (1:1000) & $\begin{array}{l}\text { Provided by Dr. Hans } \\
\text { Christian Kornau } \\
\text { (Scholz et al., 2010) }\end{array}$ \\
\hline
\end{tabular}

Table 7: List of secondary antibodies used

\begin{tabular}{|l|l|l|l|l|}
\hline \multicolumn{1}{|c|}{$\begin{array}{c}\text { Secondary Antibodies with conjugated } \\
\text { dye }\end{array}$} & \multicolumn{1}{|c|}{ Host } & $\begin{array}{c}\text { Catalogue } \\
\text { Number }\end{array}$ & Applications & Company \\
\hline Anti-guinea pig Alexa 647 & Goat & A-21450 & ICC (1:1000) & Invitrogen \\
\hline Anti-rabbit Alexa 546 & Goat & A-11010 & ICC (1:1000) & Invitrogen \\
\hline Anti-chick Alexa 405 & Goat & 175765 & ICC (1:1000) & Abcam \\
\hline Anti-mouse Alexa 488 & Donkey & A-21202 & ICC (1:1000) & Invitrogen \\
\hline HRP-coupled monoclonal mouse & Mouse & 1706516 & WB (1:2000) & Bio-Rad \\
\hline HRP-coupled rabbit polyclonal & Rabbit & 1706515 & WB (1:2000) & Bio-Rad \\
\hline Anti-guinea pig Alexa 647 & Goat & A-21450 & ICC (1:1000) & Invitrogen \\
\hline Anti-rabbit Alexa 546 & Goat & A-11010 & ICC (1:1000) & Invitrogen \\
\hline Anti-chick Alexa 405 & Goat & 175765 & ICC (1:1000) & Abcam \\
\hline
\end{tabular}

\subsection{Mammalian expression constructs}

Mammalian expression constructs used were: pHluorin-syt3, i.e., superecleptic pHluorin fused to the N-terminal end of SYT3 as previously described (Dean et al., 2012); GFP-syt3 and mCherrysyt3, sub-cloned by replacing the pHluorin in pHluorin-syt3 with GFP or mCherry, respectively; the calcium-binding mutant of syt3 (generated by Genscript) by mutagenesis of 4 amino acids (D386N, D388N, D520N, D522N) of pHluorin-syt3, where these sites correspond to the calciumbinding sites of syt1 (D230, D232, D363, D365 respectively) (Bhalla et al., 2008; Vrljic et al., 
2010); SYT3 shRNA knockdown constructs

KD1 (TGCTGTTGACAGTGAGCGACAAGCTCATCGGTCAGATCAATAGTGAAGCCACA GATGTATTGATCTGACCGATGAGCTTGGTGCCTACTGCCTCGGA), KD2 (TGCTGTTG ACAGTGAGCGCAGGTGTCAAGAGTTCAACGAATAGTGAAGCCACAGATGTATTCGT TGAACTCTTGACACCTATGCCTACTGCCTCGGA) and KD3 (TGCTGTTGACAGTGAGC CAGGATTGTCAGAGAAAGAGAATAGTGAAGCCACAGATGTATTCTCTTTCTCTGACA ATCCTTTGCCTACTGCCTCGGA) in the pGIPZ vector, co-expressing turboGFP (from Thermo Scientific Openbiosystems).

\section{- Plasmid DNA amplification}

Electrocompetent E. coli cells (Stratagene \#200249) were transformed by mixing 0.5-1 $\mu$ g plasmid DNA with $50 \mu$ of electrocompetent cells. This mixture was transferred to an electroporation cuvette (Biozym Scientific GmbH \#748010), and an 1800 Volt electric pulse was delivered (Electroporator 2510, Eppendorf). Subsequently, $1 \mathrm{ml}$ of $37^{\circ} \mathrm{C}$ autoclaved $\mathrm{LB}$ medium (Roth \#X968) was added to cells and incubated at $37^{\circ} \mathrm{C}$ for $15-30$ min while mixing at $1400 \mathrm{rpm}$ (Eppendorf Thermomixer comfort). $100 \mu \mathrm{l}$ of this cell solution was streaked with a $100 \mu \mathrm{l}$ micropipette tip onto a $10 \mathrm{~cm}$ LB-Agar dish containing $50 \mu \mathrm{g} / \mathrm{ml}$ kanamycin or $100 \mu \mathrm{g} / \mathrm{ml}$ ampicillin depending on the antibiotic resistance marker on the plasmid, and incubated overnight at $37^{\circ} \mathrm{C}$. The following day, single colonies were picked and used to inoculate $5 \mathrm{ml}$ LB liquid cultures (with appropriate antibiotic), which were incubated for 6-8 hours. This culture was used to inoculate a larger culture volume of $400 \mathrm{ml}$ for overnight incubation until $\mathrm{OD}_{600}$ reached 3-4. Cells were pelleted by centrifugation at maximum speed at $4{ }^{\circ} \mathrm{C}$ for $30 \mathrm{~min}$ in an Eppendorf 5810R centrifuge and plasmids extracted using the NucleoBond Xtra Maxi kit (Macherey Nagel). DNA yield and purity was determined with a Nanophotometer (Implen GmbH, Germany).

\subsection{Biochemistry}

All biochemistry experiments were carried out by Dr. Saheeb Ahmed and Dr. Katja Burk (Transsynaptic signalling group, ENI Göttingen). 


\section{- Subcellular fractionation from whole brain}

Rat brains were homogenized in ice-cold homogenization buffer ( $320 \mathrm{mM}$ sucrose, $4 \mathrm{mM}$ HEPES, $\mathrm{pH} 7.4$ with $\mathrm{NaOH}$ ) using 10 strokes at $900 \mathrm{rpm}$. These samples were then centrifuged at 1,000 $\mathrm{g}_{\max }$ for 10 min. The supernatant (S1) was retained. The resulting pellet (P1) contains large cell fragments and nuclei. $\mathrm{S} 1$ was then centrifuged at 15, $000 \mathrm{~g}_{\max }$ for $15 \mathrm{~min}$. The supernatant (S2) obtained from this centrifugation contains soluble proteins and the pellet (P2) contains synaptosomes. The pellet (P2) was then carefully resuspended in $1 \mathrm{ml}$ of homogenization buffer. $9 \mathrm{ml}$ of ice-cold milli-Q $\mathrm{H}_{2} 0$ was added and homogenized with three strokes at 2,000 rpm. $50 \mu \mathrm{l}$ of $1 \mathrm{M}$ HEPES and protease inhibitors were then added. The lysate was next centrifuged at 17,000 $\mathrm{g}_{\max }$ for 25 min to separate synaptosomal membranes (LP2) from synaptosomal cytosol (LS2). The LP2 pellet was resuspended in $6 \mathrm{ml}$ of $40 \mathrm{mM}$ sucrose and layered over a continuous sucrose gradient from $50 \mathrm{mM}$ to $800 \mathrm{mM}$. The sucrose cushion was then centrifuged at $28,000 \mathrm{rpm}$ for 2 hours. Following centrifugation, the region between $\sim 0.04$ and 0.4 sucrose was collected and separated by chromatography on controlled-pore glass beads (CPG column) run overnight. The first peak (PI) contained larger membrane fragments and synaptic vesicles (SVs) were found in the second peak.

\section{- Immuno-organelle isolation of synaptic vesicles}

Mouse monoclonal antibodies directed against VAMP2 and syt1 were coupled to Protein G magnetic Dynabeads (Invitrogen) in PBS for 2 hours at $4^{\circ} \mathrm{C}$. Antibody-coated beads were added to whole brain $\mathrm{S} 1$ fractions in a $1.5 \mathrm{ml}$ eppendorf tube and incubated overnight at $4^{\circ} \mathrm{C}$. Magnetic beads were separated from immuno-depleted supernatant using a magnet and washed thrice with PBS. Bound vesicles were eluted in sample buffer and analyzed by SDS-PAGE and Western blotting.

\section{- Synaptosome trypsin cleavage assay}

Synaptosomes were prepared and treated with trypsin as previously described (Ahmed, Holt, Riedel, \& Jahn, 2013; Boyken et al., 2013). Purified synaptosomes were centrifuged for $3 \mathrm{~min}$ at $8,700 \mathrm{xg}, 4^{\circ} \mathrm{C}$. The pellet was resuspended in $320 \mathrm{mM}$ sucrose, $5 \mathrm{mM}$ HEPES $(\mathrm{pH}=8)$. For trypsin cleavage, a $0.1 \mathrm{mg} / \mathrm{ml}$ trypsin stock solution was added to yield a final protein-protease ratio of 
100:1. Synaptosomes were incubated for $10,20,30,60$ or 90 min at $30^{\circ} \mathrm{C}$ with gentle agitation. Samples were then centrifuged for $3 \mathrm{~min}$ at 8,700xg and the resulting pellet was resuspended in sucrose buffer containing $400 \mu \mathrm{M}$ Pefabloc (Roche) to stop trypsin cleavage activity. Samples were then analyzed by SDS-PAGE and Western blotting.

\section{- Recombinant pulldown assays}

Recombinant His-tagged SYT3 C2AB (the soluble portion of syt3, i.e. end of transmembrane domain to C-terminus; provided by Edwin Chapman, University of Wisconsin, Madison) was expressed in E. coli and purified as previously described (Bhalla et al., 2008). Recombinant SYT3 was then incubated with solubilized rat brain homogenate for 2 hours at $4^{\circ} \mathrm{C}$. After incubation, nickel beads were added and additionally incubated for 2 hours at $4^{\circ} \mathrm{C}$. The mixture was then poured into a MT column (Biorad) and washed thrice with washing buffer (20 mM Tris pH 7.4, $500 \mathrm{mM} \mathrm{NaCl}, 20 \mathrm{mM}$ imidazole). Proteins bound to the recombinant syt 3 in the column were eluted with elution buffer (20 mM Tris pH 7.4, $500 \mathrm{mM} \mathrm{NaCl}, 400 \mathrm{mM}$ imidazole). Eluted proteins were resolved by SDS-PAGE gels and analyzed by Western blotting.

\subsection{Electrophysiology}

\section{- Whole-cell electrophysiology in dissociated hippocampal embryonic rat cultures}

Dissociated hippocampal cultures were transfected on DIV10. DIV 16-20 neurons growing on individual coverslips were placed in a custom-made recording chamber and bathed in HEPES buffered saline prepared as indicated in Table 8 except that $[\mathrm{NaCl}]=136 \mathrm{mM}$ and $\mathrm{pH}=7.2$. The temperature of the bath was maintained between $30-32^{\circ} \mathrm{C}$ by heating with a thermistor taped below the bath chamber and a DC voltage power supply (Voltcraft VLP-1302A). To record miniature excitatory post-synaptic currents (mEPSCs), $1 \mu \mathrm{M}$ tetrodotoxin (Tocris \#1069) was added to the extracellular solution to block action potentials. $50 \mu \mathrm{M}$ picrotoxin (Abcam \#ab120315), which inhibits $\mathrm{GABA}_{\mathrm{A}}$ receptors, was added to isolate glutamatergic receptor mEPSCs. An upright microscope (Olympus BX51WI) equipped with a 40X water-immersion objective, fluorescent light source (Prior Scientific Lumen 200Pro), and filters for GFP fluorescence imaging were used to visualize neurons transfected with syt3-GFP or turboGFP-expressing syt3 knockdown 
constructs. Patch pipettes were pulled from borosilicate glass (Harvard Instruments \#300060; 1.5 mm OD, 0.86 mm ID, 3-6 M ) using a P-97 micropipette puller (Sutter Instruments). The internal solution used is shown in Table 9. Whole-cell patch-clamp recordings were obtained using a HEKA EPC10 USB double patch clamp amplifier coupled to Patchmaster acquisition software. The fast capacitance, slow capacitance and series resistance were always compensated using inbuilt functions in Patchmaster. Signals were low pass filtered using a Bessel filter at $2.9 \mathrm{kHz}$ and digitized at $5 \mathrm{kHz}$. mEPSCs were recorded while holding neurons at $-60 \mathrm{mV}$ in the voltage-clamp mode. The series resistance was monitored every 1-5 min during recording to ensure it did not change by greater than $\pm 3 \mathrm{M} \Omega$, and neurons were recorded from only if uncompensated Rs $<20 \mathrm{M} \Omega$. mEPSCs were analyzed using Mini Analysis software v6.0.3 (Synaptosoft) with an amplitude threshold of 3.5 times RMS noise (maximum allowed amplitude threshold was 18 pA).

\section{- Whole-cell electrophysiology in dissociated hippocampal postnatal mouse cultures}

Miniature excitatory post-synaptic currents (mEPSCs) were recorded from DIV13 - DIV19 dissociated hippocampal neurons cultured P0 mice, after transfections on DIV 10. All recording conditions were the same as in section 'Whole-cell electrophysiology in dissociated hippocampal embryonic rat cultures' above except that the bath was at room temperature, i.e., $\sim 20^{\circ} \mathrm{C}$ and $100 \mu \mathrm{M}$ picrotoxin was added to isolate glutamatergic receptor mEPSCs. For AMPA stimulation, coverslips were transferred to $100 \mu \mathrm{M}$ S-AMPA (abcam \#ab120005) in $250 \mu 1$ prewarmed feeding medium (Table 2 on page 40 ) and returned to the incubator at $37^{\circ} \mathrm{C}$ and $5 \% \mathrm{CO}_{2}$ for 2 min. In a stimulation protocol identical to that used in the surface receptor internalization assays, the coverslips were then returned to conditioned medium in the incubator for 8 minutes. An upright microscope (Zeiss Examiner D1) equipped with a 40X-water immersion objective, fluorescent light source (Zeiss Colibri), and appropriate filters for GFP imaging was used to visualize transfected cells on a monitor. Whole-cell patch clamp recordings were obtained using an ELC03XS patch clamp amplifier (NPI electronics, Germany) with custom written data acquisition scripts for IgorPro 6.12A software (Wavemetrics), obtained from Prof. Dr. Oliver Schlüter (European Neuroscience Institute Göttingen). Recorded signals were low-pass filtered using a Bessel filter with a cut-off frequency of $3 \mathrm{kHz}$ and digitized at a sampling rate of $10 \mathrm{kHz}$ using a data acquisition interface (HEKA instruments, InstruTECH ITC-18). The fast capacitance was compensated before breaking into the cell. For neurons stimulated with S-AMPA, the time after 
stimulation was noted. For every recorded neuron, the holding current, series resistance (test pulse voltage step/ peak capacitive transient current), and input resistance (test pulse voltage step/ plateau current) were monitored every 10 seconds by application of a square voltage step pulse. Only those recordings where $\mathrm{Rs}_{\mathrm{s}}<20 \mathrm{M} \Omega$, and where Rs did not change by more than $10 \%$ were analyzed. A custom written MATLAB (Mathworks) script was used to generate random file names for each recording to blind the analyzing experimenter with respect to the genotype, transfection and stimulation condition of the recording. To set a detection threshold in Mini Analysis (Synaptosoft), average RMS noise levels were determined from five stretches of baseline that did not contain any mEPSCs. The detection threshold was set as 3.5-times the average RMS noise. The period to search for a local maximum was $30 \mathrm{~ms}$, the time before a peak to search for baseline was $20 \mathrm{~ms}$ and the period to search for decay time was $20 \mathrm{~ms}$. The decay time was defined as the time after which the amplitude reached $37 \%$ of its peak value, representing the exponential decay time constant. The area threshold was set to the value of the amplitude threshold +1 to exclude noise-related fluctuations in the baseline. For each cell, at least $200 \mathrm{mEPSC}$ events were analysed.

Table 8: Formulation of extracellular solution for whole-cell recordings in dissociated hippocampal cultures

\begin{tabular}{|c|c|c|c|}
\hline Concentration & Component & Catalogue number & Preparation Instructions \\
\hline $142 \mathrm{mM}$ & $\mathrm{NaCl}$ & Roth 9265 & \multirow{6}{*}{$\begin{array}{l}\text { Adjust pH to } 7.4 \text { with } 10 \mathrm{M} \\
\mathrm{NaOH} \text { (Roth } 9356 \text { ) for } 10 \mathrm{X} \\
\text { stock and store at } 4^{\circ} \mathrm{C} \text {. mOsm } \\
\text { of } 1 \mathrm{X} \text { buffer should be } \sim 295 \text {. } \\
\text { When storing stock longer than } \\
2 \text { weeks, exclude D-glucose. }\end{array}$} \\
\hline $2.5 \mathrm{mM}$ & $\mathrm{KCl}$ & Roth 6781 & \\
\hline $10 \mathrm{mM}$ & HEPES & Roth HN77 & \\
\hline $10 \mathrm{mM}$ & D-Glucose & Roth HN06 & \\
\hline $2 \mathrm{mM}$ & $\mathrm{CaCl}_{2}$ & Roth HN04 & \\
\hline $1.3 \mathrm{mM}$ & $\mathrm{MgCl} 2$ & Roth KK36 & \\
\hline
\end{tabular}

Table 9: Formulation of intracellular solution for whole-cell recordings from dissociated hippocampal cultures

\begin{tabular}{|l|l|l|l|}
\hline Concentration & Component & $\begin{array}{c}\text { Catalogue } \\
\text { number }\end{array}$ & \multicolumn{1}{c|}{ Preparation Instructions } \\
\hline $130 \mathrm{mM}$ & K-gluconate & Sigma P1847 & $\begin{array}{l}\text { Dissolve salts in } \sim 75 \% \text { of total solution volume at } \\
\text { room temperature. To avoid degradation of ATP }\end{array}$ \\
\hline $10 \mathrm{mM}$ & $\mathrm{NaCl}$ & Roth 9265 & \\
\hline
\end{tabular}




\begin{tabular}{|c|c|c|c|}
\hline $10 \mathrm{mM}$ & Hepes & Roth HN77 & \multirow{4}{*}{$\begin{array}{l}\text { and GTP salts by the acidic } \mathrm{pH} \text { of the solution, } \\
\text { adjust } \mathrm{pH} \text { to } \sim 7.5 \text { with } 1 \mathrm{M} \mathrm{KOH} \text { (Roth } 6751 \text { ) } \\
\text { before adding last two components. }\end{array}$} \\
\hline $1 \mathrm{mM}$ & EGTA & Roth 3054 & \\
\hline $0.133 \mathrm{mM}$ & $\mathrm{CaCl}_{2}$ & Roth HN04 & \\
\hline $2 \mathrm{mM}$ & $\mathrm{MgCl}_{2}$ & Roth KK36 & \\
\hline $3.5 \mathrm{mM}$ & $\mathrm{Na}_{2}-\mathrm{ATP}$ & Sigma A7699 & \multirow{2}{*}{$\begin{array}{l}\text { To avoid degradation of ATP and GTP salts at } \\
\text { room temperature, adjust pH to } 7.3 \text { with } 1 \mathrm{M} \mathrm{KOH} \\
\text { (Roth } 6751 \text { ) immediately after adding last two } \\
\text { components, place solution on ice and sterile filter. } \\
\text { Freeze aliquots at }-80^{\circ} \mathrm{C} \text {. Check mOsm is } \sim 285 \text {. }\end{array}$} \\
\hline $1 \mathrm{mM}$ & Na-GTP & Sigma G8877 & \\
\hline
\end{tabular}

- Whole-cell electrophysiology in acute hippocampal slices

Table 10: Formulation of NMDG cutting buffer for slicing of aute hippocampal slices for whole-cell recordings

\begin{tabular}{|c|c|c|c|}
\hline Concentration & Component & $\begin{array}{c}\text { Catalogue } \\
\text { number }\end{array}$ & Preparation Instructions \\
\hline $135 \mathrm{mM}$ & NMDG & Sigma 66930 & \multirow{5}{*}{$\begin{array}{l}\text { Adjust } \mathrm{pH} \text { to } 7.4 \text { with } 32 \% \mathrm{HCl} \\
\text { (Roth } \mathrm{P} 074)(\sim 60 \mathrm{ml} \mathrm{HCl} \text { for } 2 \text { litres } \\
\text { of } 3 \mathrm{X} \text { stock after dissolving } \\
\text { NMDG). } 3 \mathrm{X} \text { stock solution can be } \\
\text { stored indefinitely at } 4^{\circ} \mathrm{C} \text {. }\end{array}$} \\
\hline $1 \mathrm{mM}$ & $\mathrm{KCl}$ & Roth 6781 & \\
\hline $1.2 \mathrm{mM}$ & $\mathrm{KH}_{2} \mathrm{PO}_{4}$ & Roth P018 & \\
\hline $1.5 \mathrm{mM}$ & $\mathrm{MgCl} 2$ & Roth KK36 & \\
\hline $0.5 \mathrm{mM}$ & $\mathrm{CaCl}_{2}$ & Roth HN04 & \\
\hline $20 \mathrm{mM}$ & $\begin{array}{l}\text { Choline } \\
\text { bicarbonate }\end{array}$ & Sigma C7519 & \multirow{3}{*}{$\begin{array}{l}\text { Add last three components to make } \\
1 \mathrm{X} \text { buffer and check mOsm is } \sim 310 \text {. } \\
\text { Bubble with carbogen for }>15 \text { min } \\
\text { and partially freeze and mix to make } \\
\text { icy slush before use. }\end{array}$} \\
\hline $12.95 \mathrm{mM}$ & D-Glucose & Roth HN06 & \\
\hline $1 \mathrm{X}$ & cutting buffer & As above & \\
\hline
\end{tabular}

Patch pipettes with a resistance of 2.5-5 $\mathrm{M} \Omega$ were prepared from glass capillaries (Harvard Apparatus \# 300060; 1.5 mm OD, 0.86 mm ID) using a P-97 puller (Sutter Instruments). P12-P17 mouse pups were anesthetized with isoflurane (Abbott, Wiesbaden, Germany) and decapitated. The brain was carefully extricated and the cerebellum was cut out to provide a flat surface onto which the brain could be glued with its rostro-caudal axis perpendicular to a metal plate and gently 
resting against a 1.5\% agarose (Invitrogen $\# 16500$ ) block. The brain was then quickly submerged in an icy slush of NMDG cutting buffer (see Table 10). The icy slush was obtained by freezing the buffer at $-80^{\circ} \mathrm{C}$ for $30 \mathrm{~min}$ and then tapping the bottle to break the ice formed around the glass. $300 \mu \mathrm{m}$ coronal hippocampal slices were obtained with a Leica VT1200 vibratome (Wetzlar, Germany) and a stainless steel blade (Feather/ Astra Rasierklingen) in an icy slush of NMDG buffer. Slices were transferred to a submerged-type preincubation chamber with a nylon mesh bottom (Gibb AJ and Edwards FA, Chapter 10, Microelectrode techniques, The Plymouth workshop handbook) filled with ACSF (see Table 11) and incubated at $35^{\circ} \mathrm{C}$ for 0.5 hours followed by another 0.5 hours at room temperature. A bubbler (Sigma \#59277) was positioned at the edge of the cylindrical chamber outside the inner perforated sub-chamber to allow a convectional flow of oxygenated ACSF that holds the slices down on the nylon mesh. Typically, the time taken between decapitation and transfer of slices to the preincubation chamber was 15-20 min. Before transferring to the recording chamber, two cuts perpendicular to the CA3 pyramidal cell layer at the lateral end of the slice and perpendicular to the CA1 pyramidal cell layer at the medial end of the slice were made using microdissection scissors (WPI) under a stereoscopic microscope (Zeiss Stemi 2000) to prevent recurrent activation of the CA1 neurons by CA3-CA3 and CA1-entorhinal cortex circuits respectively.

Slices were then submerged in a recording chamber, weighted down between nylon fibers and perfused with carbogen-bubbled ACSF by gravity flow. Solution from the bath was removed using a peristaltic pump (Dynamax RP-1) via a micro-slit outlet (WPI \#ST-3L 64-1408) to ensure smooth and continuous perfusion. The bath was maintained at $30-32^{\circ} \mathrm{C}$ using a heated perfusion rod (ALA scientific \#HPT-2) at the bath inlet and thermistors under the chamber controlled by a temperature controller (NPI instruments, TC-20). The temperature was regularly monitored using a digital thermometer (Voltacraft \#K102) and adjusted accordingly. CA1 neurons were visualized with an upright microscope (Zeiss Examiner D1) equipped with a 40X water-immersion objective and DIC (differential interference contrast) optics. The intracellular pipette solution used is shown in Table 12 below. Whole-cell patch-clamp recordings were obtained using a ELC-03XS patch clamp amplifier (NPI electronics, Germany). Signals were low pass filtered using a Bessel filter at $3 \mathrm{kHz}$ and digitized at $10 \mathrm{kHz}$ using a data acquisition interface (HEKA instruments, InstruTECH ITC-18). A custom written data acquisition script for IgorPro 6.12A software (Wavemetrics), 
Table 11: Formulation of artificial cerebrospinal fluid (ACSF) for whole-cell recordings from acute mouse hippocampal slices

\begin{tabular}{|c|c|c|c|}
\hline Concentration & Component & Catalogue number & Preparation Instructions \\
\hline $124 \mathrm{mM}$ & $\mathrm{NaCl}$ & Roth 9265 & \multirow{7}{*}{$\begin{array}{l}\text { Make } 10 \mathrm{X} \text { stock solution } \\
\text { without } \mathrm{NaHCO}_{3} \text { and } \mathrm{D} \text { - } \\
\text { Glucose and store at } 4^{\circ} \mathrm{C} \text {. After } \\
\text { making } 1 \mathrm{X} \text { ACSF and bubbling } \\
\text { with carbogen for } 15 \mathrm{~min}, \\
\text { check that } \mathrm{pH} \text { is } \sim 7.4 \text { and } \\
\text { mOsm is } \sim 300 \text {. }\end{array}$} \\
\hline $4.4 \mathrm{mM}$ & $\mathrm{KCl}$ & Roth 6781 & \\
\hline $1 \mathrm{mM}$ & $\mathrm{NaH}_{2} \mathrm{PO}_{4}$ & Roth 2370 & \\
\hline $26.2 \mathrm{mM}$ & $\mathrm{NaHCO}_{3}$ & Roth 6885 & \\
\hline $1.3 \mathrm{mM}$ & $\mathrm{MgSO}_{4} .7 \mathrm{H}_{2} \mathrm{O}$ & Roth P027 & \\
\hline $2.5 \mathrm{mM}$ & $\mathrm{CaCl}_{2} \cdot \mathrm{H} 2 \mathrm{O}$ & Roth HN04 & \\
\hline $10 \mathrm{mM}$ & D-Glucose & Roth HN06 & \\
\hline
\end{tabular}

Table 12: Formulation of internal solution for recording evoked EPSCs from acute hippocampal slices

\begin{tabular}{|c|c|c|c|}
\hline Concentration & Component & $\begin{array}{c}\text { Catalogue } \\
\text { number }\end{array}$ & Preparation Instructions \\
\hline $130 \mathrm{mM}$ & $\mathrm{CsMeSO}_{3}$ & Sigma C1426 & \multirow{7}{*}{$\begin{array}{l}\text { Dissolve salts in } \sim 75 \% \text { of total solution volume } \\
\text { at room temperature. To avoid degradation of } \\
\text { ATP and GTP salts by the acidic } \mathrm{pH} \text { of the } \\
\text { solution, adjust } \mathrm{pH} \text { to } \sim 7.5 \text { with } 1 \mathrm{M} \mathrm{CsOH} \\
\text { (Fluka } 21000 \text { ) before adding last three } \\
\text { components. }\end{array}$} \\
\hline $2.67 \mathrm{mM}$ & $\mathrm{CsCl}$ & Sigma 203025 & \\
\hline $10 \mathrm{mM}$ & HEPES & Roth HN77 & \\
\hline $1 \mathrm{mM}$ & EGTA & Roth 3054 & \\
\hline $3 \mathrm{mM}$ & QX-314 Cl & $\begin{array}{l}\text { Tocris 2313/ } \\
\text { Sigma L1663 }\end{array}$ & \\
\hline $5 \mathrm{mM}$ & TEA-Cl & Fluka 86616 & \\
\hline $15 \mathrm{mM}$ & $\begin{array}{l}\text { Phosphocreatine } \\
\text { disodium salt }\end{array}$ & Sigma P7936 & \\
\hline $4 \mathrm{mM}$ & Mg-ATP & Sigma A9187 & \multirow{3}{*}{$\begin{array}{l}\text { To avoid degradation of ATP and GTP salts at } \\
\text { room temperature, adjust } \mathrm{pH} \text { to } 7.4 \text { with } 1 \mathrm{M} \\
\mathrm{CsOH} \text { immediately after adding last three } \\
\text { components. Place solution on ice and sterile } \\
\text { filter. Freeze aliquots at }-80^{\circ} \mathrm{C} \text {. Check that } \\
\mathrm{mOsm} \text { is } \sim 300 \text {. }\end{array}$} \\
\hline $0.3 \mathrm{mM}$ & Na-GTP & Sigma G8877 & \\
\hline 5 units $/ \mathrm{ml}$ & $\begin{array}{l}\text { Creatine Phospho- } \\
\text { kinase }\end{array}$ & Sigma C3755 & \\
\hline
\end{tabular}


obtained from Prof. Dr. Oliver Schlüter (European Neuroscience Institute, Göttingen) was used to visualize and acquire electrophysiological data. Schaffer collaterals were stimulated at the distal dendritic region of the stratum radiatum on the border of the lacunosum-moleculare at $0.1 \mathrm{~Hz}$ using a bipolar glass electrode (World precision instruments, WPI \#TST150-6) filled with ACSF and coupled to a triggerable stimulator (A.M.P.I. Isoflex).

The fast capacitance was compensated before breaking into the cell. Evoked synaptic EPSCs were first recorded at a holding potential of $-56 \mathrm{mV}$, the average measured reversal potential for pharmacologically isolated $\mathrm{GABA}_{\mathrm{A}}$ receptor IPSCs in wild-type slices. $\mathrm{GABA}_{\mathrm{A}}$ receptormediated currents were then recorded at $0 \mathrm{mV}$, the average measured reversal potential for pharmacologically isolated NMDA and AMPA receptor EPSCs. Next, $100 \mu \mathrm{M}$ picrotoxin in ACSF (Sigma \#P1675) was perfused while holding at $-56 \mathrm{mV}$ and the elimination of $\mathrm{GABA}_{\mathrm{A}}$ receptor IPSCs at $0 \mathrm{mV}$ was confirmed. The residual AMPA+NMDA receptor EPSC at $0 \mathrm{mV}$ was later subtracted from the $\mathrm{GABA}_{\mathrm{A}}$ receptor IPSC. The AMPA+NMDA receptor compound EPSC was then recorded at $+40 \mathrm{mV}$ in the presence of $100 \mu \mathrm{M}$ picrotoxin, where the amplitude of the EPSC approximately $60 \mathrm{~ms}$ after the peak is the pure NMDA receptor EPSC, since the measured AMPA receptor EPSC decay time constant was $\tau \approx 20 \mathrm{~ms}$. Because the AMPA receptor EPSCs recorded at $-56 \mathrm{mV}$ after picrotoxin perfusion were free of any $\mathrm{GABA}_{\mathrm{A}}$ receptor IPSC components, they were used in the final analysis of NMDA/AMPA and GABA/AMPA ratios. The input and series resistance $\left(R_{s}\right)$ were monitored before recording every EPSC. A minimum of 30 evoked responses was averaged for each receptor EPSC. Recordings where $R_{S}$ was $>25 M \Omega$ or changed by more than $\pm 20 \%$ during the recording were not used for analysis. Input resistances ranged between $100-400 \mathrm{M} \Omega$ and did not change by more than $\pm 20 \%$ during the course of a recording.

\section{- Extracellular recordings from acute hippocampal brain slices}

These experiments were performed by Dr. Binu Ramachandran (Trans-synaptic signaling group, European Neuroscience Institute Göttingen). Electrophysiological experiments were performed on $400 \mu \mathrm{m}$ thick hippocampal slices prepared from 8-12 week old male mice as previously described (Ramachandran \& Frey, 2009). Slices were pre-incubated for at least 3 hours in a custom built humidified interface-type chamber in ACSF (see Table 13). Following pre-incubation, the stimulation strength was set to elicit a population spike of approximately $25 \%$ maximal amplitude. 
For stimulation, biphasic constant current pulses were used. A baseline was recorded for at least $60 \mathrm{~min}$ before LTP induction. Four $0.2 \mathrm{~Hz}$ biphasic, constant-current pulses $(0.1 \mathrm{~ms}$ per polarity) were used for testing responses post-tetanus for up to 4 hours. Strong LTP was induced by a $3 \times$ TET high frequency stimulation with three stimulus trains of 100 pulses, stimulus duration $0.2 \mathrm{~ms}$ per polarity with 10 min intertrain intervals. Weak LTP was induced with a 1xTET single tetanus of 16 pulses at $100 \mathrm{~Hz}$, stimulus duration $0.2 \mathrm{~ms}$ per polarity, modified for mouse hippocampal slices from the protocol consisting of 21 pulses used for rat hippocampal slices. The fEPSP slope was used to determine potentiation of synaptic responses. The Tat-GluA2-3Y peptide (sequence YGRKKRRQRRR-869 YKEGYNVYG ${ }_{877}$, provided by Prof. Yu-Tian Wang, University of British Columbia, Vancouver, Canada) was used at a concentration of $1 \mu \mathrm{M}$ (Migues et al., 2016) and ZIP (provided by Prof. Todd Sacktor, SUNY Downstate Medical Center, New York, USA) was used at a concentration of $1 \mu \mathrm{M}$ corresponding to its $\mathrm{IC}_{50}, 1$ hour after LTP induction (Serrano et al., 2005).

Table 13: Formulation of artificial cerebrospinal fluid (ACSF) for extracellular field recordings from acute mouse hippocampal slices

\begin{tabular}{|c|c|c|c|}
\hline Concentration & Component & Catalogue number & Preparation Instructions \\
\hline $124 \mathrm{mM}$ & $\mathrm{NaCl}$ & Roth 9265 & \multirow{7}{*}{$\begin{array}{l}\text { Make } 10 \mathrm{X} \text { stock solution } \\
\text { without } \mathrm{NaHCO}_{3} \text { and } \\
\text { Glucose and store at } 4^{\circ} \mathrm{C} \text {. After } \\
\text { making } 1 \mathrm{X} \text { ACSF and bubbling } \\
\text { with carbogen for } 15 \mathrm{~min} \text {, check } \\
\text { that } \mathrm{pH} \text { is } \sim 7.4 \text { and } \mathrm{mOsm} \text { is } \\
\sim 300 \text {. }\end{array}$} \\
\hline $4.9 \mathrm{mM}$ & $\mathrm{KCl}$ & Roth 6781 & \\
\hline $1.2 \mathrm{mM}$ & $\mathrm{KH}_{2} \mathrm{PO}_{4}$ & Roth P018 & \\
\hline $24.6 \mathrm{mM}$ & $\mathrm{NaHCO}_{3}$ & Roth 6885 & \\
\hline $2 \mathrm{mM}$ & $\mathrm{MgSO}_{4} \cdot 7 \mathrm{H}_{2} \mathrm{O}$ & Roth P027 & \\
\hline $2 \mathrm{mM}$ & $\mathrm{CaCl}_{2} \cdot \mathrm{H} 2 \mathrm{O}$ & Roth HN04 & \\
\hline $10 \mathrm{mM}$ & D-Glucose & Roth HN06 & \\
\hline
\end{tabular}

\subsection{Behavioral Experiments}

Behavioral experiments were performed on 3-5 month old male mice in a blinded fashion. Mice were individually housed at the European Neuroscience Institute Göttingen, Germany animal facility in standard environmental conditions (temperature, humidity), with ad libitum access to food and water on a $12 \mathrm{~h}$ light/dark cycle from 7 AM to 7 PM. Video tracking was done with the TSE monitoring system Videomot3D. All behavioral experiments were authorized under the 
project, "Funktion des Kalzium bindenden Protein Synaptotagmin 3 auf molekulare Mechanismen des Gedächtnisses", ID\# G15.1794 granted by the 'Niedersächsisches Landesamt für Verbraucherschutz und Lebensmittelsicherheit' (LAVES, Lower Saxony, Germany). All behavior experiments were carried out by Ankit Awasthi, who successfully completed a course in laboratory animal science according to the recommendations of the FELASA (Category B) before starting behavioral experiments. The course was organized by the Central Animal Facility, University Medical Center Göttingen (UMG), Göttingen, Germany.

\section{- Open field, novel object recognition and elevated plus maze}

In the open field test, mice were introduced near the wall of an empty opaque square plexi-glass box and allowed to freely explore the arena for $5 \mathrm{~min}$. The arena was scented with $70 \%$ ethanol before every trial. Time spent in the center relative to near the walls, and the total path travelled was recorded.

For novel object recognition, mice were introduced to the open field containing two identical objects (upside down plastic lab bottle caps taped to the floor) for $5 \mathrm{~min}$ on the day after the open field test. Exploration of either object was manually scored. To test short term memory, mice were put back into the open field $\sim 12$ min later where one of the bottle caps was replaced with a LEGO block and the \% time spent exploring the LEGO block was analyzed. Animals that explored either of the two objects for $<1 \mathrm{sec}$ during training or testing were excluded from analysis.

For the elevated plus maze, mice were introduced at the intersection of two open and two closed arms in a 4-arm maze. The arena was scented with $70 \%$ ethanol before every trial. $\%$ time spent in the open arms was analysed.

\section{- Spatial novelty recognition}

Mice were tested for exploration of a novel arm of a Y-maze as previously described (D. J. Sanderson et al., 2009). Mice were introduced to one of the open arms (called start arm, see Figure 16 below) and allowed to freely explore the two open arms of a Y-maze with transparent walls and wooden chips on the floor for $5 \mathrm{~min}$ while the third arm (novel arm) was blocked from entry with an opaque obstruction. The start arm was always the same whereas the cohort was counterbalanced with respect to choice of the novel arm. The extra-maze cues consisted of standard lab equipment 
and tables. For recall of short-term spatial memory, mice were put back in the start arm 2 min after end of the habituation phase and allowed to freely explore all three arms of the Y-maze for $2 \mathrm{~min}$. The $\%$ time spent exploring the novel arm (reported as discrimination ratio) was analyzed. For recall of long-term memory, mice were habituated as before in a different room than that where short term memory was tested, for 5 min per session. Three sessions were administered overall, one every 24 hours. This room had empty walls with pieces of black paper of different shapes and sizes and lab coats hung on the walls, which were up to 1 meter away from the end of the Y-maze arms. 24 hours after the last training session, mice were allowed to explore all three arms of the Y-maze for 2 min and the discrimination ratio was analysed.

\section{- Contextual fear conditioning}

Mice were introduced to a sound isolated fear conditioning box (inner dimensions $30.5 \mathrm{~cm}$ x 24.1 $\mathrm{cm} \times 21 \mathrm{~cm}$, Med Associates Inc. \# VFC-008-LP) for $3 \mathrm{~min}$ in the context followed by $30 \mathrm{sec}$ of an auditory tone co-terminating with a $2 \mathrm{sec}$ long $0.7 \mathrm{~mA}$ shock. The context consisted of white light, $80 \mathrm{~dB}$ white noise sound and the shock grating scented with $70 \%(\mathrm{v} / \mathrm{v})$ ethanol. Movements of mice were detected by an infrared camera. Freezing behavior (no body movement except breathing) was considered when the detected motion stayed below an empirically determined threshold for at least 1 second. To test fear memory, mice were placed in the training context for $3 \mathrm{~min}$ and \% time spent freezing was analyzed. Short term memory and long term memory recall were performed $1 \mathrm{hr} 20 \mathrm{~min}$ and 24 hours after training, respectively.

\section{- Reference memory water maze}

Naive mice from two independent cohorts were trained to find a $13 \times 13 \mathrm{~cm}$ square hidden platform submerged $1.5 \mathrm{~cm}$ below the surface in a $1.1 \mathrm{~m}$ diameter circular pool filled with white opaque water at $19 \pm 2{ }^{\circ} \mathrm{C}$. Mice were trained for 4 trials per day in succession, during each of which mice swim in search of the platform for $1 \mathrm{~min}$. A trial ended when the mice spent at least $2 \mathrm{sec}$ on the platform, after which they were left on the platform for $15 \mathrm{sec}$ prior to the start of the next trial. Animals that failed to find the platform after $1 \mathrm{~min}$ were guided to it and left to stand on the platform for $15 \mathrm{sec}$. Four shapes around the pool (star, square, triangle, circle) served as visuospatial reference cues. The mice were placed into the pool facing the wall at the beginning of each 
trial, and the position of pool entry was from four different directions, the order of which was randomly shuffled daily. For probe trials, the platform was removed and mice were placed into the pool near the wall in the quadrant opposite to that of the original platform location and allowed to search for the platform for $1 \mathrm{~min}$. Two subsequent probe tests (on day 7 and day 10 for cohort 1 , or day 8 and day 11 for cohort 2) were performed to monitor learning of the first platform position and a third probe test was performed 3 days (for cohort 1) or 4 days (for cohort 2) after reversal, i.e., switching the platform position to the opposite quadrant. Only data from coincident days of training from the 2 cohorts was pooled together for analysis.

Video tracking data was analyzed using a custom written Matlab code to extract time-tagged xycoordinate information and quantify escape latency, path length, platform crossings, proximity (mean distance of all tracked path points to platform center, which is reported to be a more effective parameter than escape latency to quantify spatial specificity of watermaze search patterns (Maei, Zaslavsky, Teixeira, \& Frankland, 2009), percent time spent in target quadrant, percent time spent on platform and average swimming speed. Occupancy plots were generated by calculating normalized densities of path points within a grid size of $2.1 \mathrm{~cm} \times 2.1 \mathrm{~cm}$ (Garthe, Behr, \& Kempermann, 2009), followed by data smoothening and interpolation to plot heat maps (See page 67 below for methodology). To generate combined occupancy plots of probe trials from both cohorts, in which the platform was in different positions, the tracking data from one cohort was transposed and mirror imaged with respect to the center pool line and superimposed on data from the second cohort. A circular area encompassing platforms of both cohorts was defined as the target area (see Figure 20E below).

\section{- Delayed matching to place water maze}

The delayed matching to place task protocol was performed as previously described (Nakazawa et al., 2003) with modifications. Mice were first habituated to the task protocol by training them to swim to a visible platform (marked by a graduated cylinder coated with multi-coloured paper placed on top of a submerged platform) placed at a unique position every day for 3 days in a $1.1 \mathrm{~m}$ diameter circular pool filled with white opaque water at $19 \pm 2{ }^{\circ} \mathrm{C}$. The circular platform was submerged $1.5 \mathrm{~cm}$ below the surface and had a radius of $5 \mathrm{~cm}$. Four shapes around the pool (star, square, triangle, circle) served as visuo-spatial reference cues. 
After habituation, mice were trained to one of 16 unique hidden platform positions at two fixed distances from the pool center (11 in an outer ring and 5 in an inner ring) each day over 16 days. During training, the platform was shifted to a new random position every day in a different quadrant alternating between inner and outer rings as much as possible. All mice underwent 4 trials of 2 min every day and a trial ended when the mice spent at least $2 \mathrm{sec}$ on the platform, after which they were left on the platform for $15 \mathrm{sec}$ and then returned to their home cage. Inter-trial intervals were 5 min and mice were warmed with infrared lamps after every trial. The drop-off points on a particular day were in a random order with respect to the platform position of that day. Mice were divided into two groups for counterbalancing in which each group experienced different alternations of platform positions between inner and outer rings, to prevent non-spatial chaining search strategies in which mice search for platforms within a certain distance of the pool wall. Starting from day 10 of training, the inter-trial interval between trial 1 and trial 2 was increased to $1 \mathrm{~h} 15 \mathrm{~min}$. Trial 2 on day 16 was a probe trial, i.e., the platform was removed and the exploratory behavior of mice was recorded for $2 \mathrm{~min}$. The positional data from this trial until the first entry into the platform area was used to calculate proximity, escape latency and path length. All mice were trained at the same time of the day as far as possible, i.e. some mice were always trained in the morning while others were always trained in the evening. Some training sessions were inevitably in the dark cycle, for example until $8 \mathrm{PM}$, because of the large number of total training trials in a day.

The last 0.5 seconds of the trial were excluded to generate occupancy plots of training trials. Quantitation of search strategy was performed as previously described (Garthe et al., 2009), where a custom Matlab script was used to extract time-tagged xy-coordinate information from video tracking data of all trials. A custom written Matlab script then classified all individual trials into search strategies (Garthe et al., 2009). The following parameters were used for classification of the indicated search strategies:

1. Direct swimming strategy: total path length $\leq 1.4 \mathrm{x}$ distance between drop-off point and platform center, $\geq 80 \%$ path points within a $30^{\circ}$ goal corridor angle;

2. Focal search strategy: mean proximity to platform center $\leq 0.35 \mathrm{x}$ pool radius, mean proximity to path centroid $\leq 0.4 \times$ pool radius; 
3. Directed search strategy: $\geq 70 \%$ path points within a $30^{\circ}$ goal corridor angle;

4. Perseverance strategy: mean proximity to previous platform center $\leq 0.5 \mathrm{x}$ pool radius, mean proximity to path centroid allowed for perseverance $\leq 0.6 \mathrm{x}$ pool radius;

5. Chaining strategy: $\geq 70 \%$ path points inside annulus around the ring of platforms (inner or outer) containing the current day's platform, by 0.01-0.02 x pool radius, annulus for platforms in outer ring between $0.52 \mathrm{x}$ pool radius and $0.73 \mathrm{x}$ pool radius, annulus for platforms in inner ring between $0.22 \times$ pool radius and 0.42 x pool radius;

6. Scanning strategy: $\geq 80 \%$ of path points inside scanning radius (a circular area enclosing all platforms, 0.73 x pool radius), total $\%$ pool area scanned $\geq 10 \%$ and $\leq 50 \%$;

7. Thigmotaxis: $\geq 30 \%$ of path points within close wall zone between $0.85 \mathrm{x}$ pool radius and edge of pool, and $\geq 50 \%$ of path points within wider wall zone between 0.75 x pool radius and edge of pool;

8. Random search strategy: \% pool area scanned $\geq 50 \%$.

\section{- Occupancy plots to analyze watermaze search paths}

To extract average trends in search paths, occupancy plots were generated based on based on (Garthe et al., 2009). The occupancy plots visualize the density of space searched by mice in a heat map, generated by a custom written Matlab code based on the scattercloud function by Steve Simon (Matworks file ID \#6037). The pool was divided into a 50 x 50 square grid and the search density (number of video track points normalized to total number of points in the search path) in each bin was calculated. A search density function was calculated in the 2-dimensional plane of the pool by smoothening the calculated search density values in both directions of the plane (using the 'localsmooth' option in the scattercloud function above). For generating the average of multiple search paths, all paths were superimposed and search densities in each bin were calculated. To compare two groups of search paths, i.e. WT and syt3 KO mice, heat maps (generated using 'jet' colourmap in Matlab, ranging from dark blue for lowest values to bright red for the highest values) were linearly scaled between the minimum and maximum search densities across both groups. Using the same scaling of the heat map for both groups ensured that occupancy plot colors between two groups could be quantitatively compared. For comparison of WT and KO search, each trial was separately scaled, which means occupancy plot colors between different trials were not comparable. 
A

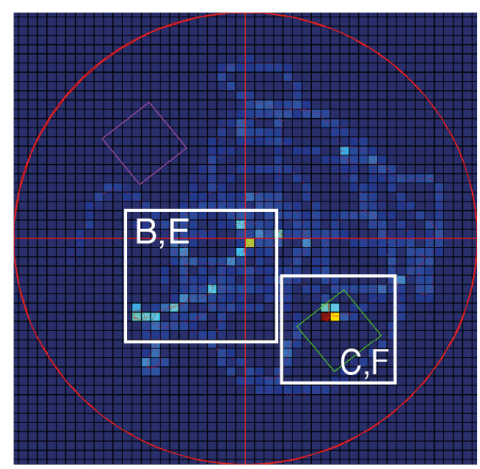

D

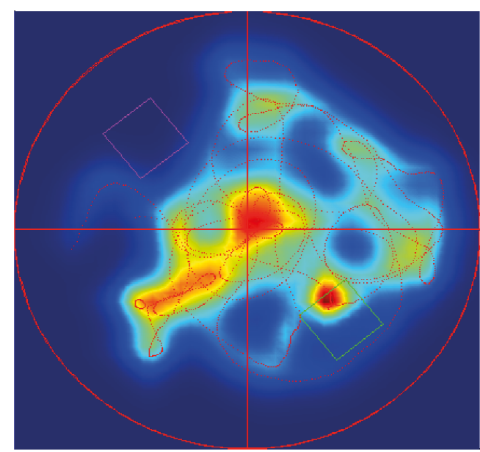

B

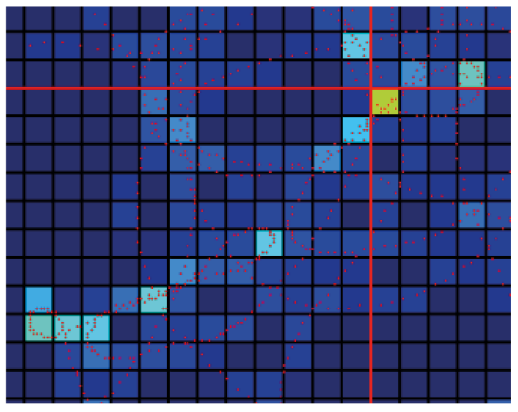

$\mathrm{E}$

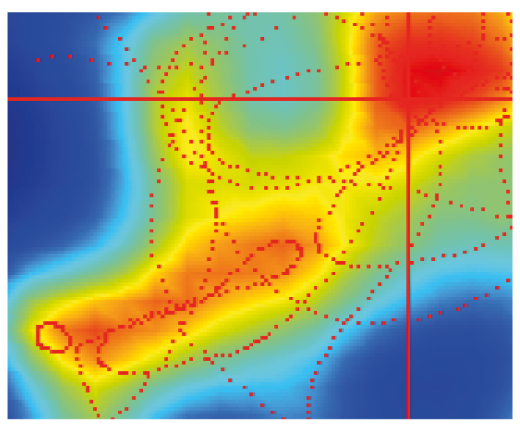

C

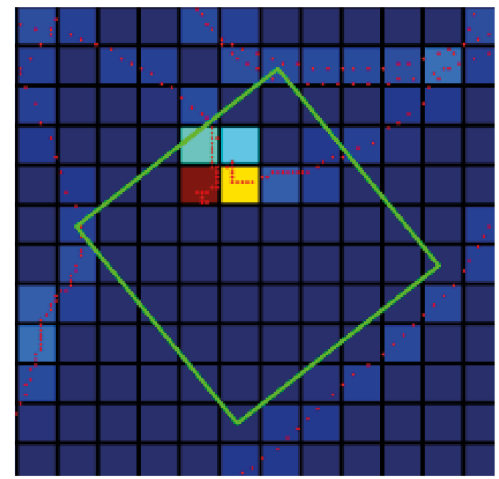

$\mathrm{F}$

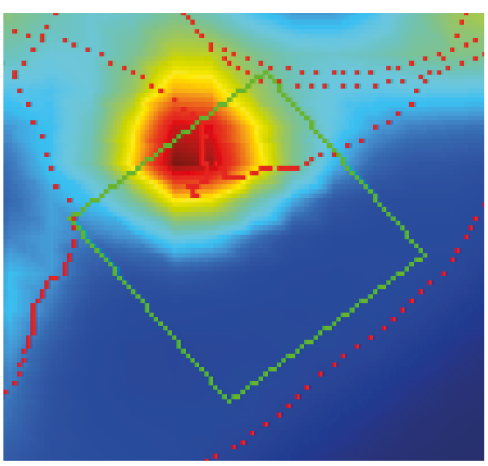

\section{Methods figure 1: Generating occupancy plots from mouse search paths}

A) Plot of a representative mouse training trial, with pool boundary lines in red, two platform positions shown in green and magenta, and the entire area divided into a $50 \times 50$ square grid. Search densities were calculated in each bin and occupancy plots generated without density smoothening and interpolation showing warmer colors for higher search densities. White boxes indicate zoomed regions in (B) and (C). Each point along the search path is indicated by red dots. As the mouse has to stand on the platform for 2 seconds for the trial to end, the platform area shows very high densities. (D-F) Heat map of occupancy plots of the same search path shown in (A-C), generated by calculating search densities in each bin, and smoothening and interpolating density data in the 2-D plane to extract general trends of spatial search.

As all training trials ended only when mice stood at the platform for 2 seconds, a high search density appeared around the platform (Methods figure 1A, C, D, F above) decreasing the resolution of the search density in the rest of the pool. Therefore, the last 0.5-1.5 seconds of the data from each trial was removed to generate final occupancy plots for search analysis. 
Two parameters, $\mathrm{N}$, the number of bins in the $\mathrm{x}$ or $\mathrm{y}$ direction, and $\mathrm{L}$, the magnitude of smoothening using the localsmooth function (within the scattercloud function) were optimized to generate occupancy plots (Methods figure 2D).

A

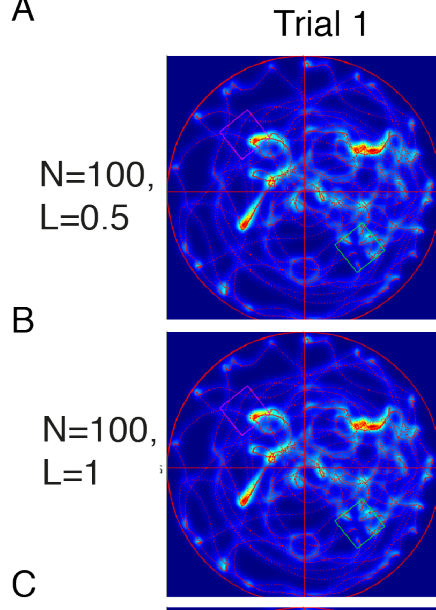

C

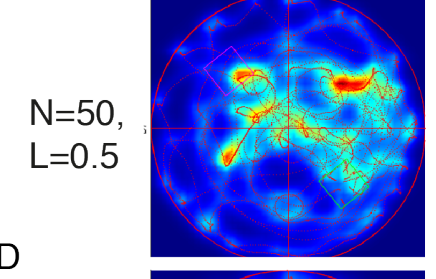

$\mathrm{D}$

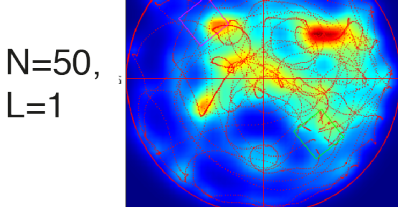

Trial 2
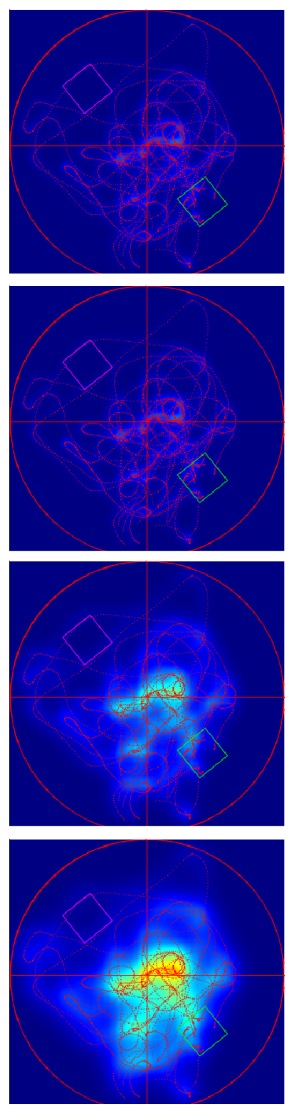

Trial 3
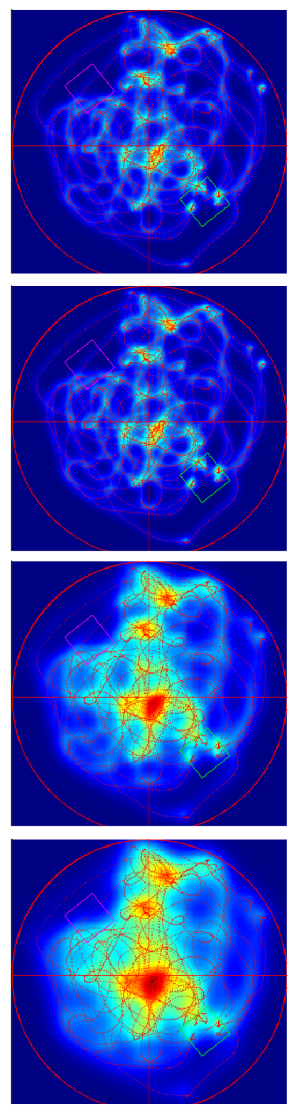

Trial 4
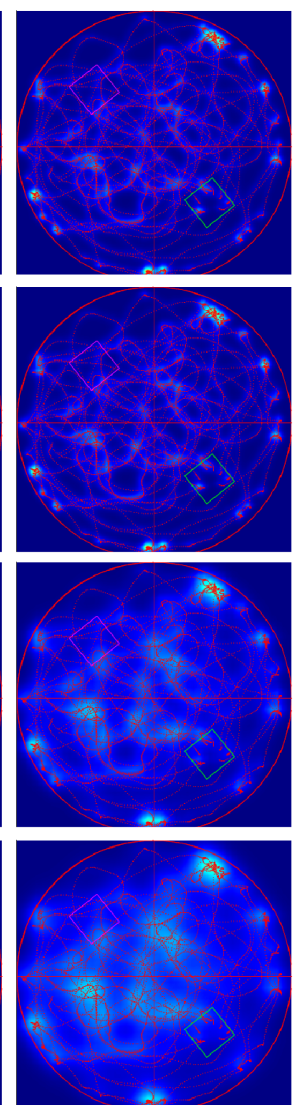

Trial 1- 4
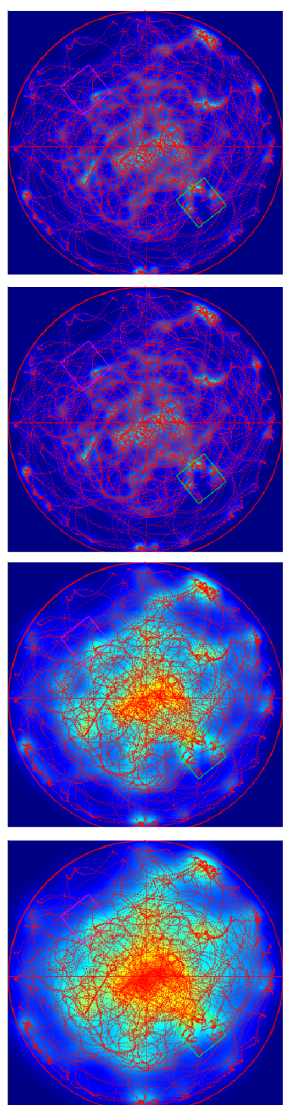

\section{Methods figure 2: Optimizing parameters for generation of occupancy plots}

(A-D) A representative training day search path dataset of all syt3 knockout mice in the reference watermaze was used to generate occupancy plots using different values for $\mathrm{N}$ and $\mathrm{L}$, i.e., a $\mathrm{N} \mathrm{x} \mathrm{N}$ square grid and $\mathrm{L}$, a parameter for the search density smoothening function, 'Localsmooth'. N=100 gave search densities too highly confined around search paths $(\mathbf{A}, \mathbf{B})$. Increasing smoothening by increasing $L=0.5$ (A) to $L=1$ (B) did not increase diffusiveness of search densities. (C, D) Decreasing the total number of bins 4-fold by $\mathrm{N}=50$ gave much more diffuse search densities. As increasing smoothening from $\mathrm{L}=0.5$ (C) to $\mathrm{L}=1$ (D) yielded a more diffusive search density pattern, $\mathrm{N}=50$ and $\mathrm{L}=1$ were chosen to generate all occupancy plots.

\section{- Strategy classification algorithm to analyze watermaze search paths}

Finding the hidden platform in the watermaze is a hippocampal dependent spatial task and wildtype mice are known to adopt more spatially specific search strategies over the course of training. 
Immediately upon being introduced to the watermaze for the first time, mice show a 'wallhugging' or thigmotactic behaviour but advance to other strategies rapidly within the first 1-3 days of training after overcoming this emotional response to a stressful situation. Mice start a 'random search strategy' as they learn that a hidden platform in the pool is the only means of escape. This strategy is then replaced with a 'scanning' strategy, where mice swim in the center of the pool and mostly avoid the walls in order to examine distal visual cues as well as possible. 'Random search' and 'scanning' lack any directional specificity. However, mice may evolve their search behaviour to 'chaining', where they swim at a fixed distance from the wall in an annulus containing the platform. PSD-95 KO mice and rats with hippocampal lesions, both of which show impaired learning, adopt a typical chaining strategy (Gallagher, Burwell, \& Burchinal, 2015; Migaud et al., 1998). As mice shift from non-spatial or egocentric search strategies to a spatial or allocentric one, they adopt strategies relying on the extramaze spatial cues and swim in a directed fashion toward the platform irrespective of their starting point. As the spatial memory becomes more precise over further training, mice take a direct path to an area around the platform, where they focus their search in a very local area in the 'focal search' strategy. The most efficient spatial strategy mice eventually learn is 'direct swimming', where they swim in an almost straight line directly to the platform. 'Perseverence' then refers to persistently returning to a previous platform position when the platform is moved to a new position. Thus, thigmotaxis and perseverance can be considered special strategies. 'Random search', 'scanning' and 'chaining' are non-spatial search strategies whereas 'directed search', 'focal search' and 'direct swimming' are spatial search strategies in order of their spatial precision (Methods figure 3 below).

A custom written Matlab code was used to sort all search paths according to genotype. Specific mathematical constraining conditions and custom written scripts to analyze specific parameters of search paths (Methods figure 3A below) were used to classify individual search paths into one of the eight possible search strategies, or as 'unrecognized'. All parameters for strategy analysis were optimized by trial and error, beginning by relaxing constraints on the spatial strategies to determine maximum level of detection and then adjusting parameters to achieve an intermediate conservative level of detection. This was then repeated for the non-spatial search strategies. The precision of a set of parameters was manually determined by visually inspecting the search paths until a satisfactory strategy classification was achieved. 
A

Thigmotaxis

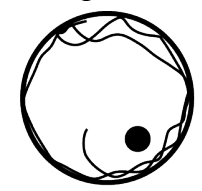

$\geq 30 \%$ of path points

inside closer wallzone

$\geq 50 \%$ of path points

inside wider wallzone

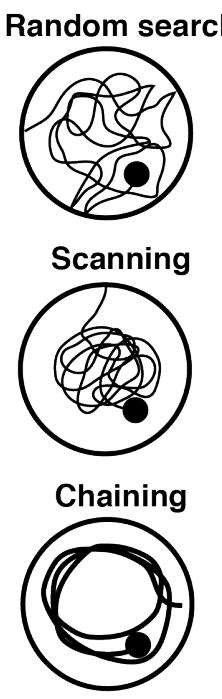

Random search

$\geq 50 \%$ pool area scanned

$\geq 80 \%$ of path points inside scanning radius

(a circular area enclosing all platforms)

$\geq 10 \%$ and $\leq 50 \%$ pool area scanned

Directed search

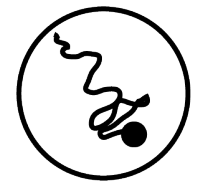

$\geq 70 \%$ path points

within a $30^{\circ}$ goal corridor

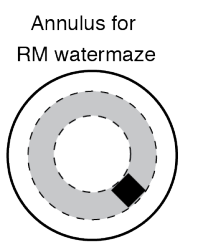

Annulus for

DMP watermaz

$\geq 70 \%$ path points

inside annulus

containing platform
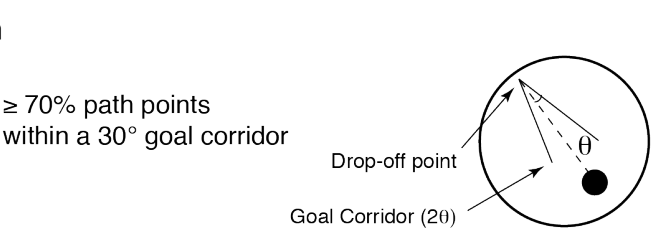

Focal search

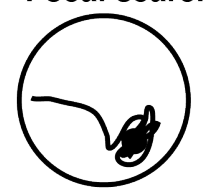

Mean proximity to platform center $\leq 35 \%$ pool radius

Mean proximity to path centroid $\leq 40 \%$ pool radius

\section{Direct swimming}

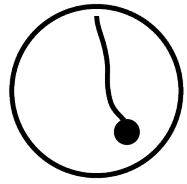

$\geq 80 \%$ path points within a $30^{\circ}$ goal corridor angle

total path length $\leq 1.4$ times distance between

drop-off point and platform center

\section{Perseverance}

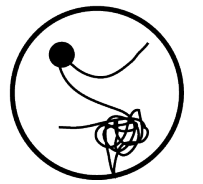

Mean proximity to previous platform center

$\leq 50 \%$ pool radius

Mean proximity to path centroid $\leq 60 \%$ pool radius
B

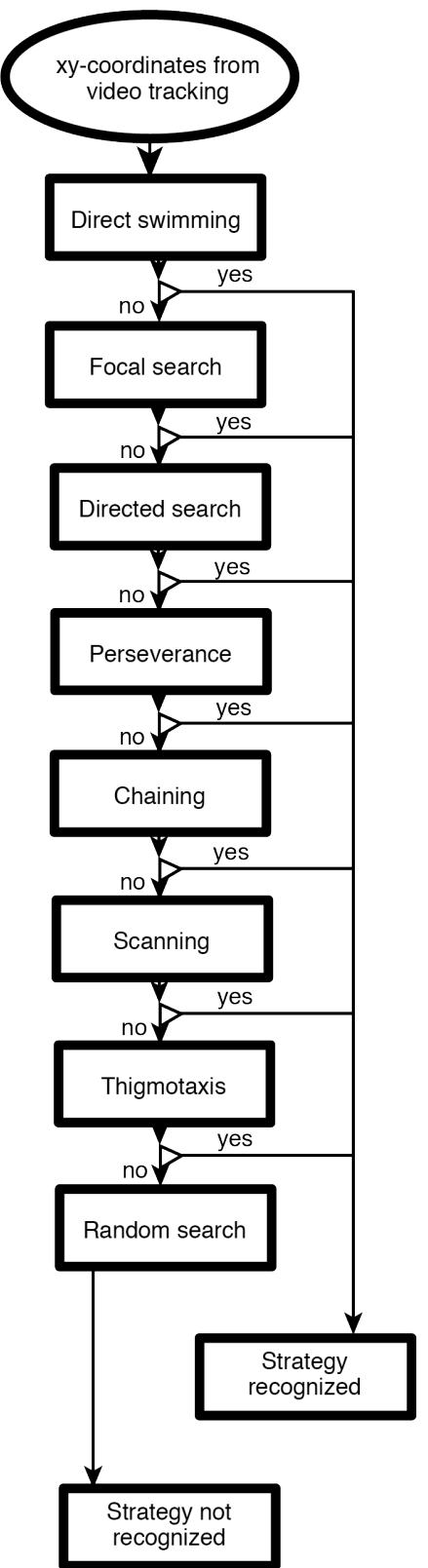

\section{Methods figure 3: Strategy classification algorithm for watermaze search path analysis}

(A) Mouse search paths, during a probe test or a training trial, illustrative of the corresponding strategy are shown. The various constraining conditions (with illustrations when needed) used to assign a search strategy to a search path are mentioned to the right of the corresponding strategy. (B) Algorithm used to classify a search path. Modified from (Figure 5, Garthe et al., 2009). 
Learning in the watermaze is traditionally analyzed by escape latency and path length for training days, and \% time spent in the target quadrant and crossings of the platform (analyzed using Matlab, Methods figure 4B, C below) for probe test performance evaluation. However, proximity and entropy are emerging as better parameters for watermaze performance evaluation (Maei et al., 2009). Analyzing search strategies over the course of training can help to explain any discrepancies in analysis from above-mentioned parameters.

A

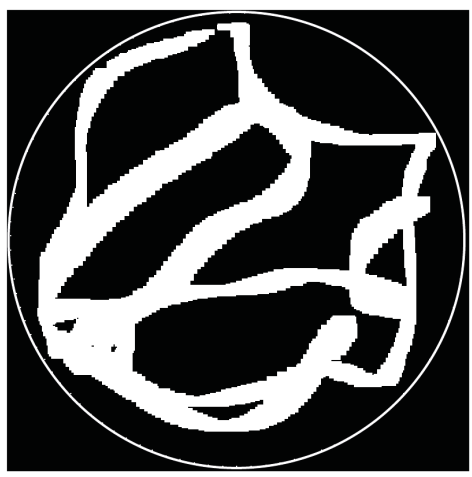

B

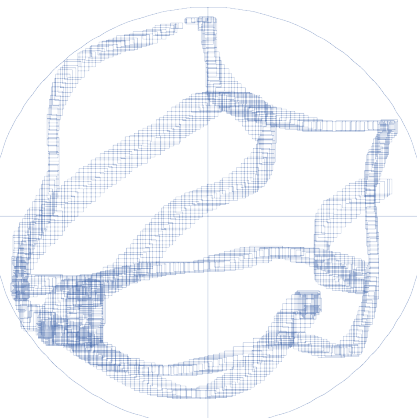

C
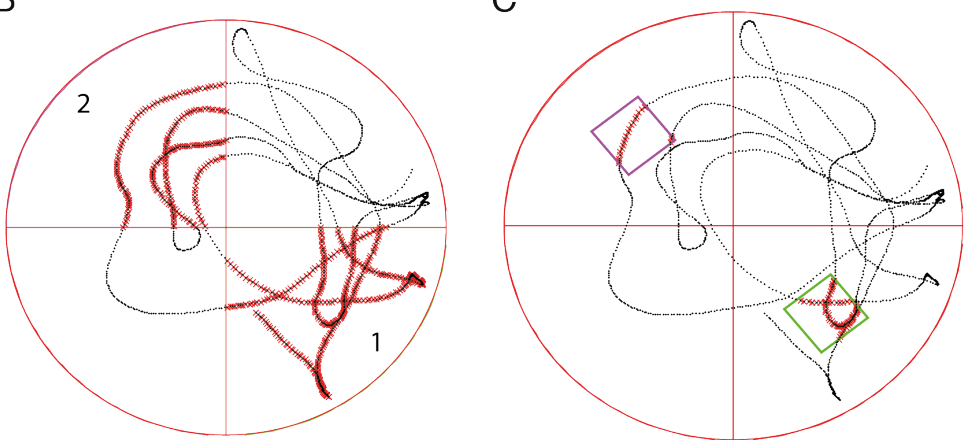

\section{Methods figure 4: Illustrations of custom written functions to calculate various watermaze}

\section{parameters}

(A) The video tracking system (Videomot 3D, TSE systems) extracts mouse centroid coordinates and vertices of bounding boxes around the mouse body for each frame of video tracking in real time. (Left) Imported data of bounding boxes for a representative mouse trial. (Right) A custom written Matlab script makes a mask of all points within the superimposed bounding boxes indicated in white. The pool outline is shown in white. This allows calculation of the \% pool area covered by a search path. (B) A custom written Matlab script calculates the \% time spent in a target quadrant by calculating the fraction of search path points inside a target quadrant, indicated by red crosses and number of crossings of a target platform by counting number of groups of consecutive search path points inside a platform area (C). For the example shown, \% time spent in quadrants 1 and 2 were $31.2 \%$ and $15.5 \%$ respectively. Number of crossings of the green and magenta platform were 3 and 2 respectively. All search path points are shown as black crosses. 


\section{Results}

\subsection{Synaptotagmin 3 is expressed on the post-synaptic plasma membrane}

\section{- A polyclonal antibody was validated to detect syt3 specifically}

In collaboration with Synaptic Systems GmbH (Göttingen), a polyclonal antibody (syt3NT antibody; catalogue number 105133) was developed for immunocytochemistry and Western blotting to detect synaptotagmin3 (syt3) specifically amongst all other isoforms. It was raised by immunizing rabbits with a peptide (amino acids 86-169) in the linker region between the syt3 transmembrane domain and the $\mathrm{C} 2 \mathrm{~A}$ domain. The linker region (amino acids 76 to 298 of the rat syt3 sequence, see Introduction figure 2) is the most variable region amongst all synaptotagmin isoforms, and thus served as the ideal epitope to raise an isoform specific antibody. To test specificity, HEK293 cells (which do not express synaptotagmins endogenously and therefore served as a clean background) were transfected with these constructs using the calcium phosphate method, fixed and immunostained (see section 2.4 above) with the syt3NT antibody. Only syt3GFP transfected cells showed a bright syt3 antibody signal whereas other synaptotagmin isoforms showed only non-specific background signal (Figure 1A below). Lysis of these transfected HEK cells and analysis by Western blotting also showed an isoform specific signal at the expected band size, (63 KDa syt3 $+27 \mathrm{KDa}$ GFP) (Figure 1B below). This validated the isoform specificity of the syt3NT antibody for use in immunocytochemistry and Western blotting. Experiments in Figure 1A and Figure 1B below were performed by Jan Schrader and Dr. Saheeb Ahmed (Trans-synaptic Signaling Group, ENI Göttingen), respectively.

\section{- Syt3 is expressed in dendrites at excitatory and inhibitory synapses}

The syt3NT antibody revealed syt 3 is expressed at high levels in brain, adipose tissue, heart and kidney relative to the pancreas, liver, skeletal muscle or lung (Figure 1C below). While a previous study using a syt3 specific antibody found syt3 expression in the rat hippocampus and cerebellum but not in the cortex or olfactory bulb (Butz et al, 1999), the syt3NT antibody revealed syt3 expression in the mouse hippocampus and cortex, but not in the cerebellum or olfactory bulb. Additionally, syt3 is expressed in thalamus and striatum but not in the hypothalamus or pituitary 
gland (Figure 1D below). We observed stable expression of syt3 from embryonic (E14) to adult (P110) time points in brain (Figure 1E below). Experiments in Figure 1C-D and Figure 1E below were performed by Dr. Saheeb Ahmed and Dr. Katja Burk (Trans-synaptic Signaling Group, ENI Göttingen), respectively.
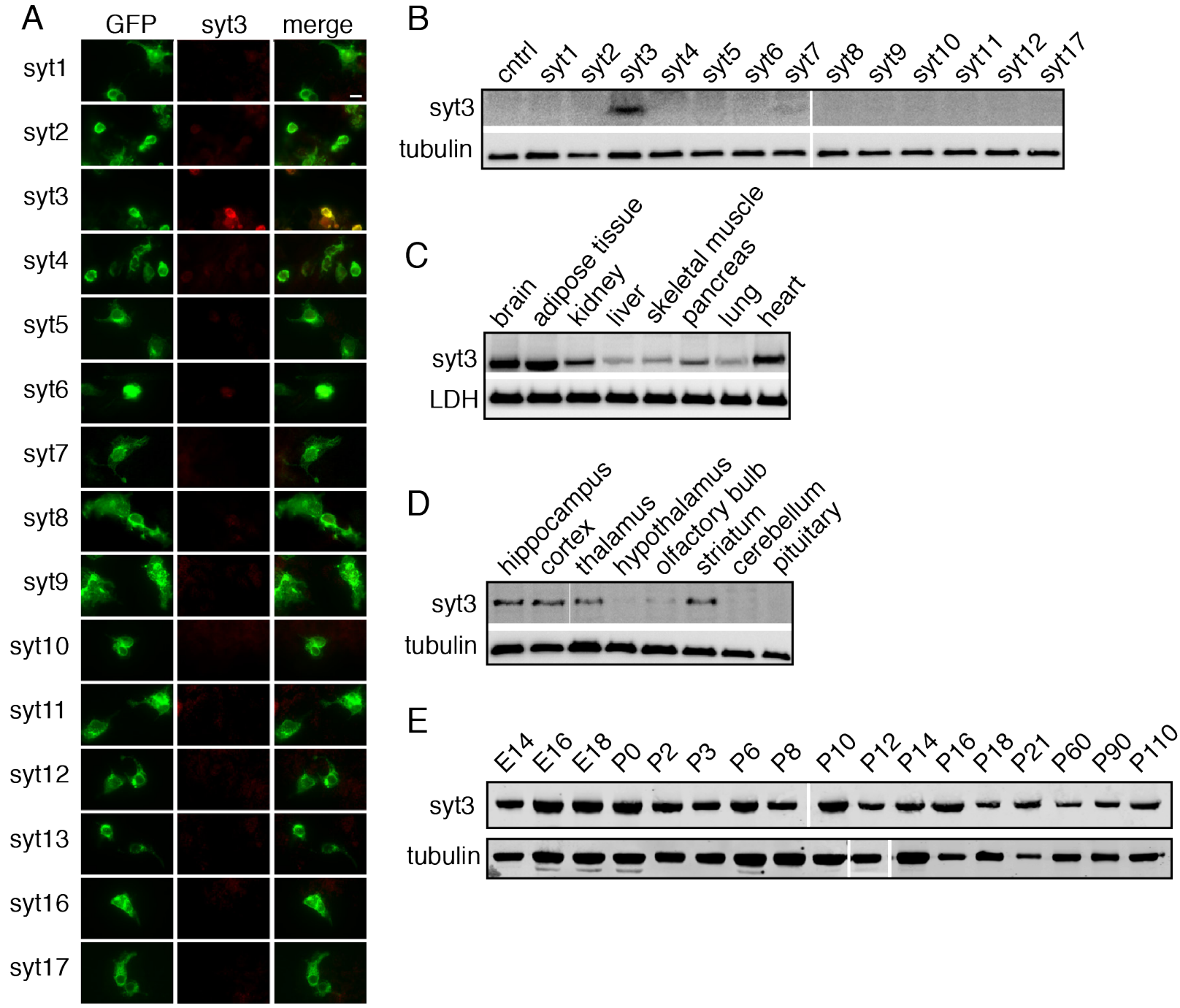

Figure 1: Syt3 is expressed in the mouse brain and other organs.

(A) Validation of the isoform specificity of a syt3 polyclonal antibody (syt3NT, see Table 6) for immunocytochemistry; the syt3NT antibody doesn't detect any other synaptotagmin isoforms expressed in HEK cells as GFP fusion constructs. Scale bar $=10 \mu \mathrm{m}$. (B) Validation of the isoform specificity of syt3NT antibody for Western blotting; the syt3NT antibody doesn't detect any other synaptotagmin isoforms in lysates from GFP-syt transfected HEK cells. (C) Syt3 is highly expressed in the brain, adipose tissue and heart compared to other organs. (D) Syt3 is highly expressed in the hippocampus, cortex, thalamus and striatum compared to other brain regions. (E) Syt3 expression remains stable from embryonic (E14) to adult (P110) ages. Tubulin and lactate dehydrogenase (LDH) served as loading controls.

These experiments were performed by Dr. Saheeb Ahmed, Dr. Katja Burk and Jan Schrader. 
To test if syt3 is indeed expressed at synapses, rat dissociated hippocampal cultures (see section 2.2 above) were immunostained (see section 2.4 above) using the syt3NT antibody. Neurons were transfected (see section 2.3 above) with EGFP, which is expressed cytoplasmically, serving as a volume marker and microtubule associated protein-2 (MAP-2) was used as a marker for dendrites. The syt3NT antibody revealed a punctate endogenous syt3 signal in dendrites but not in MAP-2 negative processes axons (Figure 2A below). Using epifluorescence microscopy, these endogenous syt 3 puncta were found to be colocalized with synaptic markers (Figure 2B-D):

A
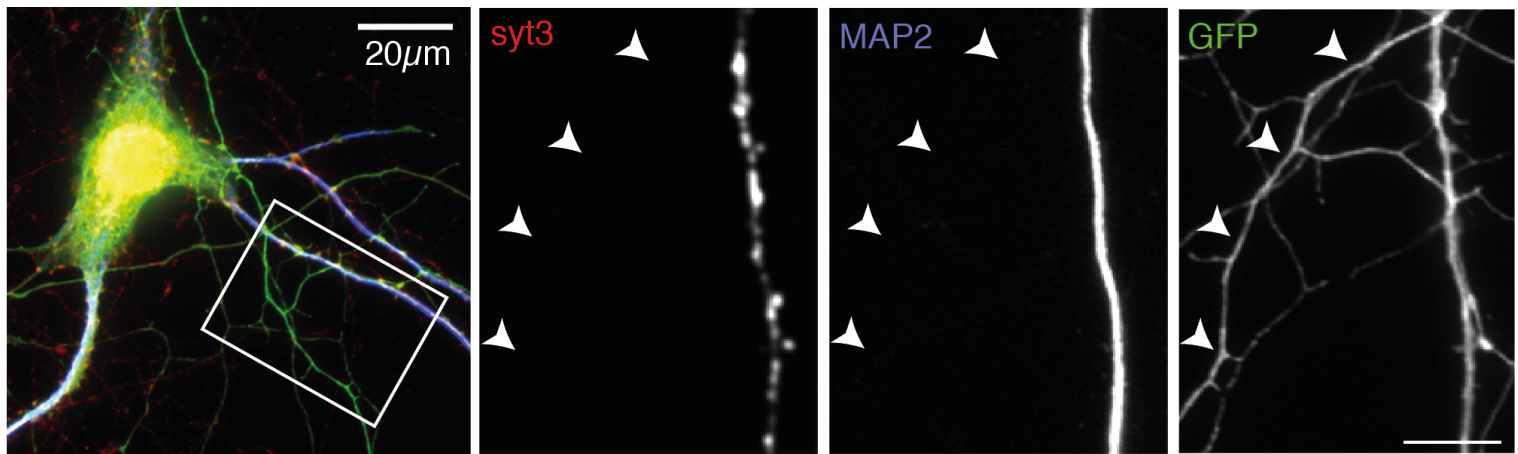

B
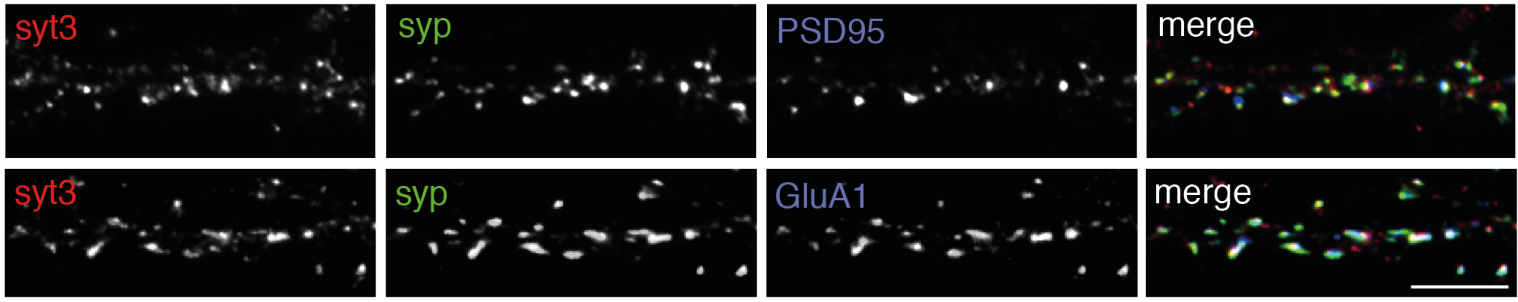

C

$\mathrm{D}$
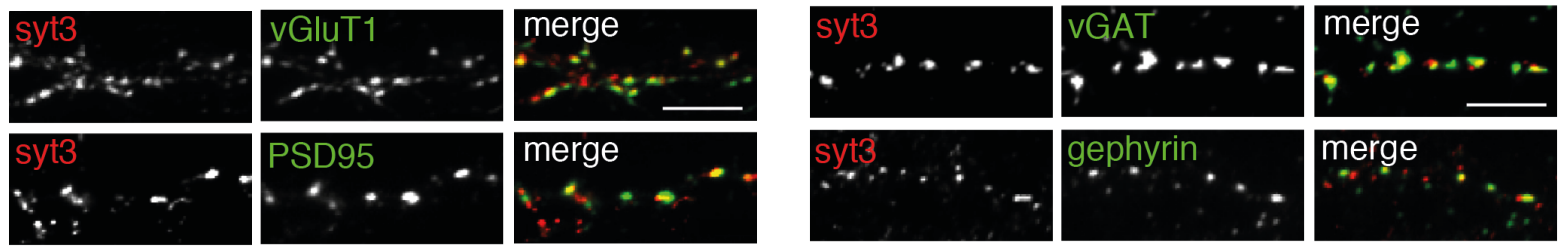

Figure 2: Endogenous syt3 is localized to dendrites at synapses

(A) A neuron in culture transfected with EGFP (left) shows endogenous syt3 on a MAP2-positive dendrite, but not on a nearby thin transfected MAP2 negative axon (arrowheads). The three panels on the right are a zoom-in of white boxed area in the left-most panel. Scale bar $=5 \mu \mathrm{m}$. (B) Syt3 colocalizes with a pre-synaptic marker, synaptophysin (syp), and the post-synaptic markers PSD-95 and GluA1, a subunit of AMPA receptors. Scale bar $=5 \mu \mathrm{m}$. (C) Syt3 is expressed at excitatory as well as inhibitory synapses. Syt3 puncta colocalize with pre- and post-synaptic excitatory synapse markers, vGlut1 and PSD-95, respectively. (D) Syt3 puncta also colocalize with pre- and postsynaptic inhibitory synapse markers, vGAT and gephyrin, respectively. Scale bar $=5 \mu \mathrm{m}$.

These experiments were performed by Dr. Yo Shinoda (ENI Göttingen). 
Synaptophysin (syp) is expressed on synaptic vesicle membranes in pre-synaptic axon terminals. Post-synaptic density protein 95 (PSD-95), also known as synapse associated protein-90 (SAP90), is an important component of the post-synaptic density, an electron dense structure just below the post-synaptic membrane which serves an important scaffolding function. GluA1 (previously known as GluR1) is a subunit of AMPA receptors, found predominantly at synaptic sites in dendrites. All experiments in Figure 2A-D above were performed by Dr. Yo Shinoda (Transsynaptic Signaling Group, ENI Göttingen). As the resolution limit of epifluorescence microscopy is not enough to resolve pre- and post-synaptic proteins, other biochemical approaches were used to determine the precise subcellular localization of syt3.

Subcellular fractionation can be used to isolate synaptosomes, which consist of axonal terminals with resealed pre-synaptic membranes attached via adhesion molecules to exposed post-synaptic membrane (Figure 3C below). The fractions obtained during subcellular fractionation of brain homogenate correspond to subcellular compartments including nucleus, cytoplasm, membranes, mitochondria, synaptosomes and synaptic vesicles. The relative enrichment of a protein in these fractions indicates its subcellular localization. In agreement with previous studies (Butz et al., 1999; Sugita et al., 2002), we found syt3 was found enriched in the crude synaptosomal fraction (P2') and the purified synaptosomal membrane fraction (LP1) (Figure 3A below). As syt3 is highly homologous to syt 1 and syt 2 , one might predict syt 3 to be present on synaptic vesicles. However, in concurrence with previous studies (Butz et al., 1999; Sugita et al., 2002), purified synaptic vesicles obtained from subcellular fractionation revealed no syt3. Immunoprecipitation of syt1 and syb2 (Synaptobrevin2/ VAMP2) to isolate synaptic vesicles also revealed that syt3 is not present on synaptic vesicles (Figure 3B).

To test if syt3 is localized to pre- or post-synaptic membranes, a trypsin cleavage assay of synaptosomes was performed. Because the pre-synaptic terminal of purified synaptosomes is sealed and the post-synaptic side of the membrane is exposed, only post-synaptic proteins are cleaved by trypsin (Boyken et al., 2013). Using this assay (see section 2.6 above), we found that syt3 was degraded like other post-synaptic proteins (GluA1, GluN1, PSD95 and Homer) (Figure 3C,D below). As expected, synaptic vesicle proteins (synaptophysin, synapsin, synaptotagmin1, rab3a, synaptobrevin2/ VAMP2), pre-synaptic scaffolding proteins (piccolo) and pre-synaptic 
plasma membrane SNARE proteins (SNAP25, and syntaxin1a) were not degraded (Figure 3D). This experiment conclusively showed for the first time that syt 3 is on post-synaptic membranes. All experiments in Figure 3A-D were performed by Dr. Saheeb Ahmed (Trans-synaptic Signaling Group, ENI Göttingen).

A

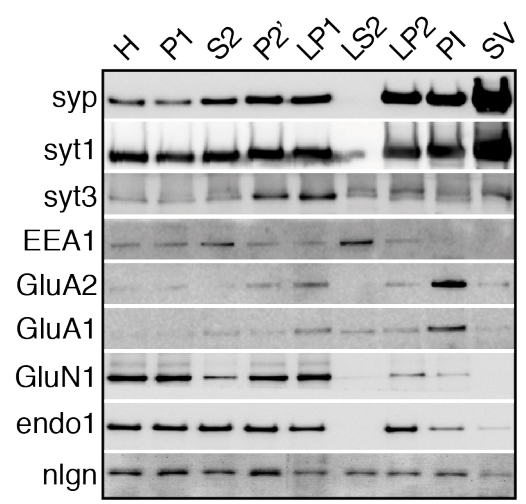

B

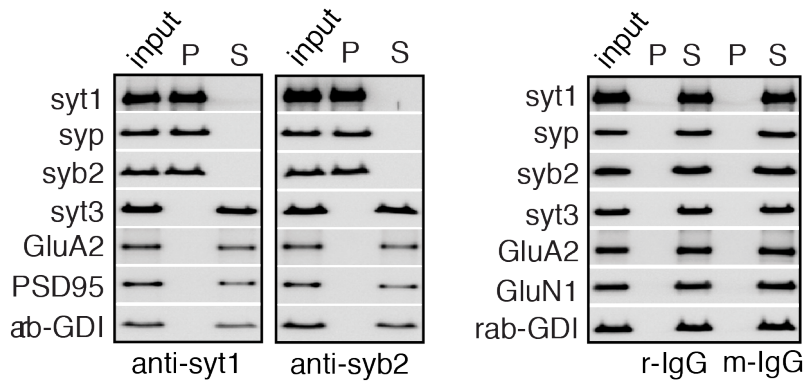

C

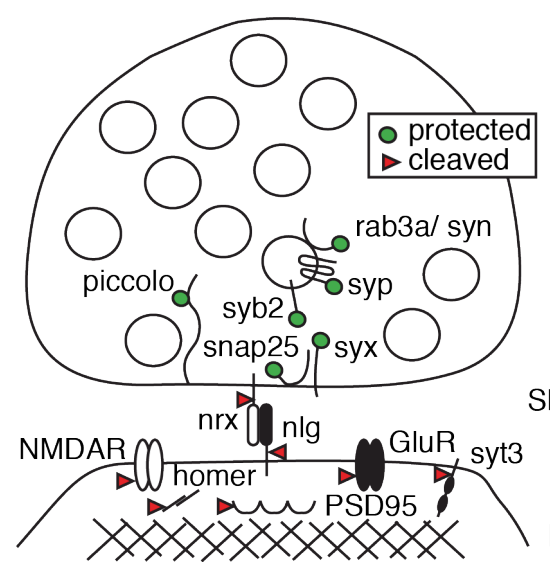

D

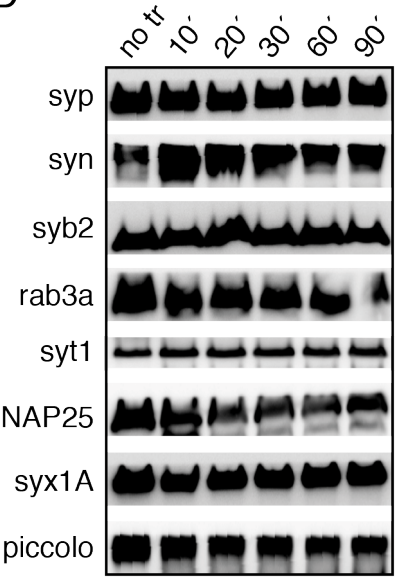

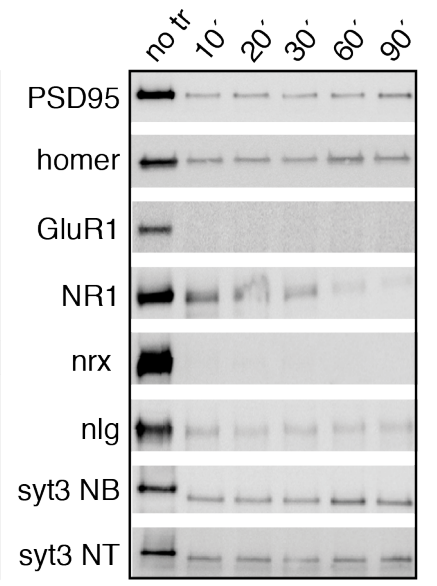

Figure 3: Syt3 is predominantly localized to post-synaptic membranes

(A) Western blot analysis of fractions obtained from subcellular fractionation of mouse brain homogenate: Homogenate $(\mathrm{H})$, P1 (nuclei and membrane fragments), crude synaptosomal fraction (P2') and corresponding supernatant (S2), synaptosomal fraction (LP1) and, synaptic vesicle fraction (LP2), PI and supernatant (LS2). (B) Immunoprecipitation using syt1 or syb2 antibodies coupled to magnetic beads and Western blot analysis showed synaptic vesicle proteins but no syt3 in the bound fraction (left). Control IPs with rabbit $\operatorname{IgG}(\mathrm{r}-\mathrm{IgG})$ and mouse $\operatorname{IgG}(\mathrm{m}-\mathrm{IgG})$ beads showed no proteins in the bound fraction (P) (right). (C) Sketch of a synaptosome, in which the pre-synaptic membrane reseals protecting its contents whereas the post-synaptic membrane does not reseal leaving post-synaptic proteins accessible to the extracellular solution. Red arrowheads and green circles show epitopes of the antibodies that were used to detect the indicated proteins by Western blotting. (D) Upon treatment of synaptosomes with trypsin, pre-synaptic proteins were protected from cleavage (left) whereas post-synaptic proteins and syt3 were degraded (right).

These experiments were done by Dr. Saheeb Ahmed (ENI Göttingen) and sketch prepared by Dr. Camin Dean (ENI Göttingen). 


\subsection{Syt3 undergoes activity-dependent endocytosis upon stimulation}

Superecliptic pHluorin (SEP) is a $\mathrm{pH}$ sensitive variant of green fluorescent protein (GFP) that can be used to monitor endo- or exocytosis of proteins of interest. pHluorins fluoresce in physiological extracellular solution of $\mathrm{pH} 7.4$ and this fluorescence decreases by $\sim 20$ fold in the acidic lumen of synaptic vesicles with pH 5.5 (Fernández-Alfonso, Kwan, \& Ryan, 2006).

Interestingly, in a screen of 12 pHluorin-syt isoforms, pHluorin-syt3 was the only isoform that endocytosed upon stimulation in culture, and did so only in dendrites (Dean et al., 2012). Phluorinsyt3 fluoresces in basal conditions indicating that the N-terminal end of a syt3 subpopulation is extracellular, i.e. pHluorin-syt3 is on the plasma membrane, in resting conditions (Figure 4A below). Upon a depolarizing stimulus by bath application of $45 \mathrm{mM} \mathrm{KCl}$ (Figure 4B), or specific activation of NMDA receptors (100 $\mu \mathrm{M} \mathrm{NMDA}+20 \mu \mathrm{M}$ CNQX) (Figure 4C) or AMPA receptors $(100 \mu \mathrm{M}$ AMPA $+50 \mu \mathrm{M}$ APV) (Figure 4D), this fluorescence exponentially decays, indicating endocytosis. The internalization of the N-terminal domain of syt3 (endocytosis) was blocked in $0 \mathrm{mM}$ extracellular $\left[\mathrm{Ca}^{2+}\right]$, suggesting that syt3 endocytosis is calcium dependent (Figure 4B-D, right panels).

Field stimulation experiments (see section 2.4 above) were used to determine the calcium source required for endocytosis of syt3. $1 \mu \mathrm{M}$ TTX was added in these experiments to block action potentials and hence, reduce variability in the response due to recurrent activity of neurons. Increasing the frequency, duration or current of the electrical field stimulation caused a gradual increase in the endocytic response (Figure 4E below). A stimulation protocol which yielded maximal response in terms of fluorescence decay was used for subsequent experiments, i.e., $20 \mathrm{~Hz}$, $30 \mathrm{sec}, 100 \mathrm{~mA}$ biphasic pulses. Blocking AMPA receptors (with $20 \mu \mathrm{M} \mathrm{CNQX)}$ and/ or NMDA receptors (with $50 \mu \mathrm{M} \mathrm{APV}$ ) caused the same reduction of pHluorin-syt3 endocytosis. This could be explained by NMDA receptors acting as the calcium source for syt3 endocytosis and AMPA receptor activation providing the depolarization to relieve the magnesium block of NMDA receptors. Blocking L-type voltage-gated calcium channels (using $10 \mu \mathrm{M}$ Nifedipine) in addition to AMPA and NMDA receptors further reduced syt3-pHluorin endocytosis, indicating L-type calcium channels are an additional calcium source for syt3. The marginal fluorescence decay in 
A
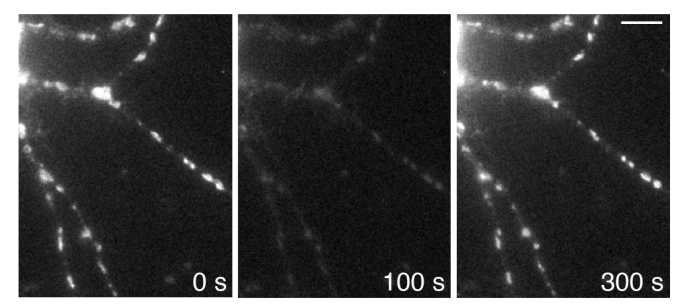

C

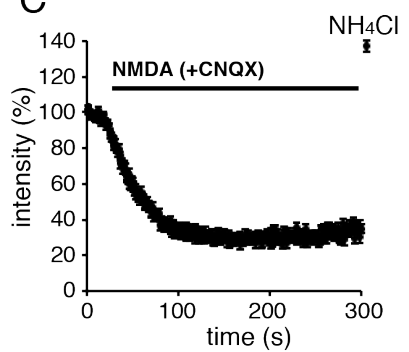

$\mathrm{E}$

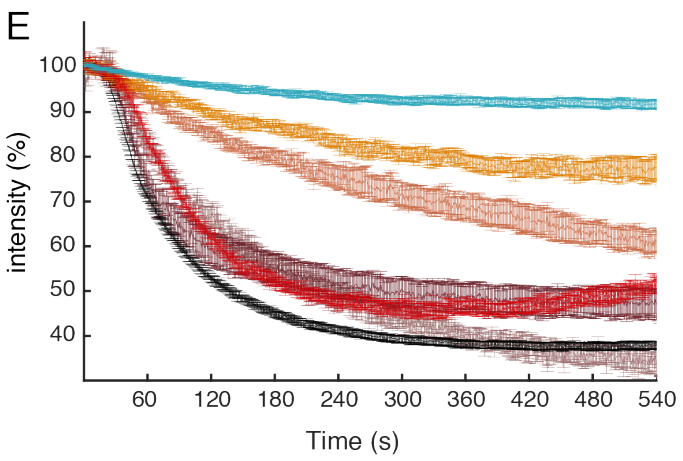

Time (s)

$$
\begin{gathered}
\text { No field stimulation }(\mathrm{n}=53 / 11 / 6) \\
5 \mathrm{~Hz}, 200 \text { pulses, } 10 \mathrm{~mA}(\mathrm{n}=7 / 1 / 1) \\
20 \mathrm{~Hz}, 200 \text { pulses, } 25 \mathrm{~mA}(\mathrm{n}=13 / 1 / 1) \\
=5 \mathrm{~Hz}, 200 \text { pulses, } 100 \mathrm{~mA}(\mathrm{n}=10 / 1 / 1) \\
20 \mathrm{~Hz}, 200 \text { pulses, } 100 \mathrm{~mA}(\mathrm{n}=7 / 1 / 1) \\
=20 \mathrm{~Hz}, 400 \text { pulses, } 75 \mathrm{~mA}(\mathrm{n}=13 / 2 / 1) \\
=20 \mathrm{~Hz}, 600 \text { pulses, } 100 \mathrm{~mA}(\mathrm{n}=239 / 19 / 7)
\end{gathered}
$$

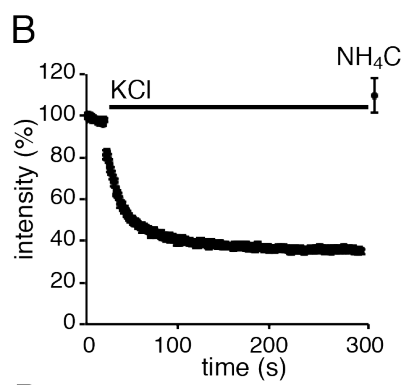

D
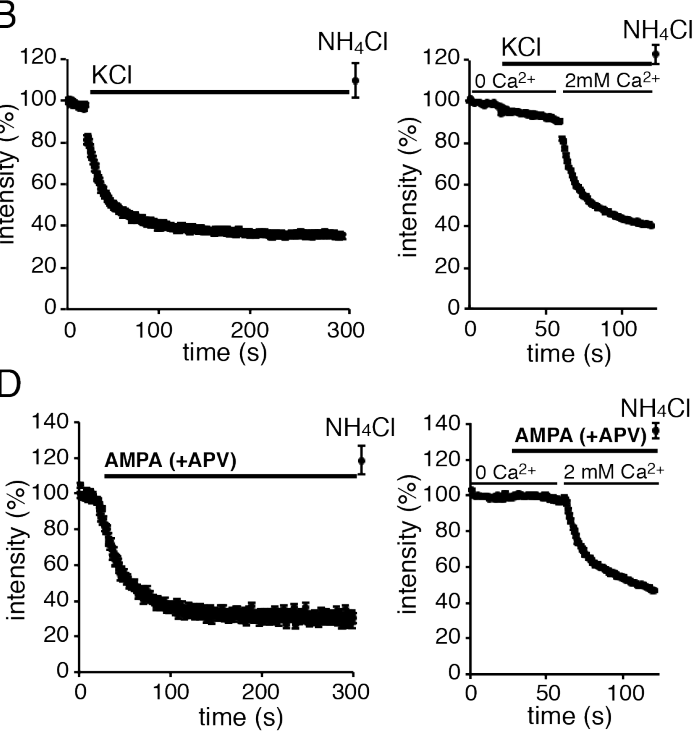

$\mathrm{F}$
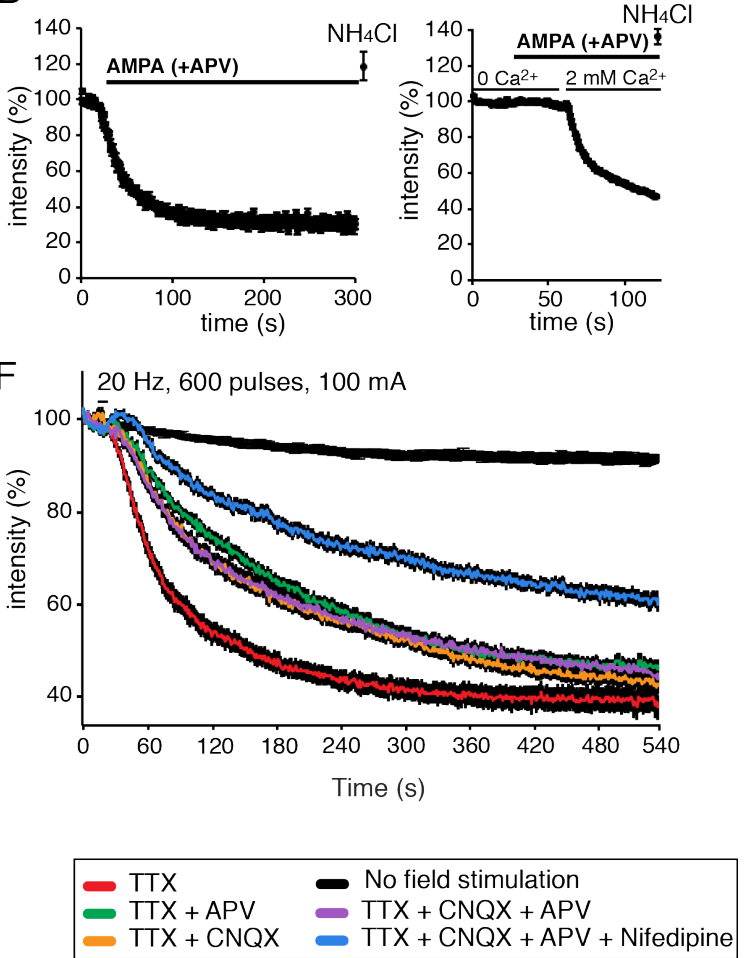

Figure 4: pHluorin-syt3 undergoes calcium dependent endocytosis upon stimulation in culture.

(A) A hippocampal neuron in culture transfected with pHluorin-syt3 is fluorescent in basal conditions (left panel, $0 \mathrm{sec}$ ) as fluorescence decays exponentially after stimulation (middle panel, $100 \mathrm{sec}$ ). Adding $\mathrm{NH}_{4} \mathrm{Cl}$ reveals internal pHluorin puncta (right panel, $300 \mathrm{sec}$ ). Scale bar $=5 \mu \mathrm{m}$. (B) Bath stimulation with $45 \mathrm{mM} \mathrm{KCl}$ induces a decay in fluorescence (left panel, $\mathrm{n}=58 \mathrm{ROIs} / 4$ neurons/ 3 cultures), which is blocked in $0 \mathrm{mM}$ extracellular $\left[\mathrm{Ca}^{2+}\right]$ (right panel, $\mathrm{n}=57 \mathrm{ROIs} / 4$ neurons/ 3 cultures). (C) Bath stimulation with $100 \mu \mathrm{M}$ NMDA (+ $20 \mu \mathrm{M}$ CNQX) induces a decay in fluorescence (left panel, $\mathrm{n}=33 \mathrm{ROIs} / 5$ neurons/ 3 cultures), which is blocked in $0 \mathrm{mM}$ extracellular $\left[\mathrm{Ca}^{2+}\right]$ (right panel, $\mathrm{n}=40 \mathrm{ROIs} / 3$ neurons/ 3 cultures). (D) Bath stimulation with $100 \mu \mathrm{M}$ AMPA ( $+50 \mu \mathrm{M} \mathrm{APV}$ ) induces a decay in fluorescence (left panel, $\mathrm{n}=37$ ROIs/ 7 neurons/ 3 cultures), which is blocked in $0 \mathrm{mM}$ extracellular $\left[\mathrm{Ca}^{2+}\right.$ ] (right panel, $\mathrm{n}=42 \mathrm{ROIs} / 6$ neurons/ 3 cultures). (E) Endocytosis of pHluorin-syt3 was correlated with the strength of field stimulation (in $1 \mu \mathrm{M}$ TTX). $\mathrm{N}=$ ROIs/ number of neurons/ number of cultures in legend. (F) Field stimulation in $50 \mu \mathrm{M}$ APV and/ or $20 \mu \mathrm{M} \mathrm{CNQX}$ reduced endocytosis of pHluorinsyt3, which was further reduced by $10 \mu \mathrm{M}$ Nifedipine. $1 \mu \mathrm{M}$ TTX was added during field stimulation. $\mathrm{n}=33 \mathrm{ROIs} /$ 5 neurons/ 3 cultures for all conditions except non-stimulated, where $n=53$ ROIs/ 11 neurons/ 6 cultures. These experiments were carried out by Dr. Yo Shinoda (ENI Göttingen) except panel (e) by Ankit Awasthi. 
the absence of field stimulation indicates the bleaching rate of pHluorin (Figure 4F above). Experiments in Figure 4A-D, F above were performed by Dr. Yo Shinoda (Trans-synaptic Signaling Group, ENI Göttingen).

\subsection{Recombinant syt3 pulls down GluA2 and BRAG2}

Since the endocytosis of pHluorin-syt3 resembles that of GluA2-pHluorin upon NMDA stimulation (D.-T. T. Lin \& Huganir, 2007) and AMPA or NMDA stimulation can induce internalization of AMPA receptors (Beattie et al., 2000; Ehlers, 2000; S. H. Lee, Simonetta, \& Sheng, 2004; S. Lee, Liu, Wang, \& Sheng, 2002; J. W. Lin et al., 2000), the binding partners of syt3 were examined for the presence of AMPA receptor internalization machinery. As multiple immunoprecipitation attempts with the syt3NT antibody failed, recombinant pull down assays were used. Soluble syt $3 \mathrm{C} 2 \mathrm{AB}$ fused to a His-tag was recombinantly expressed, affinity purified and immobilized on nickel beads (see section 2.6 above). Binding partners of syt3 were pulled down from mouse brain homogenate (Figure $5 \mathrm{~A}$ below) in the absence of calcium and in the presence of $500 \mathrm{mM} \mathrm{NaCl}$.

Syt3 indeed pulled down a subunit of AMPA receptors, GluA2, but not the other subunits GluA1 or GluA3. Syt3 did not pull down the obligatory subunit of NMDA receptors, GluN1 (Paoletti, Bellone, \& Zhou, 2013), GluN2A or a subunit of GABA receptors, GABAAR1 (Figure 5B below).

GluA2 is a key player in internalization of AMPA receptors via interacting partners of its C-tail. In the last nearly 20 years, various interacting partners of the GluA2 C-terminal tail have been discovered which regulate its trafficking (H. Dong, RJ, Fung, Lanahan, \& Worley, 1997; Hanley, Khatri, Hanson, \& Ziff, 2002; Jaafari, Henley, \& Hanley, 2012; S. Lee et al., 2002; Rocca et al., 2013; Scholz et al., 2010; Yao et al., 2008) (Figure 5C below). We found that out of these proteins, BRAG2, was pulled down by syt3, along with AP-2, but GRIP and PICK1 were not pulled down by syt3 (Figure 5B below).

As the interaction between synaptotagmin1 (syt1) and the pre-synaptic SNARE (SNAP (Soluble NSF Attachment Protein) REceptor) proteins is crucial for calcium evoked membrane fusion and 
neurotransmitter release, we also tested if syt3 pulled down any post-synaptic SNARE proteins. We found that syt3 indeed pulled down SNARE proteins implicated in LTP, SNAP47 and syntaxin3 (Jurado et al., 2013); a protein implicated in activity dependent surface trafficking of AMPA receptors, syntaxin4 (Kennedy, Davison, Robinson, \& Ehlers, 2010)'(Arendt et al., 2015); and VAMP3, which has so far only been implicated in trafficking of glutamate transporters in astrocytes (Ropert, Jalil, \& Li, 2016) and was found in Cajal-retzius cells (Barber et al., 2015) (Figure 5B). These experiments were performed by Dr. Saheeb Ahmed (Trans-synaptic Signaling

A

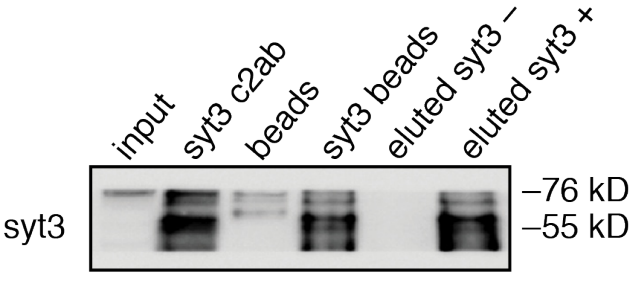

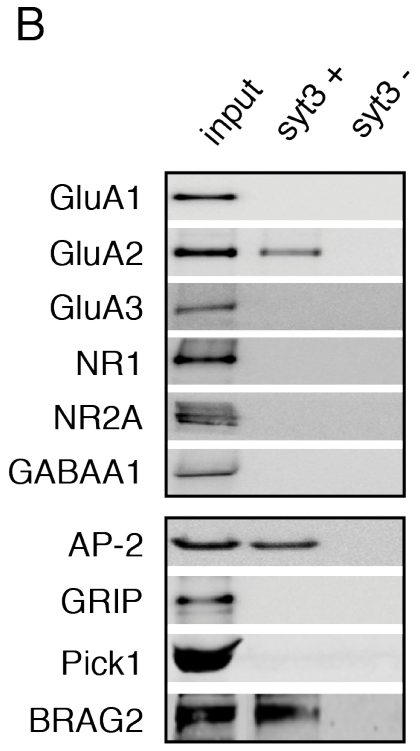

C

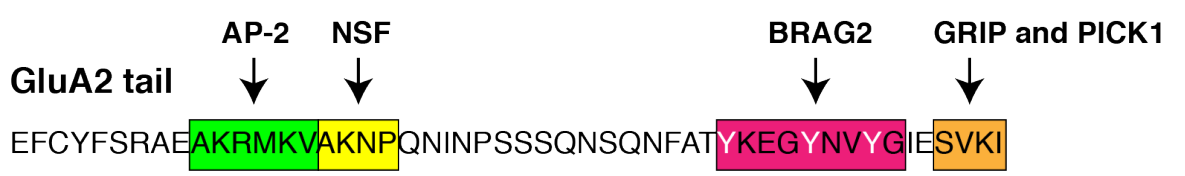

Figure 5: Recombinant syt3 pulls down GluA2, AP-2 and BRAG2 from brain homogenate

(A) Validation of recombinant pull down assay by Western blot. In brain homogenate input, syt3 is $\sim 70 \mathrm{kD}$. Recombinantly expressed and affinity purified syt3 $\mathrm{C} 2 \mathrm{AB}$ is $\sim 55 \mathrm{kD}$. (B) Western blot analysis of the pull down assay. Input was mouse brain homogenate; syt3+ indicates pulled down proteins which bound to recombinant syt3 $\mathrm{C} 2 \mathrm{AB}$ immobilized on nickel beads; syt3-indicates protein that bound non-specifically to beads alone as a negative control. (C) Diagram of the most important proteins implicated in regulating trafficking of AMPA receptors via their interaction with the GluA2 cytoplasmic C-terminal tail. AP-2: Adaptor protein complex; NSF: Nethylmaleimide-sensitive factor ATPase; BRAG2: Brefeldin-A resistant Arf guanine nucleotide exchange factor (GEF) for the guanosine triphosphate hydrolase (GTPase) Arf6 (ADP-ribosylation factor 6); GRIP: Glutamate receptor interacting protein; PICK1: protein interacting with protein kinase $\mathrm{C}$.

The recombinant pull down assays were performed by Dr. Saheeb Ahmed (ENI Göttingen). Dr. Katja Burk ran Western blots to test GluA3, PICK1 and BRAG2 pulldown. 
Group, ENI Göttingen). Dr. Katja Burk (ENI Göttingen) performed Western blot analysis for GluA3, PICK1 and BRAG2.

\subsection{Syt3 mediates AMPA and NMDA induced AMPA receptor internalization}

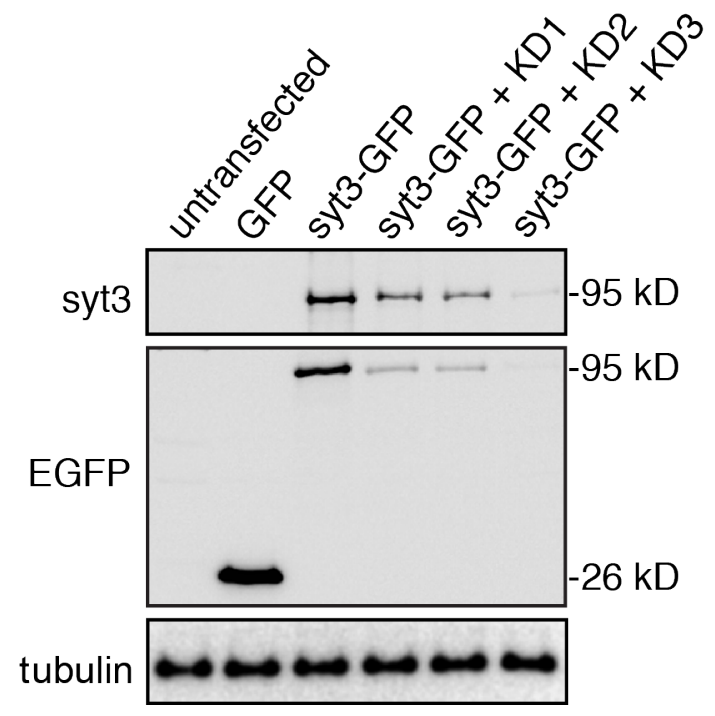

Figure 6: Validation of shRNA mediated knockdown of syt3

Western blot analysis of HEK cells expressing syt3 in the presence or absence of three distinct syt3 shRNA knockdown constructs.

This experiment was performed by Dr. Saheeb Ahmed (ENI Göttingen).

As syt3 binds GluA2, AP2 and BRAG2, we next tested if syt3 is necessary for the activity dependent internalization of AMPA receptors. Many studies have used selective agonist stimulation of ionotropic glutamatergic receptors with AMPA or NMDA to induce internalization of AMPA receptors (Beattie et al., 2000; Ehlers, 2000; S. H. Lee, Simonetta, \& Sheng, 2004; S. Lee, Liu, Wang, \& Sheng, 2002; J. W. Lin et al., 2000). Incubation of live neurons with antibodies against surface epitopes of endogenous GluA1 or GluA2 AMPA receptor subunits and subsequent selective staining of surface and internal populations with different fluorophore-conjugated secondary antibodies was used to examine the internalization of AMPA receptors upon stimulation with AMPA or NMDA (see section 2.4 above). Because the transfection method used had low efficiency, i.e., $\sim 10 \%$ cells were transfected, the analyzed neurons were predominantly innervated by wild type pre-synaptic partners. Thus, this method allows selective determination of postsynaptic effects of overexpression of wild-type syt3 (syt3-GFP), calcium mutant syt3 (syt3Cam) or small hairpin RNA (shRNA)-mediated syt3 knockdown (syt3 KD). 
A
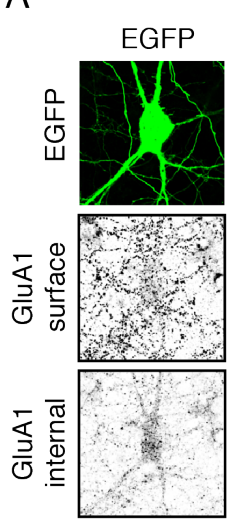

B

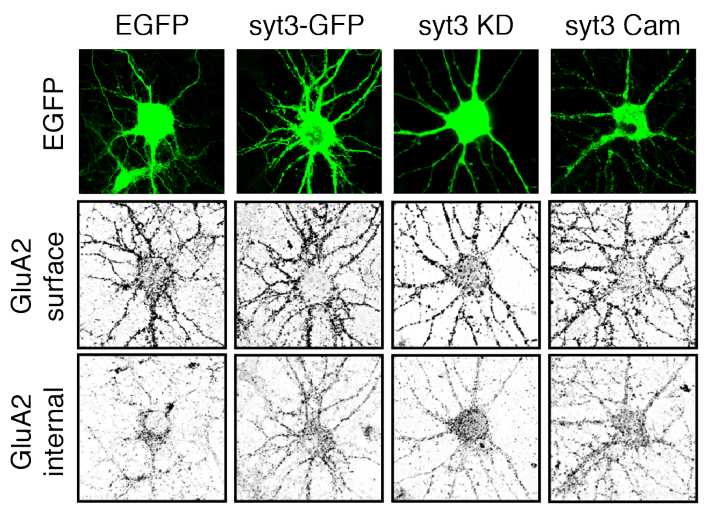

C

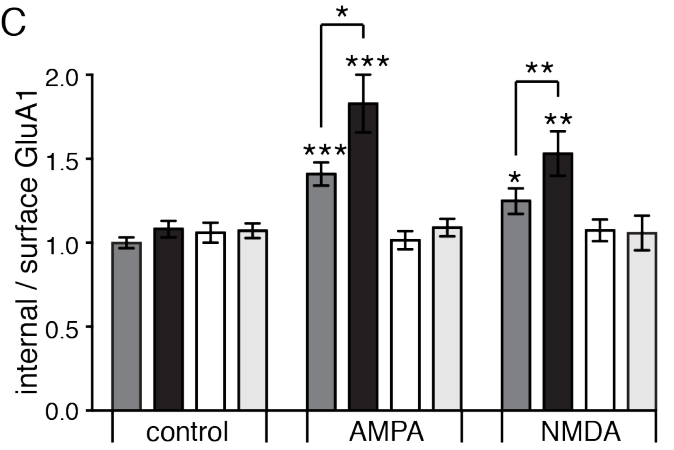

control
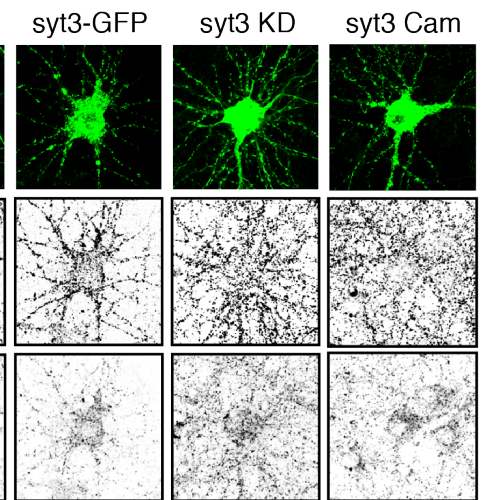

control

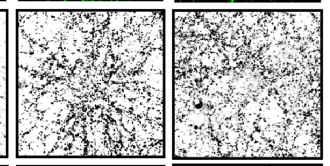

D

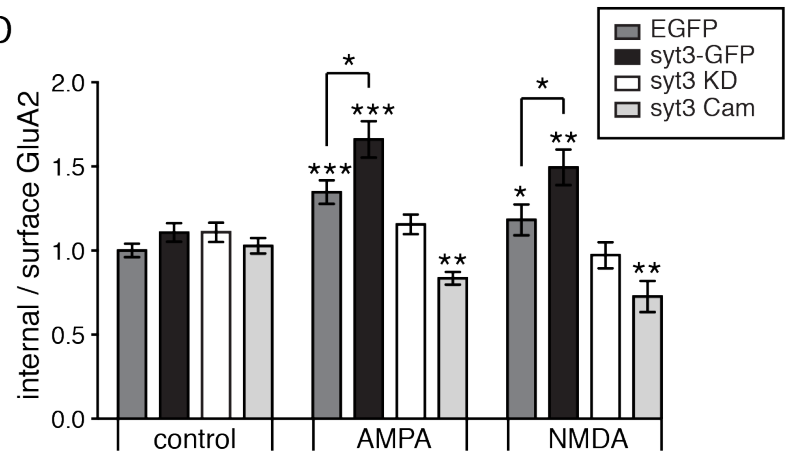

Figure 7: Post-synaptic syt3 mediates AMPA \& NMDA induced AMPA receptor internalization.

(A-B) Hippocampal neuron cultures sparsely transfected with EGFP, syt3-GFP, shRNA syt3 KD or syt3Cam (a syt3 calcium mutant) were used to alter post-synaptic syt3 (top row). Antibody uptake assays were used to distinctly label surface (middle row) and internal (bottom row) populations of endogenous GluA1 (A) and GluA2 (B)-containing AMPA receptors in the presence and absence of $100 \mu \mathrm{M}$ AMPA stimulation. (C-D) Overexpressing syt3 increased AMPA receptor internalization, whereas syt3 KD or syt3Cam blocked AMPA induced internalization of GluA1 (C) and GluA2 (D). Number of neurons analyzed for GluA1: EGFP=69 (ctrl), 46 (AMPA), 47 (NMDA), syt3-GFP=65 (ctrl), 47 (AMPA), 43 (NMDA), syt3 KD=41 (ctrl), 38 (AMPA), 24 (NMDA), syt3 Cam=37 (ctrl), 36 (AMPA), 31 (NMDA); for GluA2: EGFP=64 (ctrl), 68 (AMPA) 28 (NMDA), syt3-GFP=46 (ctrl), 46 (AMPA), 23 (NMDA), syt3 KD=51 (ctrl), 69 (AMPA), 23 (NMDA), syt3 Cam=42 (ctrl), 28 (AMPA), 27 (NMDA). Statistical significance determined by Student's t-test with Bonferroni correction. Experiments were performed by Ankit Awasthi and Dr. Camin Dean (ENI Göttingen) and analyzed by Dr. Camin Dean. 
The syt $3 \mathrm{KD}$ constructs were first validated in HEK cells. Up to $80 \%$ reduction in syt3 protein levels could be achieved by co-transfection of the three syt3 KD shRNA constructs (Figure 6 above).

AMPA or NMDA stimulation increased the internalization of GluA1 and GluA2 (Figure 7C-D, Figure 8A-B) in cell somas. Post-synaptic syt3 over-expression further enhanced the AMPA or NMDA mediated internalization of GluA1-containing and GluA2-containing AMPA receptors. On the other hand, overexpressing a calcium mutant of syt 3 or knocking down syt 3 blocked the AMPA or NMDA induced GluA1 or GluA2 internalization altogether. Overexpression of the calcium mutant of syt3, in fact, led to significantly higher surface accumulation of GluA2containing (Figure 7D) but not GluA1-containing AMPA receptors (Figure 7C) upon AMPA or NMDA stimulation. Importantly, none of the manipulations of post-synaptic syt3 had any effect on the basal surface/internal levels of GluA1-containing or GluA2-containing AMPA receptors. Thus, syt3 and its calcium binding sites are necessary for AMPA or NMDA induced internalization of GluA1-containing and GluA2-containing AMPA receptors. These experiments were performed by Ankit Awasthi and Dr. Camin Dean (ENI Göttingen) and analyzed by Dr. Camin Dean.

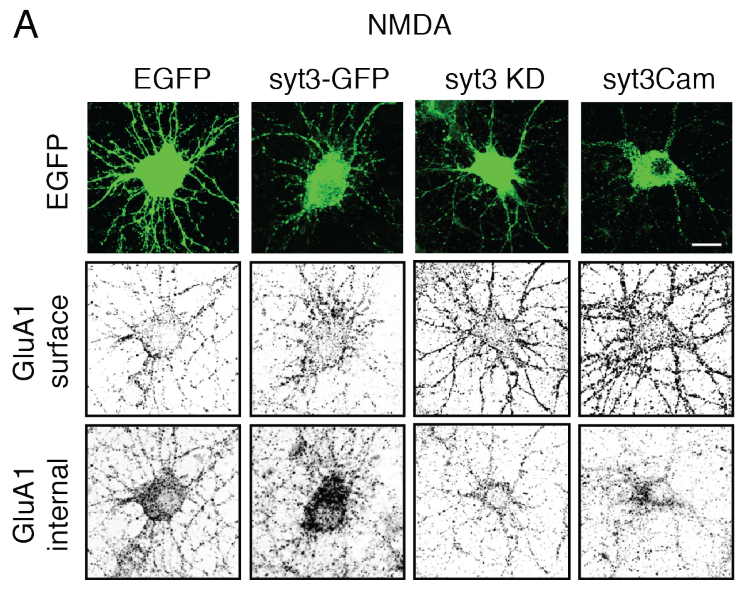

B

NMDA

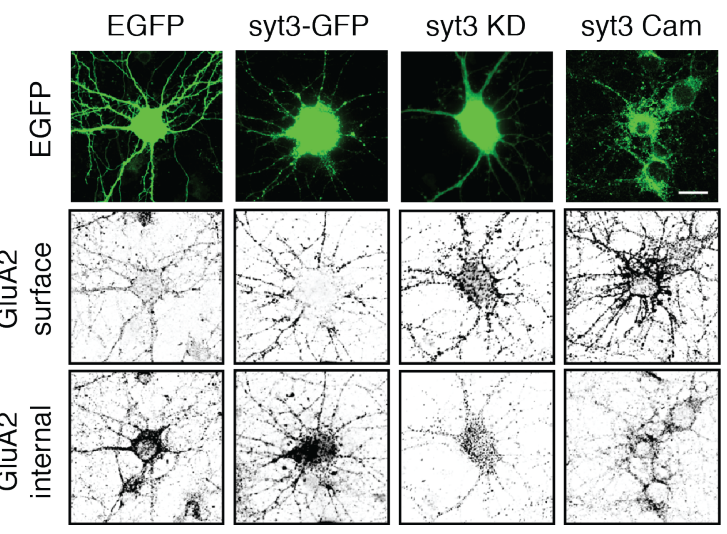

Figure 8: Syt3 is necessary for NMDA induced GluA1 and GluA2 internalization

(A-B) Representative images of GluA1 (A) and GluA2 (B) antibody uptake assays. Analysis of this dataset is shown in (Figure 7C-D above).

These experiments were performed by Ankit Awasthi and Dr. Camin Dean; analyzed by Dr. Camin Dean (ENI Göttingen) 
A

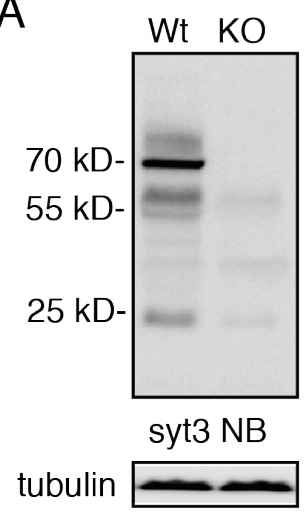

C

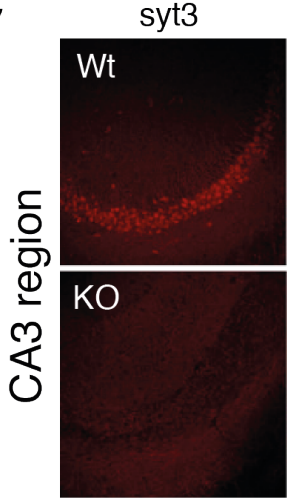

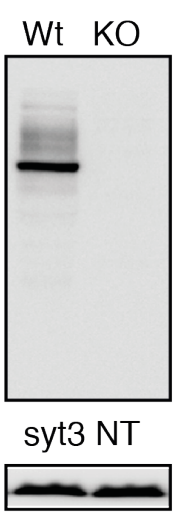

MAP2

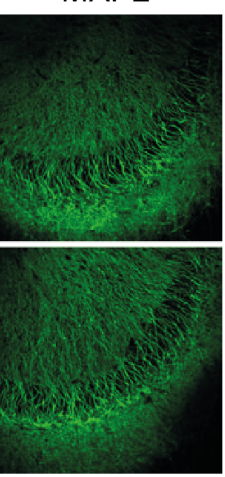

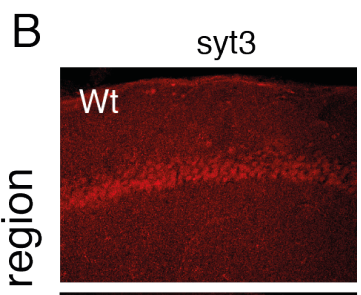

\section{$\mathrm{KO}$}
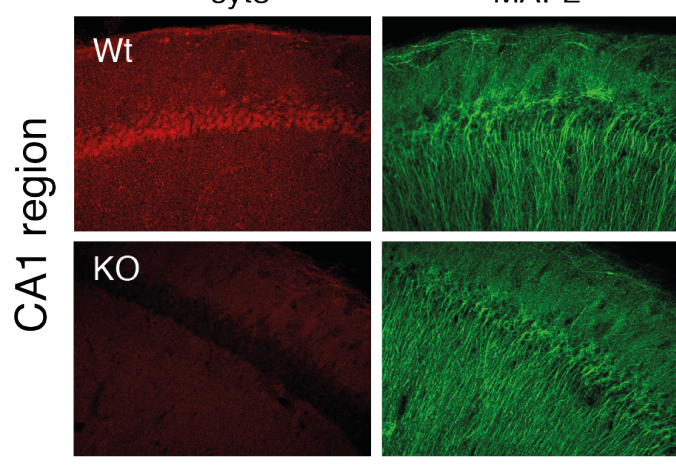

D

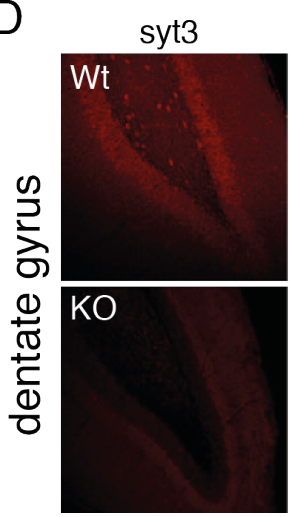

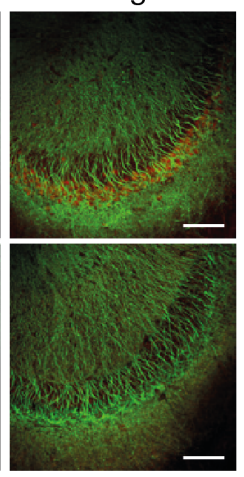

MAP2

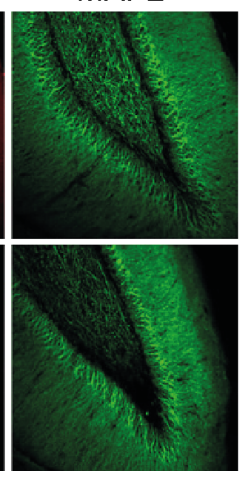

merge
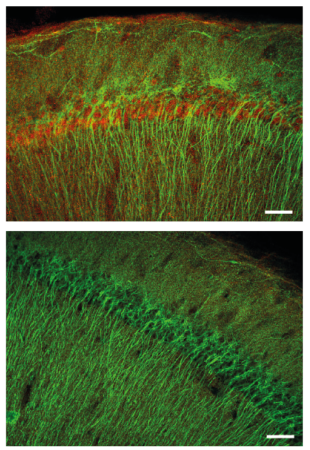

merge

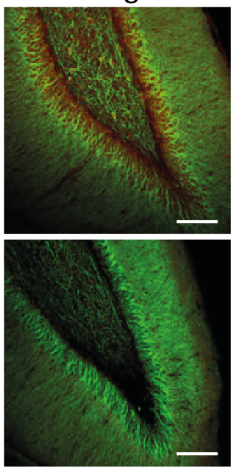

Figure 9: Validation of the syt3 knockout mouse

(A)Western blots show syt3 detected at the expected size of $\sim 70 \mathrm{KDa}$ in WT mouse brain homogenate but not in KO brain homogenate. Syt3NB refers to a syt3 antibody from Neuromab. (B-D) Syt3 was detected in somas of CA1(B) and CA3 (C) pyramidal neurons and dentate gyrus granule cells (D) in WT hippocampal slices but not in syt3 KO mouse hippocampal slices. MAP2 was used to mark dendrites. All scale bars $=50 \mu \mathrm{m}$.

Experiments in panel A were performed by Dr. Saheeb Ahmed (ENI Göttingen) and in panels B-D were performed by Dr. Binu Ramachandran (ENI Göttingen)

The syt3 knockout (KO) mouse (see section 2.1 above) was validated using the syt3NT and syt3NB (from Neuromab) antibody in Western blotting and immunohistochemistry. Syt3 was detected as a single band at the expected size of $\sim 70 \mathrm{KDa}$ in wild-type mouse brain homogenate but not in syt3 KO mouse brain homogenate (Figure 9A above). Similarly, syt3 was detected in somas of CA1 and CA3 pyramidal neurons and granule cells of the dentate gyrus in hippocampal slices from WT mice but not from syt3 KO mice (Figure 9B-D above). These experiments were performed by Dr. Saheeb Ahmed and Dr. Binu Ramachandran (ENI Göttingen). 
As the syt3 knockout mouse was available, we repeated the AMPA receptor internalization assays in hippocampal cultures from homozygous syt3 knockout mice (see section 2.2 above). AMPA and NMDA induced GluA2 internalization was blocked in syt3 KO cultures, an effect which could be mimicked by bath application of the Tat-GluA2-3Y peptide to WT cultures (Figure 10A, B), which blocks the activity dependent internalization of GluA2 containing AMPA receptors, leaving basal trafficking of AMPA receptors unaffected. The mechanism of action of the GluA2-3Y peptide is most likely via competitive inhibition of binding of BRAG2 to the dephosphorylated Y876 residue of the GluA2 C-terminal tail and the subsequent recruitment of AP2 and clathrin to

A

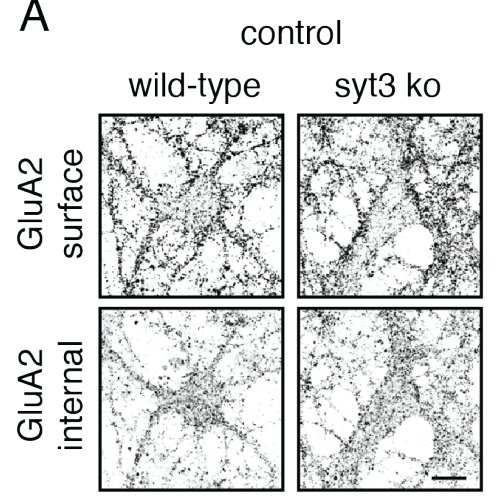

AMPA
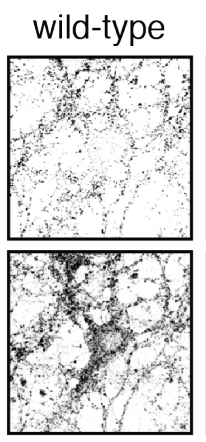

syt3 ko
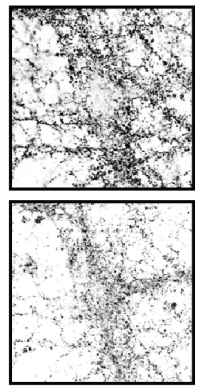
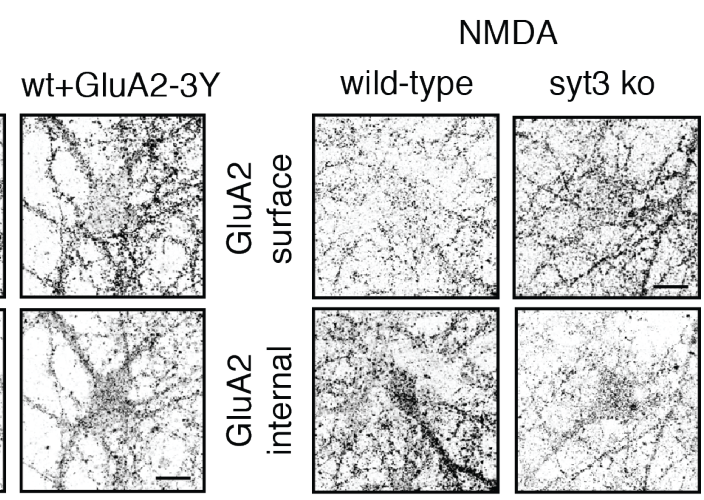

$\mathrm{B}$

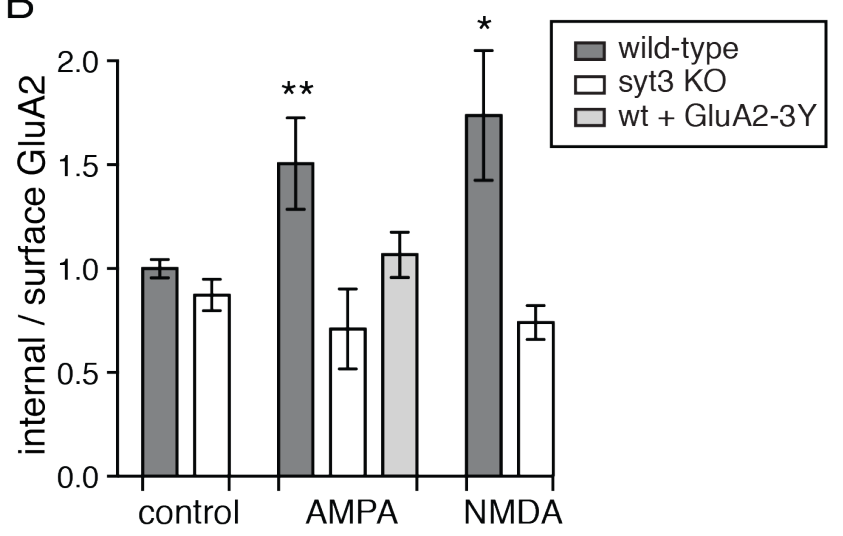

Figure 10: AMPA and NMDA induced GluA2 internalization is blocked in syt3 KO mouse cultures

(A) Representative images of surface and internal labelled GluA2 in wild type and syt3 KO mouse cultures in basal, AMPA and NMDA stimulated conditions. AMPA stimulations were also carried out in WT cultures in the presence of $1 \mu \mathrm{M}$ Tat-GluA2-3Y peptide. (B) Quantitation of GluA2 internalization index (mean \pm SEM) in the indicated conditions. AMPA and NMDA induced GluA2 internalization was blocked in syt3 KO cultures. Application of the membrane permeable GluA2-3Y peptide to WT cultures mimicked the effect of syt3 KO cultures. Scale bars $=10 \mu \mathrm{m}$. Number of neurons analyzed: $\mathrm{wt}=29$ (ctrl), 22 (AMPA), 17 (NMDA), syt3 KO=31 (ctrl), 24 (AMPA), 18 (NMDA), $w t+G l u A 2-3 Y=18$. Scale bars $=10 \mu \mathrm{m}$; Significance determined by Student's ttest with Bonferroni correction.

This experiment was performed by Ankit Awasthi and analyzed by Dr. Camin Dean. 
mediate endocytosis of GluA2 containing AMPA receptors (Ahmadian et al., 2004; Z. Dong et al., 2013, 2015; Hardt, Nader, \& Wang, 2014; Migues et al., 2016; Scholz et al., 2010).

\subsection{Syt3 does not affect basal synaptic transmission or receptor composition}

The antibody uptake/ receptor internalization assay showed that syt3 doesn't affect internalization of AMPA receptors in basal conditions but is necessary for activity dependent internalization of AMPA receptors. However, this analysis could have included many extra-synaptic receptor populations and thus, might not be directly relevant to synaptic transmission and plasticity. We, thus, checked basal synaptic receptor composition using whole-cell recordings, which exclusively measures synaptic receptors.

Miniature excitatory post-synaptic currents (miniature EPSCs/ minis) recorded from transfected neurons in hippocampal cultures were analyzed. In the presence of tetrodotoxin (TTX), EPSCs recorded from neurons arise only from spontaneous release of neurotransmitter, which is thought to be mediated by stochastic fusion of single synaptic vesicles with the pre-synaptic membrane. Since pre-synaptic release is quantal, the amplitude of mEPSCs reflects the number of postsynaptic receptors and the frequency of mEPSCs reflects the number of pre-synaptic quanta released. The mEPSC decay kinetics could be affected by the receptor subtype composition (Liu SJ et al., 2012). Over-expression or knock-down of syt3 did not affect the amplitude, frequency or decay time of mEPSCs (Figure 11A-D below). mEPSC decay time $=2.3 \pm 0.2 \mathrm{~ms}$ (EGFP), $2.1 \pm$ $0.2 \mathrm{~ms}$ (Syt3-GFP), $1.9 \pm 0.2 \mathrm{~ms}(\mathrm{Syt} 3 \mathrm{KD})(\mathrm{Mean} \pm \mathrm{SEM})$.

We corroborated these results by comparing basal synaptic transmission at the CA3-CA1 synapse in acute hippocampal slices from P12-P21 syt3 KO mice and WT littermates. The amplitude of the EPSCs evoked by stimulation of the CA3 Schaffer collaterals is dependent on the stimulation intensity which affects the number of stimulated synapses. Thus, only the ratios of the various post-synaptic currents are comparable between slices. There was no change in the NMDA/AMPA, GABA/AMPA or GABA/ NMDA ratio (Figure 11F-H below) in the syt3 KO mouse. There was also no change in the AMPAR EPSC decay time (WT: $19.4 \pm 4 \mathrm{~ms}$, KO: $21.9 \pm 4.6 \mathrm{~ms}$ ), or GABA IPSC decay time (WT: $76 \pm 4.9 \mathrm{~ms}, \mathrm{KO}: 58.8 \pm 7 \mathrm{~ms}$ ). 

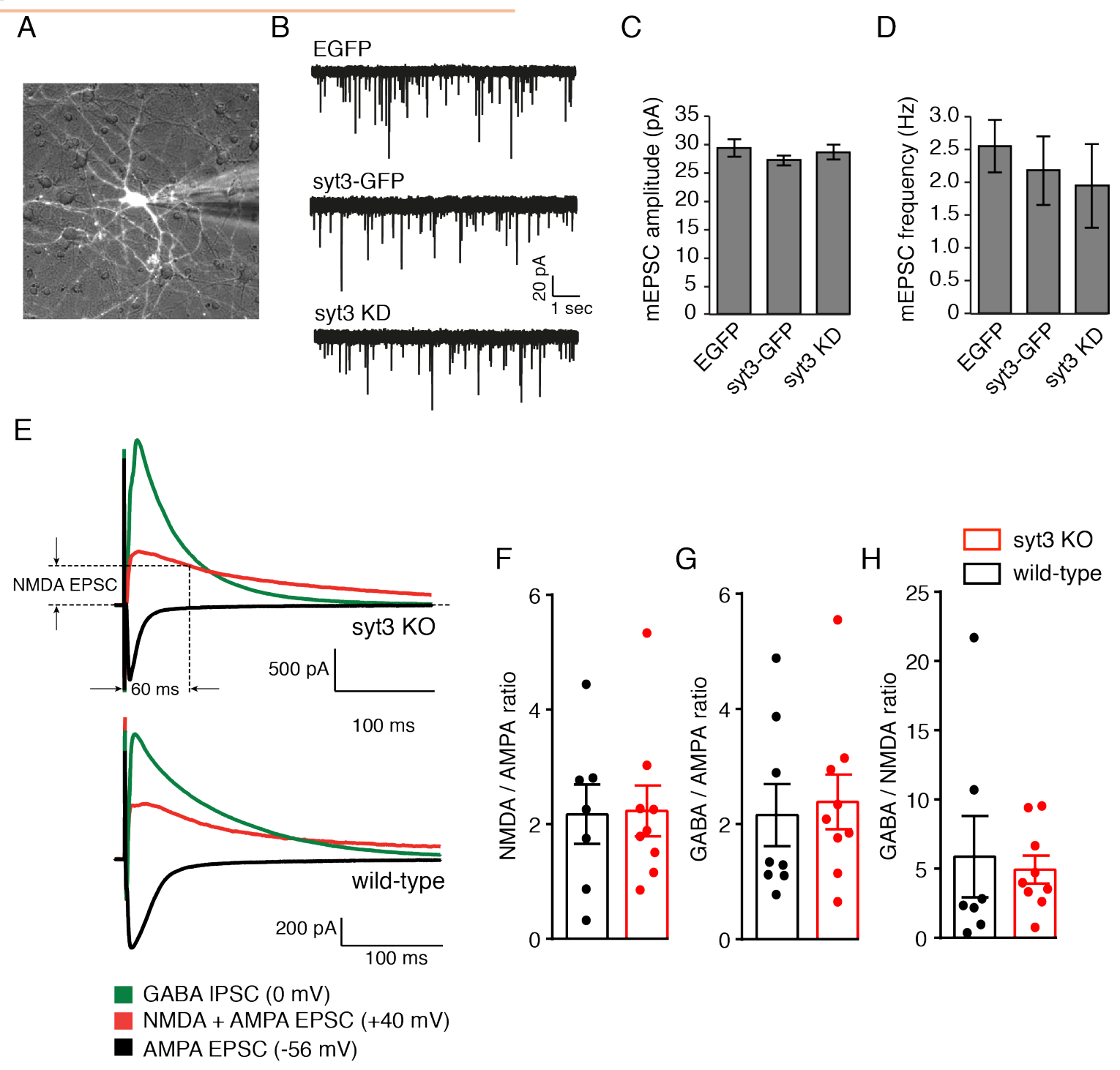

Figure 11: Syt3 does not affect basal synaptic transmission

(A) A neuron transfected with EGFP (white) in rat hippocampal culture impaled by a patch pipette. Superposition of the bright field image shows nearby untransfected neurons. (B) Representative AMPA receptor mEPSCs recorded from neurons transfected with EGFP (control), syt3-GFP (overexpression) and syt3KD constructs (knockdown) in the presence of $1 \mu \mathrm{M}$ TTX and $50 \mu \mathrm{M}$ picrotoxin at a holding potential of $-60 \mathrm{mV}$. (C-D) The amplitude (C) and average frequency (D) of mEPSCs (mean \pm SEM) was unaffected by a change in post-synaptic syt3 levels. Significance determined by Student's t-test with Bonferroni correction (EGFP $=8$ neurons $/ 2$ cultures, syt3-GFP= 15 neurons $/ 3$ cultures, syt $3 \mathrm{KD}=9$ neurons $/ 2$ cultures). (E) Representative traces of post-synaptic currents evoked in CA1 pyramidal neurons by stimulation of CA3 Schaffer collaterals in acute hippocampal slices from syt3 knockout mice and WT littermates. After recording AMPA receptor EPSCs at the measured Cl- reversal potential and GABA receptor IPSCs at the reversal potential for AMPA \& NMDA receptors, $100 \mu \mathrm{M}$ picrotoxin was perfused in order to record NMDA+AMPA receptor compound EPSCs at a holding potential of $+40 \mathrm{mV}$. The NMDA receptor EPSC was measured from the compound EPSC at $60 \mathrm{~ms}$ aftr the onset of the AMPA EPSC. (FH) Receptor ratios (mean $\pm \mathrm{SEM}$ ) at the CA3-CA1 synapse were unchanged in syt3 $\mathrm{KO}$ mice. Significance determined by Student's t-test $(n=9$ slices/neurons from 4 animals for wild-type, and 9 slices/neurons from 5 animals for syt3 knockout).

Most of the data for panels E-H were generated and analyzed by Noam Nitzan (MSc IMPRS Neuroscience Göttingen) under the supervision of Ankit Awasthi and the remaining by Ankit Awasthi. 


\subsection{Syt3 is necessary for AMPA induced synaptic AMPA receptor internalization}

\section{- Effect of syt3 on mEPSC amplitude and frequency}

Although syt3 is necessary for AMPA or NMDA induced internalization of GluA1-containing and GluA2-containing AMPA receptors (section 3.4 above), a further question remains: Is syt3 necessary for activity-dependent internalization of synaptic AMPA receptors? To test this, AMPA receptor mEPSCs were recorded by whole cell recordings at a holding potential of $-60 \mathrm{mV}$ in the presence of $1 \mu \mathrm{M}$ TTX and $100 \mu \mathrm{M}$ picrotoxin from syt3 knockout and wildtype littermate mouse hippocampal cultures. To test the effect of syt 3 on activity-dependent internalization of synaptic AMPA receptors, mEPSCs were recorded from neurons in basal conditions and after stimulation with $100 \mu \mathrm{M}$ AMPA, as in receptor internalization assays (section 3.4 above).

There was a statistically significant shift of the mEPSC amplitude distribution towards smaller amplitudes and a decrease in median amplitudes following stimulation (Figure 12A, F below). Overexpression of syt 3 caused a statistically significant increase in the fraction of events in the 5$10 \mathrm{pA}$ and 10-15 pA amplitude bins upon AMPA stimulation (Figure 12B), whereas such an increase was only observed in the 5-10 pA amplitude bin in control conditions, suggesting at least some of the GluA1- and GluA2-containing AMPA receptors internalized by syt3 in the receptor internalization assays are directly involved in synaptic transmission. However, the decrease in median mEPSC amplitude upon stimulation was not significantly enhanced upon post-synaptic syt3 overexpression (Figure 12F) indicating that some proportion of AMPA receptors internalized by syt3 are extra-synaptic.

Nevertheless, the shift in amplitude distribution and reduction in median amplitude was completely blocked in syt3 KO cultures (Figure 12C, F) and almost completely in WT cultures treated with $1 \mu \mathrm{M}$ Tat-GluA2-3Y peptide (the distribution slightly shifted to the left in Figure 12D although the median was not significantly different in Figure 12F). Preliminary data showed that the KO phenotype could be rescued by over-expressing syt3-GFP in syt3 KO cultures indicated by a leftward shift in the amplitude distribution and a decrease in median amplitude (Figure 12E, F). Thus, syt3 is necessary for the AMPA induced internalization of synaptic AMPA receptors. 
A

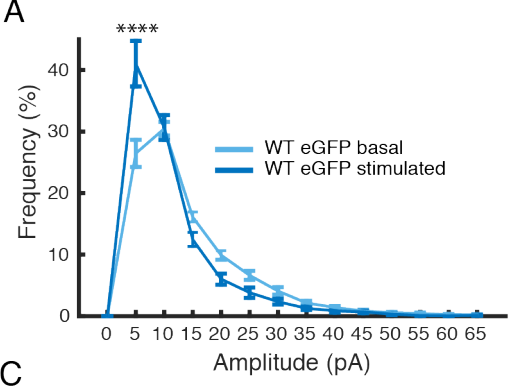

C

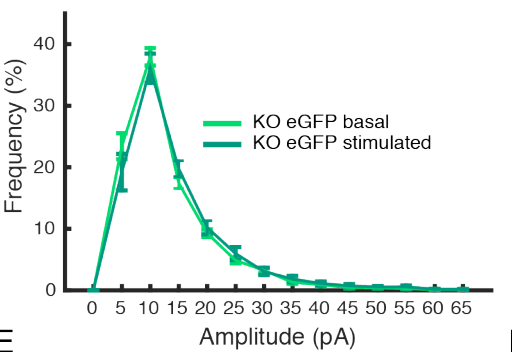

B
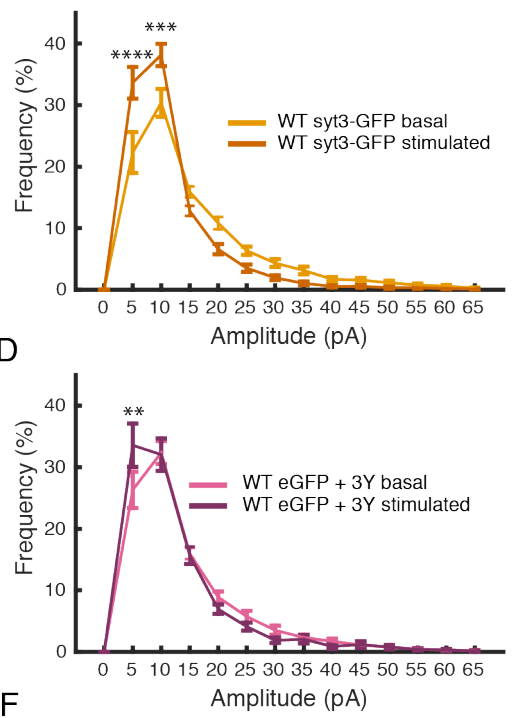
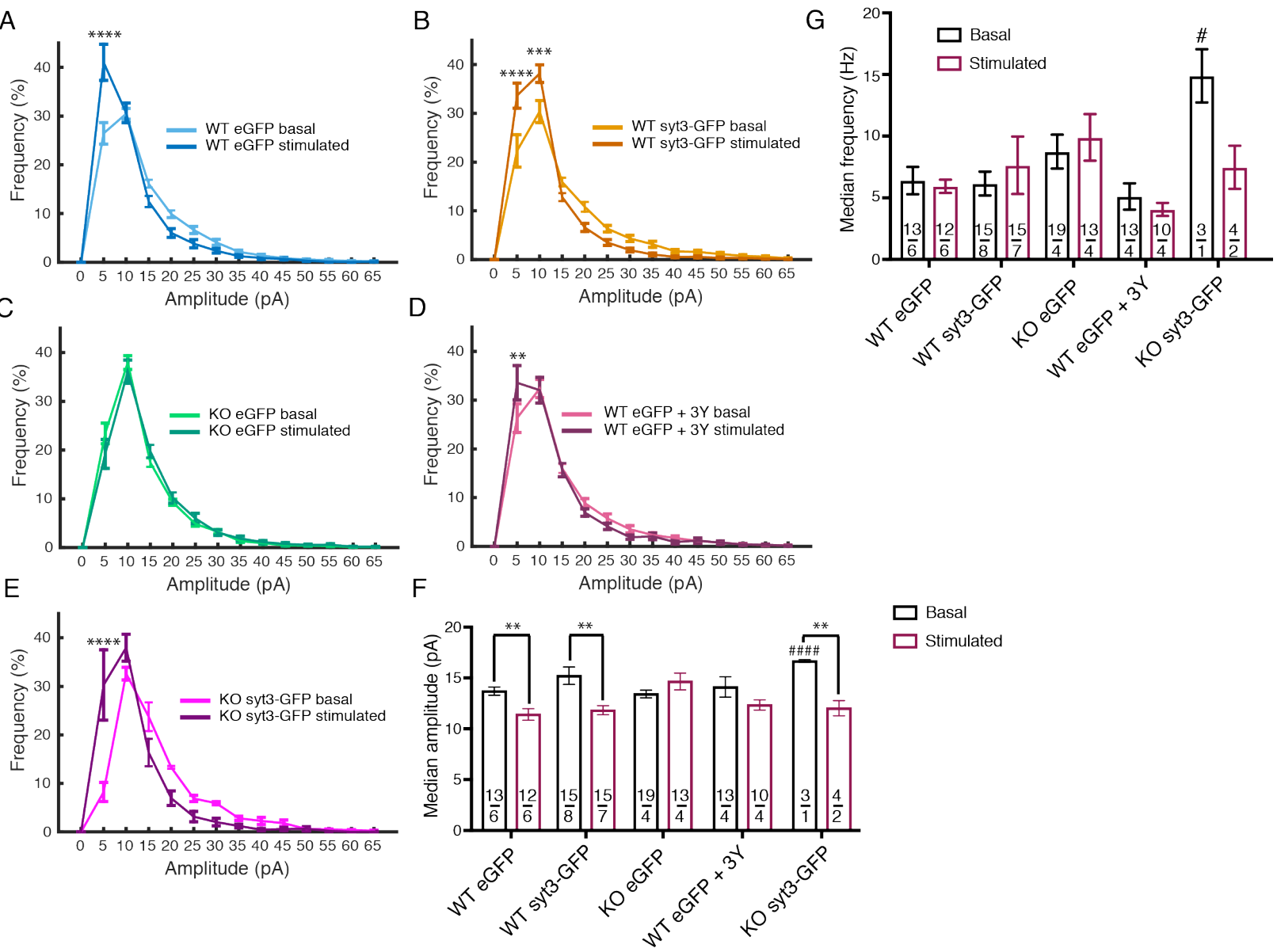

Figure 12: Syt3 is necessary for the AMPA induced internalization of synaptic AMPA receptors.

(A-D) Upon AMPA stimulation, the frequency distribution of AMPA receptor mEPSC amplitudes is shifted to smaller amplitudes in neurons from WT mouse P0 cultures transfected with EGFP (A) or syt3-GFP (B) but blocked in syt3 KO mouse P0 cultures transfected with EGFP (C) or in WT mouse P0 cultures treated with $1 \mu \mathrm{M}$ TatGluA2-3Y peptide (D). The shift of the distribution to smaller amplitudes could be rescued in syt3 KO cultures (E) by expressing syt3-GFP (preliminary dataset). Statistical significance in A-E was tested by 2-way ANOVA with Sidak's multiple comparisons test $(* *, \mathrm{p}<0.01 ; * * *, \mathrm{p}<0.001 ; * * * *, \mathrm{p}<0.01)$. (F) Quantitation of mEPSC amplitudes in panels A-E is shown as median \pm S.E. mean. Statistical significance measured by Student's t-tests between basal and stimulated conditions in each manipulation without assuming consistent standard deviations $(* *$, $\mathrm{p}<0.01$ ). Welch's t-tests between basal condition in each manipulation vs. WT EGFP basal (\#\#\#, p $<0.0001)$. (G) The median frequency of mEPSCs was unchanged. Statistical significance measured by Student's t-tests between basal and stimulated conditions in each manipulation. However, basal frequency in KO cultures transfected with syt3-GFP was higher than WT EGFP basal, WT syt3-GFP basal and WT EGFP+3Y but not syt3 KO EGFP basal conditions (\#, $\mathrm{p}<0.05$ student's t-test). $\mathrm{N}$ is shown as neurons/cultures in each bar graph. Amplitude bins higher than $70 \mathrm{pA}$ were excluded from analysis because they had an insignificant fraction of events.

Parts of the dataset were generated and analyzed by Alina Heukamp \& Tal Dankovich (MSc IMPRS Neuroscience, Göttingen) under the supervision of Ankit Awasthi and the remaining by Ankit Awasthi. 
Comparing all mEPSC amplitude distributions in basal conditions revealed a significantly larger number of events in the 10-15 pA bin in syt3 KO (2 way-ANOVA with tukey's multiple comparisons test: KO eGFP vs WT eGFP, $\mathrm{p}<0.0001$; vs WT syt3-GFP, $\mathrm{p}<0.0001$; vs WT eGFP + $3 \mathrm{Y}, \mathrm{p}=0.003$ ), an effect that was not evident in the mean mEPSC amplitude after syt3 knock down in rat dissociated hippocampal cultures (Figure 11C above) or receptor internalization assays (Figure 7, Figure 8, Figure 10). This suggests that syt3 might also be partly involved in the surface trafficking of AMPA receptors in resting conditions. However, the median mEPSC amplitude in all syt3 manipulations in basal conditions were not significantly different (One-way ANOVA with Dunnett's multiple comparisons test with WT eGFP basal, $p>0.29$ in all cases) indicating that this was not a substantial function of syt3 relative to its role in AMPA induced internalization of synaptic AMPA receptors.

Consistent with a predominantly post-synaptic function of syt 3 , there were no changes in $\mathrm{mEPSC}$ frequency, calculated as inverse of the median of the inter-event interval distribution. Expressing syt 3 in $\mathrm{KO}$ cultures gave rise to an almost $\sim 2$-fold higher frequency of mEPSCs, but this data is preliminary and therefore inconclusive.

\section{- Effect of syt3 on mEPSC decay kinetics}

Interestingly, there was a concomitant decrease in the mEPSC decay time (Figure 13 below) along with the decrease in mEPSC amplitudes upon AMPA stimulation. As GluA2-containing AMPA receptors have longer decay times (Liu \& Savtchouk, 2012), this shift could be explained by internalization of GluA2-containing AMPA receptors upon AMPA stimulation. The distribution of mEPSC decay time constant shifted to lower values (Figure 13A) and the median mEPSC decay time constant significantly decreased (by $\sim 1 \mathrm{msec}$ ) upon AMPA stimulation (Figure 13F).

Although the percentage of events in the $0-1 \mathrm{msec}$ bin upon AMPA stimulation was significantly less for overexpression of syt3 compared to control conditions, the median values were not significantly different (Figure 13F), which suggests that overexpression of syt3 only marginally supressed the internalization of GluA2 containing AMPA receptors. 
On the other hand, the AMPA induced decrease in mEPSC decay time was completely blocked in syt3 KO cultures (Figure 13C, F) or in WT cultures treated with $1 \mu \mathrm{M}$ Tat-GluA2-3Y peptide

A
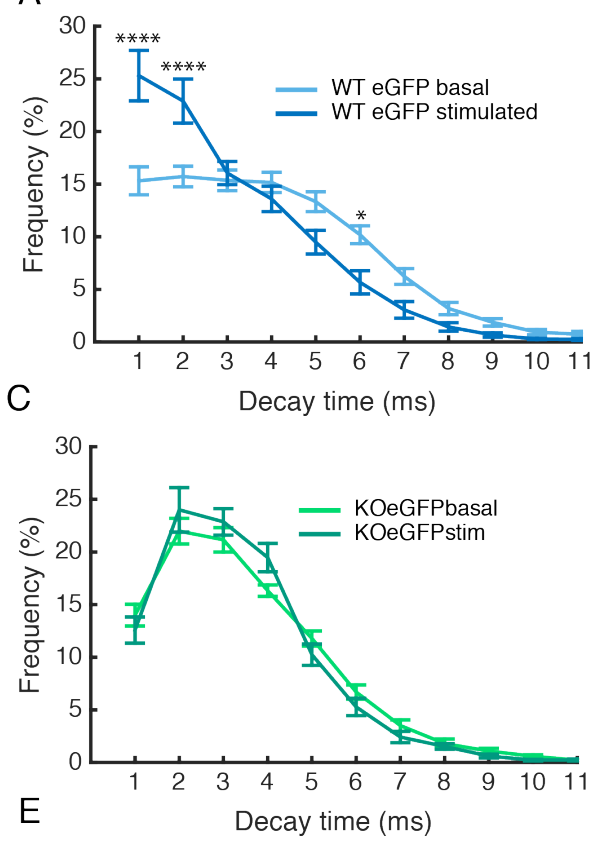

$\mathrm{E}$

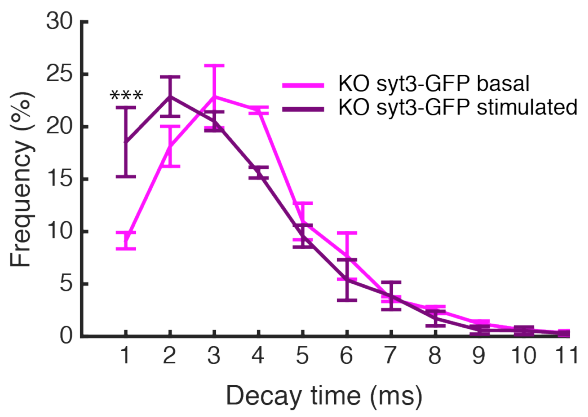

$\mathrm{B}$
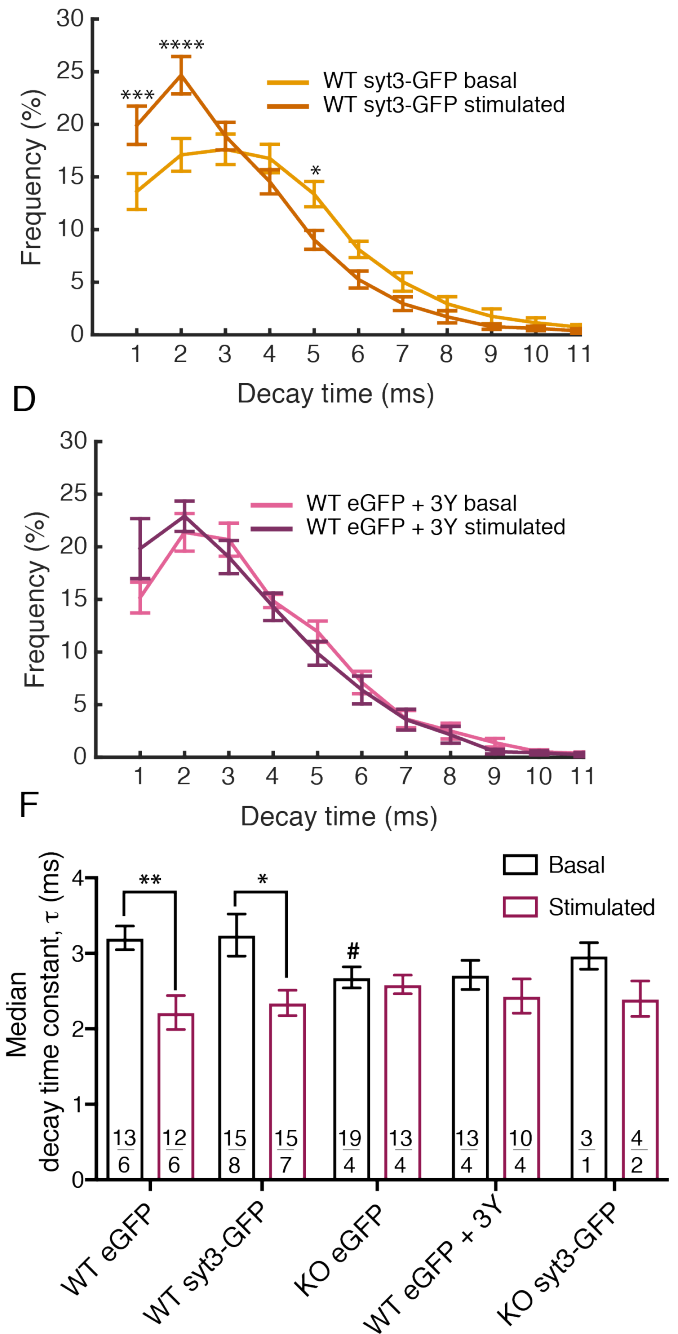

Figure 13: Syt3 is necessary for the AMPA stimulation induced decrease in mEPSC decay time

(A) Upon AMPA stimulation, the frequency distribution of AMPA receptor mEPSC decay time constant is shifted to smaller values in WT mouse neurons transfected with EGFP (A) or syt3-GFP (B) but blocked in syt3 KO mouse cultures transfected with EGFP (C) or in WT mouse P0 cultures treated with $1 \mu \mathrm{M}$ Tat-GluA2-3Y peptide (D). The shift of the distribution to smaller values could be rescued in KO cultures (E) by expressing syt3-GFP (preliminary dataset). Statistical significance in A-E was tested by 2-way ANOVA with Sidak's multiple comparisons test $\left(*, \mathrm{p}<0.05 ;{ }^{* * *}, \mathrm{p}<0.001 ; * * * *, \mathrm{p}<0.01\right)$. (F) Quantitation of median mEPSC decay time constant in panels A-E shown as median \pm S.E. mean. Statistical significance measured by Welch's t-tests between basal and stimulated conditions in each manipulation $(*, p<0.05 ; * *, p<0.01)$, and by Welch's t-tests between basal conditions in each manipulation vs. WT EGFP basal condition (\#, $<<0.05)$. N numbers are shown as neurons/ cultures in each bar graph. Decay time bins beyond $12 \mathrm{~ms}$ were excluded from analysis because they had an insignificant fraction of events.

Parts of the dataset were generated and analyzed by Alina Heukamp \& Tal Dankovich (MSc IMPRS Neuroscience, Göttingen) under the supervision of Ankit Awasthi and the remaining by Ankit Awasthi. 
(Figure 13D, F), in agreement with a complete lack of internalization of AMPA receptors (Figure 12C,D, F above). Preliminary data suggests this block could be partially rescued by expressing syt3-GFP in syt3 KO cultures (Figure 13E, F).

Comparing all mEPSC decay time constant distributions in basal conditions revealed a significant shift to smaller values in syt3 KO cultures or WT cultures treated with $1 \mu \mathrm{M}$ Tat-GluA2-3Y peptide compared to WT cultures transfected with EGFP or syt3-GFP (In the 1-2 ms bin, 2 way-ANOVA with Tukey's multiple comparisons test: KO eGFP vs WT eGFP, $\mathrm{p}<0.0001$; KO eGFP vs WT syt3-GFP, $\mathrm{p}<0.001$; WT eGFP + 3Y vs WT eGFP, p<0.001; WT eGFP + 3Y vs WT syt3-GFP, $\mathrm{p}<0.05$. In the 2-3 ms bin, 2 way-ANOVA with tukey's multiple comparisons test: KO eGFP vs WT eGFP, $\mathrm{p}<0.0001$; KO eGFP vs WT syt3-GFP, $<<0.05$; WT eGFP + 3Y vs WT eGFP, $<<0.01$. In the 5-6 ms bin, KO eGFP vs WT eGFP, $\mathrm{p}<0.05$ ). Additionally, the median mEPSC decay time constant of syt3 $\mathrm{KO}$ cultures in basal conditions was significantly reduced in comparison with controls $(\mathrm{p}<0.05)$. This effect, which was not evident in the mean mEPSC decay time after syt3 knock down in rat hippocampal cultures (section 3.5 above), could be due to less GluA2containing surface AMPA receptors in syt3 $\mathrm{KO}$ neurons, but this finding was not examined further.

\subsection{Syt3 mediates LTP decay after induction}

Because syt3 mediates activity-dependent internalization of AMPA receptors in dissociated hippocampal cultures, we hypothesized that synaptic plasticity in syt3 knockout mice may be affected.

Strong-LTP, induced by high frequency stimulation (three $1 \mathrm{~s} 100 \mathrm{~Hz}$ stimulation trains separated by $10 \mathrm{~min}$ ) in the Schaffer collateral pathway, was unchanged in syt3 knockout mouse hippocampal slices (Figure 14A below). However, weak-LTP, induced by a weaker stimulation (16 pulses at $100 \mathrm{~Hz}$ ), decayed in WT slices over the course of 1 hour but remained reinforced in syt3 KO slices for at least 4 hours (Figure 14B, D below). The decay of weak-LTP depends on activity dependent GluA2-AMPA receptor internalization via the C-terminal 3Y motif of GluA2, since competitive inhibition of this machinery via injection of the Tat-GluA2-3Y peptide into the dorsal hippocampus of rats blocked the decay of weak-LTP (Z. Dong et al., 2015). We found the 
same effect of weak-LTP reinforcement by the GluA2-3Y peptide in acute mouse hippocampal slices (Figure 14C below). This result concurs with previous results showing that the GluA2-3Y peptide blocks AMPA or NMDA induced internalization of GluA1-containing and GluA2containing AMPA receptors (Figure 10 above) and AMPA induced internalization of synaptic AMPA receptors (Figure 12D,F and Figure 13D,F above).

A

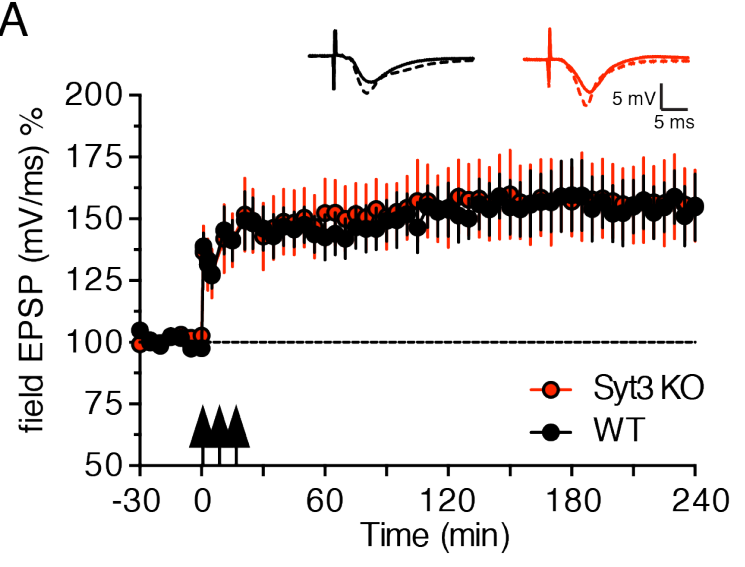

C

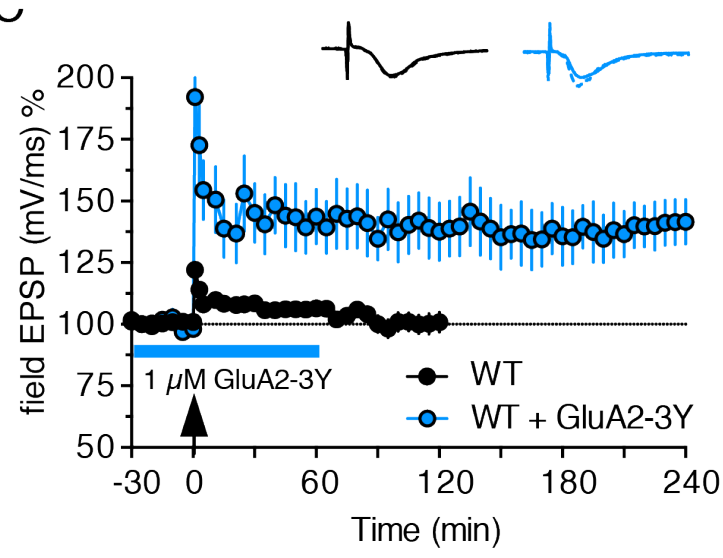

B

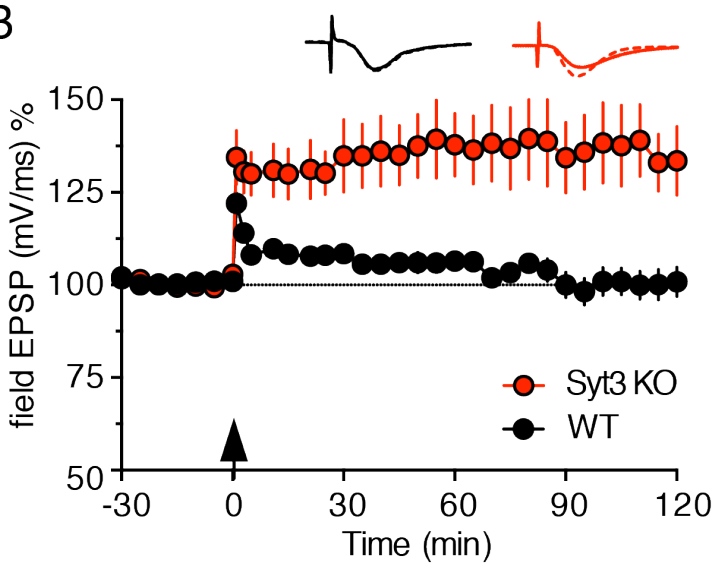

$\mathrm{D}$

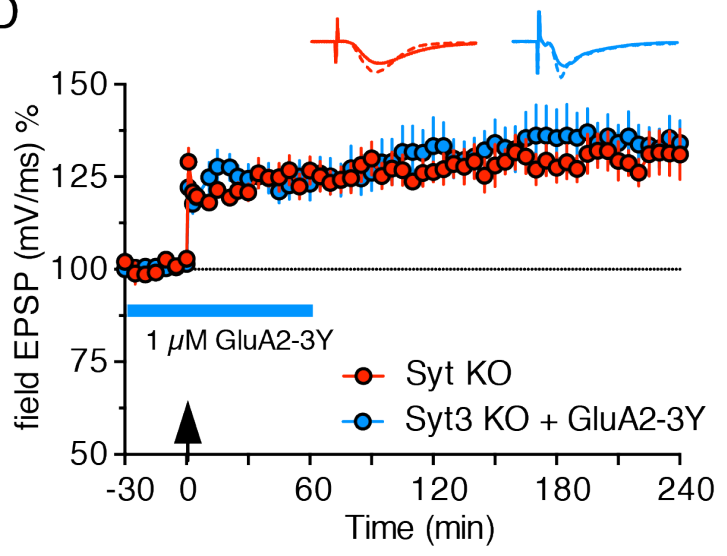

Figure 14: Weak-LTP is strongly reinforced in syt3 KO hippocampal slices

(A) Time course of field excitatory post-synaptic potentials (fEPSP) slope recorded from the stratum radiatum of acute hippocampal slices from wild-type and syt3 KO mice. Strong-LTP was induced by 3 trains of $100 \mathrm{~Hz}, 1 \mathrm{sec}$ stimulation separated by 10 minutes $(\mathrm{n}=6 \mathrm{WT}, 6 \mathrm{KO})$. Strong LTP is unaffected in syt3 KO slices. (B) Time course of fEPSP slope from WT and syt3 KO mouse hippocampal slices upon induction of weak-LTP by 1 train of $100 \mathrm{~Hz}$, 160 msec stimulation ( $\mathrm{n}=10 \mathrm{WT}, 11 \mathrm{KO}$ ). Weak LTP is reinforced in syt3 KO slices. (C) Effect of $1 \mu \mathrm{M}$ TatGluA2-3Y peptide on weak-LTP recorded from WT mouse hippocampal slices upon induction with 1 train of $100 \mathrm{~Hz}, 160 \mathrm{msec}$ stimulation (n=9 WT, $7 \mathrm{WT}+$ Tat-GluA2-3Y). The GluA2-3Y peptide strongly reinforces weak LTP. (D) Effect of $1 \mu \mathrm{M}$ Tat-GluA2 3 Y peptide on weak-LTP recorded from syt3 KO mouse hippocampal slices upon induction with 1 train of $100 \mathrm{~Hz}, 160 \mathrm{msec}$ stimulation ( $\mathrm{n}=6 \mathrm{KO}, 7 \mathrm{KO}+$ Tat-GluA2-3Y). The effect of the GluA2-3Y peptide is occluded in syt3 KO slices.

This experiment was performed by Dr. Binu Ramachandran (ENI Göttingen). 
As syt3 pulled down GluA2, AP2 and BRAG2 (Figure 5B above) and is necessary for activity dependent AMPA receptor internalization (section 3.4 and 3.6 above), it appears that syt3 is part of the internalization machinery which is inhibited by the GluA2-3Y peptide. The extent of mechanistic overlap between knocking out syt3 and applying the GluA2-3Y peptide was tested. In terms of reinforcement of weak-LTP, knocking out syt3 completely occluded the effect of the GluA2-3Y peptide (Figure 14D above).

The "3Y" mechanism behind the decay of strong or weak-LTP (which mediates activity dependent internalization of AMPA receptors and is inhibited by the GluA2-3Y peptide) is also inhibited by an atypical protein kinase $\mathrm{C}$ isoform called Protein kinase $\mathrm{C}$ isoform zeta, or PKM $\zeta$ (Z. Dong et al., 2015). Bath application of $1 \mu \mathrm{M}$ ZIP (Zeta inhibitory peptide, a membrane permeable peptide whose sequence matches the consensus sequence of the regulatory domain of protein kinase $\mathrm{C}$ and therefore inhibits its catalytic domain) 1 hour after LTP induction can lead to decay of strong-LTP, which otherwise persists for hours (Serrano, Yao, \& Sacktor, 2005; Yao et al., 2008). The GluA2$3 \mathrm{Y}$ peptide prevents the ZIP mediated decay of strong-LTP indicating that the $3 \mathrm{Y}$ internalization machinery is necessary for decay of strong-LTP. However, the 3Y internalization machinery does not seem to be active throughout the persistent phase of LTP because application of the GluA2$3 Y$ peptide alone an hour after strong-LTP induction does not cause an increase in potentiation (Z. Dong et al., 2015). As GluA2-3Y renders strong-LTP insensitive to ZIP, the effect of ZIP in the maintenance phase of strong-LTP in syt3 KO slices was tested.

Although ZIP caused decay of strong-LTP at the CA3-CA1 synapse in WT mouse acute hippocampal slices (Figure 15A below), this decay was blocked in syt3 KO slices supporting our hypothesis (Figure 15B). Extending the results from Z. Dong et al., 2015, who showed that the GluA2-3Y peptide renders strong-LTP insensitive to ZIP, weak-LTP reinforced by the GluA2-3Y peptide in WT hippocampal slices was also found to be insensitive to ZIP (Figure 15C). Confirming the necessity of syt3 in the $3 \mathrm{Y}$ machinery, weak-LTP in syt3 KO mice was also found to be insensitive to ZIP (Figure 15D).

All experiments in Figure 14 and Figure 15 were performed by Dr. Binu Ramachandran (ENI Göttingen). 
A

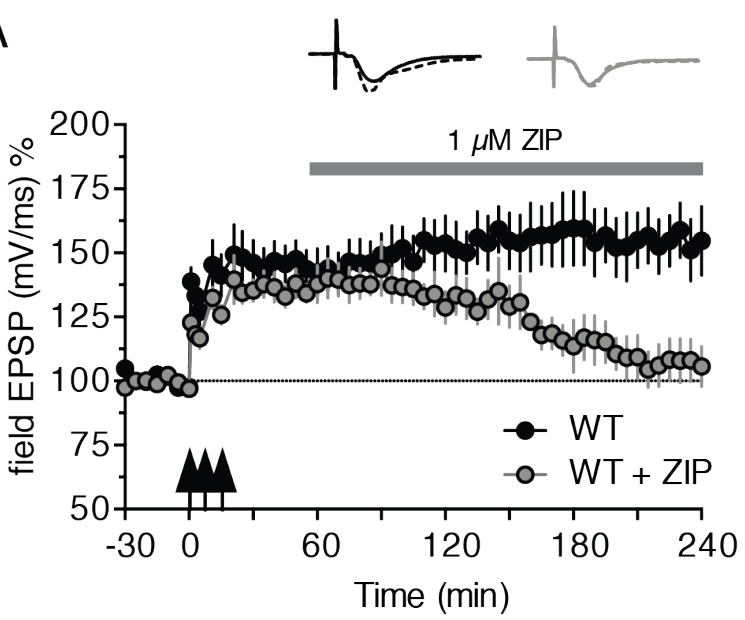

C

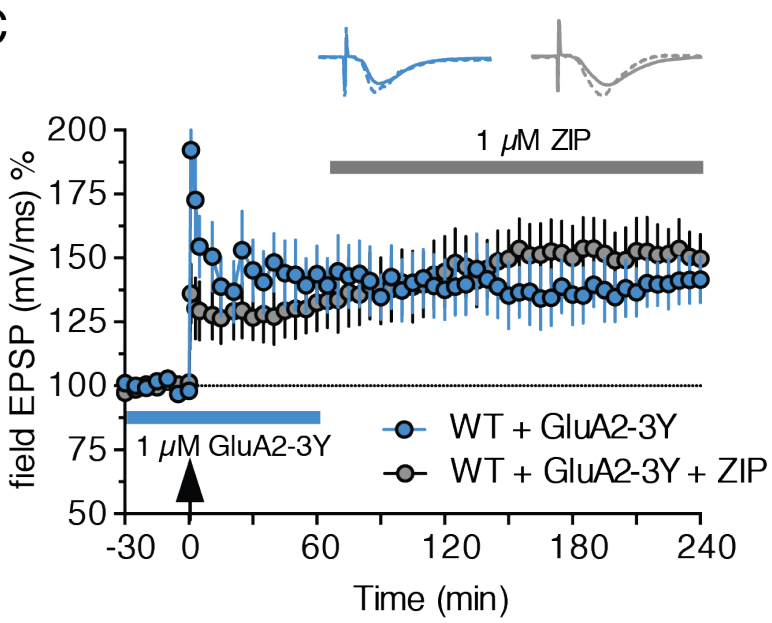

B
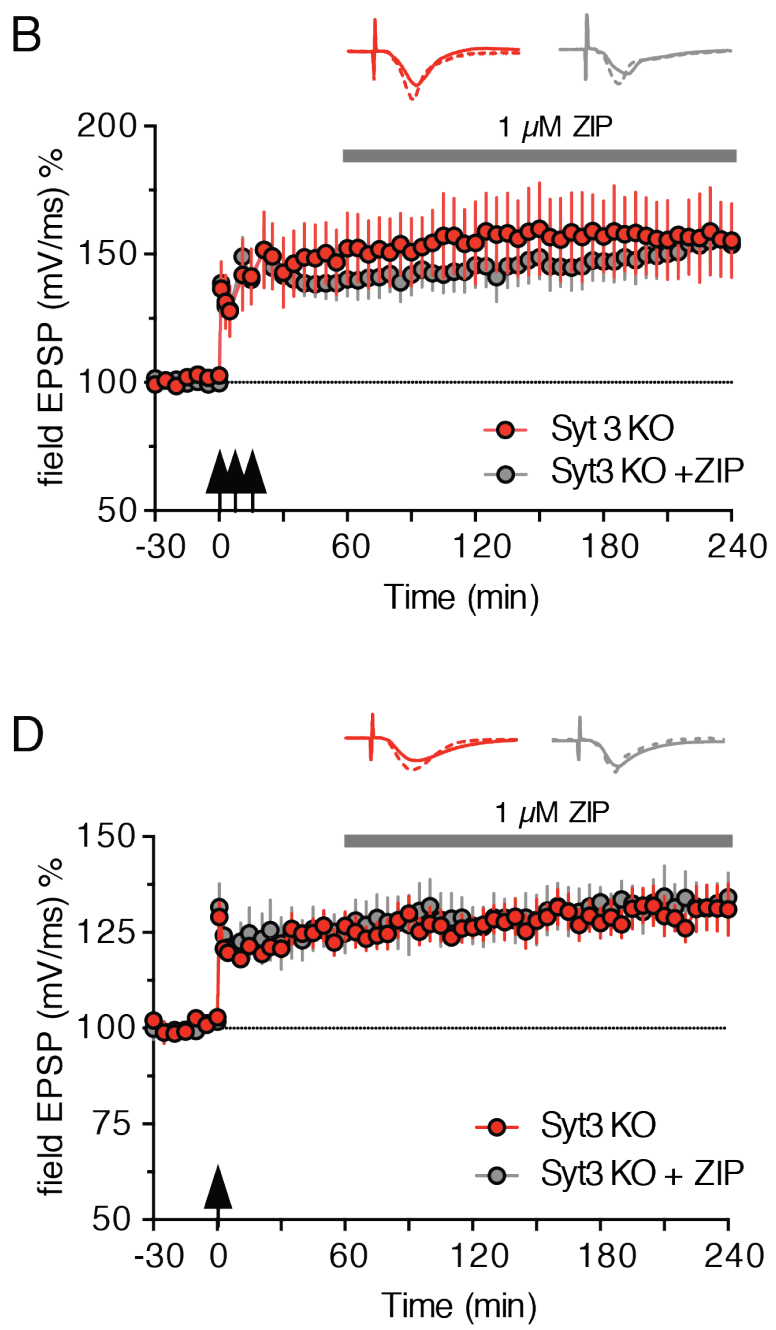

Figure 15: ZIP mediated decay of LTP is blocked in the syt3 KO mice

(A) Time course of fEPSP slope from the CA3-CA1 synapse of WT hippocampal slices upon induction of strongLTP. Application of $1 \mu \mathrm{M}$ ZIP (Zeta inhibitory peptide) 1 hour after LTP induction leads to decay of strong-LTP. (n=6 WT, $6 \mathrm{WT}+\mathrm{ZIP})$. (B) Time course of fEPSP slope from the CA3-CA1 synapse of syt3 KO hippocampal slices upon induction of strong-LTP. Application of $1 \mu \mathrm{M}$ ZIP 1 hour after LTP induction does not lead to decay of strongLTP. ( $\mathrm{n}=6 \mathrm{KO}, 6 \mathrm{KO}+\mathrm{ZIP}$ ). (C) Time course of fEPSP slope from the CA3-CA1 synapse of WT hippocampal slices upon induction of weak-LTP. Application of $1 \mu \mathrm{M}$ ZIP 1 hour after LTP induction does not lead to decay of Tat-GluA2-3Y reinforced weak-LTP (n=7 WT, 7 WT+ZIP). (D) Time course of fEPSP slope from the CA3-CA1 synapse of syt3KO hippocampal slices upon induction of weak-LTP. Application of $1 \mu \mathrm{M}$ ZIP 1 hour after LTP induction does not lead to decay of Tat-GluA2-3Y reinforced weak-LTP (n=6 KO, $6 \mathrm{KO}+\mathrm{ZIP})$.

This experiment was performed by Dr. Binu Ramachandran (ENI Göttingen). 


\subsection{Syt3 KO mice show normal learning but impaired forgetting}

As syt3 is a necessary component of the $3 \mathrm{Y}$ machinery and hence, necessary for the activity dependent internalization of AMPA receptors and synaptic depression, the effect of syt 3 in decay of memories, forgetting, was tested. As weak-LTP at the CA3-CA1 synapse in the hippocampus was reinforced into strong-LTP in syt3 $\mathrm{KO}$ mice in vitro, we also tested if short-term memory was reinforced into long-term memory or if the syt $3 \mathrm{KO}$ mouse could learn tasks better than WT mice, or if older memories interfered with expression of a newer memory.

\section{- Syt3 KO mice show no anxiety, hyperactivity or impairments in recognition memory}

Syt3 KO mice were tested on standard behavioural tests including the open field and elevated plus maze to test for anxiolytic behaviour. The exploration pattern of the elevated plus maze and the open field indicated that syt3 KO mice have normal anxiety (Figure 16A, D). Syt3 KO mice weigh less than their WT littermates (Figure 16B). Syt3 KO mice did not show any hyperactivity (Figure 16D). Thus, anxiety or hyperactivity cannot be confounding factors for the spatial memory and fear memory tests conducted on the syt3 $\mathrm{KO}$ mice.

The novel object recognition task, which is a visual recognition task, involves the perirhinal cortex (S. Griffiths et al., 2008). Short-term novel object recognition memory, recalled 12 min after habituation to objects was not improved in syt3 KO mice (Figure 16E). We then tested short-term and long-term memory in a hippocampal task of spatial exploration. GluA1 knockout mice showed impaired short term memory but enhanced long-term memory in this task, indicating it can be used to study both kinds of memory (D. J. Sanderson et al., 2009). However, both short-term and longterm spatial recognition memory were unchanged in the syt3 KO mouse (Figure 16F). The task was perhaps not optimized enough to test long-term memory because WT mice showed a discrimination ratio of only 0.5 . Thus, we tested syt $3 \mathrm{KO}$ mice in other hippocampal dependent tasks. 
A

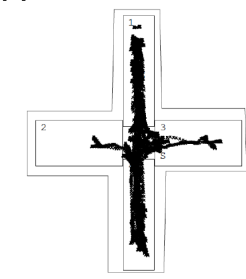

C

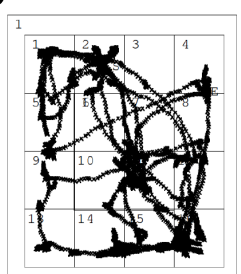

E

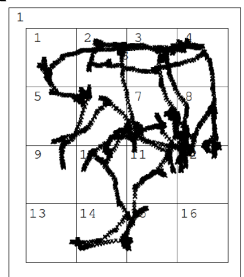

$\mathrm{F}$
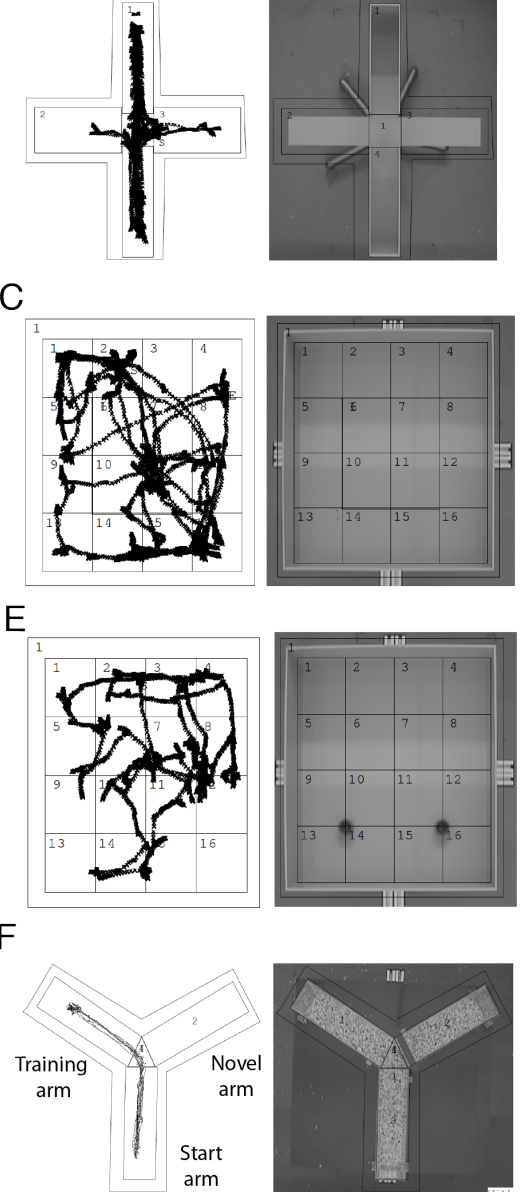
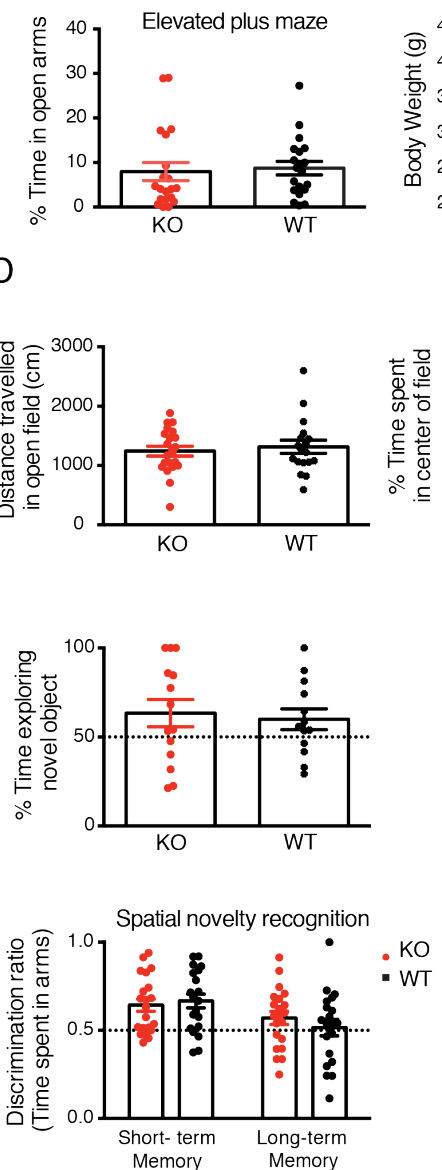

$\mathrm{D}$

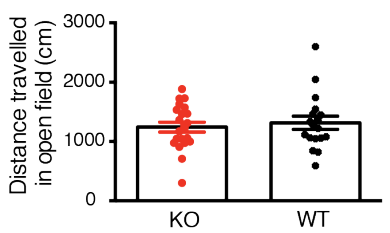

Memory Mery
B
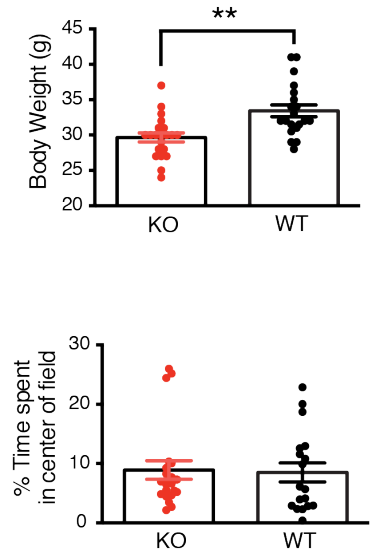

\section{Figure 16: Syt3 KO mice show no abnormalities in anxiety, hyperactivity or spatial memory}

(A) Syt3 KO mice show normal anxiety in the elevated plus maze. (Left) Video tracking results of a typical trial, where the position of the mouse in every frame is shown as a black cross. Mice typically avoid open spaces like the open arms. (Middle) A single frame from the video camera. The open arms are the horizontal arms. (Right) Syt3 KO mice spend the same \% time in open arms as WT mice, indicating no anxiolytic behaviour ( $\mathrm{n}=20 \mathrm{WT}$, $20 \mathrm{KO}$ ). (B) Syt3 KO mice are smaller and weigh lesser on average ( $\mathrm{n}=20 \mathrm{WT}, 21 \mathrm{KO}$ ). (C) Syt3 KO mice show normal anxiety in the open field test. (Left) Video tracking results of a single trial, where the position of the mouse in every frame is shown as a black cross. Mice typically avoid open spaces like the 4 central squares away from the walls. (Right) A single frame from the video camera. Mice typically avoid the 4 central squares out of the 16 squares. (D) (Left) Syt3 KO mice walk the same distance as WT mice, indicating no hyperactivity. (Right) Syt3 $\mathrm{KO}$ mice spend the same \% time in the central 4 squares of the open field as WT mice, indicating no anxiolytic behaviour ( $\mathrm{n}=20 \mathrm{WT}, 21 \mathrm{KO}$ ). (E) (Left) Video tracking results of a typical trial, where the position of the mouse in every frame is shown as a black cross. Mice habituated to the open field explore objects (in this case, two identical bottle caps placed upside down) by cautiously approaching them and sniffing or touching them with their whiskers or poking their nose into cavities. Each approach can be distinctly seen. (Middle) A single frame from the video camera. (Right) Syt3 KO mice spent the same time exploring the novel object as WT mice, indicating no differences in short term ( 12 min) novel object recognition memory (n=13 WT, 14 KO). (F) (Left) Video tracking results of a typical training trial, where the entry into the novel arm is blocked. The position of the mouse in every frame is shown as a black cross. Mice explore the training arms and associate them with the extrinsic spatial cues. (Middle) A single frame from the video camera. (Right) Syt3 KO mice showed similar recognition of the novel arm as WT mice, indicating no differences in spatial recognition memory $(\mathrm{n}=20 \mathrm{WT}, 21 \mathrm{KO})$. 


\section{- Syt3KO mice can acquire short-term and long-term fear memories}

Contextual fear conditioning is a widely-used memory test based on Pavlovian conditioning. Mice are trained to fear a certain environment (context) by giving them a mild electric shock in it. The context entails a conditioned stimulus (CS), in this case the Skinner box with electric grating, specific lighting conditions, auditory stimulus of white noise presented throughout the task, specific shape and texture of walls and the faint smell of ethanol that all surfaces were cleaned with before every trial. Fear conditioning is known to give rise to robust memories with a single training session. During a training session, mice habituate to an innocuous context and form a sensory representation. The shock presented at the end of the training trial entails the unconditioned stimulus (US) which evokes hard-wired escape responses in the animals. Mice associate a previously innocuous CS with a US, such that when they are exposed to the CS at a later time point, they exhibit fear memory induced freezing behaviour, or conditioned response (CR), wherein mice do not show any movements except breathing.

A

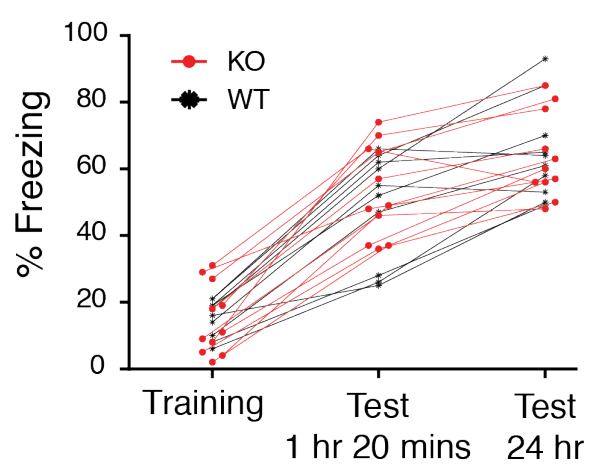

B

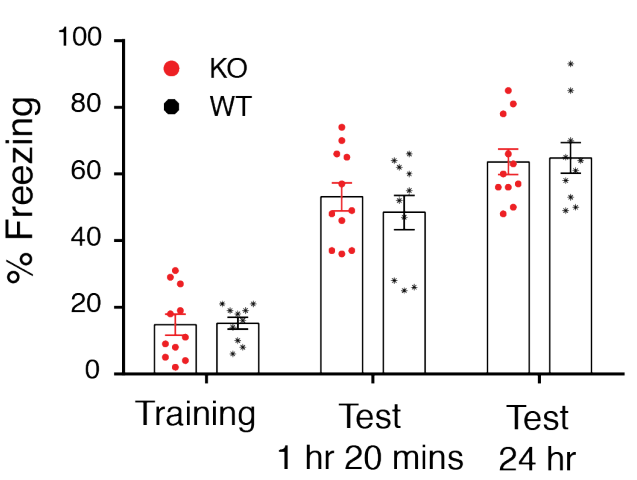

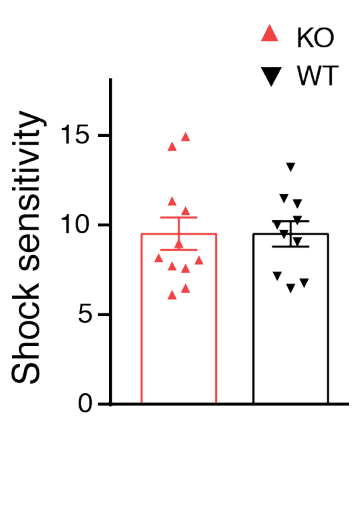

Figure 17: Syt3 KO mice consolidate short-term and long-term memories in contextual fear conditioning as well as WT mice

(A) (Left) Quantitation of freezing behaviour of individual mice from a single naive cohort over the course of training with a $0.7 \mathrm{~mA}$ shock, memory recall after $1 \mathrm{hr} 20$ mins and a subsequent recall 24 hours later. All mice show robust increases in freezing during both tests indicating acquisition of contextual fear memories. (Right) Summary data from left panel, shown as mean \pm SEM. \% freezing time, an indicator of fear memory, was not significantly different in syt3 KO mouse compared to WT mice in both the short-term and long-term memory test. (B) Although syt3 KO mice were smaller, their response to shock was not different compared to WT mice, suggesting their sensory perception of the shock was similar to WTs. This makes the $\%$ freezing values comparable between syt3 KO and WT mice (n= 11 WT, $10 \mathrm{KO})$. 
Syt3 KO mice consolidated short-term and long-term fear memories to the same extent as wildtype mice, as indicated by a test $1 \mathrm{hr} 20 \mathrm{~min}$ after training and 24 hours after training, respectively (Figure 17A). Although syt3 KO mice were smaller in size, their shock sensitivity (average increase in motion index in response to the shock relative to habituation period before shock) was not different in comparison to WT mice (Figure 17B), indicating their smaller size did not confound the acquisition of fear memory. Thus, syt3 KO mice can consolidate memories as well as WT mice, in agreement with normal strong-LTP at the CA3-CA1 synapse (Figure 14 above).

The syt3KO mice were next tested for impairments in forgetting in the Morris water maze, which is a hippocampus dependent spatial memory task (M. Gallagher et al., 2015; C.V. Vorhees et al., 2006).

\subsection{Syt3 KO mice acquire a spatial memory normally in the reference memory watermaze but persevere to the original platform position after reversal}

\section{- Syt3 KO mice learn as well as or better than WT mice}

In the reference watermaze task, originally described by Prof. Richard Morris in 1981, mice learn to swim to a hidden platform in a circular pool filled with opaque cold water using extrinsic spatial cues to develop allocentric strategies of navigation (Figure 18A below). Each of the 4 training trials each day ends with the mouse standing on the platform for 15 seconds, irrespective of whether the mouse finds or doesn't find the platform (Figure 18B). On day 1, mice are stressed because of the new environment and swim around the perimeter of the pool looking for possible escape. Such 'wall hugging' behaviour is called thigmotaxis and rapidly decays over the first 2-3 days of training. As the mice gradually learn that reaching the platform means escape from the cold water to the comfort of the home cage, their search paths evolve into more spatially specific and focussed ones (Figure 18C). To test spatial memory after $\sim 6-10$ days of training when escape latency has plateaued, probe tests are performed where mice swim in the pool in the absence of the platform for 60 seconds. Probe tests are usually performed at least 24 hours after the last training session to ensure mice are recalling long-term memory during the test. Spending more than $25 \%$ of the total time in the quadrant with the target platform is considered to be an indication of consolidated spatial memory. 
A

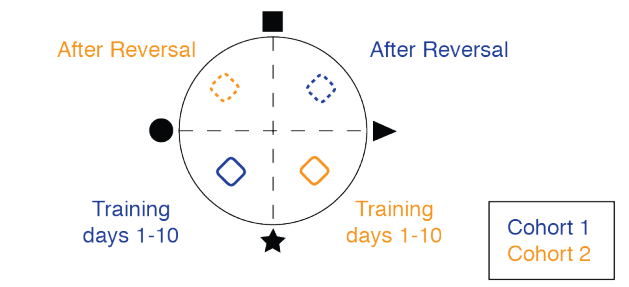

C

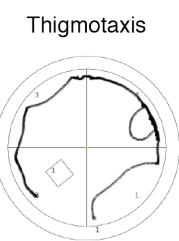

Day 1

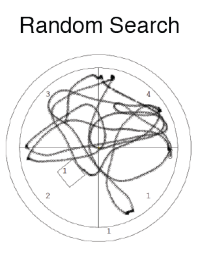

Day 3

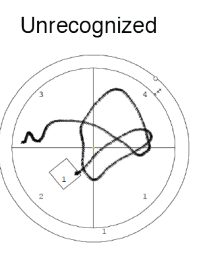

Day 5

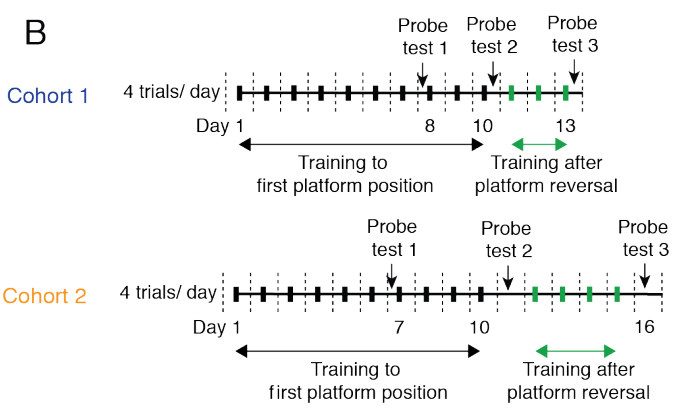

D

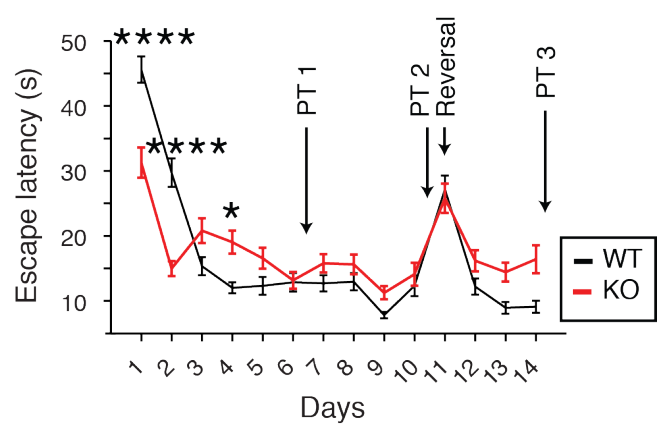

$\mathrm{F}$
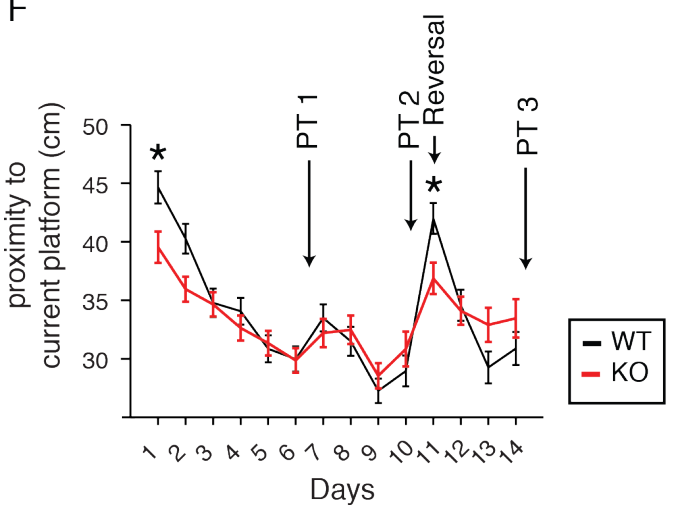

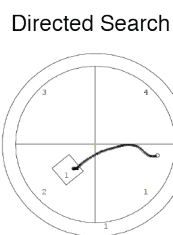

Day 7

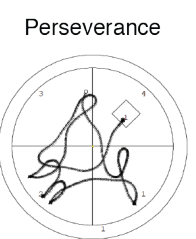

Day 11

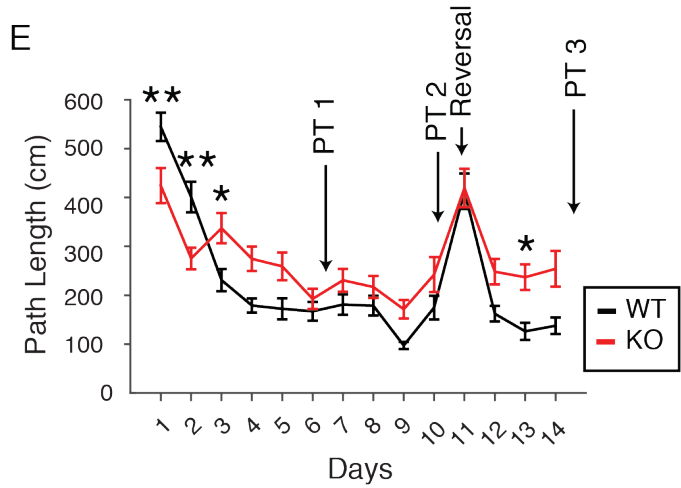

$\mathrm{G}$

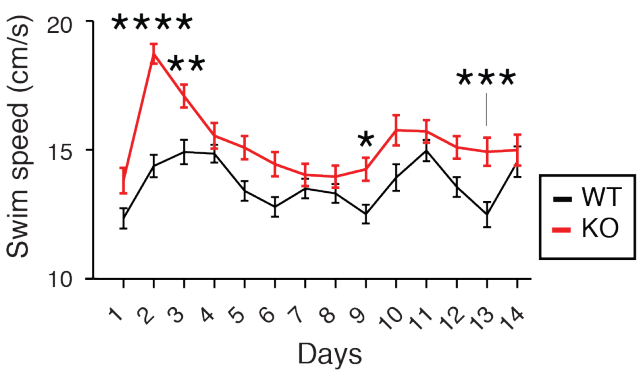

Figure 18: Syt3 KO mice learn the platform position better than or as well as WT mice, both before and after platform reversal in the reference memory watermaze task.

(A) Layout of the four extrinsic spatial cues around the pool and the platform positions before and after reversal. (B) Time course of training protocol. Solid boxes are training trials and dotted lines represent the boundaries of training days. (C) Video tracked typical single mouse trials across training days. (D-G) Time course of escape latency (D), path length (E), proximity to current platform (F) and swimming speed over training days (G) for pooled cohort data (mean \pm SEM), $n=24$ WT and $22 \mathrm{KO}$ (cohort 1: $\mathrm{n}=10 \mathrm{WT}, 9 \mathrm{KO}$; cohort 2: $\mathrm{n}=14 \mathrm{WT}, 13$ syt3 $\mathrm{KO})$. Statisitcal significance tested by 2-way ANOVA with Bonferroni's multiple comparisons test $\left({ }^{*}, \mathrm{p}<0.05\right.$; **, $\mathrm{p}<0.01 ; * * *, \mathrm{p}<0.001 ; * * * *, \mathrm{p}<0.0001)$. 
The escape latency, or time taken to reach the platform has been the most commonly used parameter to evaluate performance in training trials. However, this parameter doesn't take into account the spatial specificity of the search path. For instance, PSD-95 KO mice (Migaud et al., 1998) or rats with hippocampal lesions (Gallagher et al., 2015) have severe deficits in memory acquisition but manage to learn the distance of the platform from the wall and circle the pool in an annulus and therefore, manage to keep their escape latencies low. Thus, proximity, or the average distance of the search path from the center of the platform, is a better indicator of performance as it is based on spatial specificity of search (Maei et al., 2009).
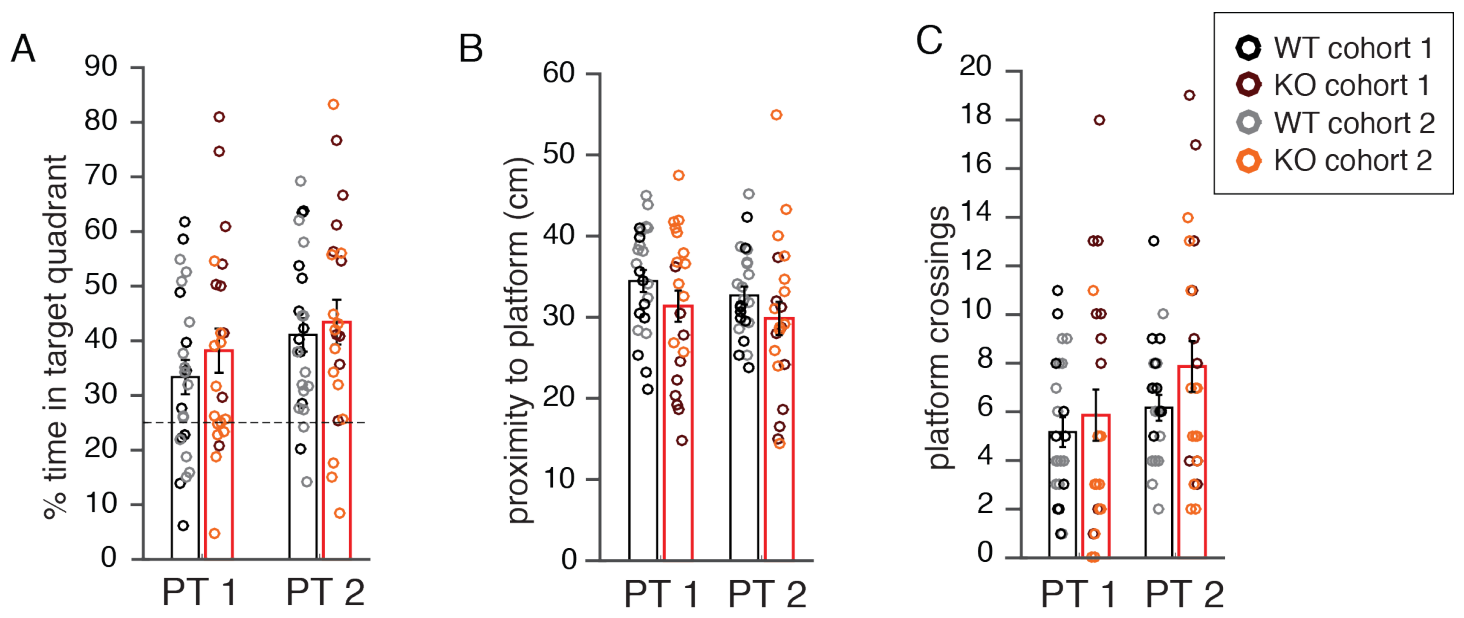

Figure 19: Syt3 KO mice perform better or as well as WT mice in reference watermaze probe tests.

(A-C) Cohort-wise quantitation of performance (mean \pm SEM) in probe tests 1-2 using $\%$ time in target quadrant (A), proximity to target platform (B) and Number of crossings of target platform (C). n=24 WT and $22 \mathrm{KO}$ (cohort 1: $\mathrm{n}=10 \mathrm{WT}, 9 \mathrm{KO}$; cohort 2: $\mathrm{n}=14 \mathrm{WT}, 13$ syt3 KO). Statistical significance tested by Welch's t-test for A and B, Mann-whitney's U-test for C.

Syt3 KO mice seem to perform much better than WT mice on days 1-2, indicated by significantly shorter escape latencies and path lengths and smaller proximities (Figure 18D-F) but this is most likely because of a highly reduced thigmotactic behaviour, clearly evident from strategy analysis (Appendix Figure 6 on page 148) and the occupancy plots in both cohorts (Appendix Figure 1 on page 143 and Appendix Figure 2 on page 144). Therefore, although syt3 KO mice exhibited no anxiolytic behaviour in the elevated plus maze or open field maze (Figure 16A,C,D above), they show what appears to be anxiolytic behavior in the watermaze. 
Over training days 3-10, the syt3 KO mice (in cohort 2 but not cohort 1) adopted a scanning strategy to a much larger extent than WT mice, but this gradually decreased over time (from $50 \%$ more syt $3 \mathrm{KO}$ scanning trials on day 3 to $\sim 20 \%$ on average till the end of the task for cohort 2 , Appendix Figure 6 on page 148) accompanied by a stabilization of swimming speeds (from $\sim 18 \mathrm{~cm} / \mathrm{sec}$ on day 3 for syt3 $\mathrm{KO}$ to $\sim 15 \mathrm{~cm} / \mathrm{sec}$ on average till the end of the task, Figure $18 \mathrm{G}$ above). Syt3 KO mice were not chaining, as might be expected in the case of a major hippocampal or spatial memory acquisition deficit throughout the training days (Appendix Figure 6 on page 148). The scanning strategy is not as spatially specific as the focal search and directed search strategies. However, the proximity to the platform of syt3 KO mice was identical to WT mice (Figure 18F). Also, there were no major differences in the adoption of the spatially specific search strategies, like directed search, focal search and direct swimming (Appendix Figure 6 on page 148). Most importantly, the performance of syt $3 \mathrm{KO}$ mice in probe test 1 and probe test 2 (Figure 19 above) was as good as, or in some cases better than WT mice.

Probe test performance is considered to be a robust indicator of spatial memory. Two probe tests (PT1 and PT2) were performed to monitor the rate of memory consolidation. Pooled data from both cohorts indicated that syt3 KO mice had acquired a spatially specific search in PT1 and PT2 to the first platform position. However, cohort 1 performed significantly better in PT1, indicating faster learning. This could be an effect of the reinforced weak-LTP we observed in syt3 KO hippocampal slices. The \% time spent on the platform was significantly higher in syt3 KO mice (Student's t-test, $\mathrm{p}=0.049$ ), proximity to platform was significantly lower in syt3 KO mice (Student's t-test, $\mathrm{p}=0.027$ ) and the $\%$ time spent in target quadrant was higher but not statistically significant in syt3 KO mice (Student's t-test, $\mathrm{p}=0.057$ ). In cohort 2 , the $\%$ time spent on the platform was higher and close to significant (Student's t-test, $\mathrm{p}=0.084$ ). The individual search paths of syt3 KO mice also appeared spatially more focussed compared to WT mice upon visual inspection in PT 1 (Appendix Figure 3 on page 145). Thus, syt3 KO mice can acquire spatial memories at least as well as WT mice. These results are in agreement with normal strong-LTP in syt3 KO acute hippocampal slices (Figure 14A above). 


\section{- Syt3 KO mice lack within-trial extinction in probe tests}

The retrieval of a fear memory is known to temporarily destabilize the memory via NMDA receptor-dependent internalization of GluA2-containing AMPA receptors (Figure 4E,F, from I. Hong et al., 2013). A similar destabilization of spatial memory is known to happen during the course of a probe test. The proximity to the platform is known to reach a minimum during the 10$20 \mathrm{sec}$ time bin of a $60 \mathrm{sec}$ probe test while the crossings of the platform reach a maximum during the same time, i.e., WT mice successfully retrieve the spatial memory. However, a 'within-trial' extinction is seen over the course of the remainder of the probe test, indicated by a gradual increase in proximity (Maei et al., 2009), perhaps because of destabilization of the memory mediated by GluA2-containing AMPA receptor internalization. As expected, WT mice showed within-trial extinction during PT 1 and PT2, however, syt3 KO mice lacked within-trial extinction. This effect is visible in the occupancy plots for PT 1 and PT 2 (Figure 20A, C below) but quantitation of proximities indicated a statistically significant lack of extinction in syt3 KO mice only in the last time bin of PT 2 (Figure 20B, D below).

\section{- An older memory doesn't interfere with acquisition of a newer one in syt3 KO mice}

Injection of the GluA2-3Y peptide in the dorsal hippocampus did not cause 'proactive interference', i.e., acquisition of an object location memory did not interfere with acquisition of a new object location memory in the same context (Migues et al, 2016). The acquisition of a new hidden platform spatial memory was tested in the syt3 $\mathrm{KO}$ mouse by platform reversal after training to an initial hidden platform. Platform reversal in the reference memory watermaze is used to test cognitive flexibility or the ability to form a new memory in the same context and retrieve it when needed. After platform reversal in the reference memory watermaze, mice must acquire a new spatial memory and forget the older memory, either by erasing the older memory or blocking its retrieval. Syt3 KO mice could acquire the new spatial memory as well as WT mice in reversal training, indicating that the older memory did not interfere with acquisition of the new one. Syt3 KO mice spent $>25 \%$ time in the new platform quadrant in PT3 and their proximity to and number of crossings of the new platform were not significantly different from WT mice (Figure 21A-C below). In fact, on the first day of training after reversal (Day 11, Figure 18F above), syt3 KO 
A
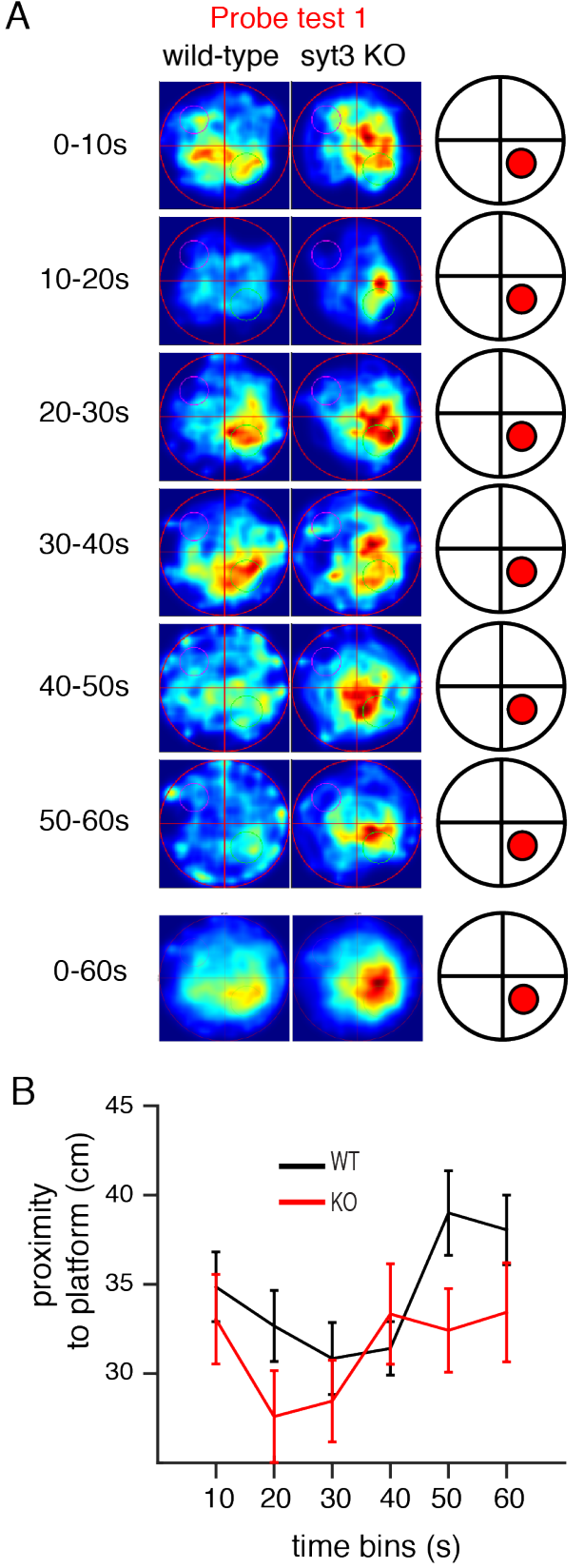

C

Probe test 2 wild-type syt3 KO

$0-10$ s

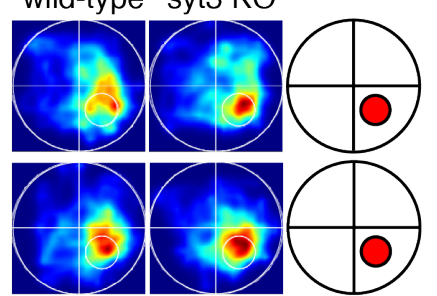

$E$

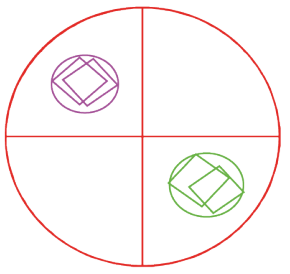

20-30s

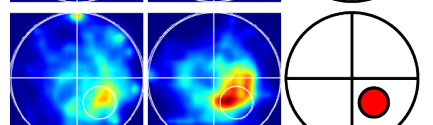

$30-40$ s
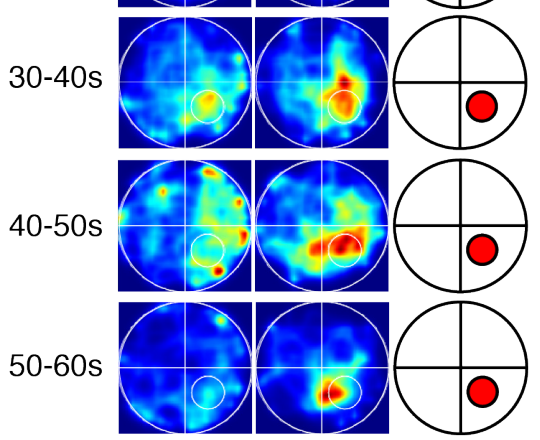

$0-60 \mathrm{~s}$

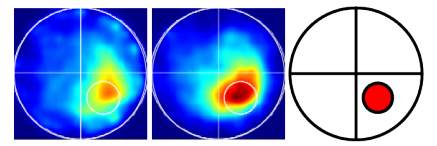

D

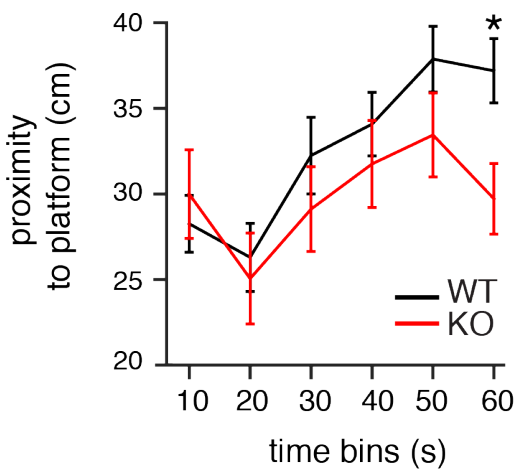

Figure 20: Syt3 KO mice lack within-trial extinction in watermaze probe tests

(A) Time binned occupancy plots of WT and syt3 KO mice, after pooling data from both cohorts, during probe test 1 . The schematic on the right shows the location of the platform. Syt3 KO mice show stronger spatial focus in their search for the platform than WT mice, not only in each time bin but also on average. (B) Quantitation of the proximity (mean \pm SEM) to the platform in PT 1 indicates no significant difference between WT and syt3 KO mice. (C) Same as A but for probe test 2. Syt3 KO mice show stronger spatial focus in their search for the platform than WT mice, not only in each time bin but also on average. (D) Quantitation of the proximity (mean \pm SEM) to the platform in PT 2 indicates a significant lack of within trial extinction in syt3 KO mice in the last time bin. (E) Data from two cohorts (in which the platform position was different) was pooled by taking a mirror image of all search paths from cohort 1, superimposing on cohort 2 and generating occupancy plots. The schematic shows a circular region enclosing the superimposed platforms, which was used as the platform area for this dataset. $\mathrm{n}=24 \mathrm{WT}$ and $22 \mathrm{KO}$ (cohort 1: $\mathrm{n}=10 \mathrm{WT}, 9 \mathrm{KO}$; cohort 2: $\mathrm{n}=14 \mathrm{WT}, 13$ syt3 KO). Statistical significance tested by Student's t-test. 
A

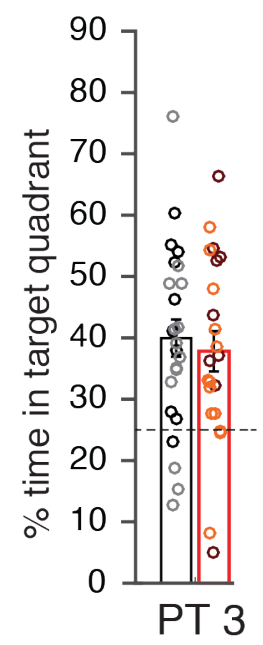

B

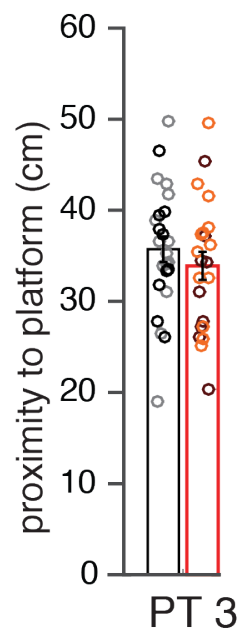

C

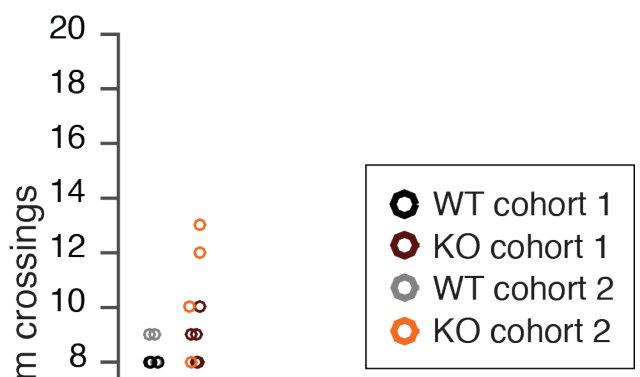

Figure 21: Syt3 KO mice acquire the new platform position memory as well as WT mice, showing no proactive interference from the original platform position memory.

(A-C) Quantitation (mean \pm SEM) of \% time in quadrant with the new platform (A), proximity to new platform position (B) and number of crossings of the new platform (C) during probe test 3 after reversal indicate that syt3 KO mice acquired a memory of the new platform position as well as WT mice. $\mathrm{n}=24$ WT and $22 \mathrm{KO}$ (cohort 1: $\mathrm{n}$ $=10 \mathrm{WT}, 9 \mathrm{KO}$; cohort 2: $\mathrm{n}=14 \mathrm{WT}, 13$ syt3 KO). Statistical significance tested by Welch's t-test for A and B, Mann-Whitney's U-test for C.

mice had significantly lower proximity to the new platform, suggesting syt3 $\mathrm{KO}$ mice learn faster than WT mice.

\section{- Syt3 KO mice persevere to the original platform after reversal}

Recent studies have shown that inhibition of the $3 \mathrm{Y}$ internalization machinery using the TatGluA2-3Y peptide can block the 'natural' forgetting of memories (Migues et al., 2016). If older memories are forgotten to a lesser extent, they have a stronger chance of being retrieved along with the retrieval of newly formed ones. Rats injected with the GluA2-3Y peptide systemically showed perseverance to the original platform on the second day of training after reversal (Figure 2 from Z. Dong et al., 2013). In concordance with this study, analysis of training days after platform reversal indicated that syt3 KO mice persevered significantly more to the original platform on the third day (Figure 22A below). Additionally, a significantly higher perseverance to the original platform position was evident in probe test 3 after reversal. Syt3 KO mice were significantly closer to the original platform position and crossed it significantly more than WT 
mice (Figure 22B, C). Visual inspection of occupancy plots also clearly indicated a higher perseverance of syt3 KO mice to the original platform (Figure 22D), which could also be quantified as lower proximity to the original platform in multiple time bins of probe test 3 (Figure 22E). Thus, syt3 $\mathrm{KO}$ mice exhibit impaired forgetting in the reference memory watermaze, indicated by higher retrieval of a remote memory when a recent memory was recalled.

A

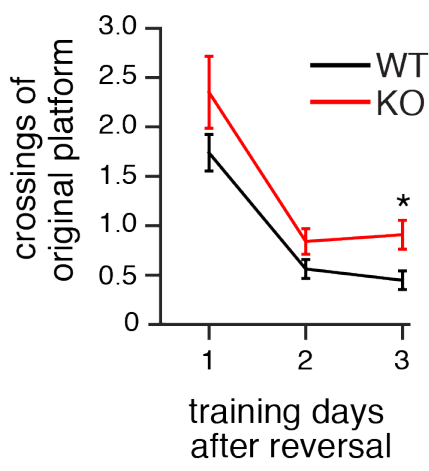

B

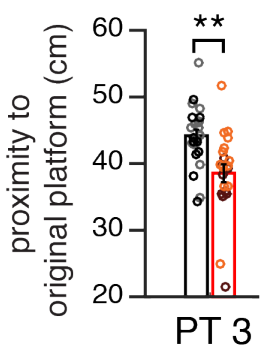

C

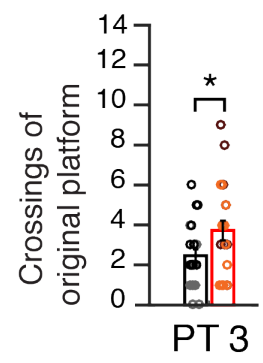

D

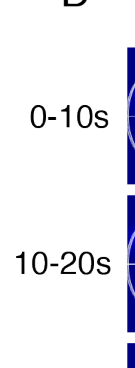

20-30s

Probe test 3 wild-type syt3 $\mathrm{KO}$
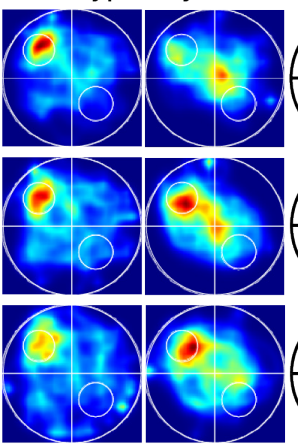

$30-40$ s
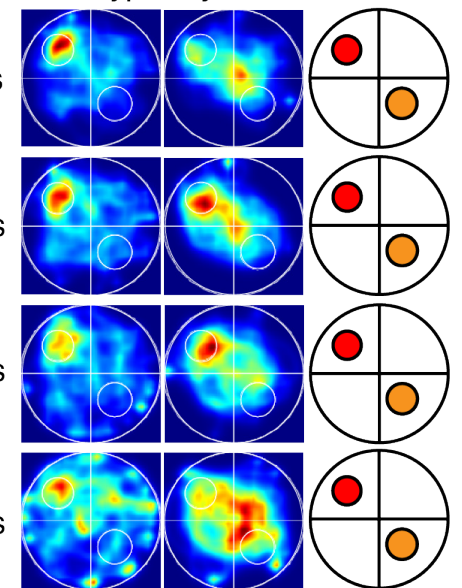

40-50s
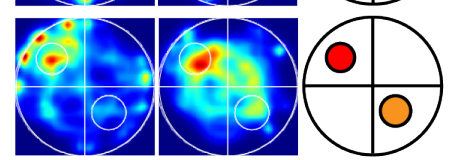

50-60s

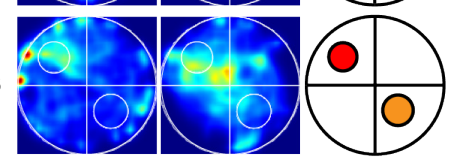

O WT cohort 1

- KO cohort 1

- WT cohort 2

O KO cohort 2

\section{PT 3}

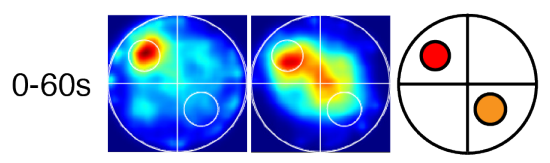

E

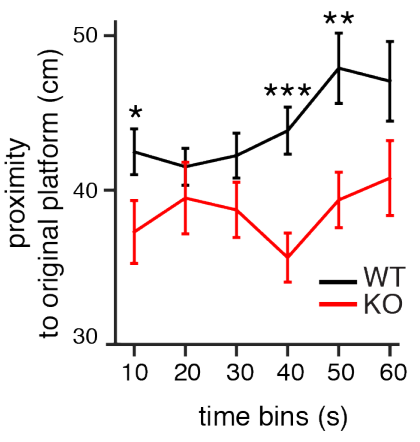

\section{Figure 22: Syt3 KO mice persevere to original platform after reversal}

(A) Time course of number of crossings of original platform over the training days after reversal (mean \pm SEM). (B-C) Quantitation (mean \pm SEM) of proximity to original platform (B) and number of crossings of original platform (C) on probe test 3 after reversal indicate that syt3 $\mathrm{KO}$ mice persevere to the original platform significantly more than WT mice. (D) Time binned occupancy plots of WT and syt3 KO mice, after pooling data from both cohorts, during probe test 3 indicate perseverance of syt3 $\mathrm{KO}$ mice to the original platform. (right) Platform in orange is the original platform, and in red is the platform after reversal. (E) Quantitation (mean \pm SEM) of the proximity to the original platform in PT 3 indicates syt3 $\mathrm{KO}$ mice have significantly lower proximities than WT in multiple time bins. $\mathrm{n}=24 \mathrm{WT}$ and $22 \mathrm{KO}$ (cohort 1: $\mathrm{n}=10 \mathrm{WT}, 9 \mathrm{KO}$; cohort 2: $\mathrm{n}=14 \mathrm{WT}, 13$ syt3 KO). Statistical significance tested by Kruskal Wallis's test with Dunn's multiple comparison for A, Welch's t-test for B, E and Mann-whitney's U-test for C. $\left({ }^{*}, \mathrm{p}<0.05 ;{ }^{* *}, \mathrm{p}<0.01 ; * * *, p<0.001\right)$. 
To quantitatively test an impairment in forgetting in the syt3 $\mathrm{KO}$ mouse, performance in a more demanding version of the watermaze was tested.

\subsection{Syt3 KO mice persevere to older platform positions in the delayed matching to place watermaze task}

\section{- The delayed matching to place (DMP) watermaze is a test for working memory}

A less commonly used variant of the reference memory watermaze is the DMP watermaze where the hidden platform position is changed every day to a new position in the pool. Each day the position remains unchanged over the course of four training trials (Figure 23A below). Although mice perform badly on the first trial of any given day as they have no way to predict where a platform will be on that day, they perform much better once they learn that the position doesn't change over the course of any given day. This improvement in performance over the last three trials of the day, called savings, relies on the short-term/ working memory ability of mice to remember the platform position on very limited exposure and also to 'forget' previous platform positions. Thus, while the reference memory watermaze relies on long-term memory consolidation over multiple days, most likely correlating with strong-LTP, the DMP watermaze relies on shortterm memory, perhaps correlating with weak-LTP at the synaptic level. As weak-LTP is strongly reinforced in syt3 KO mouse hippocampal slices (Figure 14B above), they might perform better than WT mice in this task. On the other hand, as syt3 $\mathrm{KO}$ mice persevere to the older memory in the reference memory watermaze (section 3.9 above), they may perform worse than WT mice in this task.

Mice were dropped from four different points around the pool, which were shuffled in a pseudorandom manner with reference to the platform position across days. The platform was placed in a different quadrant on each consecutive day as far as possible. To avoid any biased search caused by picking platforms in a regular pattern across the inner and outer ring of platforms, the cohort was counterbalanced with respect to the order in which platforms were picked in the two platform rings. Mice were first habituated to the DMP task for 3 days by training them to swim to a visually cued platform, placed at a different position every day. All mice learned to swim to the platform and remain on it for 30 seconds before being picked up by the experimenter. As in the reference 
memory watermaze, syt3 KO mice showed anti-thigmotactic behaviour, indicated by much lower search densities of syt3 KO mice at the wall compared to WT mice. As indicated by the occupancy plots for this phase of the task, both WT and syt3 KO mice showed no thigmotactic behaviour by day 2 or day 3 (Figure 23B below).

A

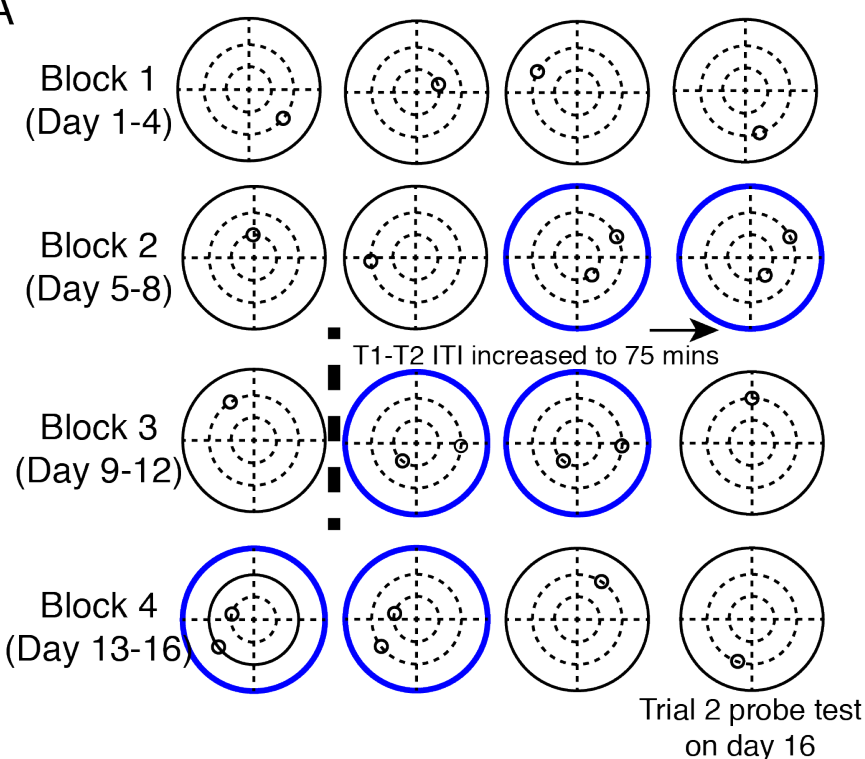

B

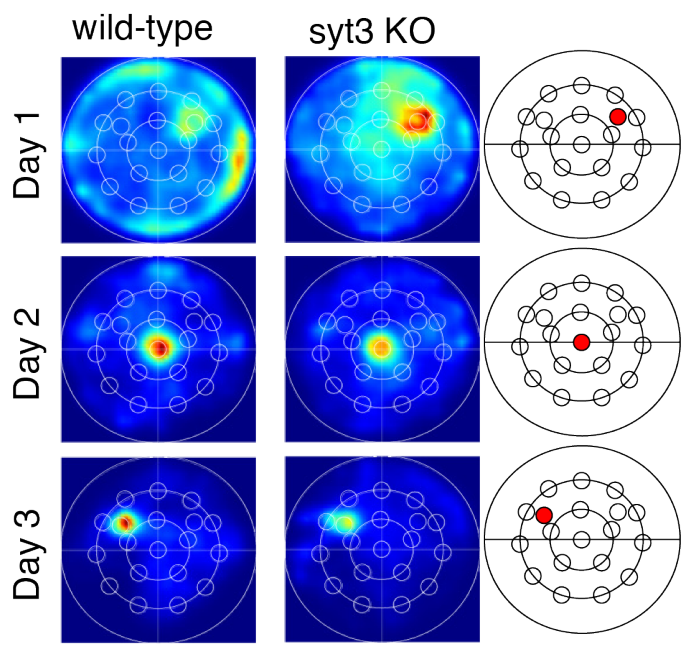

Figure 23: Design of the DMP watermaze task

(A) Schematic of all 16 platform positions used in the task, distributed into four blocks of four days each. Blue outlined mazes indicate days where all mice were counterbalanced with respect to platforms being present in inner or outer ring of platforms. The trial 1 - trial 2 inter-trial interval was increased to 75 min from day 10 onwards. (B) Habituation phase of DMP watermaze. Daily average occupancy plots of all WT and syt3 KO mice upon training to swim to a visually cued platform, located at the position indicated by red in the schematic. Syt3 KO mice show no deficits in visual acuity.

\section{- Syt3 KO mice are strongly impaired in the DMP watermaze}

The analyzed parameters were averaged across the 4 days in a training block to minimize variability in the savings parameter and to extract general trends. Savings were calculated by normalizing parameters with respect to the mean trial 1 parameter value for that genotype. All mice failed to improve in the last three trials of the day during the first block of training as they acclimatized to the task and the changing positions every day. From block 2 onwards, WT mice showed savings in escape latency, path length and proximity over the last three trials of the day. Syt3 KO mice were highly impaired at the DMP task, indicated by the significantly smaller savings in proximity, escape latency and path length (Figure 24A-C below). Increasing the delay period 
between trial 1 and trial 2 to $75 \mathrm{~min}$ did not affect the impairments in parameter savings in syt 3 KO mice. As impairments in the DMP savings can occur because of increased perseverance to previous platform positions, we next used the strategy analysis algorithm to quantify the fraction of perseverance trials and proximity to previous platform positions. Syt3 $\mathrm{KO}$ mice also swam
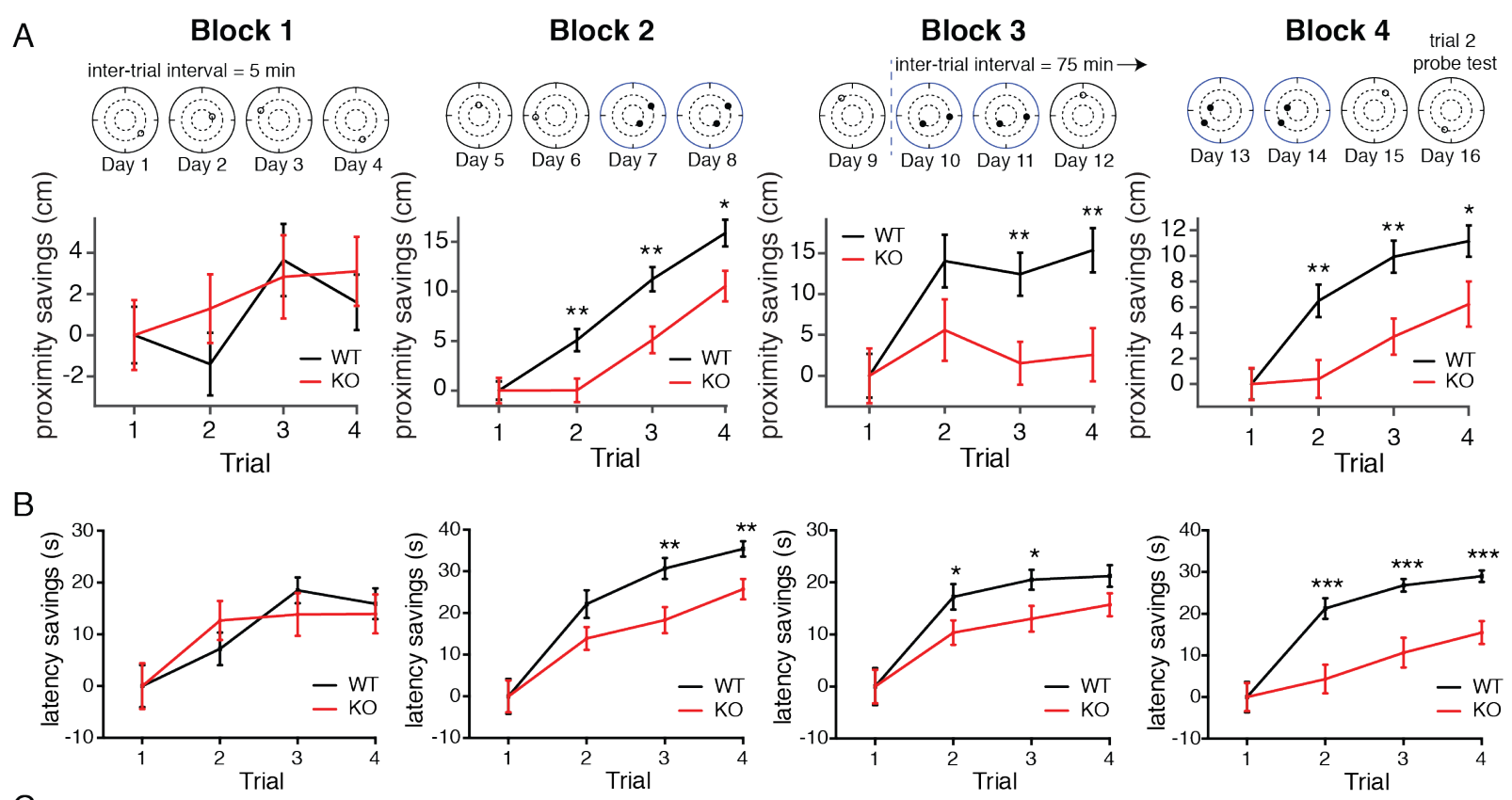

$\mathrm{C}$
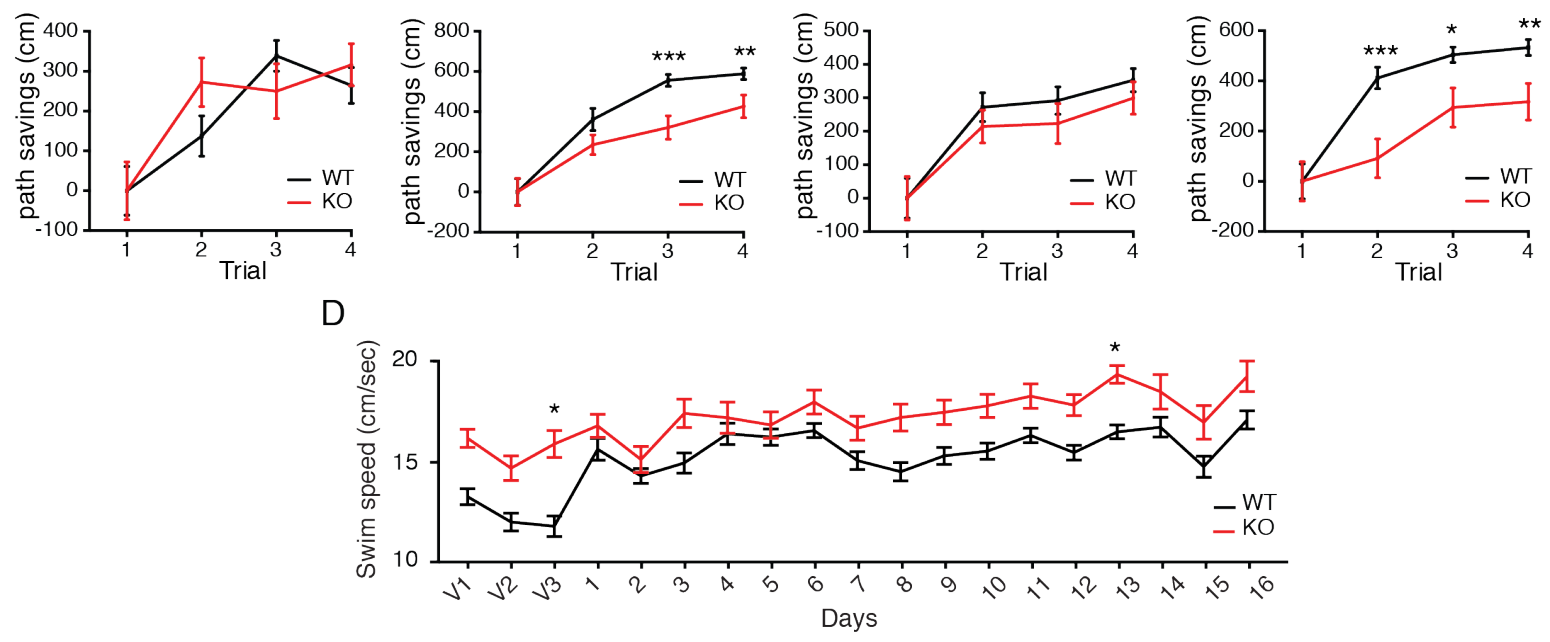

Figure 24: Syt3 KO mice are strongly impaired in the DMP watermaze task

(A-C) Quantitation (mean \pm SEM) of proximity (A), escape latency (B) and path length savings (C) with respect to trial 1 over the course of four blocks of training. Results across the four days in a block are averaged. Platform positions used on each day are shown on the schematic on top. Syt3 KO mice show consistently worse savings compared to WT mice over all blocks of training. The search path until the first latency to cross the target platform on the probe test (day 16 trial 2) was used to calculate savings. (D) Quantitation (mean $\pm \mathrm{SEM}$ ) of swimming speed over the course of all training days. 2-way ANOVA for swimming speed of WT vs KO was significant $(\mathrm{p}<0.0001)$. $\mathrm{n}=20 \mathrm{WT}$ and $14 \mathrm{KO}$. Statistical significance determined by Student's t-test for A-C, 2-way ANOVA with Bonferroni's multiple comparisons test for $\mathrm{D}\left({ }^{*}, \mathrm{p}<0.05 ; * *, \mathrm{p}<0.01 ; * * *, \mathrm{p}<0.001\right)$. 
significantly faster than WT mice almost throughout the task (Figure 24D above), increasing the importance of analyzing proximity rather than escape latency or path lengths, as they can be confounded by swimming speed.

On visual inspection of occupancy plots of both counterbalanced sub-cohorts (labelled CB1 and CB2), some convincing examples could be found showing higher perseverance of syt3 KO mice to platform positons from one or two days before the current day of training (Figure 25A below). In terms of strategy classification, very few spatially direct strategies could be detected in spite of relaxing the criteria of detection for direct swimming or direted search strategies. This could be because spatial memories were weak in this task because of very limited exposure of mice to platform positions. Systematic analysis of all search paths in pooled data from both sub-cohorts showed that syt $3 \mathrm{KO}$ mice had a greater \% of trials on most days that were classified as scanning (Appendix Figure 9 on page 151) and perseverance to previous days' positions (Figure 25B below) compared to WT mice. On the other hand, WT mice had more random search strategies (Appendix Figure 9). Considering that all platform positions were at two fixed distances from the walls, chaining could be an easy workaround strategy but very few WT or syt3 KO mice adopted chaining strategies (Figure 25C below).

To test for spatial memory, a probe test was performed on day 16 by removing the platform in trial 2. Syt3 KO mice showed a dramatically different search pattern compared to WT mice. Syt3 $\mathrm{KO}$ mice seemed to focus their search on an annulus between the two rings containing the platforms whereas WT mice searched relatively randomly throughout the pool, although showing higher focus on the day 16 platform position relative to most other areas of the pool (Figure 25A below). As expected from this search pattern, syt3 $\mathrm{KO}$ mice had lower proximities to most previous platform positions. The lower proximities were statistically significant to four previous positions that were all in the top left quadrant, perhaps because the density of platform positions in that quadrant was one of the highest in the pool (Figure 25D). Thus, syt3 KO mice had impaired DMP savings on any given day because they forgot previous platform positions to a lesser extent than WTs and persevered to these previous positions. 
A
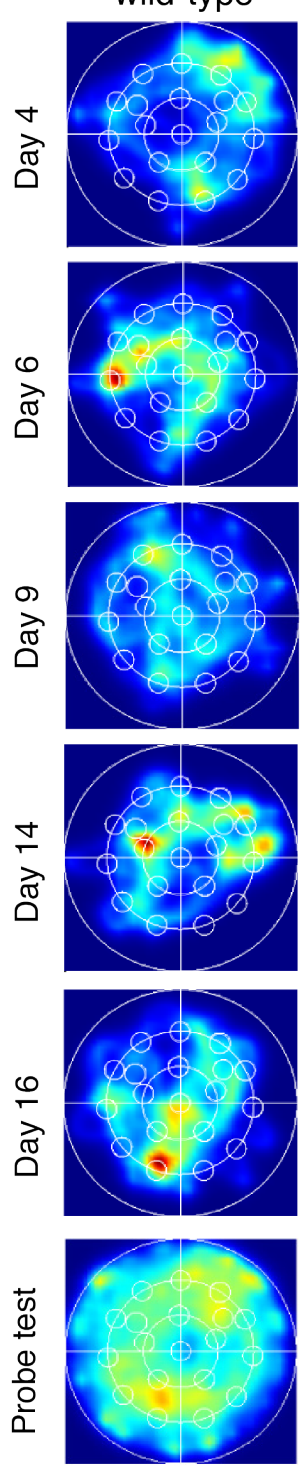

syt3 ko
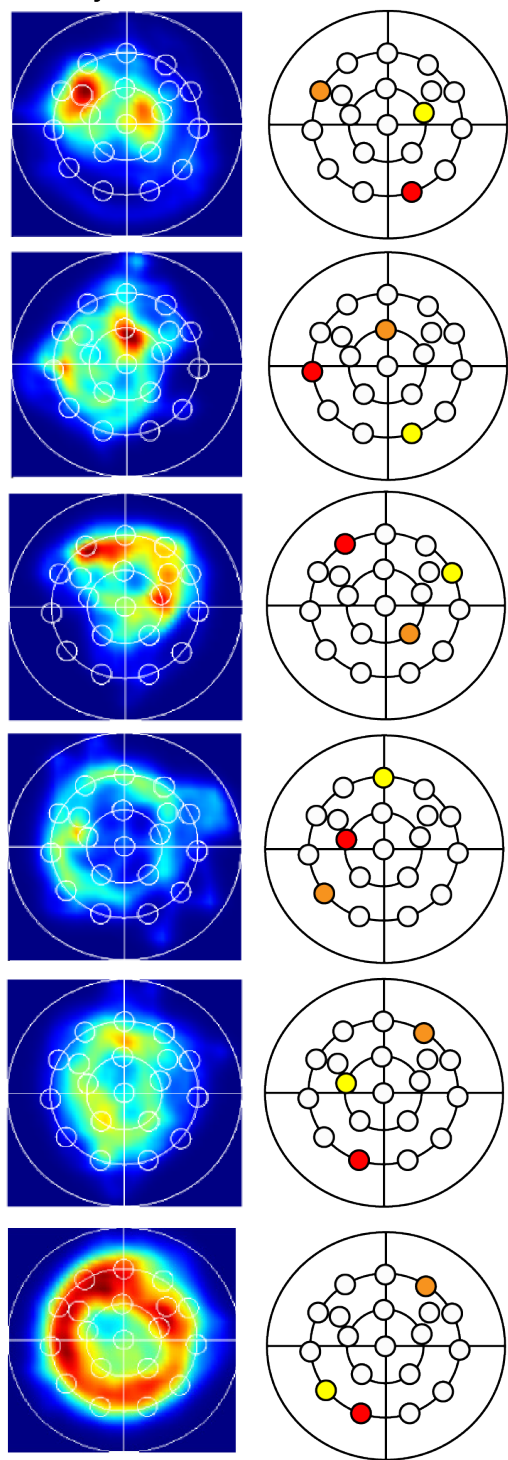

B

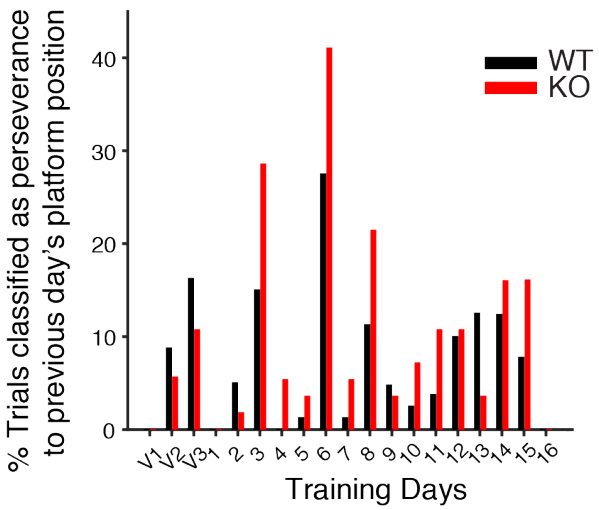

C

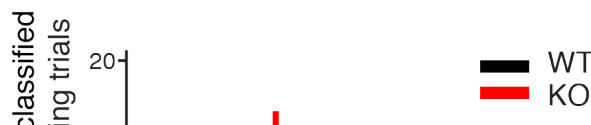

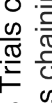

$\circ$ \&

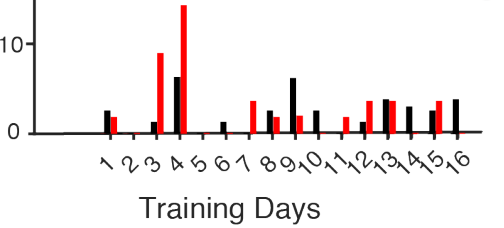

$\mathrm{D}$
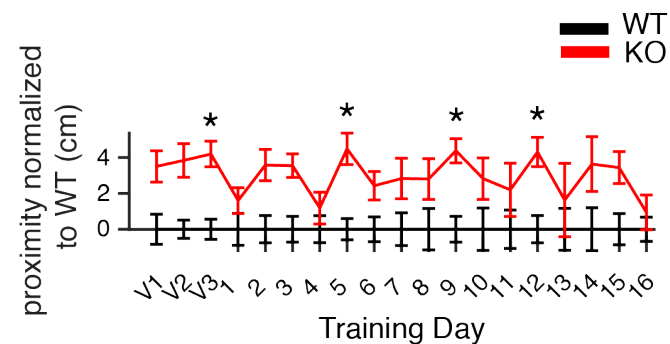

Figure 25: Syt3 KO mice perform worse in the DMP watermaze because of impaired forgetting

(A) Occupancy plots of all WT and syt3 KO mice from a sub-cohort in representative sample trials across all training blocks showing higher perseverance of syt3 $\mathrm{KO}$ mice to previous platform positions in comparison to WT mice. (Right) Schematic showing current day's platform in red, the previous day in orange, and the platform two days previously in yellow. (B) \% trials on all training days classified as perseverance to previous day's platform position using strategy analysis. (C) \% trials on all training days classified as chaining using strategy analysis. (D) Quantitation of proximity (mean \pm SEM) to all previous platform positions in the day 16 probe test, normalized to WT. A positive value indicates a lower proximity of KO with respect to WT. V1, V2 and V3 are visual cued platform training days. Syt3 KO mice show decreased proximity to all platform positions and significantly decreased proximity to 4 previous platform positions compared to WT. 2-way ANOVA for genotype effect, $\mathrm{p}<0.0001$; Bonferonni's correction for multiple comparisons for platform $\mathrm{V} 3$ : $\mathrm{p}=0.044$, day $5: \mathrm{p}=0.02$, day 9: $\mathrm{p}=0.028$, day 12: $\mathrm{p}=0.033$. $\mathrm{n}=20 \mathrm{WT}$ and $14 \mathrm{KO}$ for B-D. 


\section{Discussion}

\subsection{Syt3 is expressed on post-synaptic membranes}

Butz et al 1999, who were the first to use a syt3 antibody (validated in syt3 knockout mice), found high levels of syt3 protein in the hippocampus and the cerebellum in brain and much lower levels in the cortex and the olfactory bulb. Our findings were partially in agreement, where we found high expression in the hippocampus and the cortex but almost none in the cerebellum or olfactory bulb. Additionally, we found syt3 expression in the striatum and the thalamus but none in the hypothalamus and pituitary (Figure 1D). High levels of syt3 were also detected in the mesencephalon, hindbrain and the spinal cord (Butz et al., 1999). Many early studies detected syt3 protein expression in pancreatic beta cells (H. Brown et al., 2000; Mizuta et al., 1994, 1997), which secrete insulin in response to glucose. However, a later study using an affinity purified antibody highly specific to syt3 (Gut et al., 2001) detected high levels of syt3 in rat brain homogenate, but not in INS-1 pancreatic beta cell lines. Syt3 was detected in somatostatin positive delta-cells (which constitute $10 \%$ of all islet cells), but not in their secretory vesicles. Thus, syt 3 is not in beta-cells of primary islet of Langerhans cells and is most likely not involved in insulin exocytosis in the pancreas, in agreement with the weak expression of syt 3 we observed in the pancreas relative to the brain (Figure 1C).

Syt1 expression starts before birth and increases gradually after P0 (Butz et al., 1999). In contrast, syt3 expression was shown to start around birth (P0) and reach a maximum between P4 and P11 (Butz et al., 1999). However, we found syt3 expression at embryonic stages as early as E14, which remained relatively stable between P14 and P110 (adult) (Figure 1E). The only difference between the two studies was that we used mouse brain homogenate, whereas Butz et al. used rat brain homogenate. It remains to be rigorously tested if syt3 expression begins before birth (P0) or after synaptogenesis ( P10 to P14), and would additionally be interesting to test if the developmental expression profile of syt 3 is different in different brain areas.

We found that syt3 has punctate staining and is localized to synapses in dissociated hippocampal cultures. Butz et al showed synaptic staining of syt3 which was very similar to syt 1 in the outer 
and inner plexiform layers of the bovine retina (Butz et al., 1999). By light microscopy we found that syt 3 colocalises with both pre- and post-synaptic markers. However these experiments alone cannot distinguish pre from post-synaptic localization. Resolving pre- and post-synaptic proteins is only optically possible using super-resolution microscopy. Three color 3D STORM (Stochastic Optical Reconstruction Microscopy), for example, has a resolution of $14 \mathrm{~nm}$ in the xy-plane and $35 \mathrm{~nm}$ in the z-direction (Dani, Huang, Bergan, Dulac, \& Zhuang, 2010). Using bassoon and homer as pre-and post-synaptic reference points, the centroids of the two markers were found to be separated by $154 \mathrm{~nm}$, allowing many pre-and post-synaptic proteins to be resolved, even when they are on synaptic plasma membranes (Dani et al., 2010). The plasma membranes itself cannot be visualized with such methods, but it can be done by electron microscopy. It would therefore be interesting to test if syt 3 is present on the post-synaptic plasma membrane by immunogold labelling, although this technique has the caveat that only a subset of molecules in each preparation are labelled.

CRISPR-Cas9 (clustered regularly interspaced short palindromic repeat/Cas9) based genetic editing is now possible in postmitotic neurons in vitro and in vivo using homology independent targeted integration (HITI) (K. Suzuki et al., 2016). Thus an alternative approach to endogenous antibody labelling to detect protein localization (which may or may not work in some preparations, depending on the antibody), is to knock in peptide tags (HA- or myc- tags, for which high affinity antibodies are available) and localize endogenous proteins of interest using electron microscopy. This method could also be used to perform antibody uptake assays to monitor intracellular trafficking of endogenous levels of protein. SLENDR (single-cell labeling of endogenous proteins by CRISPR-Cas9- mediated homology-directed repair) can be used to sparsely knock in desired tags via in utero electroporation, making imaging in backgrounds with large number of synapses easy (Mikuni, Nishiyama, Sun, Kamasawa, \& Yasuda, 2016).

The subcellular localization of proteins can also be determined biochemically by subcellular fractionation. (Butz et al., 1999) showed that syt3 is enriched in the synaptic plasma membrane fraction but not in the purified synaptic vesicle fraction from brain homogenates, in contrast to syt1, which was enriched in both (Butz et al., 1999). They also found that syt1, but not syt3, was enriched in the purified synaptic vesicle fraction. In agreement with Butz et al., we found that syt3 
was enriched in synaptosomal membrane fractions but not in synaptic vesicle fractions, or purified synaptic vesicle fractions (Figure 3A). Immuno-organelle isolation of synaptic vesicles confirmed the absence of syt3 (Figure 3B).

Both our experiments, and those of Butz et al. indicate that syt3 is present on synaptosomal plasma membranes. However, these fractionation experiments do not distinguish if syt3 is present on the pre- or post-synaptic plasma membrane. To test this we used a synaptosome trypsin cleavage assay in which presynaptic proteins are distinguished by being protected from cleavage, while postsynaptic proteins are cleaved. In the synaptosome trypsin cleavage assay, the presynaptic plasma membrane protein syntaxin1a was protected from cleavage because only a small portion of its sequence is extracellular, whereas the presynaptic protein neurexin, which has a significantly larger extracellular domain, is accessible to cleavage (Figure 3C,D). The short N-terminal domain of syt 3 must be extracellular because pHluorin fused to the N-terminus of syt3 fluoresces in basal conditions, meaning it is in contact with extracellular solution (Figure 4). If syt3 was on the presynaptic membrane, its cleavage pattern would have been like that of syntaxin1a, which has a very small extracellular domain. However, no large fragment of syt3 remained following cleavage, and multiple small cleavage products were observed (full blot not shown), unambiguously showing that syt3 is on post-synaptic plasma membranes.

Various proteins involved in AMPA receptor internalization including BRAG2 (Scholz et al., 2010), PICK1 (Rocca et al., 2013) and hippocalcin (Palmer et al., 2005) are enriched in the postsynaptic density (PSD) fraction, which contains internal post-synaptic compartments as well as plasma membrane, and which can be isolated biochemically. It would be interesting to test for enrichment of syt 3 in detergent extracts of post-synaptic densities before and after inducing AMPA receptor internalization. We hypothesize that the proportion of internal syt3 at PSDs would increase following stimulation to induce AMPA receptor internalization.

\subsection{Syt3 endocytoses upon stimulation}

SEP (super ecliptic pHluorin) was originally developed to monitor exocytosis of synaptic vesicles by attaching it to the lumenal domain of integral synaptic vesicle associated proteins where there 
is no fluorescence in basal conditions when the pHluorin is inside acidified internal synaptic vesicles, and any increase in fluorescence can be interpreted as vesicles fusing such that the pHluorin moeity comes in contact with the more basic extracellular solution. However, it has been shown that NMDA bath application of neurons transfected with pHluorin-GluA2, which is partially present in non-acidified internal dendritic compartments, can cause acidification of these compartments and a corresponding decrease in fluorescence, confounding the interpretation of a decrease in fluorescence as endocytosis of pHluorin-GluA2 on the surface (Ashby, 2004; Rathje et al., 2013). Similarly, N-terminally tagged syt3-pHluorin shows a robust decrease in fluorescence upon stimulation, which is interpreted as endocytosis. Since $\sim 23 \%$ of total syt3-pHluorin is expressed in non-acidified internal compartments, $\sim 57 \%$ in acidified internal compartments and $\sim 20 \%$ on the surface (Dean et al., 2012), this observed decrease in fluorescence could be partly due to the acidification of internal syt3-pHluorin populations.

However, the kientics of endocytosis we observed were similar by four different methods of stimulation - AMPA, NMDA, $45 \mathrm{mM} \mathrm{KCl}$ and field stimulation - and could be completely blocked in 0 extracellular $\mathrm{Ca}^{2+}$ with the first three kinds of stimulation (Figure 4B-F on page 79), suggesting that the decrease in fluorescence was indeed endocytosis of plasma membrane syt3 into acidified internal comparmtents (and this endocytosis was calcium-dependent). Nevertheless, the internalization of syt 3 could be tested by GFP antibody uptake assays in syt3 pHluorin-expressing cells, in future experiments. To our knowledge there is no currently existing antibody which detects the extracellular domain of syt3, which could be used to assay internalization of endogenous syt 3 in antibody uptake experiments. However, one could examine the recycling of endogenous syt3 in basal and stimulated conditions by surface biotinylation assays (Ehlers, 2000).

\subsection{Syt3 is a novel addition to the GluA2 $3 Y$ internalization machinery}

With the discovery of syt 3 , which acts via the 3 Y region of the GluA2 cytoplasmic tail, we uncover a novel addition to the $3 \mathrm{Y}$ machinery. Both a peptide corresponding to the $3 \mathrm{Y}$ region, and knockout of syt3 robustly block activity-dependent, but not constitutive, AMPA receptor internalization at the cellular level, ZIP mediated decay of strong-LTP, and forgetting at the behavioral level (Z. Dong et al., 2013, 2015; Migues et al., 2016). Although we didn't quantify the proportion of 
synapses that express syt3, the fact that syt3 is the third most abundant syt isoform (Butz et al 1999) suggests that syt 3 could play a global role in activity-dependent synaptic weakening in the hippocampus and also perhaps in other brain regions.

Both syt3 and syt7 have been classified as plasma membrane isoforms (Jackman, Turecek, Belinsky, \& Regehr, 2016; Sugita et al., 2002). Transfection of PC12 neuroendocrine cells with YFP-fusion constructs showed that both syt3 and syt7 have an exclusively membrane localization, in stark contrast to syt1, which is present mainly on vesicles in these cells (Sugita et al 2002). In neurons, it has recently been shown that syt7 is the calcium sensor mediating paired pulse facilitation on the pre-synaptic membrane at neuronal synapses (Jackman et al., 2016), while we show syt3 is on the post-synaptic membrane, where it regulates receptor trafficking. The C2A domains of both syt3 and syt7 isoforms show $\sim 5-20$ times higher $\mathrm{Ca}^{2+}$ affinity than syt1 (Sugita et al 2002). However, an interesting difference between the two isoforms is that although syt7 C2B and syt3 $\mathrm{C} 2 \mathrm{~B}$ domains have high sequence similarity, syt7-C2B has high $\mathrm{Ca}^{2+}$ regulatedphospholipid binding affinity, while syt3 $\mathrm{C} 2 \mathrm{~B}$ did not show any phospholipid binding even at very high calcium concentrations in a liposome cosedimentation assay (Sugita et al 2002). Similarly, it was shown that syt3-C2A, syt7-C2A and syt7-C2B but not syt1-C2A or syt3-C2B have correlated phospholipid binding profile to calcium sensitivity in an in vitro assay of norepinephrine exocytosis from PC12 cells (Sugita et al 2002). In addition, while syt1-C2A required $200 \mu \mathrm{M}$ $\left[\mathrm{Ca}^{2+}\right]$ for syntaxin binding, syt3-C2A and syt7-C2A required much lower $\left[\mathrm{Ca}^{2+}\right]$ ( $\mathrm{Li}$ et al 1995). Syt1 may be tuned to respond to nanodomain calcium concentrations near docked synaptic vesicles in presynaptic active zones, while syt 3 responds to lower calcium concentrations in microdomains lateral to the post-synaptic density.

What is the precise molecular mechanism by which syt3 mediates AMPA receptor internalisation? The findings that a) syt3 is expressed on the post-synaptic plasma membrane (Figure 3D), b) the calcium binding ability of syt3 is necessary for receptor internalization (Figure 7), c) the syt3 C2A and $\mathrm{C} 2 \mathrm{~B}$ domains undergo a large relative displacement upon binding calcium in the presence of a SNARE complex in vitro (Vrljic et al., 2010), and d) syt3 pulls down GluA2 and AP2 from brain homogenate in 0 extracellular calcium (Figure 5 on page 81 ) suggest that syt3 is one of the first players in the internalization pathway. Syt 3 probably binds $\mathrm{Ca}^{2+}$ coming into the cell through 
NMDA receptors and L-type voltage gated $\mathrm{Ca}^{2+}$ channels (Figure 4F on page 79) at the plasma membrane, and may promote the clustering of AP2 and GluA2 at nucleation sites of clathrin coated pits (Godlee \& Kaksonen, 2013; Kirchhausen et al., 2014; Schmid \& McMahon, 2007). It will be interesting to examine the binding partners of syt 3 in different calcium concentrations and at different ionic strengths, both of which are known to affect binding in vitro (Vrljic et al., 2010, Sugita et al., 2002), to further test activity-dependent regulation of syt3 to its binding partners.

Which binding motifs are likely to mediate syt3 function? The syt1 residues, K326A and K327A, which are necessary for syt1-AP2 binding and highly conserved among synaptotagmins, implicate the homologous residues in syt3, R483 and K484, in syt3-AP2 interaction (Grass et al., 2004; Haucke, Wenk, Chapman, Farsad, \& De Camilli, 2000). If the syt3-AP2 interaction is necessary for its function, a syt3 R483A/K484A mutant should not be able to rescue the decrease in mEPSC amplitude upon AMPA stimulation observed in syt3 knockout neurons (Figure 12E on page 90). Neurons expressing GluA2 R845A, which can't bind AP2, showed normal AMPA-induced internalization (Lee et al., 2002). But AMPA-induced internalization was abolished in syt3 knockouts. It is therefore possible that AMPA-induced AMPA receptor internalization is mediated by syt3 as an adaptor between GluA2 and AP2, since syt3 binds both GluA2 and AP2.

Complexin, syntaxin3, syntaxin4 and SNAP47 are necessary for AMPA receptor exocytosis (Ahmad et al., 2012; Jurado et al., 2013; Arendt et al., 2015). Syt3 also binds syntaxin3, syntaxin4 and SNAP47, and not syntaxin1 or SNAP25, suggesting it is a component of the post-synaptic (and not pre-synaptic) fusion machinery (Figure 5B). Its binding to SNARE proteins suggests a possible role in exocytosis in addition to endocytosis. Interestingly, we occasionally observed exocytotic events in pHluorin-syt3 experiments performed in lower calcium concentrations (i.e. 1 $\mathrm{mM}$ instead of $2 \mathrm{mM}$ ). Syt3 may therefore promote recycling of receptors both to and from the membrane, but be predisposed to endocytose receptors at physiological calcium concentrations. As post-synaptic complexin KD in vivo didn't affect LTD (Ahmad et al, 2012), endocytic functions are most likely complexin independent.

Syt3 did not pulldown PICK1 in $0 \mathrm{Ca}^{2+}$ conditions (Figure 5B on page 81 ), which binds to GluA2 to a small extent in basal conditions (Fiuza et al., 2017) and is important for maintaining basal 
transmission via PICK1-Arf1 interactions (Rocca et al., 2013). As PICK1 is necessary for LTD (Terashima et al., 2008) and is required for NMDA mediated AMPA receptor internalization (Fiuza et al., 2017), it would be interesting to test if syt3 binds to PICK1 at physiological $\mathrm{Ca}^{2+}$ concentrations. BRAG2 requires dephosphorylated Y876 on GluA2 (Scholz et al., 2010) to be activated and internalize receptors, while Y876 phosphorylation is necessary to stabilize AMPA receptors at synapses (Hayashi and Huganir., 2004). Binding of syt3 to BRAG2 (Figure 5B on page 81) could recruit BRAG2 to GluA2 with dephosphorylated Y876 and cause GluA2 internalization. Because syt3 specifically mediates activity-dependent internalization of GluA2, binding of syt3-BRAG2 and syt3-AP2 in physiological $\mathrm{Ca}^{2+}$ concentrations or after induction of chemical LTD could be increased, and would be interesting to test.

\subsection{Syt3 is necessary for AMPA/ NMDA induced AMPA receptor internalization}

The flux of AMPA receptors going into intracellular compartments and back onto the surface is constantly changing. The internalization index (Figure 7C,D and Figure 10B), or the proportion of internalized receptors relative to those remaining on the surface quantifies the overall amount of internalization of AMPA receptors at specific timepoints. Internalization assays revealed that syt 3 is needed for activity-dependent but not constitutive AMPA receptor internalization. The protocol we used, allowing antibody to bind for $15 \mathrm{~min}$ before the assay should lead to saturated labelling, as shown in Lin et al 2000, where maximal AMPA stimulation dependent receptor internalization occurs $\sim 15$ mins after stimulation. We stimulated hippocampal cultures (Figure 7, Figure 10 and Figure 12) with $100 \mu \mathrm{M}$ AMPA which could have depolarized NMDA receptors as well, leading to AMPA receptor internalization by multiple mechanisms. However, previous studies found only minor differences in internalization with $100 \mu \mathrm{M}$ AMPA in comparison to $100 \mu \mathrm{M}$ AMPA + $100 \mu \mathrm{M}$ APV conditions in with NMDA receptors are blocked (Lin et al., 2000).

An advantage of our receptor internalization assays in comparison to other studies, is that we performed internalization assays on endogenous AMPA receptors. Transfected individual AMPA receptor subunits are expressed as homomeric AMPA receptors in neurons (Lee et al., 2004), which are rarely found in the adult brain. In addition, overexpression of AMPA receptor subunits 
often leads to unwanted potentiation of synapses under investigation (if such receptors are efficiently targeted to the synaptic surface), which can additionally confound the interpretation of the results. Nonetheless, many studies of subunit rules of AMPA receptor trafficking (Lee et al., 2002; Lee et al., 2004; Lin et al., 2000; Ahmadian et al., 2004; Hayashi \& Huganir., 2004) still found various C-terminal sequence determinants of trafficking using such 'unphysiological' AMPA receptors.

A complete abolishment of activity-induced AMPA receptor internalization upon expression of a syt3 calcium mutant indicates that its expression exerts dominant negative effects. This could indicate homo-oligomerization of syt3 in physiological conditions, but this remains to be tested. Expression of a syt3 calcium mutant also led to significantly higher surface expression of GluA2containing AMPA receptors, but not GluA1-containing receptors, following stimulation (Figure 7D). As the majority of hippocampal AMPA receptors in principal neurons are GluA1/GluA2 and GluA2/GluA3 AMPA receptors and those in interneurons are GluA4 containing (Henley \& Wilkinson, 2016), this effect could be specifically related to GluA3, but this was not further tested due to a lack of antibodies against the extracellular domain of GluA3. In addition, we show for the first time that the Tat-GluA2-3Y peptide ( similar to syt3 knockout) also abolishes AMPA-induced internalization of endogenous GluA2-containing AMPA receptors in dissociated mouse hippocampal cultures (Figure 10).

A decrease in mEPSC amplitudes upon NMDA stimulation has been shown in neurons (Davidson, Xiao, Dai, \& Bergson, 2009), but we chose to stimulate cultures with AMPA as it had a somewhat stronger effect (Figure 7C). While neurons were fixed 8 minutes after AMPA stimulation in internalization assays (Figure 7 and Figure 10), mEPSCs were recorded after AMPA simulation between 10 and 90 minutes after stimulation. The rate of surface recycling of AMPA receptors equals the rate of internalization $\sim 15$ minutes after stimulation (S. H. Lee et al., 2004). Thus, the decrease in mEPSC amplitude should be maximal for whole cell recordings performed $\geq 15 \mathrm{~min}$ after AMPA stimulation. However, the effect of syt3 overexpression on AMPA-induced reduction of mEPSC amplitude (Figure 12F above) was not as striking as that observed in the internalization assays. This may be because signal in somas was analyzed in internalization assays (as per previously published protocols) where syt3-GFP overexpression was prominent, while mEPSCs 
detect changes in surface AMPA receptors specifically at synapses, where syt3 overexpression was sometimes weaker. Overexpressed syt3-GFP (or pHluorin-syt3; Figure 4A) in wild-type neurons was mostly confined to the soma and proximal dendritic shafts but Syt3-GFP signals could be detected at synapses, including distal synapses, by immunocytochemistry (data not shown). Alternatively, syt3 overexpression may lead to enhanced receptor internalization of predominantly extra-synaptic receptors, consistent with previous studies in which components of endocytic zones are observed peri-synaptically. In any case, abolishment of AMPA-induced decreases in mEPSC amplitude in syt3 $\mathrm{KO}$ neurons indicates that syt 3 is indeed necessary for internalization of synaptic AMPA receptors.

The cytoplasmic tails of AMPA receptor subunits possess the positively charged motif KRMVK, conserved between GluA1-3, which is known to bind AP2. $\mathrm{Ca}^{2+}$ influx at the post-synaptic plasma membrane may lead to conformational changes in syt3 that trigger increased binding to AP2, either directly, or indirectly via the RRLKKRK motif of AP2 and a Stonin-2 like adaptor molecule, promoting AMPA receptor internalization. The Y876 residue of GluA2, which is dephosphorylated as a downstream consequence of stimulation, may promote clathrin coat formation by activation of the Arf6 GTPase by BRAG2 (Kirchenhausen et al., 2014); Arf6-GTP has been shown to promote clathrin-AP2 to pre-synaptic membranes (Krauss et al., 2003).

\subsection{Syt3 is necessary for decay of LTP}

A major research effort has been aimed at understanding the mechanistic underpinnings of strongLTP since its discovery. A well-established 'plasticity related protein' is PKMzeta, which is necessary for the persistence of strong-LTP. Recently, studies have reported a mechanism of 'inertia' at synapses, which reverses any activity-induced increases in the number of synaptic AMPA receptors. The GluA2-3Y machinery, is necessary for this reversal, and the decay of weakLTP to baseline. However, it is inhibited by PKMzeta to sustain strong-LTP (Z. Dong et al., 2015). These opposing forces ensure that, depending on stimulation parameters, synapses undergo sustained potentiation, or short-term increases in strength, which then decay to "normal" levels. We have discovered a novel player, syt3, in the GluA2 3Y-dependent pathway, that mediates LTP decay. 
Compared to mechanisms of induction and maintenance of LTP, very few studies have examined the mechanisms of decay of LTP, which is widely thought to result from a decrease in surface GluA2 receptors by internalization. The decay of weak-LTP is abolished by APV application (Xiao et al., 1996). Thus, NMDA receptor mediated internalization of GluA2 AMPA receptors is necessary for decay of LTP. Injecting the dorsal hippocampus of rats with the GluA2-3Y peptide could rescue a remote memory (Migues et al, 2016). In addition, blocking NMDA receptors with CPP infusions blocked decay of a spatial memory in rats (Villarreal et al., 2002). Thus, NMDA receptor mediated internalization of GluA2 AMPA receptors is also necessary for forgetting at the behavioral level.

PKMzeta is also well known to play a role in forgetting. An object location memory, which is hippocampus dependent, in rats required PKMzeta during the first week of training, but this memory 'naturally' decayed by day 35 after training, suggesting that the PKMzeta recruited upon memory consolidation gradually decreases in activity or amount, perhaps leading to 3Y machinery-mediated decay of memory (Hardt et al., 2010). These experiments suggest a competition model for the sustenance of strong-LTP, i.e., maintenance of memory by PKMzeta mediated surface expression of GluA2-AMPA receptors versus internalization of GluA2-AMPA receptors by the $3 \mathrm{Y}$ machinery. Metaplastic changes, or changes in synaptic NMDA receptor composition from GluN2B containing to GluN2A containing NMDA receptors, could reduce postsynaptic calcium influx. This would prevent stimuli that would normally decrease PKMzeta and cause depotentiation, to become innocuous and thus safely lock away a memory for much longer periods of time (Zinebi F. et al., 2003).

\subsection{Syt3 is necessary for forgetting of spatial memories}

\section{- Syt3 KO mice show impaired forgetting in the reference watermaze}

We used syt 3 knockout mice for behavioral assays to ensure a complete absence of syt 3 and avoid possible nonspecific effects of knockdown. However, given that the syt3 knockout mice are consistitutive, we cannot exclude possible confounding effects of syt3 knockout in extrahippocampal brain regions. The only verifiable "non-hippocampal" effects (most likely not related 
to memory) we observed in syt3 $\mathrm{KO}$ mice were smaller body size and faster swimming speeds, and less thigmotaxis and higher scanning in the watermaze.

Recently developed transgenic mice which lack NMDA receptors in the CA1 and dentate gyrus regions of the hippocampus performed better than controls in the spatial reference memory watermaze task, raising doubts whether hippocampal LTP is really needed to acquire spatial memories. Interestingly, in these mice, the retrieval of the spatial memory of a hidden platform suffered from interference from previously acquired memories in the watermaze (Bannerman et al., 2012).

We found that syt3 knockout mice showed a similar prevalence of previously acquired memories in the watermaze. Syt3 KO mice could acquire spatial memories as well or better than controls in the reference memory watermaze. However, like rats injected with the GluA2-3Y peptide in the dorsal hippocampus (Dong et al., 2013), syt3 KO mice showed stronger perseverance to the original platform on the second day of training after reversal, compared to wild-type mice. Although platform reversal might not lead to complete forgetting of the original platform position (Lattal, Mullen and Abel 2003), perseverance to the original platform could indicate stronger consolidation or increased retrieval of the original platform memory. The latter is more likely to be true for the syt3 KO mouse, since learning of the original platform position was similar to controls. The fact that the original memory is not really forgotten, could also perhaps explain why the perseverance effects observed in the syt $3 \mathrm{KO}$ mice were quantitatively small, i.e., syt $3 \mathrm{KO}$ mice were $\sim 5 \mathrm{~cm}$ closer in proximity to the original platform in probe tests compared to WT mice. Although the average distance between platforms is as large as $59 \mathrm{~cm}$, the effect of "normal forgetting' in WT mice decreased the proximity to the original platform by only $11.5 \mathrm{~cm}$. Thus, one might not expect large changes in proximity in a mouse strain with deficits in forgetting. The largest difference in proximity to a hidden platform during a probe test repoted to date is only $\sim 13$ $\mathrm{cm}$ in data pooled from 370 control mice and 388 mice with severe learning deficits (Maei et al, 2009). Thus, a difference in proximity of $\sim 5 \mathrm{~cm}$ is quite large by comparison.

To ensure these effects were indeed because of an impairment in forgetting, one could estimate the maximum possible difference in proximity, or quantify changes in proximity normalized to 
maximum differences in proximity throughout training, as \% forgetting. An ideal experiment to demonstrate impairments in forgetting would be to induce extinction of the original platform position by injecting mice with anisomycin 1 hour before a probe test, since anisomycin abolishes reconsolidation (Suzuki et al, 2004) and presumably promotes 3Y machinery-mediated AMPA receptor internalization (Hong et al, 2013). Anisomycin-injected syt3 KO mice should show impaired extinction or forgetting, and continue to remember the original platform after platform reversal, and anisomycin-injected wild-type mice would be expected to completely forget the original position. We also observed a lack of a within-trial extinction in probe tests in syt3 knockout mice, presumably because of a lack of GluA2-AMPA receptor internalization upon memory retreival (Hong et al, 2013). The strongest evidence for an impaired forgetting in syt3 KO mice was in the last probe test following reversal, when the biggest differences in proximity to original platform of up to $\sim 8 \mathrm{~cm}$ were observed in syt3 $\mathrm{KO}$ mice in all time bins except 10-30 secs. There were no significant differences in the time bins 10-30 sec, probably because this is when the current memory (in this case, memory of the current platform position after reversal) is retrieved most effectively.

\section{- Syt3 KO mice show impaired forgetting in the DMP watermaze}

We hypothesized that the reinforced weak-LTP in syt3 KO mice may result in deficits in working memory and ability to forget previous platform positions and remember new ones in the delayed matching to place (DMP) task - a working-memory learning task, in which the hidden platform is moved to a new position each day for 16 days, where each day the mice have 4 trials to learn the new position. Mice with NMDA receptors specifically knocked out in CA3 neurons in the hippocampus (Nakazawa et al, 2003) and forebrain specific calcineurin knockout mice showed deficits in this task (Zeng et al, 2001). We hypothesized that syt3 KO mice would be maximally different from WT mice when the delay retention period between trial 1 and trial 2 was increased to $75 \mathrm{~min}$, if decay of weak LTP (which decays with this same time course) is important for

forgetting previous platform positions and learning new ones. The syt3 KO mice were highly impaired in the delayed matching to place (DMP) watermaze - a working-memory learning task. However, there was no conspicuous difference upon increasing the trial 1 and trial 2 inter-trial interval from $5 \mathrm{~min}$ to $75 \mathrm{~min}$. The perseverance of syt3 $\mathrm{KO}$ mice to older platform positions suggests that their inability to "forget" previous positions may result from enhanced consolidation 
of the memory of previous platform positions over the course of several days, resulting in impaired forgetting in syt3 $\mathrm{KO}$ mice.

The probe trial performance in the DMP watermaze task in rats reaches chance levels in 24 hours (Da Silva et al, 2013). However, it is not clear if LTD or depotentiation (i.e. synaptic depression below basal levels or depression of previously potentiated synapses, respectively) underlies this forgetting. Extrapolating to mice, we would expect that WT mice should forget the previous day's platform position in the DMP task. The higher perseverance of syt3 KO mice to the previous day's platform position compared to WT mice on almost all days of training clearly showed that syt3 KO mice have either a) impaired forgetting, or b) stronger consolidation of working memory, both of which are in agreement with reinforced weak LTP observed at the CA3-CA1 synapse in syt3 KO mice. In the probe test of the DMP task, which is the most reliable indicator of memory (Da Silva et al., 2013), syt3 KO mice show a strikingly different pattern of search focus compared to WT mice; syt $3 \mathrm{KO}$ mice are $\sim 4 \mathrm{~cm}$ more proximal to most platform centres from previous days. It is important to note that increased perseverance of syt3 $\mathrm{KO}$ mice to all previous platform positions indicates that multiple spatial memories could be consolidated. Unconsolidated memories cannot be retrieved and strategy analysis indicated that perseverance trials were not due to a random search path near previous platform positions. Thus, syt3 $\mathrm{KO}$ mice can consolidate and remember a remarkably large number of unique platform positions in the same spatial context.

In summary, we discovered that syt3 is predominantly on the post-synaptic membrane, where it regulates AMPA receptor trafficking via the $3 \mathrm{Y}$ motif of GluA2. It does not affect constitutive trafficking but only activity dependent internalization of AMPA receptors to counteract synaptic potentiation and promote forgetting. 


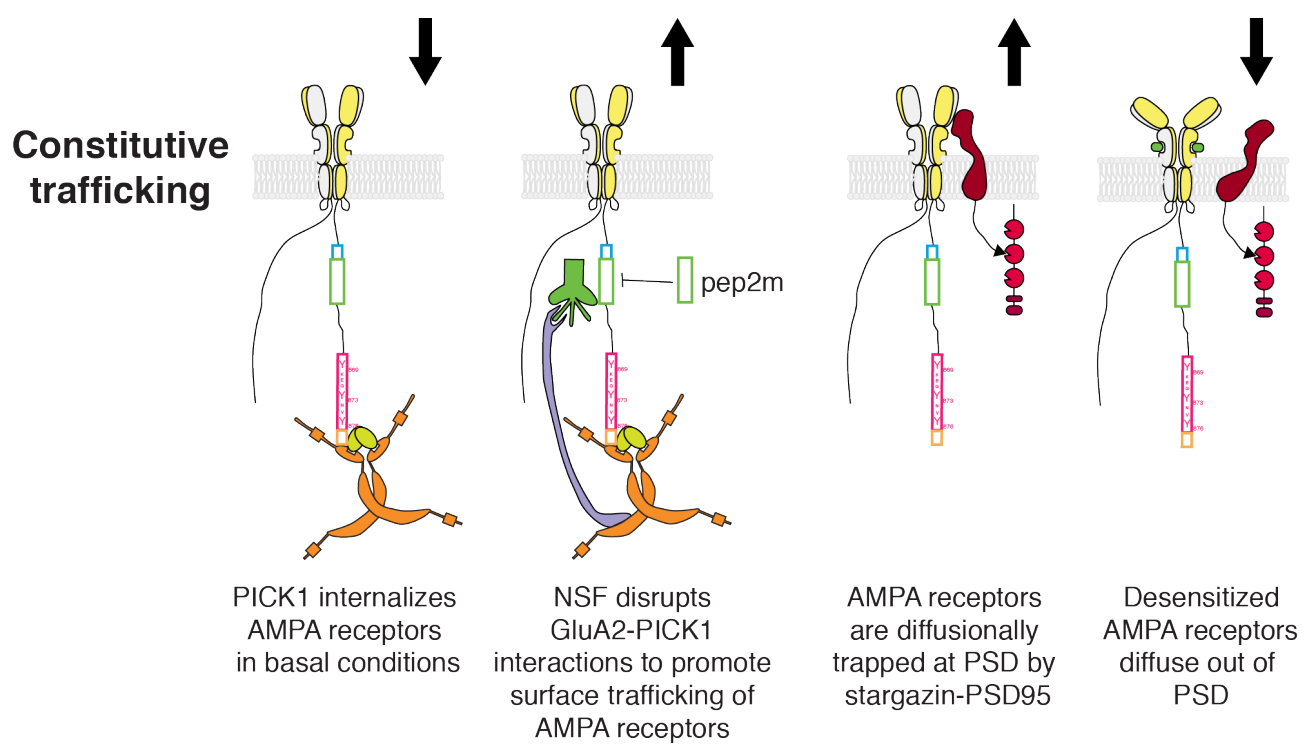

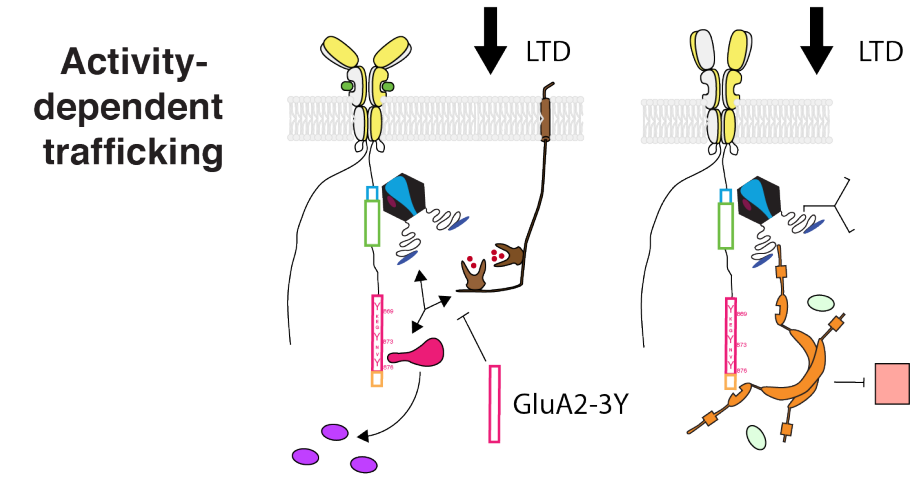

The $3 Y$ internalization machinery is necessary for GluA2-AMPA receptor internalization during NMDA receptor induced LTD
PICK1 recruits AMPA receptors to clathrin coated pits during NMDA receptor induced LTD

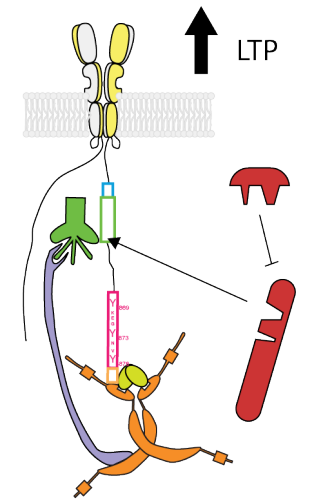

PKMzeta upregulates NSF mediated surface trafficking of AMPA receptors during NMDA receptor induced strong-LTP

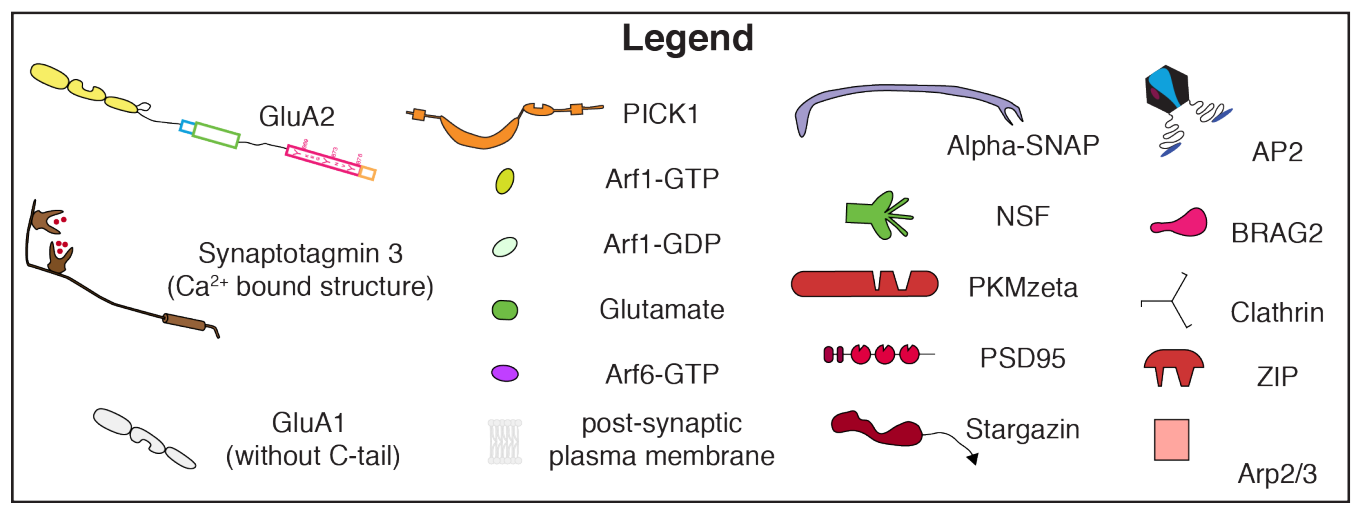

\section{Figure 26: Summary of the role of syt3 in AMPA receptor trafficking}

Illustrations show AMPA receptor trafficking pathways. Black arrows on top of each illustration indicate net effect of AMPA receptor trafficking on synaptic depression or potentiation. Syt3 is a component of the the activitydependent AMPA receptor $3 \mathrm{Y}$ internalization machinery. 


\section{Bibliography}

A, H.-T., Yagishita, S., Nakamura, M., Shirai, F., Wu, Y., Loshbaugh, A., ... Kasai, H. (2015). Labelling and optical erasure of synaptic memory traces in the motor cortex. Nature, 525(7569), 333-8. https://doi.org/10.1038/nature15257

Adesnik, H., \& Nicoll, R. A. (2007). Conservation of Glutamate Receptor 2-Containing AMPA Receptors during Long-Term Potentiation. Journal of Neuroscience, 27(17), 4598-4602. https://doi.org/10.1523/JNEUROSCI.0325-07.2007

Ahmadian, G., Ju, W., Liu, L., Wyszynski, M., Lee, S. H., Dunah, A. W., ... Wang, Y. T. (2004). Tyrosine phosphorylation of GluR2 is required for insulin-stimulated AMPA receptor endocytosis and LTD. EMBO J., 23(5), 1040-50. https://doi.org/10.1038/sj.emboj.7600126

Ahmed, S., Holt, M., Riedel, D., \& Jahn, R. (2013). Small-scale isolation of synaptic vesicles from mammalian brain., 8(5), 998-1009. https://doi.org/10.1038/nprot.2013.053

Arendt, K. L., Zhang, Y., Jurado, S., Malenka, R. C., Südhof, T. C., \& Chen, L. (2015). Retinoic Acid and LTP Recruit Postsynaptic AMPA Receptors Using Distinct SNARE-Dependent Mechanisms. Neuron. https://doi.org/10.1016/j.neuron.2015.03.009

Ashby, M. C. (2004). Removal of AMPA Receptors (AMPARs) from Synapses Is Preceded by Transient Endocytosis of Extrasynaptic AMPARs. Journal of Neuroscience, 24(22), 51725176. https://doi.org/10.1523/JNEUROSCI.1042-04.2004

Bannerman, D. M., Bus, T., Taylor, A., Sanderson, D. J., Schwarz, I., Jensen, V., ... Sprengel, R. (2012). Dissecting spatial knowledge from spatial choice by hippocampal NMDA receptor deletion. Nature Neuroscience, 15(8), 1153-1159. https://doi.org/10.1038/nn.3166

Barber, M., Arai, Y., Morishita, Y., Vigier, L., Causeret, F., Borello, U., ... Pierani, A. (2015). Migration Speed of Cajal-Retzius Cells Modulated by Vesicular Trafficking Controls the Size of Higher-Order Cortical Areas. Current Biology, 25(19), 2466-2478. https://doi.org/10.1016/j.cub.2015.08.028

Bartlett, T. E., \& Wang, Y. T. (2011). Illuminating synapse-specific homeostatic plasticity. Neuron, 72(5), 682-5. https://doi.org/10.1016/j.neuron.2011.11.009

Beattie, E., Carroll, R., Yu, X., Morishita, W., Yasuda, H., von, Z. M., \& Malenka, R. (2000). Regulation of AMPA receptor endocytosis by a signaling mechanism shared with LTD., 3(12), 1291-300. https://doi.org/10.1038/81823

Berridge, M. (1998). Neuronal calcium signaling., 21(1), 13-26. https://doi.org/10.1016/S08966273(00)80510-3

Bhalla, A., Chicka, M. C., \& Chapman, E. R. (2008). Analysis of the synaptotagmin family during reconstituted membrane fusion. Uncovering a class of inhibitory isoforms. J. Biol. Chem., 283(31), 21799-807. https://doi.org/10.1074/jbc.M709628200 
Blanpied, T. A., Scott, D. B., \& Ehlers, M. D. (2002). Dynamics and Regulation of Clathrin Coats at Specialized Endocytic Zones of Dendrites and Spines, 36(3), 435-449. https://doi.org/10.1016/S0896-6273(02)00979-0

Bliss, T. V., \& Lømo, T. (1973). Long-lasting potentiation of synaptic transmission in the dentate area of the anaesthetized rabbit following stimulation of the perforant path. The Journal of Physiology, 232(2), 331-356.

Borst, J. G. G., \& Soria van Hoeve, J. (2012). The Calyx of Held Synapse: From Model Synapse to Auditory Relay. Annual Review of Physiology, 74(1), 199-224. https://doi.org/10.1146/annurev-physiol-020911-153236

Boyken, J., Grønborg, M., Riedel, D., Urlaub, H., Jahn, R., \& Chua, J. (2013). Molecular Profiling of Synaptic Vesicle Docking Sites Reveals Novel Proteins but Few Differences between Glutamatergic and GABAergic Synapses. Neuron, 78(2), 285-297. https://doi.org/10.1016/j.neuron.2013.02.027

Brown, H., Meister, B., Deeney, J., Corkey, B., Yang, S., Larsson, O., ... Fried, G. (2000). Synaptotagmin III isoform is compartmentalized in pancreatic beta-cells and has a functional role in exocytosis., 49(3), 383-391. https://doi.org/10.2337/diabetes.49.3.383

Brown, T. C., Tran, I. C., Backos, D. S., \& Esteban, J. A. (2005). NMDA Receptor-Dependent Activation of the Small GTPase Rab5 Drives the Removal of Synaptic AMPA Receptors during Hippocampal LTD. Neuron, 45(1), 81-94. https://doi.org/10.1016/j.neuron.2004.12.023

Butz, S., R, F.-C., Schmitz, F., Jahn, R., \& Südhof, T. (1999). The subcellular localizations of atypical synaptotagmins III and VI. Synaptotagmin III is enriched in synapses and synaptic plasma membranes but not in synaptic vesicles., 274(26), 18290-6. https://doi.org/10.1074/jbc.274.26.18290

Carroll, R., Beattie, E., von Zastrow, M., \& Malenka, R. (2001). Role of AMPA receptor endocytosis in synaptic plasticity. Nat. Rev. Neurosci., 2(5), 315-24. https://doi.org/10.1038/35072500

Carroll, R., Beattie, E., Xia, H., Lüscher, C., Altschuler, Y., Nicoll, R., ... von Zastrow, M. (1999). Dynamin-dependent endocytosis of ionotropic glutamate receptors. Proc. Natl. Acad. Sci. U.S.A., 96(24), 14112-7. https://doi.org/10.1073/pnas.96.24.14112

Carroll RC, Lissin DV, von Zastrow M, Nicoll RA, Malenka RC. (1999). Rapid redistribution of glutamate receptors contributes to long-term depression in hippocampal cultures. Nature neuroscience.

Choquet, D., \& Triller, A. (2013). The dynamic synapse., 80(3), 691-703. https://doi.org/10.1016/j.neuron.2013.10.013

Chowdhury, S., Shepherd, J. D., Okuno, H., Lyford, G., Petralia, R. S., Plath, N., ... Worley, P. F. (2006). Arc/Arg3.1 Interacts with the Endocytic Machinery to Regulate AMPA Receptor Trafficking. Neuron, 52(3), 445-459. https://doi.org/10.1016/j.neuron.2006.08.033 
Chung HJ, Xia J, Scannevin RH, Zhang X, Huganir RL. (2000). Phosphorylation of the AMPA Receptor Subunit GluR2 Differentially Regulates Its Interaction with PDZ DomainContaining Proteins. J. Neurosc.

Collingridge, G. L., Isaac, J. T., \& Wang, Y. (2004). Receptor trafficking and synaptic plasticity, 5(12), 952-962. https://doi.org/10.1038/nrn1556

Collingridge, G. L., Kehl, S. J., \& McLennan, H. t. (1983). Excitatory amino acids in synaptic transmission in the Schaffer collateral-commissural pathway of the rat hippocampus. The Journal of Physiology, 334(1), 33-46.

Collingridge, G., Peineau, S., Howland, J., \& Wang, Y. (2010). Long-term depression in the CNS., 11(7), 459-73. https://doi.org/10.1038/nrn2867

Constals, A., Penn, A. C., Compans, B., Toulmé, E., Phillipat, A., Marais, S., ... Choquet, D. (2015). Glutamate-induced AMPA receptor desensitization increases their mobility and modulates short-term plasticity through unbinding from Stargazin. Neuron, 85(4), 787803. https://doi.org/10.1016/j.neuron.2015.01.012

Cooper, L. N., \& Bear, M. F. (2012). The BCM theory of synapse modification at 30: interaction of theory with experiment, 13(11), 798-810. https://doi.org/10.1038/nrn3353

Coutts AA, Anavi-Goffer S, Ross RA, MacEwan DJ, Mackie K, Pertwee RG, Irving AJ. (2001). Agonist-induced internalization and trafficking of cannabinoid $\mathrm{CB} 1$ receptors in hippocampal neurons. J. Neurosc.

da Silva, B. M., Bast, T., \& Morris, R. G. (2014). Spatial memory: behavioral determinants of persistence in the watermaze delayed matching-to-place task. Learn. Mem., 21(1), 28-36. https://doi.org/10.1101/1m.032169.113

Dan Y, Poo MM. (1992). Hebbian depression of isolated neuromuscular synapses in vitro. Science.

Dani, A., Huang, B., Bergan, J., Dulac, C., \& Zhuang, X. (2010). Superresolution Imaging of Chemical Synapses in the Brain. Neuron, 68(5), 843-856. https://doi.org/10.1016/j.neuron.2010.11.021

DaSilva, L. L. P., Wall, M. J., P. de Almeida, L., Wauters, S. C., Januario, Y. C., Mu ller, J., \& Correa, S. A. L. (2016). Activity-Regulated Cytoskeleton-Associated Protein Controls AMPAR Endocytosis through a Direct Interaction with Clathrin-Adaptor Protein 2. eNeuro, 3(3). https://doi.org/10.1523/ENEURO.0144-15.2016

Davidson, H. T., Xiao, J., Dai, R., \& Bergson, C. (2009). Calcyon is necessary for activitydependent AMPA receptor internalization and LTD in CA1 neurons of hippocampus. European Journal of Neuroscience, 29(1), 42-54. https://doi.org/10.1111/j.14609568.2008.06563.x

Dean, C., Dunning, F., Liu, H., Ewa, B.-W., Martens, H., Bharat, V., ... Chapman, E. R. (2012). Axonal and dendritic synaptotagmin isoforms revealed by a pHluorin-syt functional screen., 23(9), 1715-27. https://doi.org/10.1091/mbc.E11-08-0707

Delvendahl, I., \& Hallermann, S. (2016). The Cerebellar Mossy Fiber Synapse as a Model for High-Frequency Transmission in the Mammalian CNS. Trends in Neurosciences, 39(11), 722-737. https://doi.org/10.1016/j.tins.2016.09.006 
Derkach, V. A., Oh, M. C., Guire, E. S., \& Soderling, T. R. (2007). Regulatory mechanisms of AMPA receptors in synaptic plasticity. Nat. Rev. Neurosci., 8(2), 101-13. https://doi.org/10.1038/nrn2055

Dev K. K., Nishimune A., Henley J.M., Nakanishi S. (1999). The protein kinase Ca binding protein PICK1 interacts with short but not long form alternative splice variants of AMPA receptor subunits. Neuropharmacology, 38, 635-644. DOI: 10.1016/S00283908(98)00230-5

Dong, H., RJ, O., Fung, E., Lanahan, A., \& Worley, P. (1997). GRIP: a synaptic PDZ domaincontaining protein that interacts with AMPA receptors. https://doi.org/10.1038/386279a0

Dong, Z., Bai, Y., Wu, X., Li, H., Gong, B., Howland, J. G., ... Wang, Y. T. (2013). Hippocampal long-term depression mediates spatial reversal learning in the Morris water maze. Neuropharmacology, 64, 65-73. https://doi.org/10.1016/j.neuropharm.2012.06.027

Dong, Z., Han, H., Li, H., Bai, Y., Wang, W., Tu, M., ... Wang, Y. T. (2015). Long-term potentiation decay and memory loss are mediated by AMPAR endocytosis. J. Clin. Invest., 125(1), 234-47. https://doi.org/10.1172/JCI77888

D'Souza-Schorey, C., \& Chavrier, P. (2006). ARF proteins: roles in membrane traffic and beyond. Nature Reviews Molecular Cell Biology, 7(5), 347-358. https://doi.org/10.1038/nrm1910

Edelmann, E., Cepeda-Prado, E., Franck, M., Lichtenecker, P., Brigadski, T., \& Leßmann, V. (2015). Theta Burst Firing Recruits BDNF Release and Signaling in Postsynaptic CA1 Neurons in Spike-Timing-Dependent LTP. Neuron, 86(4), 1041-1054. https://doi.org/10.1016/j.neuron.2015.04.007

Eggermann, E., Bucurenciu, I., Goswami, S. P., \& Jonas, P. (2011). Nanodomain coupling between $\mathrm{Ca} 2+$ channels and sensors of exocytosis at fast mammalian synapses. Nature Reviews Neuroscience, 13(1), 7-21. https://doi.org/10.1038/nrn3125

Ehlers, M. (2000). Reinsertion or degradation of AMPA receptors determined by activitydependent endocytic sorting. Neuron, 28(2), 511-25. https://doi.org/10.1016/S08966273(00)00129-X

Ferguson, S. M., \& De Camilli, P. (2012). Dynamin, a membrane-remodelling GTPase. Nature Reviews Molecular Cell Biology. https://doi.org/10.1038/nrm3266

Fernández-Alfonso, T., Kwan, R., \& Ryan, T. A. (2006). Synaptic Vesicles Interchange Their Membrane Proteins with a Large Surface Reservoir during Recycling. Neuron, 51(2), 179186. https://doi.org/10.1016/j.neuron.2006.06.008

Fitzjohn, S. M., \& Bashir, Z. I. (2010). BRAGging about Mechanisms of Long-Term Depression. Neuron, 66(5), 627-630. https://doi.org/10.1016/j.neuron.2010.05.027

Fiuza M, Rostosky CM, Parkinson GT, Bygrave AM, Halemani N, Baptista M, et al (2017). PICK1 regulates AMPA receptor endocytosis via direct interactions with AP2 $\alpha$-appendage and dynamin. J. Cell Biol. 2017; 216:3323-38. DOI: 10.1083/jcb.201701034

Frankland PW, Josselyn SA. (2016). In search of the memory molecule. Nature.

Fredj, N. B., \& Burrone, J. (2009). A resting pool of vesicles is responsible for spontaneous vesicle fusion at the synapse., 12(6), 751-8. https://doi.org/10.1038/nn.2317 
Fukuda M et al. (1999). Conserved N-terminal cysteine motif is essential for homo- and heterodimer formation of synaptotagmins III, V, VI, and X. J. Biol. Chem.

Gallagher, M., Burwell, R., \& Burchinal, M. (2015). Severity of spatial learning impairment in aging: Development of a learning index for performance in the Morris water maze., 129(4), 540. https://doi.org/10.1037/bne0000080

Garthe, A., Behr, J., \& Kempermann, G. (2009). Adult-generated hippocampal neurons allow the flexible use of spatially precise learning strategies. PLoS ONE, 4(5), e5464. https://doi.org/10.1371/journal.pone.0005464

Geppert M et al. (1994). Synaptotagmin I: a major Ca2+ sensor for transmitter release at a central synapse. Cell.

Gina G. Turrigiano, Kenneth R. Leslie, Niraj S. Desai, \& Lana C. Rutherford \& Sacha B. Nelson. (1998). Activity-dependent scaling of quantal amplitude in neocortical neurons. Nature.

Glebov, O. O., Tigaret, C. M., Mellor, J. R., \& Henley, J. M. (2015). Clathrin-independent trafficking of AMPA receptors. J. Neurosci., 35(12), 4830-6. https://doi.org/10.1523/JNEUROSCI.3571-14.2015

Godlee, C., \& Kaksonen, M. (2013). Review series: From uncertain beginnings: initiation mechanisms of clathrin-mediated endocytosis. J. Cell Biol., 203(5), 717-25. https://doi.org/10.1083/jcb.201307100

Govindarajan, A., Israely, I., Huang, S., \& Tonegawa, S. (n.d.). The dendritic branch is the preferred integrative unit for protein synthesis-dependent LTP. Neuron, 69(1), 132-46. https://doi.org/10.1016/j.neuron.2010.12.008

Grass, I., Thiel, S., Honing, S., \& Haucke, V. (2004). Recognition of a Basic AP-2 Binding Motif within the C2B Domain of Synaptotagmin Is Dependent on Multimerization. Journal of Biological Chemistry, 279(52), 54872-54880. https://doi.org/10.1074/jbc.M409995200

Graziane, N. M., Sun, S., Wright, W. J., Jang, D., Liu, Z., Huang, Y. H., ... Dong, Y. (2016). Opposing mechanisms mediate morphine- and cocaine-induced generation of silent synapses. Nature Neuroscience, 19(7), 915-925. https://doi.org/10.1038/nn.4313

Griffiths, S., Scott, H., Glover, C., Bienemann, A., Ghorbel, M. T., Uney, J., ... Bashir, Z. I. (2008). Expression of Long-Term Depression Underlies Visual Recognition Memory. Neuron, 58(2), 186-194. https://doi.org/10.1016/j.neuron.2008.02.022

Groc, L., Heine, M., Cognet, L., \& Brickley, K. (2004). Differential activity-dependent regulation of the lateral mobilities of AMPA and NMDA receptors. Nature .... https://doi.org/10.1038/nn1270

Groemer, T. W., \& Klingauf, J. (2007). Synaptic vesicles recycling spontaneously and during activity belong to the same vesicle pool. Nature Neuroscience, 10(2), 145-147. https://doi.org/10.1038/nn1831

Gut, A., Kiraly, C. E., Fukuda, M., Mikoshiba, K., Wollheim, C. B., \& Lang, J. (2001). Expression and localisation of synaptotagmin isoforms in endocrine $(\beta)$-cells: their function in insulin exocytosis. Journal of Cell Science, 114(9), 1709-1716. 
Hanley, J. G. (2010). Endosomal sorting of AMPA receptors in hippocampal neurons: Figure 1. Biochemical Society Transactions, 38(2), 460-465. https://doi.org/10.1042/BST0380460

Hanley, J. G., Khatri, L., Hanson, P. I., \& Ziff, E. B. (2002). NSF ATPase and alpha-/beta-SNAPs disassemble the AMPA receptor-PICK1 complex. Neuron, 34(1), 53-67. https://doi.org/10.1016/S0896-6273(02)00638-4

Hanley JG, Henley JM. (2005). PICK1 is a calcium-sensor for NMDA-induced AMPA receptor trafficking. EMBO J.

Hardt, O., Nader, K., \& Nadel, L. (2013). Decay happens: the role of active forgetting in memory. Trends in Cognitive Sciences, 17(3), 111-120. https://doi.org/10.1016/j.tics.2013.01.001

Hardt, O., Nader, K., \& Wang, Y.-T. T. (2014). GluA2-dependent AMPA receptor endocytosis and the decay of early and late long-term potentiation: possible mechanisms for forgetting of short- and long-term memories. Philos. Trans. R. Soc. Lond., B, Biol. Sci., 369(1633), 20130141. https://doi.org/10.1098/rstb.2013.0141

Harnett, M. T., Makara, J. K., Spruston, N., Kath, W. L., \& Magee, J. C. (2012). Synaptic amplification by dendritic spines enhances input cooperativity., 491(7425), 599-602. https://doi.org/10.1038/nature11554

Haucke, V., Wenk, M., Chapman, E., Farsad, K., \& De Camilli, P. (2000). Dual interaction of synaptotagmin with mu2- and alpha-adaptin facilitates clathrin-coated pit nucleation. EMBO J., 19(22), 6011-9. https://doi.org/10.1093/emboj/19.22.6011

Hayashi, T. (2004). Tyrosine Phosphorylation and Regulation of the AMPA Receptor by Src Family Tyrosine Kinases. Journal of Neuroscience, 24(27), 6152-6160. https://doi.org/10.1523/JNEUROSCI.0799-04.2004

Hayashi, T., \& Huganir, R. L. (2004). Tyrosine phosphorylation and regulation of the AMPA receptor by SRC family tyrosine kinases. J. Neurosci., 24(27), 6152-60. https://doi.org/10.1523/JNEUROSCI.0799-04.2004

Hayashi-Takagi, A., Yagishita, S., Nakamura, M., Shirai, F., Wu, Y. I., Loshbaugh, A. L., ... Kasai, H. (2015). Labelling and optical erasure of synaptic memory traces in the motor cortex. Nature, 525(7569), 333-338. https://doi.org/10.1038/nature15257

Henley, J. M., \& Wilkinson, K. A. (2016). Synaptic AMPA receptor composition in development, plasticity and disease. Nat. Rev. Neurosci., 17(6), 337-50. https://doi.org/10.1038/nrn.2016.37

Hoffman, D., Sprengel, R., \& Sakmann, B. (2002). Molecular dissection of hippocampal thetaburst pairing potentiation. Proc. Natl. Acad. Sci. U.S.A., 99(11), 7740-5. https://doi.org/10.1073/pnas.092157999

Hong, I., Kim, J., Kim, J., Lee, S., Ko, H., Nader, K., ... Choi, S. (2013). AMPA receptor exchange underlies transient memory destabilization on retrieval. Proc Natl Acad Sci US A, 110(20), 8218-23. https://doi.org/10.1073/pnas.1305235110

Hou, Q., Gilbert, J., \& Man, H.-Y. Y. (2011). Homeostatic regulation of AMPA receptor trafficking and degradation by light-controlled single-synaptic activation. Neuron, 72(5), 806-18. https://doi.org/10.1016/j.neuron.2011.10.011 
Hou, Q., Zhang, D., \& Jarzylo, L. (2008). Homeostatic regulation of AMPA receptor expression at single hippocampal synapses. Proceedings of the .... https://doi.org/10.1073/pnas.0706447105

Hua, Y., Sinha, R., Martineau, M., Kahms, M., \& Klingauf, J. (2010). A common origin of synaptic vesicles undergoing evoked and spontaneous fusion., 13(12), 1451-3. https://doi.org/10.1038/nn.2695

Isaac, J., Ashby, M. C., \& J, M., Chris. (2007). The Role of the GluR2 Subunit in AMPA Receptor Function and Synaptic Plasticity, 54(6), 859-71. https://doi.org/10.1016/j.neuron.2007.06.001

Ito M, \& Kano M. (1982). Long-lasting depression of parallel fiber-Purkinje cell transmission induced by conjunctive stimulation of parallel fibers and climbing fibers in the cerebellar cortex. Neuroscience Letters.

Jaafari, N., Henley, J. M., \& Hanley, J. G. (2012). PICK1 Mediates Transient Synaptic Expression of GluA2-Lacking AMPA Receptors during Glycine-Induced AMPA Receptor Trafficking. Journal of Neuroscience, 32(34), 11618-11630. https://doi.org/10.1523/JNEUROSCI.5068-11.2012

Jackman, S. L., Turecek, J., Belinsky, J. E., \& Regehr, W. G. (2016). The calcium sensor synaptotagmin 7 is required for synaptic facilitation. Nature, 529(7584), 88-91. https://doi.org/10.1038/nature16507

Jarousse, N., Wilson, J. D., Arac, D., Rizo, J., \& Kelly, R. B. (2003). Endocytosis of synaptotagmin 1 is mediated by a novel, tryptophan-containing motif., 4(7), 468-78. https://doi.org/10.1034/j.1600-0854.2003.00101.x

Josselyn, S. A., Köhler, S., \& Frankland, P. W. (2015). Finding the engram. Nature Reviews Neuroscience, 16(9), 521-534. https://doi.org/10.1038/nrn4000

Jurado, S., Goswami, D., Zhang, Y., Molina, A. J., Südhof, T. C., \& Malenka, R. C. (2013). LTP requires a unique postsynaptic SNARE fusion machinery., 77(3), 542-58. https://doi.org/10.1016/j.neuron.2012.11.029

Kastning K, Kukhtina V, Kittler JT, Chen G, Pechstein A, Enders S, Lee SH, Sheng M, Yan Z, Haucke V. (2007). Molecular determinants for the interaction between AMPA receptors and the clathrin adaptor complex AP-2. Proc Natl Acad Sci U S A.

Kelly BT, Graham SC, Liska N, Dannhauser PN, Höning S, Ungewickell EJ, Owen DJ. (2014). AP2 controls clathrin polymerization with a membrane-activated switch. Science.

Kennedy, M. J., Davison, I. G., Robinson, C. G., \& Ehlers, M. D. (2010). Syntaxin-4 defines a domain for activity-dependent exocytosis in dendritic spines., 141(3), 524-35. https://doi.org/10.1016/j.cell.2010.02.042

Kimura, R., Silva, A. J., \& Ohno, M. (2008). Autophosphorylation of CaMKII is differentially involved in new learning and unlearning mechanisms of memory extinction. Learning \& Memory, 15(11), 837-843. https://doi.org/10.1101/1m.1049608 
Kirchhausen, T., Owen, D., \& Harrison, S. C. (2014). Molecular Structure, Function, and Dynamics of Clathrin-Mediated Membrane Traffic. Cold Spring Harbor Perspectives in Biology, 6(5), a016725-a016725. https://doi.org/10.1101/cshperspect.a016725

Krauss, M., Kinuta, M., Wenk, M. R., De Camilli, P., Takei, K., \& Haucke, V. (2003). ARF6 stimulates clathrin/AP-2 recruitment to synaptic membranes by activating phosphatidylinositol phosphate kinase type I $\gamma$. The Journal of Cell Biology, 162(1), 113124. https://doi.org/10.1083/jcb.200301006

Lattal, K. M., Mullen, M. T., \& Abel, T. (2003). Extinction, renewal, and spontaneous recovery of a spatial preference in the water maze. Behavioral Neuroscience, 117(5), 1017-1028. https://doi.org/10.1037/0735-7044.117.5.1017

LeBlancq, M. J., McKinney, T. L., \& Dickson, C. T. (2016). ZIP It: Neural Silencing Is an Additional Effect of the PKM-Zeta Inhibitor Zeta-Inhibitory Peptide. Journal of Neuroscience, 36(23), 6193-6198. https://doi.org/10.1523/JNEUROSCI.4563-14.2016

Lee, A. M., Kanter, B. R., Wang, D., Lim, J. P., Zou, M. E., Qiu, C., ... Messing, R. O. (2013). Prkcz null mice show normal learning and memory. Nature, 493(7432), 416-419. https://doi.org/10.1038/nature11803

Lee HK, Kameyama K, Huganir RL, Bear MF. (1998). NMDA Induces Long-Term Synaptic Depression and Dephosphorylation of the GluR1 Subunit of AMPA Receptors in Hippocampus. Neuron.

Lee, P. Y., Costumbrado, J., Hsu, C.-Y. Y., \& Kim, Y. H. (2012). Agarose gel electrophoresis for the separation of DNA fragments. J Vis Exp, (62). https://doi.org/10.3791/3923

Lee, S. H., Simonetta, A., \& Sheng, M. (2004). Subunit rules governing the sorting of internalized AMPA receptors in hippocampal neurons. Neuron, 43(2), 221-36. https://doi.org/10.1016/j.neuron.2004.06.015

Lee, S., Liu, L., Wang, Y., \& Sheng, M. (2002). Clathrin Adaptor AP2 and NSF Interact with Overlapping Sites of GluR2 and Play Distinct Roles in AMPA Receptor Trafficking and Hippocampal LTD, 36(4), 661-674. https://doi.org/10.1016/S0896-6273(02)01024-3

Li C et al. (1995). $\mathrm{Ca}(2+)$-dependent and -independent activities of neural and non-neural synaptotagmins. Nature.

Li, L., Stefan, M. I., \& Le Novère, N. (2012). Calcium Input Frequency, Duration and Amplitude Differentially Modulate the Relative Activation of Calcineurin and CaMKII. PLoS ONE, 7(9), e43810. https://doi.org/10.1371/journal.pone.0043810

Lin, D.-T. T., \& Huganir, R. L. (2007). PICK1 and phosphorylation of the glutamate receptor 2 (GluR2) AMPA receptor subunit regulates GluR2 recycling after NMDA receptor-induced internalization. J. Neurosci., 27(50), 13903-8. https://doi.org/10.1523/JNEUROSCI.175007.2007

Lin, J. W., Ju, W., Foster, K., Lee, S., Ahmadian, G., Wyszynski, M., ... Sheng, M. (2000). Distinct molecular mechanisms and divergent endocytotic pathways of AMPA receptor internalization. Nature ..., 3(12), 1282-1290. https://doi.org/10.1038/81814 
Ling, D., Benardo, L. S., Serrano, P. A., Blace, N., Kelly, M. T., Crary, J. F., \& Sacktor, T. C. (2002). Protein kinase $M \zeta$ is necessary and sufficient for LTP maintenance, 5(4), 295-296. https://doi.org/10.1038/nn829

Lisman, J. E., Raghavachari, S., \& Tsien, R. W. (2007). The sequence of events that underlie quantal transmission at central glutamatergic synapses, 8(8), 597-609. https://doi.org/10.1038/nrn2191

Lisman, J., Yasuda, R., \& Raghavachari, S. (2012). Mechanisms of CaMKII action in long-term potentiation., 13(3), 169-82. https://doi.org/10.1038/nrn3192

Liu, S., \& Savtchouk, I. (2012). Ca2+ permeable AMPA receptors switch allegiances: mechanisms and consequences, 590(1), 13-20. https://doi.org/10.1113/jphysiol.2011.213926

Loebrich, S., Benoit, M. R., Konopka, J. A., Cottrell, J. R., Gibson, J., \& Nedivi, E. (2016). CPG2 Recruits Endophilin B2 to the Cytoskeleton for Activity-Dependent Endocytosis of Synaptic Glutamate Receptors. Curr. Biol., 26(3), 296-308. https://doi.org/10.1016/j.cub.2015.11.071

Lomo, T. (2003). The discovery of long-term potentiation. Philosophical Transactions of the Royal Society B: Biological Sciences, 358(1432), 617-620. https://doi.org/10.1098/rstb.2002.1226

Lowel S, Singer W. (1992). Selection of intrinsic horizontal connections in the visual cortex by correlated neuronal activity. Science.

Lu, J., Helton, T. D., Blanpied, T. A., Rácz, B., Newpher, T. M., Weinberg, R. J., \& Ehlers, M. D. (2007). Postsynaptic Positioning of Endocytic Zones and AMPA Receptor Cycling by Physical Coupling of Dynamin-3 to Homer. Neuron, 55(6), 874-889. https://doi.org/10.1016/j.neuron.2007.06.041

Lüscher C, Xia H, Beattie EC, Carroll RC, von Zastrow M, Malenka RC, Nicoll RA. (1999). Role of AMPA Receptor Cycling in Synaptic Transmission and Plasticity. Neuron.

MacGillavry, H. D., Song, Y., Raghavachari, S., \& Blanpied, T. A. (2013). Nanoscale Scaffolding Domains within the Postsynaptic Density Concentrate Synaptic AMPA Receptors. Neuron, 78(4), 615-622. https://doi.org/10.1016/j.neuron.2013.03.009

Maei, H. R. (2009). What is the most sensitive measure of water maze probe test performance? Frontiers in Integrative Neuroscience, 3. https://doi.org/10.3389/neuro.07.004.2009

Maei, H. R., Zaslavsky, K., Teixeira, C. M., \& Frankland, P. W. (2009). What is the most sensitive measure of water maze probe test performance?, 3, 4. https://doi.org/10.3389/neuro.07.004.2009

Man, H.-Y., Lin, J. W., Ju, W. H., Ahmadian, G., Liu, L., Becker, L. E., ... Wang, Y. (2000). Regulation of AMPA Receptor-Mediated Synaptic Transmission by Clathrin-Dependent Receptor Internalization, 25(3), 649-662. https://doi.org/10.1016/S0896-6273(00)810673

Mao, S.-C. (2006). Extinction Training in Conjunction with a Partial Agonist of the Glycine Site on the NMDA Receptor Erases Memory Trace. Journal of Neuroscience, 26(35), 88928899. https://doi.org/10.1523/JNEUROSCI.0365-06.2006 
Maritzen, T., Podufall, J., \& Haucke, V. (2010). Stonins-Specialized Adaptors for Synaptic Vesicle Recycling and Beyond? Traffic, 11(1), 8-15. https://doi.org/10.1111/j.16000854.2009.00971.x

Martens, S., Kozlov, M. M., \& T, M., Harvey. (2007). How synaptotagmin promotes membrane fusion., 316(5828), 1205-8. https://doi.org/10.1126/science.1142614

McMahon, H. T., \& Boucrot, E. (2011). Molecular mechanism and physiological functions of clathrin-mediated endocytosis. Nature Reviews Molecular Cell Biology, 12(8), 517-533. https://doi.org/10.1038/nrm3151

Migaud, M., Charlesworth, P., Dempster, M., Webster, L. C., Watabe, A. M., Makhinson, M., ... others. (1998). Enhanced long-term potentiation and impaired learning in mice with mutant postsynaptic density-95 protein. Nature, 396(6710), 433-439.

Migues, P. V., Hardt, O., Wu, D. C., Gamache, K., Sacktor, T. C., Wang, Y. T., \& Nader, K. (2010). PKMzeta maintains memories by regulating GluR2-dependent AMPA receptor trafficking. Nat. Neurosci., 13(5), 630-4. https://doi.org/10.1038/nn.2531

Migues, P. V., Liu, L., Archbold, G. E., Einarsson, E. Ö., Wong, J., Bonasia, K., ... Hardt, O. (2016). Blocking Synaptic Removal of GluA2-Containing AMPA Receptors Prevents the Natural Forgetting of Long-Term Memories. J. Neurosci., 36(12), 3481-94. https://doi.org/10.1523/JNEUROSCI.3333-15.2016

Mikuni, T., Nishiyama, J., Sun, Y., Kamasawa, N., \& Yasuda, R. (2016). High-Throughput, HighResolution Mapping of Protein Localization in Mammalian Brain by In Vivo Genome Editing. https://doi.org/10.1016/j.cell.2016.04.044

Mizuta, M., Inagaki, N., Nemoto, Y., Matsukura, S., Takahashi, M., \& Seino, S. (1994). Synaptotagmin III is a novel isoform of rat synaptotagmin expressed in endocrine and neuronal cells. Journal of Biological Chemistry, 269(16), 11675-11678.

Mizuta, M., Kurose, T., Miki, T., Shoji-Kasai, Y., Takahashi, M., Seino, S., \& Matsukura, S. (1997). Localization and functional role of synaptotagmin III in insulin secretory vesicles in pancreatic $\beta$-cells. Diabetes, 46(12), 2002-2006.

Moult, P. R., Gladding, C. M., Sanderson, T. M., Fitzjohn, S. M., Bashir, Z. I., Molnar, E., et al.(2006). Tyrosine phosphatases regulate AMPA receptor trafficking during metabotropic glutamate receptor-mediated long-term depression. The Journal of neuroscience, 26(9), 2544-54. doi: 10.1523/JNEUROSCI.4322-05.2006.

Moult, P. R., Corrêa, S. A. L., Collingridge, G. L., Fitzjohn, S. M., \& Bashir, Z. I. (2008). Coactivation of p38 mitogen-activated protein kinase and protein tyrosine phosphatase underlies metabotropic glutamate receptor-dependent long-term depression: Signalling mechanisms underlying synaptic mGluR-LTD. The Journal of Physiology, 586(10), 24992510. https://doi.org/10.1113/jphysiol.2008.153122

Myers, K., \& Davis, M. (2007). Mechanisms of fear extinction. Mol. Psychiatry, 12(2), 120-50. https://doi.org/10.1038/sj.mp.4001939

Myers, K. M., Ressler, K. J., \& Davis, M. (2006). Different mechanisms of fear extinction dependent on length of time since fear acquisition, 13(2), 216-223. https://doi.org/10.1101/lm.119806 
Nabavi, S., Fox, R., Proulx, C., Lin, J., Tsien, R., \& Malinow, R. (2014). Engineering a memory with LTD and LTP. Nature, 511(7509), 348-52. https://doi.org/10.1038/nature13294

Nabavi, S., Fox, R., Proulx, C., Lin, J., Tsien, R., \& Malinow, R. (n.d.). Engineering a memory with LTD and LTP. Nature. https://doi.org/10.1038/nature13294

Nader K, Schafe GE, Le Doux JE. (2000). Fear memories require protein synthesis in the amygdala for reconsolidation after retrieval. Nature.

Nair, R., Lauks, J., Jung, S., Cooke, N. E., de Wit, H., Brose, N., .. Rhee, J. (2013). Neurobeachin regulates neurotransmitter receptor trafficking to synapses, 200(1), 61-80. https://doi.org/10.1083/jcb.201207113

Nakazawa, K., Sun, L. D., Quirk, M. C., Laure, R.-R., Wilson, M. A., \& Tonegawa, S. (2003). Hippocampal CA3 NMDA receptors are crucial for memory acquisition of one-time experience. Neuron, 38(2), 305-15.

Nicoll RA, Oliet SH, Malenka RC. (1998). NMDA receptor-dependent and metabotropic glutamate receptor-dependent forms of long-term depression coexist in CA1 hippocampal pyramidal cells. Neurobiol Learn Mem.

Nishiki, T. -i. (2004). Synaptotagmin I Synchronizes Transmitter Release in Mouse Hippocampal Neurons. Journal of Neuroscience, 24(27), 6127-6132. https://doi.org/10.1523/JNEUROSCI.1563-04.2004

Palmer, C. L., Lim, W., Hastie, P. G., Toward, M., Korolchuk, V. I., Burbidge, S. A., ... Henley, J. M. (2005). Hippocalcin functions as a calcium sensor in hippocampal LTD., 47(4), 48794. https://doi.org/10.1016/j.neuron.2005.06.014

Paoletti, P., Bellone, C., \& Zhou, Q. (2013). NMDA receptor subunit diversity: impact on receptor properties, synaptic plasticity and disease., 14(6), 383-400. https://doi.org/10.1038/nrn3504

Park, M., Penick, E. C., Edwards, J. G., Kauer, J. A., \& Ehlers, M. D. (2004). Recycling endosomes supply AMPA receptors for LTP. Science, 305(5692), 1972-5. https://doi.org/10.1126/science.1102026

Park, P., Volianskis, A., Sanderson, T. M., Bortolotto, Z. A., Jane, D. E., Zhuo, M., ... Collingridge, G. L. (2013). NMDA receptor-dependent long-term potentiation comprises a family of temporally overlapping forms of synaptic plasticity that are induced by different patterns of stimulation. Philosophical Transactions of the Royal Society B: Biological Sciences, 369(1633), 20130131-20130131. https://doi.org/10.1098/rstb.2013.0131

Petralia, R. S., Wang, Y.-X. X., \& Wenthold, R. J. (2003). Internalization at glutamatergic synapses during development. Eur. J. Neurosci., 18(12), 3207-17. https://doi.org/10.1111/j.1460-9568.2003.03074.x

Petrini, E. M., Lu, J., Cognet, L., Lounis, B., Ehlers, M. D., \& Choquet, D. (2009). Endocytic trafficking and recycling maintain a pool of mobile surface AMPA receptors required for synaptic potentiation., 63(1), 92-105. https://doi.org/10.1016/j.neuron.2009.05.025

Pheng, L. H., Dumont, Y., Fournier, A., Chabot, J.-G., Beaudet, A., \& Quirion, R. (2003). Agonistand antagonist-induced sequestration/internalization of neuropeptide $\mathrm{Y} \mathrm{Y}_{1}$ receptors in 
HEK293 cells. British Journal of Pharmacology, 139(4), 695-704. https://doi.org/10.1038/sj.bjp.0705306

Philpot, B. D., Cho, K. K. A., \& Bear, M. F. (2007). Obligatory Role of NR2A for Metaplasticity in Visual Cortex. Neuron, 53(4), 495-502. https://doi.org/10.1016/j.neuron.2007.01.027

Picazo, M. G., \& García-Olmo, D. C. (2015). DNA from tissues of young mice is optimal for genotyping. Electronic Journal of Biotechnology, 18(2), 83-87. https://doi.org/10.1016/j.ejbt.2014.12.002

Plant, K., Pelkey, K. A., Bortolotto, Z. A., Morita, D., Terashima, A., McBain, C. J., ... Isaac, J. T. R. (2006). Transient incorporation of native GluR2-lacking AMPA receptors during hippocampal long-term potentiation. Nature Neuroscience, 9(5), 602-604. https://doi.org/10.1038/nn1678

Poo, M., Pignatelli, M., Ryan, T. J., Tonegawa, S., Bonhoeffer, T., Martin, K. C., ... Stevens, C. (2016). What is memory? The present state of the engram, 14(1), 1-18. https://doi.org/10.1186/s12915-016-0261-6

Rácz, B., Blanpied, T. A., Ehlers, M. D., \& Weinberg, R. J. (2004). Lateral organization of endocytic machinery in dendritic spines. Nature Neuroscience, 7(9), 917-918. https://doi.org/10.1038/nn1303

Ramachandran, B., \& Frey, J. U. (2009). Interfering with the Actin Network and Its Effect on Long-Term Potentiation and Synaptic Tagging in Hippocampal CA1 Neurons in Slices In Vitro. Journal of Neuroscience, 29(39), 12167-12173. https://doi.org/10.1523/JNEUROSCI.2045-09.2009

Ramirez, D. M., Khvotchev, M., Trauterman, B., \& Kavalali, E. T. (2012). Vtila identifies a vesicle pool that preferentially recycles at rest and maintains spontaneous neurotransmission., 73(1), 121-34. https://doi.org/10.1016/j.neuron.2011.10.034

Ramirez, S., Liu, X., Lin, P., Suh, J., Pignatelli, M., Redondo, R., ... Tonegawa, S. (2013). Creating a false memory in the hippocampus. Science, 341(6144), 387-91. https://doi.org/10.1126/science.1239073

Rathje, M., Fang, H., Bachman, J. L., Anggono, V., Gether, U., Huganir, R. L., \& Madsen, K. L. (2013). AMPA receptor pHluorin-GluA2 reports NMDA receptor-induced intracellular acidification in hippocampal neurons. Proc. Natl. Acad. Sci. U.S.A., 110(35), 14426-31. https://doi.org/10.1073/pnas.1312982110

Raymond, C. R. (2007). LTP forms 1, 2 and 3: different mechanisms for the "long" in long-term potentiation. Trends in Neurosciences, 30(4), 167-175. https://doi.org/10.1016/j.tins.2007.01.007

Redondo, R. L., Kim, J., Arons, A. L., Ramirez, S., Liu, X., \& Tonegawa, S. (2014). Bidirectional switch of the valence associated with a hippocampal contextual memory engram. Nature. https://doi.org/10.1038/nature13725

Reymann, K. G., \& Frey, J. U. (2007). The late maintenance of hippocampal LTP: requirements, phases, "synaptic tagging", "late-associativity" and implications. Neuropharmacology, 52(1), 24-40. https://doi.org/10.1016/j.neuropharm.2006.07.026 
Robinson, M. S. (2004). Adaptable adaptors for coated vesicles. Trends in Cell Biology, 14(4), 167-174. https://doi.org/10.1016/j.tcb.2004.02.002

Rocca, D. L., Amici, M., Antoniou, A., Blanco Suarez, E., Halemani, N., Murk, K., ... Hanley, J. G. (2013). The Small GTPase Arf1 Modulates Arp2/3-Mediated Actin Polymerization via PICK1 to Regulate Synaptic Plasticity. Neuron, 79(2), 293-307. https://doi.org/10.1016/j.neuron.2013.05.003

Ropert, N., Jalil, A., \& Li, D. (2016). Expression and cellular function of vSNARE proteins in brain astrocytes. Neuroscience, 36-83. https://doi.org/10.1016/j.neuroscience.2015.10.036

Roy, D. S., Arons, A., Mitchell, T. I., Pignatelli, M., Ryan, T. J. J., \& Tonegawa, S. (2016). Memory retrieval by activating engram cells in mouse models of early Alzheimer's disease. Nature, 531(7595), 508-12. https://doi.org/10.1038/nature17172

Ryan, T. J., Roy, D. S., Pignatelli, M., Arons, A., \& Tonegawa, S. (2015). Engram cells retain memory under retrograde amnesia. Science, 348(6238), 1007-1013. https://doi.org/10.1126/science.aaa5542

Ryan, TJ, Roy, DS, Pignatelli, M, Arons, A, \& Tonegawa, S. (n.d.). Engram cells retain memory under retrograde amnesia. Science. https://doi.org/10.1126/science.aaa5542

Sabatini, B. L., Oertner, T. G., \& Svoboda, K. (2002). The Life Cycle of Ca2+ Ions in Dendritic Spines, 33(3). https://doi.org/10.1016/S0896-6273(02)00573-1

Sacktor, T. C. (2011). How does PKM $\zeta$ maintain long-term memory? Nat. Rev. Neurosci., 12(1), 9-15. https://doi.org/10.1038/nrn2949

Sanderson, D. J., Good, M. A., Skelton, K., Sprengel, R., Seeburg, P. H., Rawlins, J., \& Bannerman, D. M. (2009). Enhanced long-term and impaired short-term spatial memory in GluA1 AMPA receptor subunit knockout mice: evidence for a dual-process memory model. Learn. Mem., 16(6), 379-86. https://doi.org/10.1101/1m.1339109

Sanderson, T. M. (2012). Molecular Mechanisms Involved in Depotentiation and Their Relevance to Schizophrenia, 48(1), 1-6. https://doi.org/10.4068/cmj.2012.48.1.1

Schmid, E. M., \& McMahon, H. T. (2007). Integrating molecular and network biology to decode endocytosis. Nature, 448(7156), 883-888. https://doi.org/10.1038/nature06031

Schnell E, Sizemore M, Karimzadegan S, Chen L, Bredt DS, Nicoll RA. (2002). Direct interactions between PSD-95 and stargazin control synaptic AMPA receptor number. Proc Natl Acad Sci U S A.

Scholz, R., Berberich, S., Rathgeber, L., Kolleker, A., Köhr, G., \& Kornau, H.-C. (2010). AMPA receptor signaling through BRAG2 and Arf6 critical for long-term synaptic depression., 66(5), 768-80. https://doi.org/10.1016/j.neuron.2010.05.003

Schwabe, L., Nader, K., \& Pruessner, J. C. (2013). $\beta$-Adrenergic blockade during reactivation reduces the subjective feeling of remembering associated with emotional episodic memories. Biol Psychol, 92(2), 227-32. https://doi.org/10.1016/j.biopsycho.2012.10.003 
Serrano, P., Yao, Y., \& Sacktor, T. C. (2005). Persistent phosphorylation by protein kinase Mzeta maintains late-phase long-term potentiation. J. Neurosci., 25(8), 1979-84. https://doi.org/10.1523/JNEUROSCI.5132-04.2005

Shepherd, J. D., \& Bear, M. F. (2011). New views of Arc, a master regulator of synaptic plasticity. Nature Neuroscience, 14(3), 279-284. https://doi.org/10.1038/nn.2708

Shepherd, J. D., \& Huganir, R. L. (2007). The Cell Biology of Synaptic Plasticity: AMPA Receptor Trafficking. Annu. Rev. Cell Dev. Biol., 23(1), 613-643. https://doi.org/10.1146/annurev.cellbio.23.090506.123516

Südhof, T. C. (2002). Synaptotagmins: why so many?, 277(10), 7629-32. https://doi.org/10.1074/jbc.R100052200

Sugita, S., Shin, O.-H. H., Han, W., Lao, Y., \& Südhof, T. C. (2002). Synaptotagmins form a hierarchy of exocytotic $\mathrm{Ca}(2+)$ sensors with distinct $\mathrm{Ca}(2+)$ affinities. EMBO J., 21(3), 270-80. https://doi.org/10.1093/emboj/21.3.270

Sutton, R., Ernst, J., \& Brunger, A. (1999). Crystal structure of the cytosolic C2A-C2B domains of synaptotagmin III. Implications for $\mathrm{Ca}(+2)$-independent snare complex interaction. $J$. Cell Biol., 147(3), 589-98. https://doi.org/10.1083/jcb.147.3.589

Suzuki, A., Josselyn, S. A., Frankland, P. W., Masushige, S., Silva, A. J., \& Kida, S. (2004). Memory reconsolidation and extinction have distinct temporal and biochemical signatures., 24(20), 4787-95. https://doi.org/10.1523/JNEUROSCI.5491-03.2004

Suzuki, K., Tsunekawa, Y., Hernandez-Benitez, R., Wu, J., Zhu, J., Kim, E. J., ... Belmonte, J. C. I. (2016). In vivo genome editing via CRISPR/Cas9 mediated homology-independent targeted integration. Nature, 540(7631), 144-149. https://doi.org/10.1038/nature20565

Tao-Cheng, J.-H., Crocker, V. T., Winters, C. A., Azzam, R., Chludzinski, J., \& Reese, T. S. (2011). Trafficking of AMPA Receptors at Plasma Membranes of Hippocampal Neurons. Journal of Neuroscience, 31(13), 4834-4843. https://doi.org/10.1523/JNEUROSCI.474510.2011

Terashima, A., Pelkey, K. A., Rah, J.-C., Suh, Y. H., Roche, K. W., Collingridge, G. L., ... Isaac, J. T. R. (2008). An Essential Role for PICK1 in NMDA Receptor-Dependent Bidirectional Synaptic Plasticity. Neuron, 57(6), 872-882. https://doi.org/10.1016/j.neuron.2008.01.028

Tovote, P., Fadok, J., \& Lüthi, A. (2015). Neuronal circuits for fear and anxiety. Nat Rev Neurosci, 16(6), 317-331. https://doi.org/10.1038/nrn3945

Tsokas $\mathrm{P}$ et al. (2016). Compensation for PKMz in long-term potentiation and spatial long-term memory in mutant mice. eLife.

Turrigiano, G. G., \& Nelson, S. B. (2004). Homeostatic plasticity in the developing nervous system., 5(2), 97-107. https://doi.org/10.1038/nrn1327

Villarreal, D. M., Do, V., Haddad, E., \& Derrick, B. E. (2002). NMDA receptor antagonists sustain LTP and spatial memory: active processes mediate LTP decay. Nat. Neurosci., 5(1), 4852. https://doi.org/10.1038/nn776 
Volk, L. J., Bachman, J. L., Johnson, R., Yu, Y., \& Huganir, R. L. (2013). PKM- $\zeta$ is not required for hippocampal synaptic plasticity, learning and memory. Nature, 493(7432), 420-3. https://doi.org/10.1038/nature11802

Vorhees, C. V., \& Williams, M. T. (2006). Morris water maze: procedures for assessing spatial and related forms of learning and memory. Nature Protocols, 1(2), 848-858. https://doi.org/10.1038/nprot.2006.116

Vrljic, M., Strop, P., Ernst, J. A., Sutton, R., Chu, S., \& Brunger, A. T. (2010). Molecular mechanism of the synaptotagmin-SNARE interaction in Ca2+-triggered vesicle fusion. Nat. Struct. Mol. Biol., 17(3), 325-31. https://doi.org/10.1038/nsmb.1764

Wang, S., Sheng, T., Ren, S., Tian, T., \& Lu, W. (2016). Distinct Roles of PKC $/ \lambda$ and PKM $\zeta$ in the Initiation and Maintenance of Hippocampal Long-Term Potentiation and Memory. Cell Reports, 16(7), 1954-1961. https://doi.org/10.1016/j.celrep.2016.07.030

Wang YT, Linden DJ. (2000). Expression of Cerebellar Long-Term Depression Requires Postsynaptic Clathrin-Mediated Endocytosis. Neuron.

Waung, M. W., Pfeiffer, B. E., Nosyreva, E. D., Ronesi, J. A., \& Huber, K. M. (2008). Rapid Translation of Arc/Arg3.1 Selectively Mediates mGluR-Dependent LTD through Persistent Increases in AMPAR Endocytosis Rate. Neuron, 59(1), 84-97. https://doi.org/10.1016/j.neuron.2008.05.014

Wilhelm, B. G., Groemer, T. W., \& Rizzoli, S. O. (2010). The same synaptic vesicles drive active and spontaneous release. Nature Neuroscience, 13(12), 1454-1456. https://doi.org/10.1038/nn.2690

Willox, A. K., \& Royle, S. J. (2012). Stonin 2 Is a Major Adaptor Protein for Clathrin-Mediated Synaptic Vesicle Retrieval. Current Biology, 22(15), 1435-1439. https://doi.org/10.1016/j.cub.2012.05.048

Xiao, M., Niu, Y., \& Wigström, H. (1996). Activity-dependent decay of early LTP revealed by dual EPSP recording in hippocampal slices from young rats. Eur. J. Neurosci., 8(9), 191623.

Yao, J., Kwon, S. E., Gaffaney, J. D., Dunning, F., \& Chapman, E. R. (2012). Uncoupling the roles of synaptotagmin I during endo- and exocytosis of synaptic vesicles., 15(2), 243-9. https://doi.org/10.1038/nn.3013

Yao, Y., Kelly, M. T., Sajikumar, S., Serrano, P., Tian, D., Bergold, P. J., ... Sacktor, T. C. (2008). PKM zeta maintains late long-term potentiation by N-ethylmaleimide-sensitive factor/GluR2-dependent trafficking of postsynaptic AMPA receptors. J. Neurosci., 28(31), 7820-7. https://doi.org/10.1523/JNEUROSCI.0223-08.2008

Yoshihara T, Yonoki Y, Saito M, Nakahara T, Sakamoto K, Ishii K. (2013). Agonist-Induced Receptor Internalization in Chinese Hamster Ovary Cells Stably Co-expressing $\beta 1$ - and $\beta 2$-Adrenergic Receptors. Bio. Pharm. Bull.

Yu, S. Y., Wu, D. C., Liu, L., Ge, Y., \& Wang, Y. T. (2008). Role of AMPA receptor trafficking in NMDA receptor-dependent synaptic plasticity in the rat lateral amygdala. $J$. Neurochem., 106(2), 889-99. https://doi.org/10.1111/j.1471-4159.2008.05461.x 
Zeng, H., Chattarji, S., Barbarosie, M., L, R.-R., Philpot, B., Miyakawa, T., ... Tonegawa, S. (2001). Forebrain-specific calcineurin knockout selectively impairs bidirectional synaptic plasticity and working/episodic-like memory. Cell, 107(5), 617-29.

Zhang, J., Davletov, B., Südhof, T., \& Anderson, R. (1994). Synaptotagmin I is a high affinity receptor for clathrin AP-2: implications for membrane recycling. Cell, 78(5), 751-60.

Zheng, N., Jeyifous, O., Munro, C., Montgomery, J. M., \& Green, W. N. (2015). Synaptic activity regulates AMPA receptor trafficking through different recycling pathways. Elife, 4. https://doi.org/10.7554/eLife.06878

Zhou, Q., Lai, Y., Bacaj, T., Zhao, M., Lyubimov, A. Y., Uervirojnangkoorn, M., ... Brunger, A. T. (2015). Architecture of the synaptotagmin-SNARE machinery for neuronal exocytosis. Nature, 525(7567), 62-67. https://doi.org/10.1038/nature14975

Zinebi F. et al. (2003). NMDA Currents and Receptor Protein Are Downregulated in the Amygdala during Maintenance of Fear Memory. J. Neurosc. 


\section{Appendix}

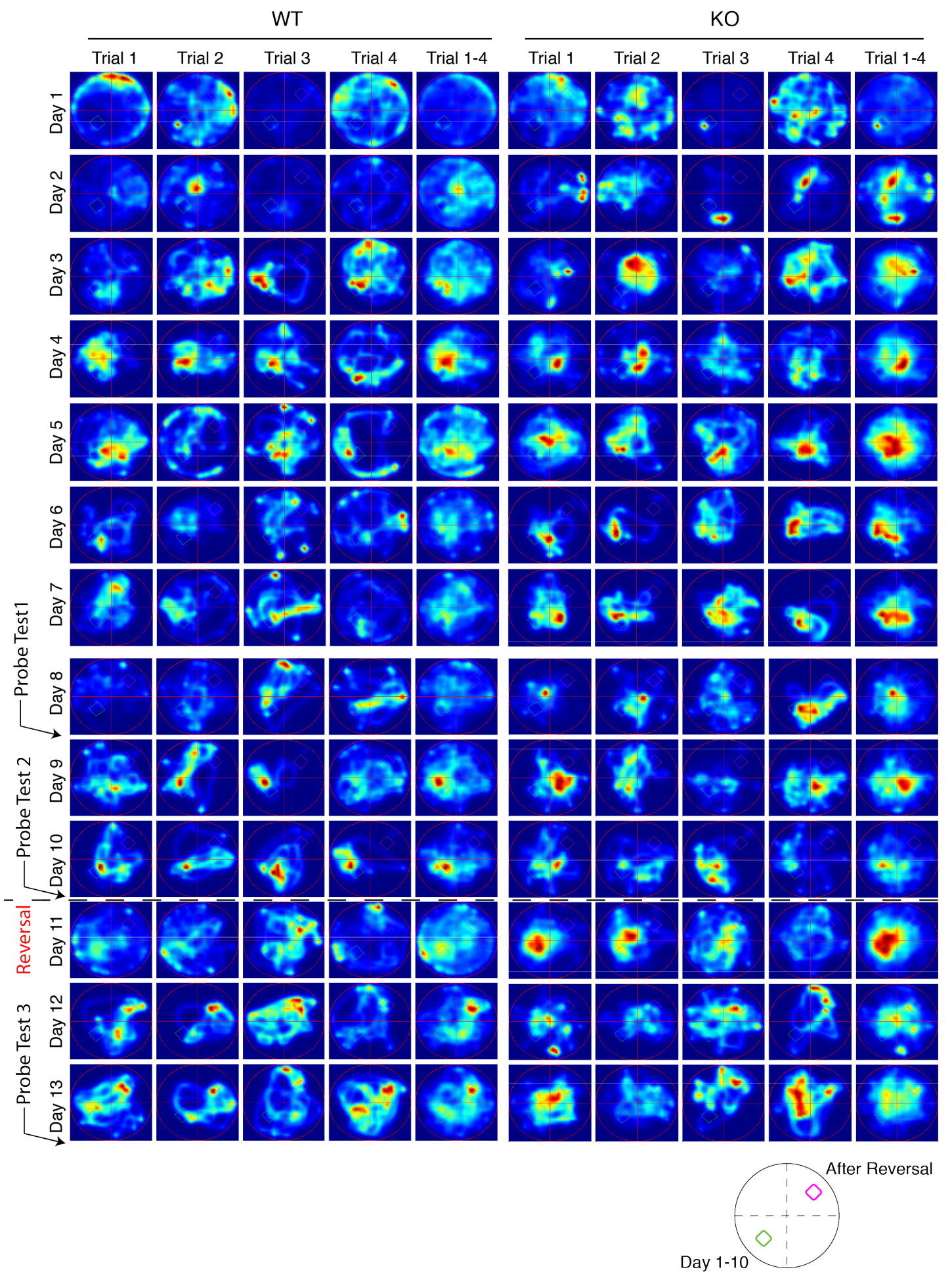

Appendix Figure 1: Occupancy plots for cohort 1 in reference memory watermaze 


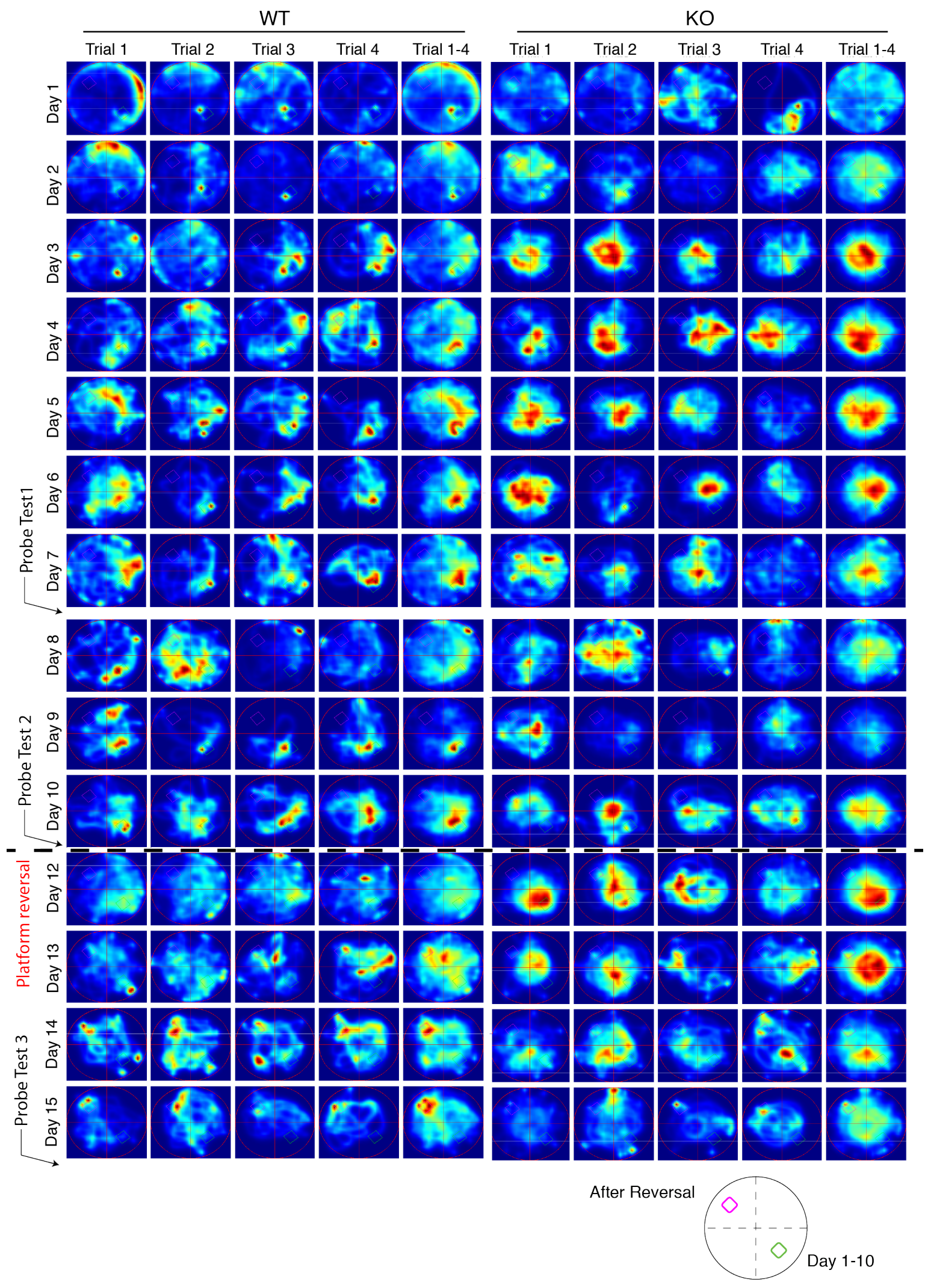

Appendix Figure 2: Occupancy plots for cohort 2 in reference memory watermaze 


\section{Cohort 1}

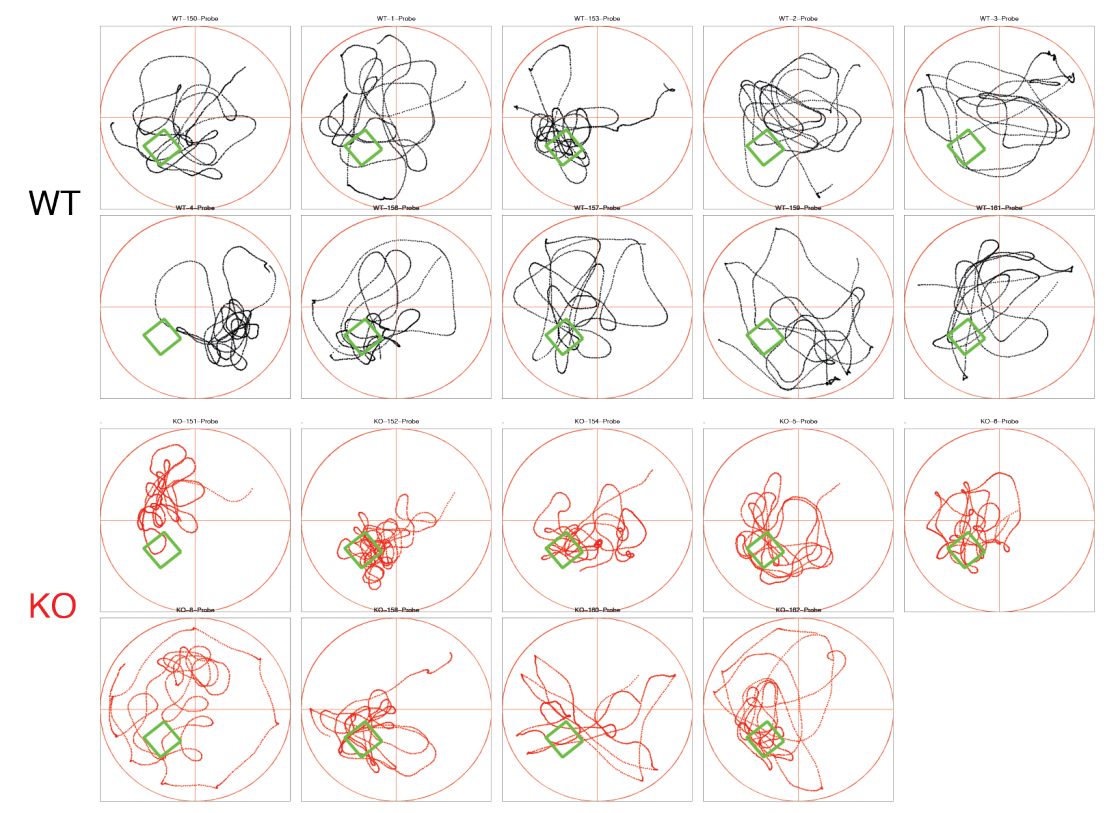

Platform
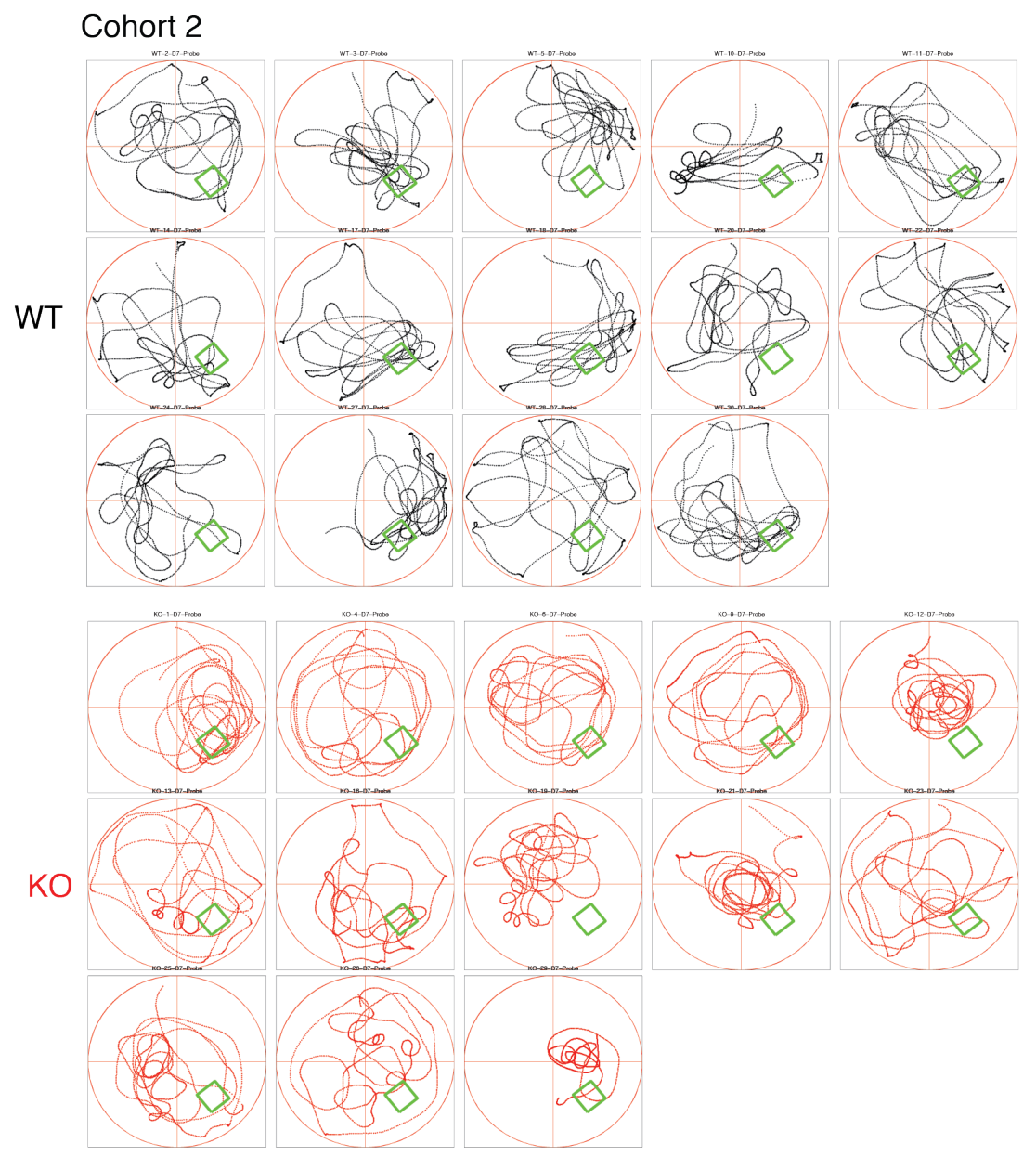

Appendix Figure 3: Individual mouse trajectories in probe test 1 of reference memory watermaze 

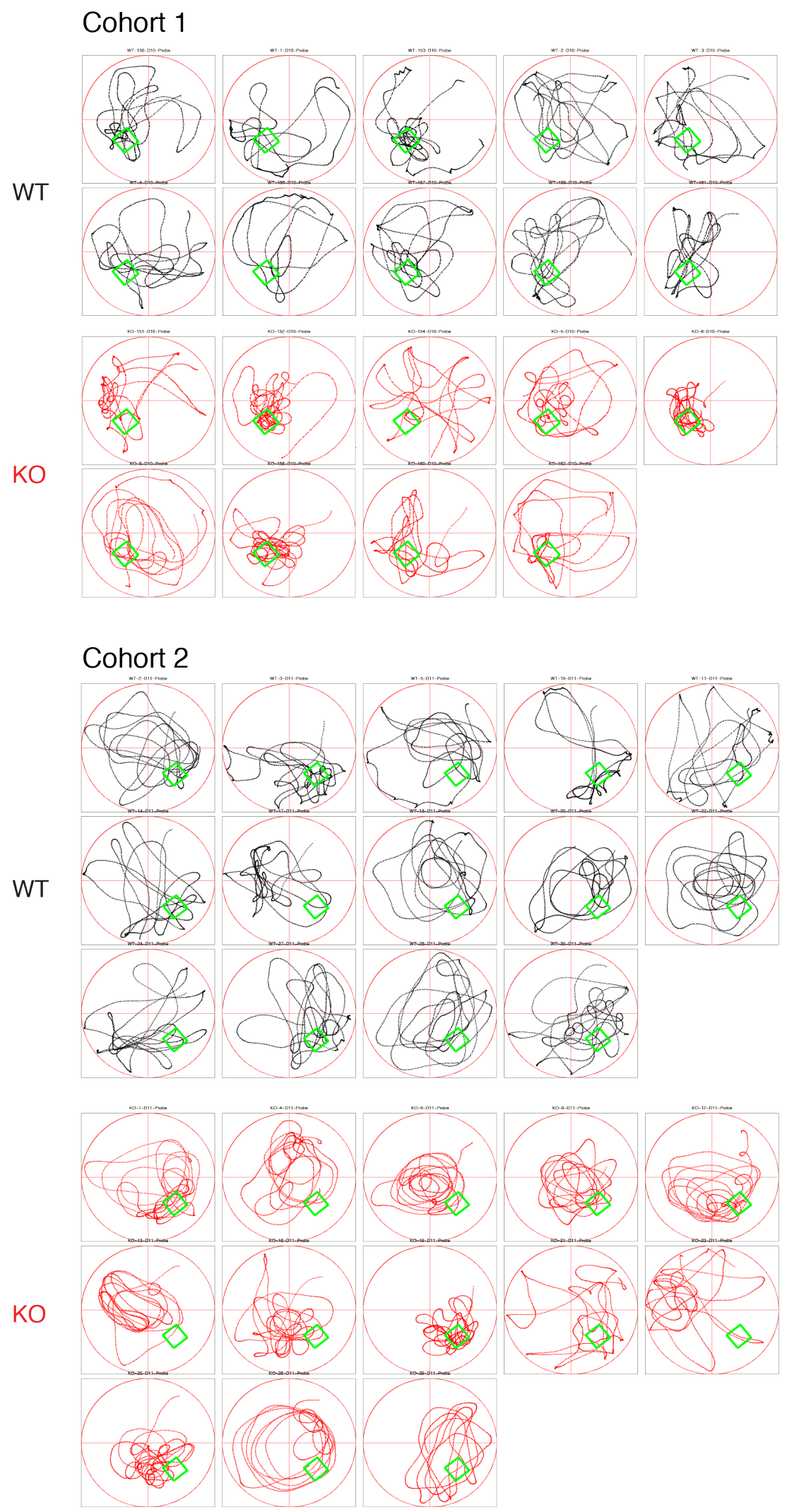

Appendix Figure 4: Individual mouse trajectories in probe test 2 of reference memory watermaze 

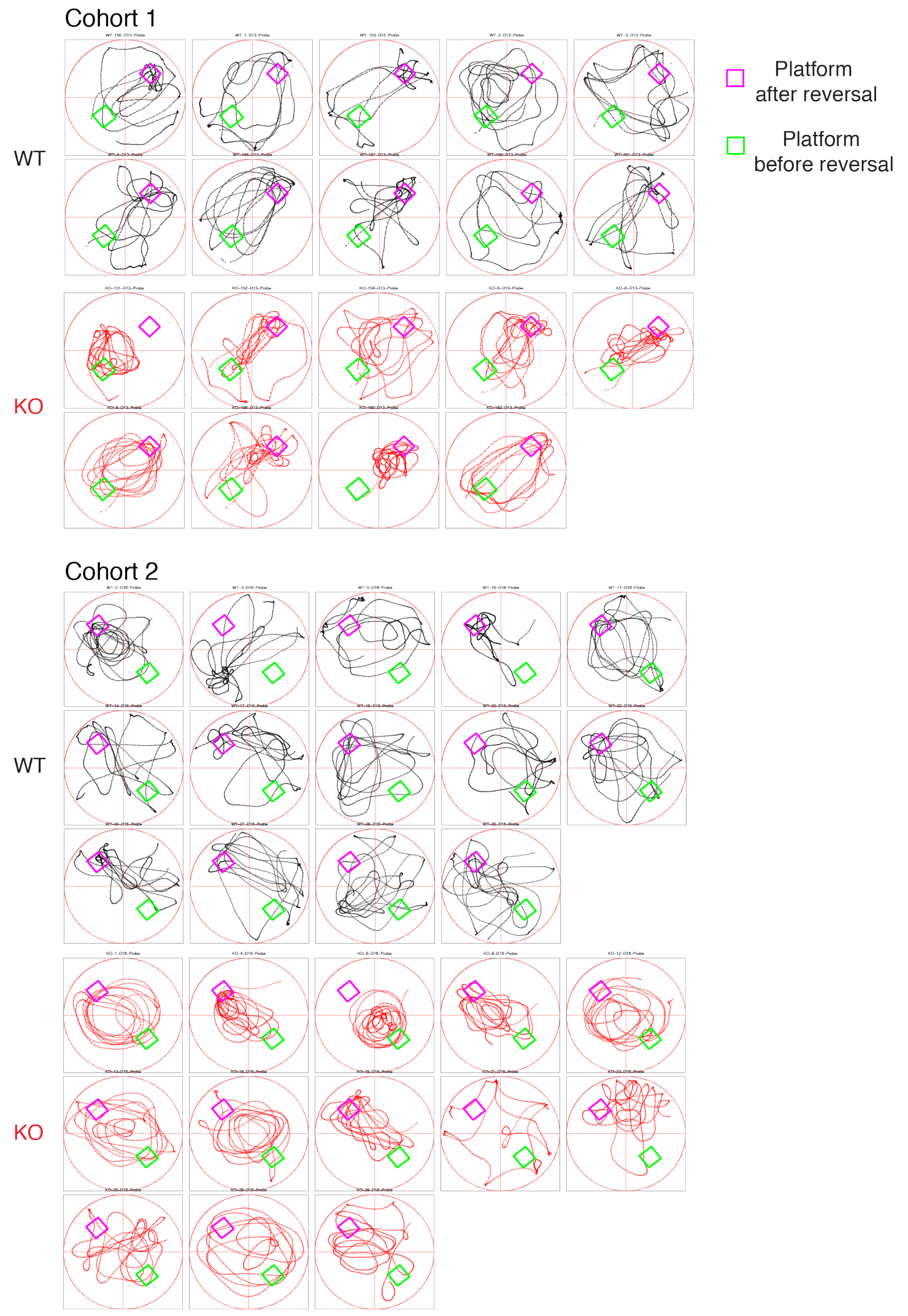

Appendix Figure 5: Individual mouse trajectories in probe test 3 of reference memory watermaze 
Cohort 1
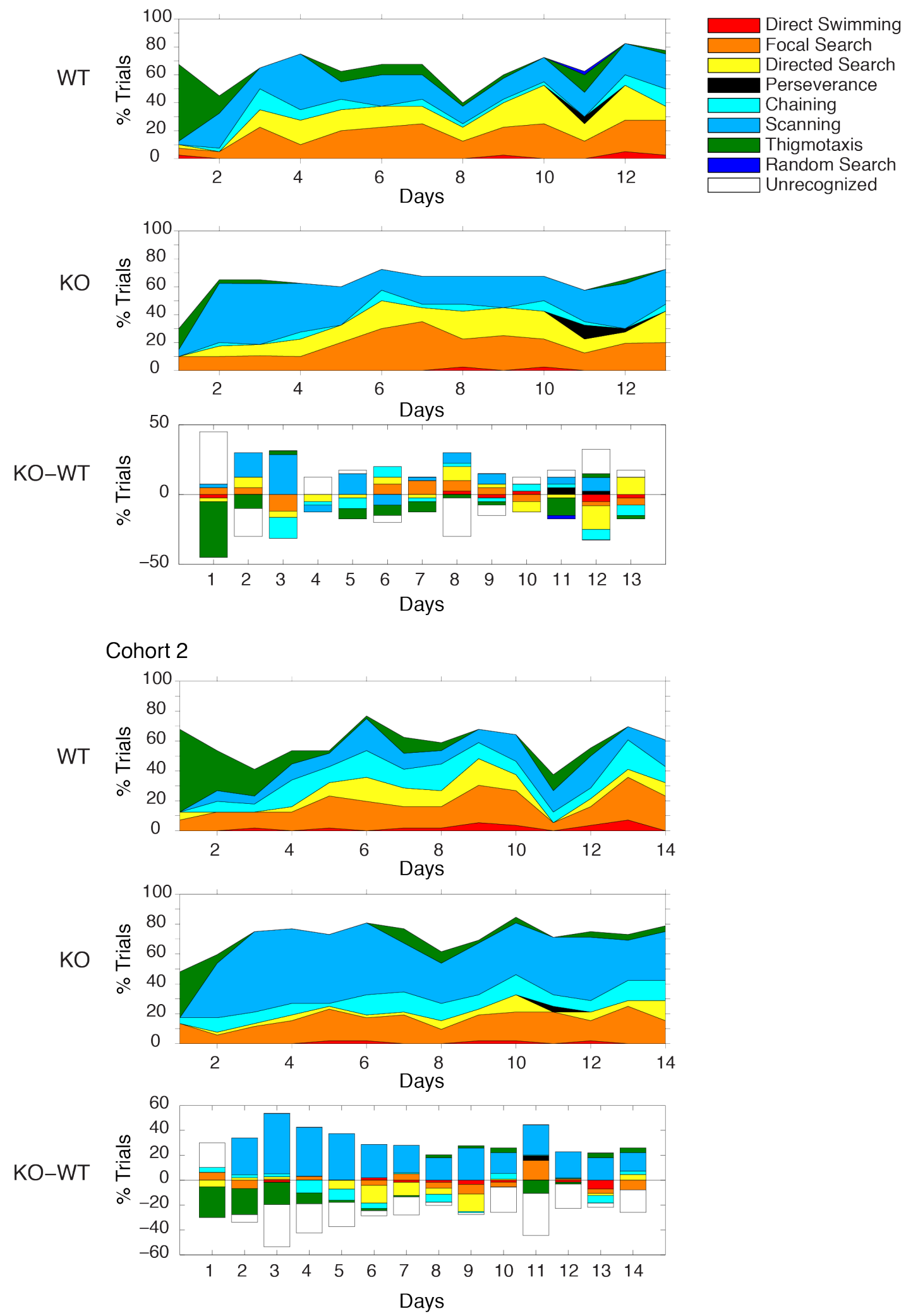

Appendix Figure 6: Strategy analysis of reference memory watermaze 


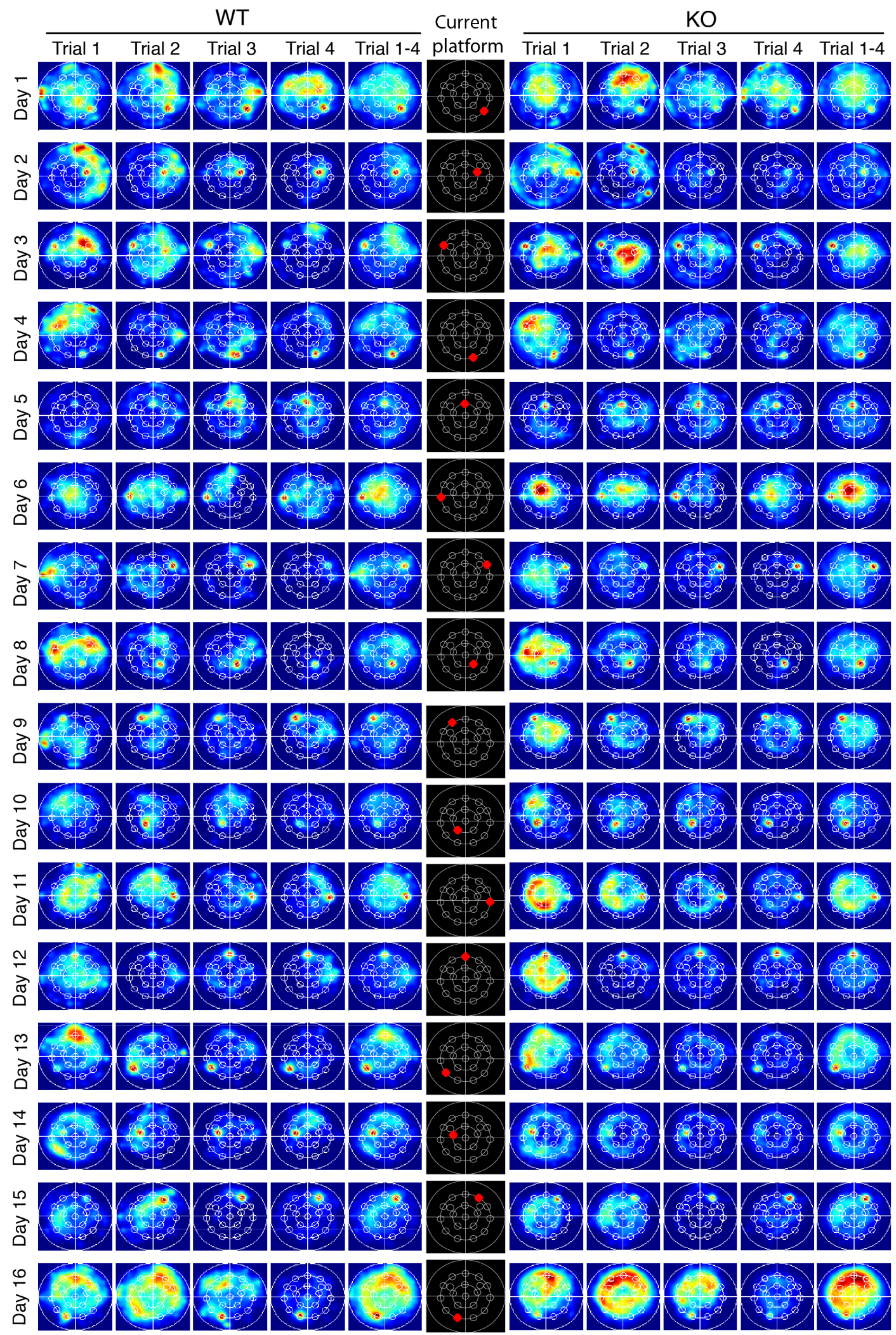

Appendix Figure 7: Occupancy plots for sub-cohort CB 1 in delayed matching to place watermaze 


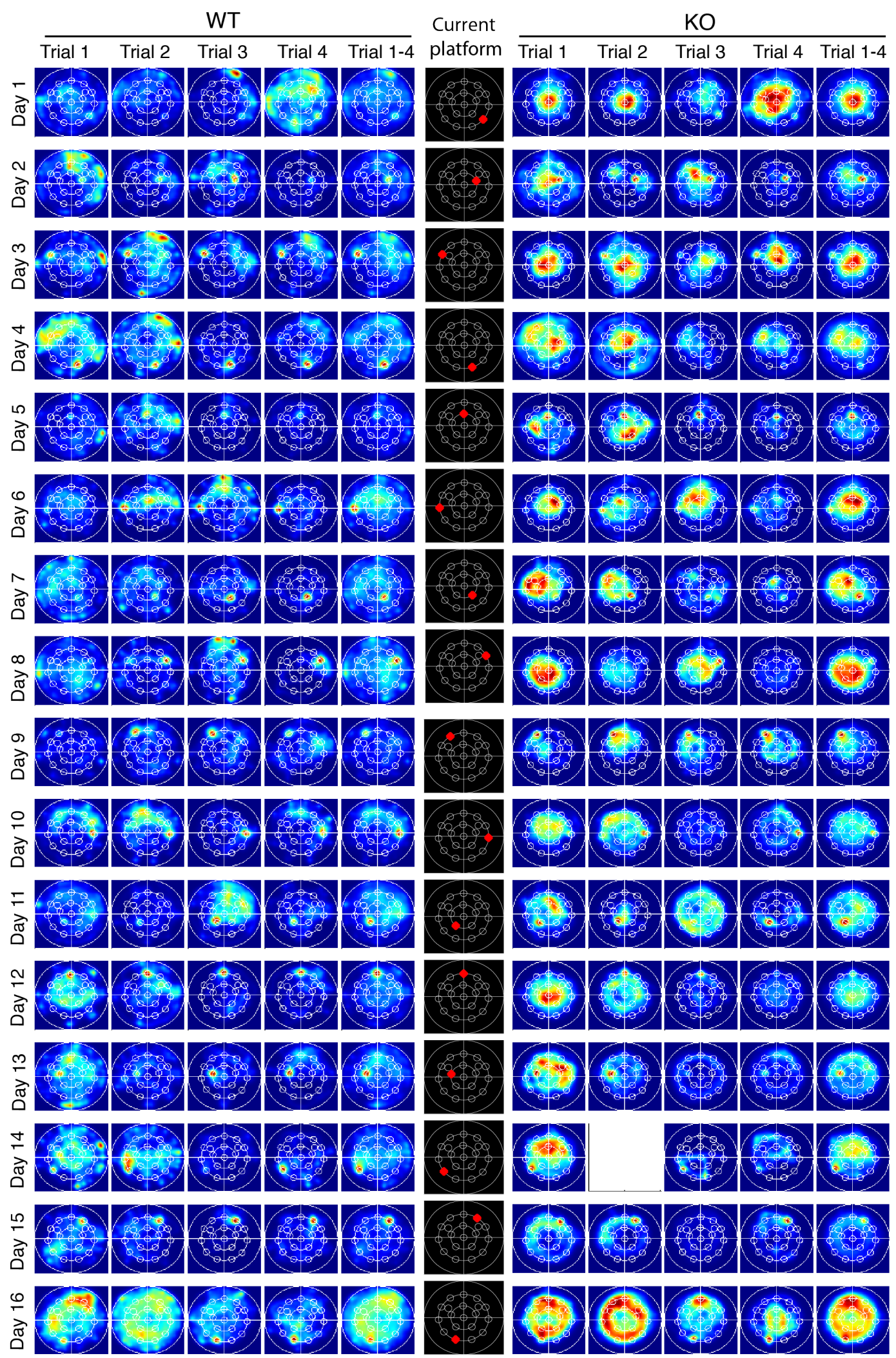

Appendix Figure 8: Occupancy plots for sub-cohort CB 2 in delayed matching to place watermaze 

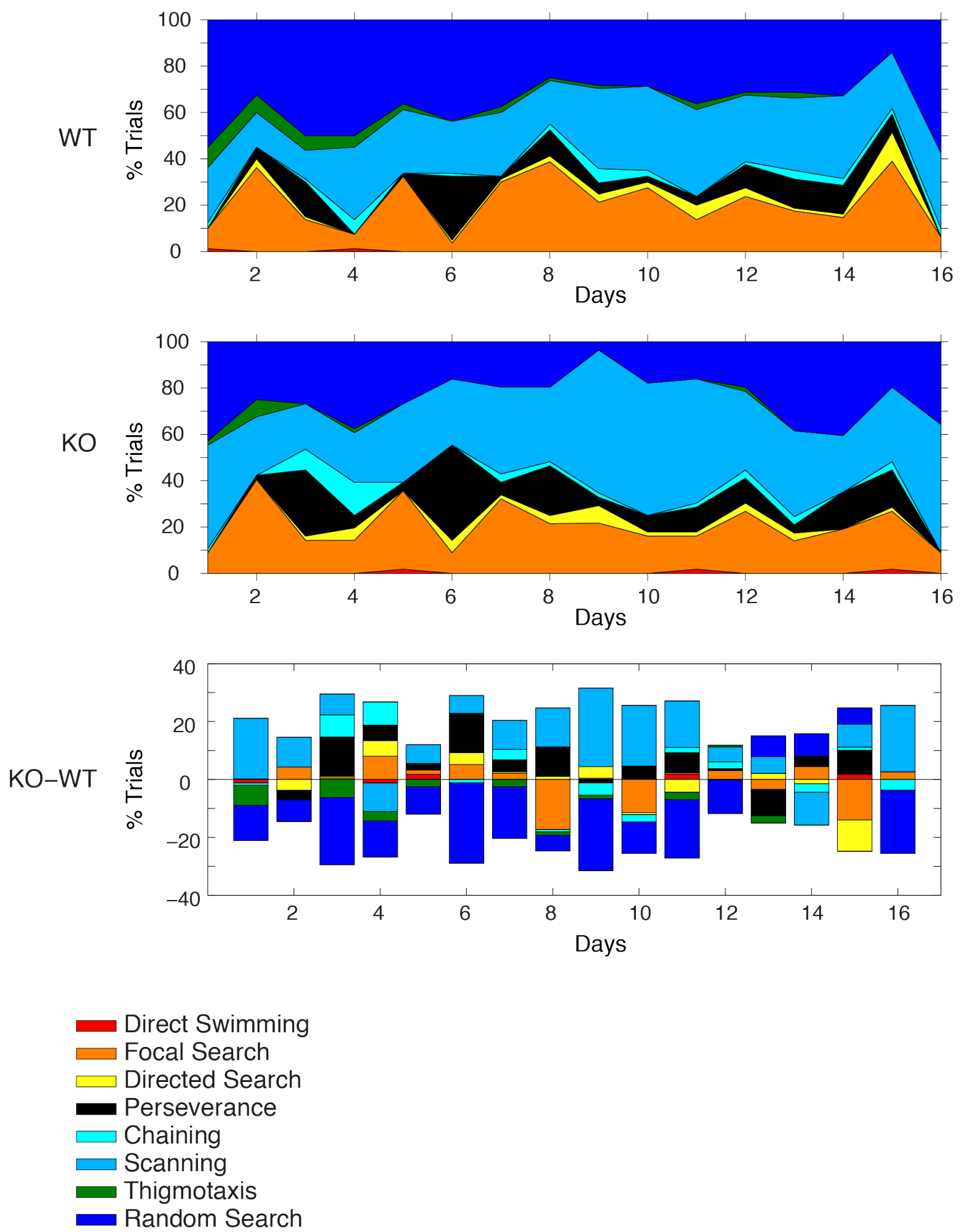

Appendix Figure 9: Strategy analysis of delayed matching to place watermaze 
[Type here]

\section{List of abbreviations}

\begin{tabular}{|c|c|}
\hline Abbreviation & Expansion \\
\hline${ }^{\circ} \mathrm{C}$ & Degree celsius \\
\hline $\mathrm{ADP}$ & Adenosine diphosphate \\
\hline AMPA & $\alpha$-amino-3-hydroxy-5-methyl-4-isoxazolepropionic acid \\
\hline ANOVA & Analysis of variance \\
\hline AP2 & Adaptor protein-2 \\
\hline $\mathrm{APV} / \mathrm{AP} 5$ & (2R)-amino-5-phosphonovaleric acid \\
\hline Arc & Activity-regulated cytoskeleton-associated protein \\
\hline Arf & ADP ribosylation factor \\
\hline Arp & Actin related protein \\
\hline ATP & Adenosine triphosphate \\
\hline BAPTA & 1,2-bis(o-aminophenoxy) ethane-N,N, $\mathrm{N}^{\prime}, \mathrm{N}^{\prime}$-tetraacetic acid \\
\hline BRAG & Brefeldin A-resistant Arf Guanine Nucleotide Exchange Factor \\
\hline C57B6/J & B6/ B6J/ Black 6/ C57 Black mice \\
\hline $\mathrm{CA}$ & Cornu ammonis \\
\hline $\mathrm{Ca}^{2+}$ & Calcium \\
\hline Cas9 & CRISPR associated protein 9 \\
\hline $\mathrm{CB} 1$ and $\mathrm{CB} 2$ & Counterbalanced sub-cohort 1 and 2 (in the DMP watermaze task) \\
\hline $\mathrm{cm}$ & Centimeter \\
\hline CNQX & 6-cyano-7-nitroquinoxaline-2,3-dione \\
\hline CPG & Controlled pore glass \\
\hline CRISPR & Clustered regularly interspaced short palindromic repeats \\
\hline DHPG & (S)-3,5-dihydroxyphenylglycine \\
\hline DIV & Day in vitro \\
\hline DMP & Delayed matching to place \\
\hline dNTP & Deoxynucleotide triphosphate \\
\hline$E^{\prime} x^{\prime}$ & Embryonic age in ' $\mathrm{x}$ ' days, for example E19 is a 19-day old embryo \\
\hline EEA1 & Early endosome antigen 1 \\
\hline eGFP & Enhanced green fluorescent protein \\
\hline EGTA & Ethylene glycol-bis( $\beta$-aminoethyl ether)-N,N,N',N'-tetraacetic acid \\
\hline Eps 15 & Epidermal growth factor receptor substrate 15 \\
\hline EPSC & Excitatory post-synaptic current \\
\hline
\end{tabular}




\begin{tabular}{|c|c|}
\hline EZ & Endocytotic zone \\
\hline GABA & Gamma-aminobutyric acid \\
\hline GAP & GTPase-activating proteins \\
\hline GDP & Guanosine diphosphate \\
\hline GEF & Guanine nucleotide exchange factor \\
\hline GFP & Green fluorescent protein \\
\hline GluA & Subunit of AMPA receptors \\
\hline GluN & Subunit of NMDA receptors \\
\hline GRIP & Glutamate receptor interacting protein \\
\hline GTP & Guanosine triphosphate \\
\hline $\mathrm{h} / \mathrm{hr}$ & Hour/ hours \\
\hline HEK & Human embryonic kidney (HEK293) cell line \\
\hline HFS & High frequency stimulation \\
\hline $\mathrm{Hz}$ & Hertz \\
\hline $\mathrm{InsP}_{3} \mathrm{R}$ & Inositol triphosphate receptor \\
\hline IPSC & Inhibitory post-synaptic current \\
\hline KD & Knock-down \\
\hline $\mathrm{KDa}$ & Kilodalton \\
\hline $\mathrm{KO}$ & Knockout \\
\hline LFS & Low frequency stimulation \\
\hline LTD & Long term depression \\
\hline MAP2 & Microtubule associated protein 2 \\
\hline mEPSC & Miniature excitatory post-synaptic current/mini \\
\hline mGluR & Metabotropic glutamate receptor \\
\hline $\min$ & Minute/ minutes \\
\hline $\mathrm{ms}$ & Millisecond \\
\hline NASPM & 1-Naphthyl acetyl spermine \\
\hline NMDA & N-Methyl-D-aspartic acid \\
\hline NSF & $\begin{array}{l}\text { N-ethylmaleimide-sensitive factor/ N-ethylmaleimide sensitive fusion } \\
\text { protein }\end{array}$ \\
\hline $\mathrm{OV}$ & Sodium orthovanadate \\
\hline PAO & Phenylarsine oxide \\
\hline PICK1 & Protein interacting with protein kinase $\mathrm{C}-1$ \\
\hline $\mathrm{PIP}_{2} / \operatorname{PtdIns}(4,5) \mathrm{P}_{2}$ & Phosphatidylinositol 4,5-bisphosphate \\
\hline
\end{tabular}




\begin{tabular}{|c|c|}
\hline PKM $\zeta$ & Protein kinase $\mathrm{C}$ isoform Mzeta \\
\hline PMCA & Plasma membrane $\mathrm{Ca}^{2+}$ ATPase \\
\hline PP & Protein phosphatase \\
\hline PSD & Post-synaptic density \\
\hline PT & Probe test (in watermaze) \\
\hline$P^{\prime} x^{\prime}$ & Postnatal rodent age in ' $\mathrm{x}$ ' days, for example $\mathrm{P} 0$ is a just born pup \\
\hline Rme1 & Eps15 homology domain protein (EHD)1/Rme1 \\
\hline RNA & Ribonucleic acid \\
\hline RNAi & RNA interference \\
\hline RyR & Ryanodine receptors \\
\hline $\mathrm{s} / \mathrm{sec}$ & Second/ seconds \\
\hline SEM & Standard error of mean \\
\hline SEP & Super-ecliptic pHluorin \\
\hline SERCA & Sarco/endoplasmic reticulum $\mathrm{Ca}^{2+}$-ATPase \\
\hline shRNA & Small-hairpin RNA \\
\hline$\alpha / \beta$-SNAP & Alpha/ Beta N-ethylmaleimide-sensitive factor attachment protein \\
\hline SNAP25 & Synaptosomal-associated protein 25 \\
\hline SNARE & SNAP (Soluble NSF Attachment Protein) REceptor \\
\hline STED & Stimulated emission depletion microscopy \\
\hline STORM & Stochastic optical reconstruction microscopy \\
\hline Syp & Synaptophysin \\
\hline Syt & Synaptotagmin \\
\hline TARP & Transmembrane AMPA receptor regulatory protein \\
\hline TTX & Tetrodotoxin \\
\hline VAMP & Vesicle-associated membrane protein \\
\hline vGAT & Vesicular GABA transporter \\
\hline vGluT & Vesicular glutamate transporter \\
\hline WT & Wild-type \\
\hline ZIP & Zeta inhibitory peptide \\
\hline
\end{tabular}




\section{ANKIT AWASTHI}

Email: a.awasthi@eni-g.de

Mobile: +49157 72814047

ACADEMIC BACKGROUND

\begin{tabular}{ccllc}
$2013-2017$ & PhD & $\begin{array}{l}\text { Molecular \& cellular } \\
\text { neurobiology, behavioral } \\
\text { neuroscience }\end{array}$ & $\begin{array}{l}\text { Group leader Camin Dean, } \\
\text { European Neuroscience } \\
\text { Institute Göttingen, Germany }\end{array}$ & $\begin{array}{c}\text { Summa } \\
\text { cum laude }\end{array}$ \\
$2010-2012$ & MSc & $\begin{array}{l}\text { Developmental, Neural } \\
\text { \& Behavioral Biology }\end{array}$ & $\begin{array}{l}\text { Georg August University } \\
\text { Göttingen, Germany }\end{array}$ & $\begin{array}{c}1.4 \\
\text { (Best }=1, \\
\text { Worst }=4)\end{array}$ \\
SCHOLARSHIPS AND ACADEMIC ACHIEVEMENTS & Biotechnology & $\begin{array}{l}\text { Indian Institute of } \\
\text { Technology Roorkee, India }\end{array}$ & $\begin{array}{c}8.256 \\
\text { (Best }=10, \\
\text { Worst }=5)\end{array}$ \\
\hline
\end{tabular}

2010 Erasmus Mundus ECW ‘Eurindia’ scholarship (Eurindia):

Awarded complete stipend by the European Commission to pursue MSc studies in Germany.

Working Internships in Science and Engineering (WISE):

2009 Awarded complete stipend by the German academic exchange service (DAAD) to pursue a summer internship during bachelors studies.

Indian Institute of Technology-Joint Entrance Examination (IIT-JEE):

2006 Secured a position among top $1 \%$ of around 500,000 participants at the national level in India to pursue bachelor's studies at India's premier engineering institutes.

National Talent Search scholarship (NTSE):

2004 A highly coveted scholarship awarded to only around $0.5 \%$ of 150,000 applicants at the national level by the government of India after 10th grade.

\section{SCIENTIFIC SKILLS}

Whole-cell recordings in dissociated hippocampal cultures (mEPSCs, mIPSCs, Electrophysiology simultaneous fast application system for chemical stimulation) and acute mouse hippocampal slices (evoked EPSCs, IPSCs from the CA3-CA1 synapse). LTP recordings of upto 4 hours at the CA3-CA1 synapse in acute mouse hippocampal slices.

Imaging Immunocytochemistry in dissociated hippocampal cultures and differentiated human neuronal cell lines using epifluorescence or confocal microscopy, antibody uptake assays to determine post-synaptic receptor recycling, pHluorin timelapse imaging using epifluorescence microscopy.

Cell culture

Rat embryonic (E19) and mouse P0 dissociated hippocampal cultures, calcium phosphate/ lipofectamine methods of transfection in cultures, HEK293 cell assays.

Behavioral

Experiments

Open Field, Novel Object Recognition, Elevated plus maze, standard morris water maze, delayed matching to place (DMP) version of watermaze, contextual fear conditioning, spatial novelty recognition task, startle response test.

Biochemistry Western Blotting, Protein isolation and estimation, immuno-organelle isolation, antibody pull-down assays, PCR, DNA electrophoresis.

MATLAB for analysing a) spontaneous events in calcium imaging data, b) Spatia memory and mouse search strategy in the reference memory watermaze and delayed matching to place watermaze. 


\section{POSTER PRESENTATIONS}

2017 FENS Brain conference 'Learning, memory and synaptic plasticity' in Copenhagen, Denmark

2015 The German Neuroscience society meeting in Göttingen, Germany

2013 Neurizons, a student organised neuroscience conference in Göttingen, Germany

2013 Society for Neuroscience (SFN) annual meeting in San Diego, USA

\section{PUBLICATIONS}

Ankit Awasthi*, Binu Ramachandran*, Saheeb Ahmed, Yo Shinoda, Noam Nitzan, Alina Heukamp, Henrik Martens, Jonas Barth, Katja Burk, Eva Benito, Yu tian Wang, André Fischer, Camin Dean. A post-synaptic 'forgetting' mechanism controlled by synaptotagmin-3. (Under revision at Nature since October 2016)

Joaquin I. Hurtado-Zavala, Binu Ramachandran, Saheeb Ahmed, Rashi Halder, Christiane Bolleyer, Ankit Awasthi, Markus Stahlberg, Robin Wagener, Kristin Anderson, Ryan Drenan, Henry Lester, Julie Miwa, Jochen Staiger, André Fischer, Camin Dean. TRPV1 regulates excitatory innervation of OLM neurons in the hippocampus. (Nature Communications, 2017. DOI:10.1038/ncomms15878)

Katja Burk*, Binu Ramachandran*, Saheeb Ahmed*, Joaquin I. Hurtado-Zavala*, Ankit Awasthi*, Eva Benito, Ruth Faram, Hamid Ahmad, Aarti Swaminathan, Jeffrey Mcllhinney, André Fischer, Pavel Perestenko, Camin Dean. Regulation of dendritic spine morphology in hippocampal neurons by copine- 6 . (Cerebral Cortex, 2017. DOI 10.1093/cercor/bhx009)

Anne C. Wolfes, Saheeb Ahmed, Ankit Awasthi, Markus Stahlberg, Ashish Rajput, Daniel Magruder, Stefan Bonn, Camin Dean. A novel method for culturing stellate astrocytes reveals spatially distinct $\mathrm{Ca} 2+$ signalling and vesicle recycling in astrocytic processes. (Journal of physiology, 2016. DOI: 10.1085/jgp.201611607)

Eva Benito, Hendrik Urbanke, Binu Ramachandran, Jonas Barth, Rashi Halder, Ankit Awasthi, Gaurav Jain, Vincenzo Capece, Susanne Burkhardt, Magdalena Navarro-Sala, Sankari Nagarajan, Anna-Lena Schütz, Steven Johnsen, Stefan Bonn, Reinhardt Lührmann, Camin Dean, André Fischer. HDAC inhibitor-dependent transcriptome and memory reinstatement in cognitive decline models.

(Journal of Clinincal Investigations, 2015. DOI 10.1172/JCl79942)

${ }^{*}$ Co-first author

\section{EXTRACURRICULAR ACTIVITIES}

2014-2016 Student representative for PhD program, 'Molecular physiology of the brain'

2015 Main organizer and co-ordinator of student volunteers of Encephalon, a biennial neuroscience symposium of the 'Molecular physiology of the brain' PhD program, invited leading scientists from all over Europe

\section{REFEREES}

$\begin{array}{lll}\text { Dr. Camin Dean } & \text { Dr. Dr. Oliver Schlüter } & \text { Prof. Dr. Andre Fischer } \\ \text { Group Leader, } & \text { Group Leader, } & \text { Group Leader, } \\ \text { Trans-synaptic signaling group, } & \text { Molecular Neurobiology group, } & \text { Laboratory for Aging and } \\ \text { European Neuroscience Institute, } & \text { European Neuroscience Institute, } & \text { cognitive disesaes, } \\ \text { 37077 Göttingen, Germany. } & \text { 37077 Göttingen, Germany. } & \text { German Center for neuro- } \\ \text { c.dean@eni-g.de } & \text { o.schlueter@eni-g.de } & \text { degenerative diseases (DZNE), } \\ & & 370775 \text { Göttingen, Germany. } \\ & & \text { andre.fischer@dzne.de }\end{array}$




\section{Acknowledgements}

First and foremost, I would like to thank Camin for her amazing mentorship. Starting from knowing very little about what a neuron is to have studied forgetting in mice, I have had the best neurobiology research experience I could ever ask for. I was always given the freedom, and encouraged, to come with ideas for experiments. You took the great neuroscience exposure I got from Göttingen, to another level, by encouraging me to go to international conferences.

I would like to thank my lab: Vinita, Joaquin, Markus, Charlie, Katja, Anne, Yo, Saheeb, Binu, Jan and Gesa for fostering a relaxed and fun atmosphere. I have learnt lots from all of you. I would like to especially thank Charlie and Markus, for bringing up $\sim 60$ nice publications over the last few years in our 3-man journal club and also for the LAN parties!. I wouldn't have kept pace with the coolest things happening in neuroscience without them. I would like to thank all the students I supervised for being good students =) Amelia, Oli, Subhadeep, Noam, Alina, Tal, Bastian. None of the behavioural experiments would have been possible without the support of the Andre Fischer group: Eva, Jonas, and Gaurav. I am also greatful to Oliver Schlüter for his help and advice, and also the technical support from Sandra, Avani, Plinio, Lei, Manho, Tanmoy, Joana, Derya and Anja.

Göttingen wouldn't have been home if it were not for all my friends. Thank you for the warm dinners, gaming nights and the great company. Alina, Pawan, Sumir, Soham, Kundan, Divya, Vinita, Heena, Veena, Avani, Mayur, Ishwar, Arnab, Vidya, Pritesh, Upasana, Priyanka, Oliwa, David, Somu, Pranav, Ants, Ani, Panchi, Sakshi, Harsha: I will cherish my 6 years in Göttingen, thanks to you.

Thank you mmi, papa and di for the constant affection and love. You saw me grow up and shaped me in the biggest way to become what I am today. I dedicate this thesis to you. 
